Portland State University

PDXScholar

Spring 5-23-2014

\title{
School District Bond Campaigns: Strategies That Ensure Successful Outcomes
}

\author{
Linda L. Florence \\ Portland State University
}

Follow this and additional works at: https://pdxscholar.library.pdx.edu/open_access_etds

Part of the Educational Administration and Supervision Commons, and the Public Relations and Advertising Commons

Let us know how access to this document benefits you.

\section{Recommended Citation}

Florence, Linda L., "School District Bond Campaigns: Strategies That Ensure Successful Outcomes" (2014). Dissertations and Theses. Paper 1847.

https://doi.org/10.15760/etd.1846

This Dissertation is brought to you for free and open access. It has been accepted for inclusion in Dissertations and Theses by an authorized administrator of PDXScholar. Please contact us if we can make this document more accessible: pdxscholar@pdx.edu. 
School District Bond Campaigns: Strategies That

Ensure Successful Outcomes

by

Linda L. Florence

A dissertation submitted in partial fulfillment of the requirements for the degree of

Doctor of Education

in

Educational Leadership: Administration

\author{
Dissertation Committee: \\ Tom Chenoweth, Chair \\ Patrick Burk \\ Margaret Everett \\ Deborah Peterson \\ Judith Ramaley
}

Portland State University

2014 
(C) 2014 Linda L. Florence 


\begin{abstract}
When the polls close and the ballots are counted, the best sound is the roar of ecstatic cheering from delighted but exhausted campaign committee members. A bond campaign takes an inordinate amount of work, but the results are worth the effort when the campaign is managed in a systematic way. Districts can be successful bond recipients when they effectively market their schools to gain the support of their constituents.

Public schools across the United States are in dire need of major repairs, remodeling, and rebuilding to meet the educational needs of students. Unfortunately, passing a school bond election is entrusted to school superintendents and other district leaders, who are often inexperienced and ill-prepared and have neither the time nor inclination to focus on tasks that take them far from their primary purpose of teaching and learning.
\end{abstract}

Attaining voter support in a school bond election requires a thorough understanding of school and community issues. The literature review focuses on communication theory and research to garner support of school district's internal and external stakeholders. Communication is instrumental in the passage of a construction bond election.

This dissertation is theoretically grounded in problem-based learning and the research and development process. The tested product is a handbook for superintendents 
or other district-level administrators on strategies and practices that assist in passing a construction bond election. In the Preliminary and Main field tests, superintendents and other district leaders used the handbook in a workshop. Survey results provided summative data to assess the efficacy of the handbook and the workshop. Formative results also provided rich information to improve and revise the handbook and workshop. 


\section{Dedication}

To my husband, Bill, an accomplished author, who encouraged me to complete what I started.

To my mom, who valued education, aspired to be educated in her adult life, and instilled in me a passion to learn. She continues to be my inspiration. 


\section{Acknowledgments}

I would like to thank my dissertation committee members, Dr. Tom Chenoweth, Dr. Patrick Burk, Dr. Margaret Everett, Dr. Deborah Peterson, Dr. Judith Ramaley, for their excellent suggestions and thought-provoking questions.

My advisor, Dr. Tom Chenoweth, deserves special recognition for his enthusiasm, encouragement and support throughout the process. I feel so blessed that I was welcomed into a cohort that had already begun one to two years earlier. Dr. Chenoweth immediately made me feel a special part of the cohort. I am grateful for his knowledge and depth of understanding of Problem-Based Learning and the Research and Development process because it was the perfect solution to the challenge of my writing my dissertation.

I also want to thank Dr. Randy Hitz who, in a "meet and greet" in August 2012, encouraged me to re-enter the doctoral program and finish my dissertation. He helped to remove roadblocks, making the transition into the program an easy step. If he had not initiated that first meeting, I would not have considered re-entering the program.

I wish to thank the Confederation of Oregon School Administrators for appreciation and support of my work by assisting me with email contacts and providing a conference room for the workshop.

And I also wish to thank Connie Philibert and Andrea Watson for their assistance and skills in helping to improve my products-the handbook, workshop, and dissertation. 


\section{Table of Contents}

Page

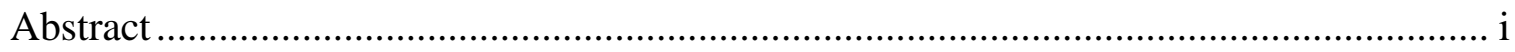

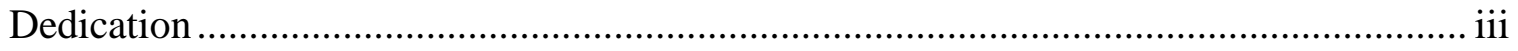

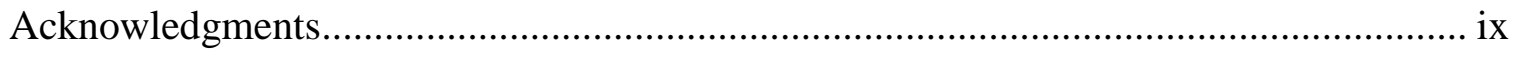

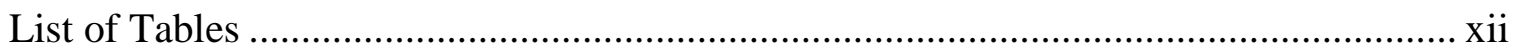

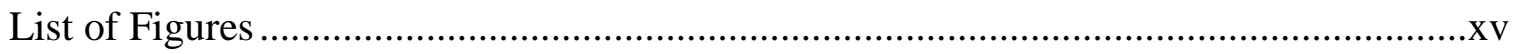

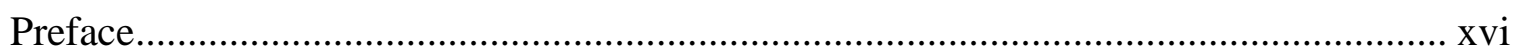

\section{CHAPTER}

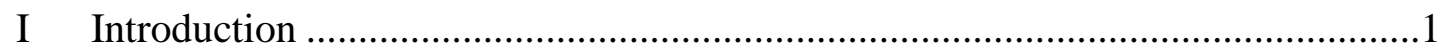

Statement of the Problem......................................................................2

Need for Capital Improvements and New Construction .................2

Complexity of Bond Campaigns..............................................4

School and District Reputation ...........................................6

Voting and the Composition of the Electorate..............................8

Sluggish Economy and Bond Cost ..........................................12

Citizen Campaign Members .....................................................14

School and District Communications ......................................15

Changing District Demographics.............................................20

Skill Set of District Leadership .............................................23 
Purpose and Significance of the Study ..............................................25

Research Methodology ...............................................................27

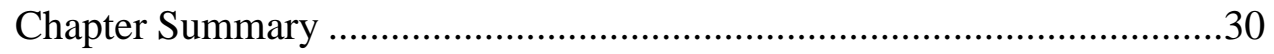

Definition of Terms........................................................................... 31

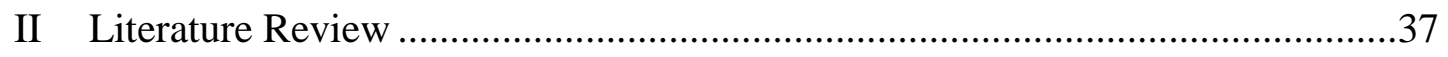

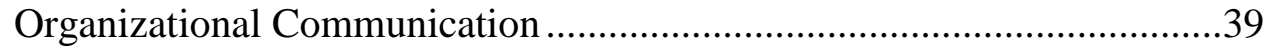

Formal and Informal Communication ...................................41

One-Way and Two-Way Communication ................................45

Communication With Internal and External Publics ...................49

Communication as a Leadership Skill .....................................59

School and Community Relations .....................................................60

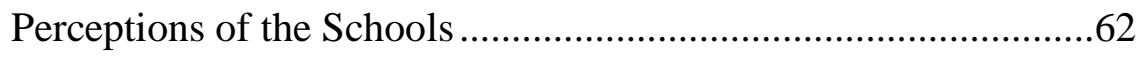

Strategies for Internal and External Communication....................66

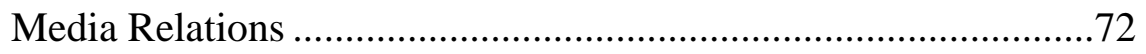

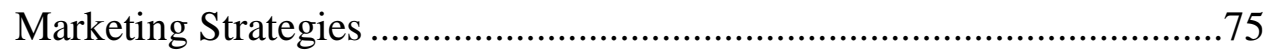

Marketing Techniques, Tools, and Publications.........................76

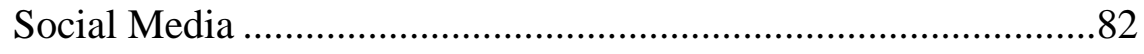

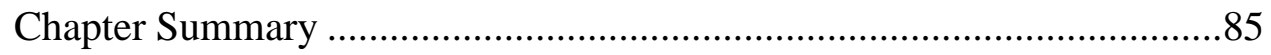

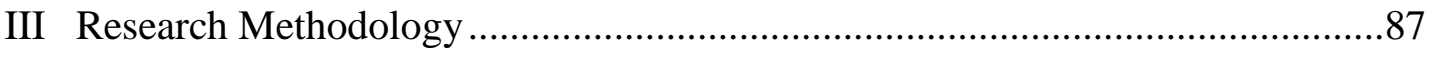

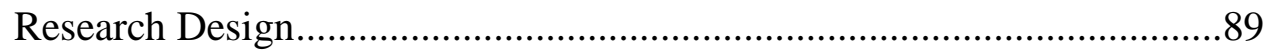

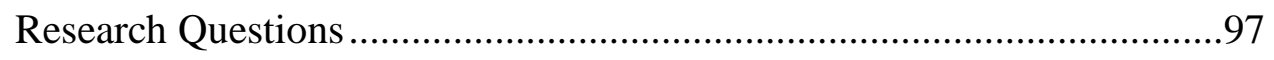

Data Collection Procedures............................................................99 
Data Analysis Strategies .......................................................................103

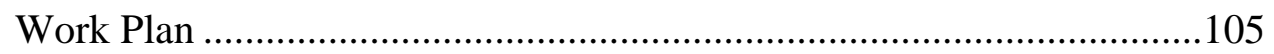

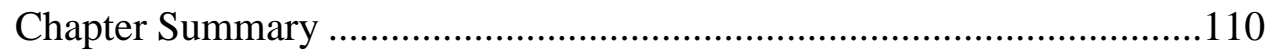

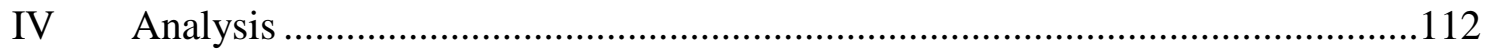

Review of the Research Questions and Goals ........................................115

Research Questions .................................................................115

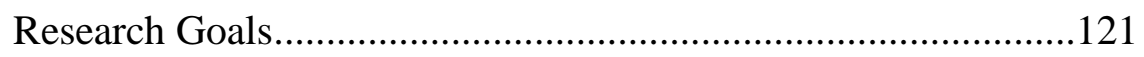

Development and Implementation: Field Testing the PBL ......................121

Step 2: Small-Scale Testing .....................................................123

Step 4: Preliminary Field Testing .................................................130

Step 6: Main Field Testing ...........................................................167

Evaluation of Results ........................................................................181

Summative Evaluation of the Results .........................................181

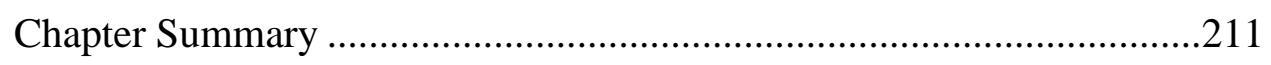

V Conclusions, Speculations, and Recommendations for Leadership ..................213

Revisions of the Handbook and Workshop …………….........................214

Launching of the Handbook.........................................................216

Step 3: Develop Preliminary Form of the Product........................218

Step 5: Main Product Revisions.....................................................222

Step 7: Operational Product Revisions ........................................226

Conclusion: Step 7, Operational Product Revision.......................237

Conclusions and Assessment of the Experience........................................237 
Operational Field Testing and Final Product Revision .242

Step 8: Operational Field Testing

Step 9: Final Product Revision .244

Step 10: Dissemination, Implementation, and Institutionalization .245

Recommendations for Leadership .246

Chapter Summary .250

References

Appendices

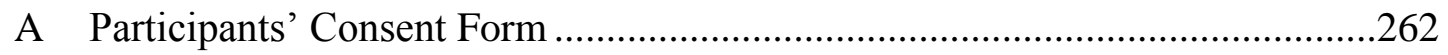

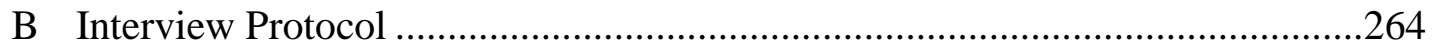

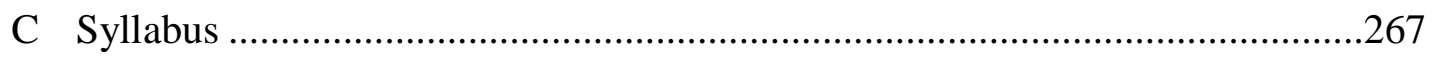

D Workshop PowerPoint Presentation .......................................................271

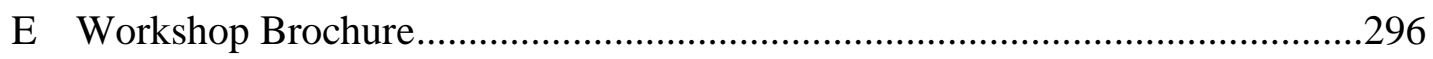

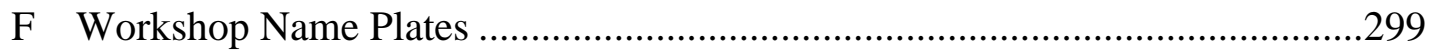

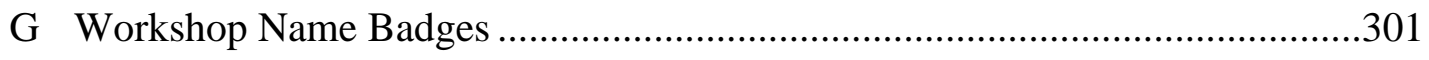

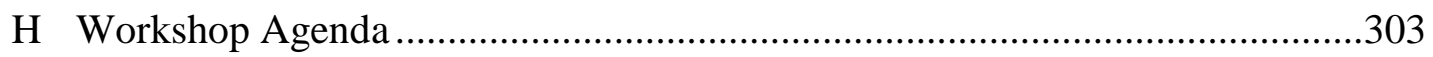

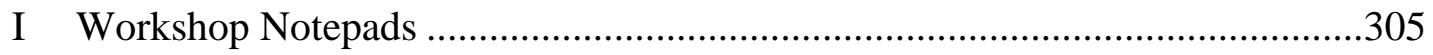

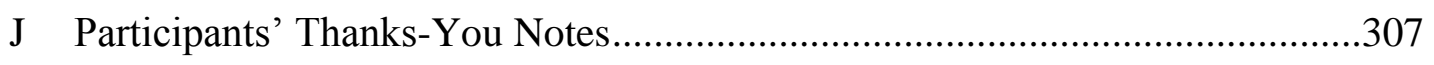

K Holding Successful School Bond Campaigns: Not for Dummies.....................309 


\section{List of Tables}

Table

Page

1 Formal and Informal Communication ....................................................42

2 Strategic Communications Plan Outline ......................................................49

3 Marketing Tools, Definition, and Characteristics ....................................... 80

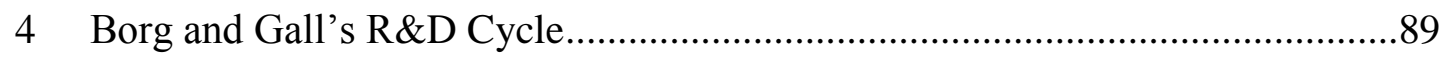

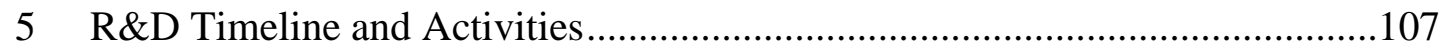

6 Interview Questions Used in Steps 2 and 3 of the R\&D Cycle .......................118

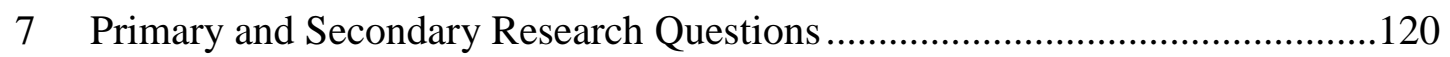

8 Small-Scale Testing: Interview Participant Demographic Information............124

9 Major Themes That Emerged From Four Combined, Coded Interviews...........127

10 Formative Interview Feedback: Primary Handbook Improvement Areas/ Advice

11 Pretest and Posttest: Communication and Campaign Strategies

Self-Assessment

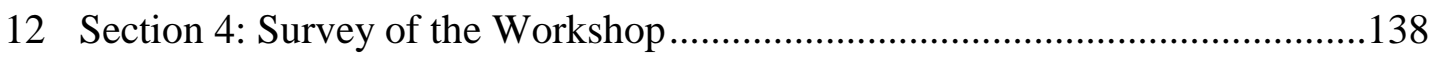

13 Preliminary Field Test Participant Demographic Data ..................................141

14 Preliminary Field Test: Familiarity of Communication Theory and Practices

15 Preliminary Field Test: Comfort of Communication Theory and Practices......147

16 Preliminary Field Test: Communication Topics-Participants Needing the Most Help 
17 Preliminary Field Test: Familiarity of Campaign Strategies.

18 Preliminary Field Test: Comfort of Campaign Strategies

19 Preliminary Field Test: Campaign Strategies Participants Need the Most Help 154

20 Preliminary Field Test: Usefulness of the Handbook 156

21 Preliminary Field Test: Effectiveness of the Handbook

22 Preliminary Field Test: Importance of the Handbook

23 Preliminary Field Test: Format and Style of the Handbook

24 Preliminary Field Test: Evaluation of the Workshop 163

25 Preliminary Field Test: Formative Results 166

26 Preliminary Field Test Surveys, Topics Covered, and Number of Questions...168

27 Areas of the Handbook Evaluated for Usefulness, Effectiveness, and Importance

28 Main Field Test Participant Demographic Data. 176

29 Participants' Level of Familiarity of Communication Theory and Practices ....183

30 Participants' Level of Comfort of Communication Theory and Practices .........186

31 Communication Topics Participants Perceive They Need the Most Help ........188

32 Participants' Level of Familiarity of Campaign Strategies .................................190

33 Participants' Level of Comfort of Campaign Strategies

34 Campaign Strategies Participants Perceive They Need the Most Help

35 Evaluation of the Usefulness of the Handbook

36 Evaluation of the Effectiveness of the Handbook .200

37 Evaluation of the Importance of the Handbook .202 
38 Evaluation of Format and Style of the Handbook .......................................206

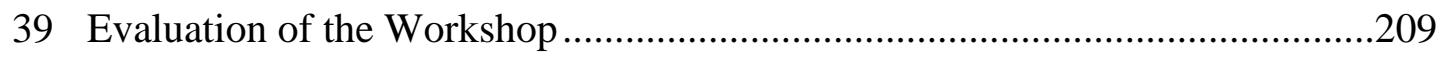

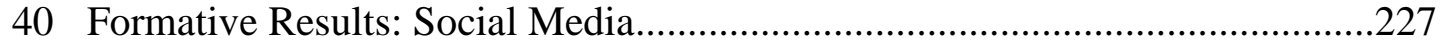

41 Number of Participants Choosing Least or Not Useful, Effective, or

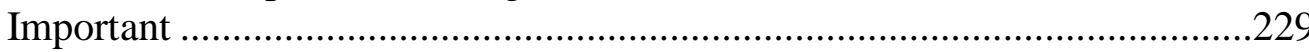

42 Formative Results: Format and Style of the Handbook ….............................233

43 Formative Results: Workshop ................................................................. 236 


\section{List of Figures}

$\begin{array}{lll}\text { Figure } & \text { Page }\end{array}$

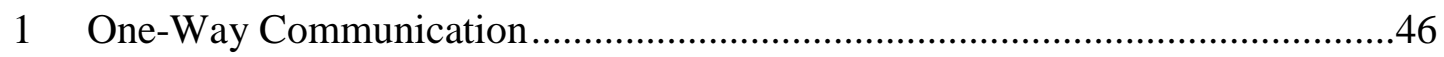

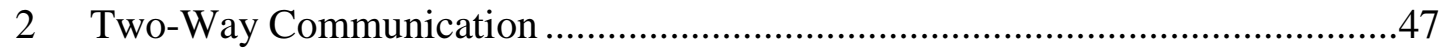

3 District Communication With Internal Stakeholders .......................................51

4 District Communication With External Stakeholders ....................................53

5 Continuum of Communication Media and Richness.......................................65 
Preface

\section{Complexities of Passing School Construction Bonds: The Tale of Two Districts}

Passing a construction bond measure is as difficult or as easy as sailing a yacht. Sailing requires a strong captain, a committed crew, appropriate preparation and supplies, good sailing weather, and a charted course. Removing one requirement will interfere with the outcomes. Just as unpredictable as sailing can be, so it is in running a construction bond campaign. Some districts seemingly sail the open seas with skill, and the voters reject the bond. Did the angry weather churn the waters, causing the rough ride? Other districts may float in the shallows, protected from danger, and pass a bond with little effort.

Why do some districts pass bond levies while others do not? Holding a bond campaign is demanding and complicated work with an unpredictable ending. A district, however, can incorporate certain steps and activities to increase the likelihood of a favorable outcome or clear sailing. That is the purpose of this handbook.

The following scenarios of Novato School District \#1 and Talent School District \#2, while fictional and embellished, describe the actual complexities associated with holding a construction bond campaign. Leaders of a campaign must be able to provide the voters with specific information about the district's capital needs. They need to have experience in conducting a bond campaign. They must assess the district's reputation and know how to communicate with the district's constituents. And they must understand the 
demographic makeup of the district and its current socioeconomic conditions in relation to the campaign.

Superintendent Young, inexperienced but confident, does not have the skills or knowledge to plot his course for a successful bond campaign and generates one poor decision after another. His destination is inevitable. Conversely, because of her rich experiences of both failed and successful bond elections, Superintendent Masters has developed the skills and knowledge. While the sailing may not always be through calm seas, her destination is in sight.

\section{Novato School District \#1}

A rural school district with a highly diverse student enrollment, Novato School District \#1 suffered repeated rejections from the voters on construction bond levies. Superintendent Young was entirely baffled with the most recent failure last night. He felt voters had been well informed about the school buildings' dire need of repair. In his estimation, construction of a new elementary school, while more expensive, was a more efficient use of taxpayer money than remodeling the old elementary school; however, he personally reduced the amount of the bond when voters rejected a costlier one that included a new elementary school. He hoped voters would see his flexibility as a positive change and support the second bond. But that was not the outcome.

The election results from the night before proved otherwise. The superintendent believed that if the district could just pass a bond that included deferred maintenancesafe, warm, and dry-with much lower costs, then buildings could be sustained for a few more years. In the past year, four bond elections were held and all substantially defeated. 
The campaign work took so much time and effort. He felt like such a failure. What happened? He sat in his executive chair, elbows planted on his desk, his hands cupping his face, and gazed out the window. Across the street was the old elementary building. In its place could have been a new elementary school or perhaps a remodeled building. But after this fourth attempt, he was ready to throw in the towel. What led to the series of defeated efforts?

Two years previously, Superintendent Young began contemplating a bond election to upgrade the five schools in the district. He had just been hired as superintendent. To his credit, he came up through the ranks of District \#1, having first served the district as a classroom teacher and then as an elementary principal. He knew the district well. He was excited about his new position and all the challenges that came with it. Now that he was at the top, he wanted to make an impression on the school board and community. Schools were in need of remodeling. What better way to demonstrate leadership than to pass a bond levy!

The district, however, did not have money to hire an engineering company or firm to evaluate the condition of the school facilities. A new architectural firm, Xavier, Inc., had contacted him about free services. If he hired Xavier as the architect for the bond projects, then the firm would conduct the district facilities audit and facilities plan including estimated costs, provide support during the bond campaign, and proceed as the architects for the bond projects once the voters approved the bond. Xavier would be paid for services already provided after the successful bond election. If the bond did not pass, the architects would still help with future bond campaigns. 
Superintendent Young sold the idea to the board, and he immediately began working with Xavier. A facilities plan was first on the agenda. Superintendent Young developed a facilities planning committee, comprised of district personnel: one principal from each level, teachers from each level, the district business manager, district curriculum director, district office classified employees, and two school board members. While it first appeared as if there were no parents or community members involved, Superintendent Young rationalized the decision by characterizing the board members as representatives of the business community and the teachers and classified employees as parents of children in the district. Xavier, Inc., led the facilities planning process during that first year and developed the plan that included deferred maintenance, capital projects, and a new elementary school.

A new subdivision directly across the street from the high school was slated for 75 stand-alone homes when completed. He knew that the infrastructure for streets, sewer, and water would begin in the fall of his second year, just in time for the public to understand that the houses equaled additional students in the district, another reason to build a new school. The superintendent thought that land adjacent to the subdivision would be in the best location for a new elementary school, and the bond could pay for the land needed. Xavier, Inc., architects began drawing up a rough sketch of plans for a new elementary school in that location in anticipation of the bond campaign.

Superintendent Young spoke with his board about the most opportune time to hold a bond election. Would an election be more favorable in November or May? More voters would vote in November and fewer in May. Which time of year would generate 
more "yes" voters? A decision was made to hold the election in November. If the bond did not pass, another election could be held in March and/or May. Even though the time of year was mid-August, it still allowed 10 weeks to campaign. The board supported the superintendent and passed a resolution to hold a \$22 million bond election in November which, when approved, would fund all of the work identified in the facilities plan including construction of a new elementary school.

Now the work would begin. First, the campaign needed a budget for advertising. To accomplish this task, he asked administrators, teachers, staff, the board, and friends in the community to contribute. Unfortunately, several employees were not receptive to personal contributions, but thought they would need to donate or be spurned by the superintendent. He pulled the former facilities planning committee members together and asked them to become the campaign committee and he encouraged them to involve their friends. He developed various committees. Committees in charge of fundraising, marketing and advertising, and voter registration were needed for the campaign. He asked everyone to volunteer for a committee and to appoint one member of each committee to lead it. He felt good about the campaign preparation.

In addition to serving two towns with a high degree of poverty, the district also served affluent families who were large landowners in the agricultural business. The school district was comprised of about $45 \%$ Latino families and an overall district poverty rate of $60 \%$ as measured by the National School Lunch Program. Twenty percent of the students were second language learners whose parents were not U.S. citizens and, 
therefore, could not vote. To save campaign dollars, Superintendent Young determined that this group did not require campaign literature.

A vocal group of district parents refused to send their children to the high school once their children graduated from the K-8 country school. After their children's eighth grade year, parents filled out paperwork for inter-district transfers to send their children to a neighboring district where they believed the high school offered better courses for their children. Superintendent Young did not want to cater to this group either. He was convinced that the affluent families in his district held the key to passing the bond, so his energies were spent building relationships with them to convince them to vote for the bond. He did not want to spend his valuable time informing people about the needs of the district when they either could not vote or would not vote in favor of the bond.

During the campaign, he recognized that an increasing number of constituents spoke out against the bond. The cost was too much. It would create an undue burden on the taxpayer. Large landowners calculated their taxes and thought they could not manage the additional expense. But Superintendent Young did not let the naysayers deter him; he continued advocating for the new school and the remodeling of the other schools. Grumblings also gushed from school administrators' conversations. They were overwhelmed with too many evening meetings and too many "volunteer" activities. Several administrators also reflected on the multiple elections violations such as conducting campaign business during district work time.

Superintendent Young should not have been surprised with the outcome of the November election. Sixty-two percent voted against the bond. The superintendent 
immediately regrouped, hired a survey company, and studied the results of the community members' perceptions of the district and the amount the taxpayers would be willing to spend. The results were not stellar. The survey outcomes concluded that there was little support for the bond at any cost. So the superintendent took a different approach, and the board approved a second bond election in May, which omitted the new elementary school, and lowered the cost to $\$ 15.5$ million. It, too, failed by a slightly higher margin. Regrouping a third time, he raised the amount to $\$ 19.5$ in a September election. He had heard from someone that voters often support a higher bond, but that too failed at an even higher level of $71 \%$.

Now, Superintendent Young was desperate. Something needed to be done. He felt as if the entire community was against him. What should he do? With optimism refreshed and additional determination, he thought of the adage: "If at first you don't succeed, try, try again.” In one last-ditch effort, he took a $\$ 4.5$ million bond to the voters in November. His idea was to complete deferred maintenance projects only: roofs, heating systems, lights, and electrical. Certainly, the taxpayers would support this one. But the resounding "no" from $82 \%$ of the voters last night told him his vision for the district did not match the community's vision. A new elementary school was not an option. Remodeling the old elementary school was not an option. Completing any safe, warm, and dry projects were not options.

"Was there anything that I would have done differently?" he pondered. "Probably not." Leaning back in his chair, turning and then staring at his computer, he decided it 
was time to search for superintendent openings in other districts. His work was finished in Novato.

\section{Talent School District \#2}

“The perfect storm!” Newly hired Superintendent Masters heard this comment for the second time during the meeting of the Facilities Task Force. She jokingly interjected that she hoped she did not sink during this perfect storm. Dr. Samuels, a local physician and graduate of the Talent School District \#2 high school, made the comment during his introductory remarks and now again as he talked about next steps. The new superintendent brought a new direction to the district, one of transparency, trust, respect, and collaboration.

She had already met with several groups of people including the civic clubs like Lions, Elks, Rotary, and Kiwanis. Her speaking engagement at the Chamber of Commerce luncheon in July was attended by more than 100 interested business professionals. There was standing room only. The audience's ovations during and after her speech about student achievement, school facilities, communications, and celebrations told her that her openness and honesty about district goals were valued and refreshing. Superintendent Masters knew that she had to make connections with district constituents well before a bond levy could be brought to their attention. A bond was the direction of the board and one of the reasons she was hired. Her previous experience in passing bond levies and her strong communication skills were qualities the members of the board sought in their superintendent search. She immediately became an active member of Chamber, the Chamber board, and Kiwanis Club. Her schedule included 
regular meetings with the publisher of the local newspaper, the mayor, the president of the college, CEOs of the hospitals and several other leaders in the community. Communication with all these groups and civic leaders would be a key factor in passing a bond.

Communication with city leadership was not her only challenge. During the previous decade, the community and district demographics had been rapidly changing. Because year-round work was plentiful in this agricultural area, Latino families, who used to be migrant farm workers, made the small city their permanent residence. This school year's demographics placed Latino students more than $60 \%$ of student body. The federally-funded free and reduced lunch counts had risen to more than $70 \%$ districtwide. The entire county also held the distinction of having the highest poverty rate in the state. In addition, only $23 \%$ of the registered voters had children in schools. A communication plan would have to be developed to ensure that each group received accurate information about the school district whether in meetings or by mail. Print materials would need to not only address each group's needs but also be translated in their home language. Passing a bond would be a challenge on several fronts.

The Facilities Task Force was a large group of committed community and business leaders, parents, board members, and a few employees of the district totaling about 50 people. Dr. Samuels was unanimously selected as the chairman of the Task Force. Both he and his wife were passionate about the school district passing a bond. His business depended on the growth of the small city. Well cared for schools indicated community support and would attract more businesses and industry to the area. The Task 
Force had initiated the facilities planning process and compiled a comprehensive document of all district facilities, culminating into a 20-year master plan, completed two years before the new superintendent was hired. Previous attempts at a bond levy had been unsuccessful. In fact, the district had not passed a bond for 30 years. In a bond attempt the previous year, voters cited district leadership as one of the reasons for voting against it in a post-bond survey. One of the leaders of that group was now a board member and an active member of the Facilities Task Force. The district had a tarnished record, and that record had to be rectified before voters would have enough faith in the district to support a bond.

The district and Task Force developed a four-phase master plan. Phase 1 was the district's responsibility to demonstrate a good faith effort in maintaining and improving existing facilities. That was accomplished during the prior two years with finishing touches in July to the high school athletic fields and gymnasiums. Phases 2 through 4 would be the voters' responsibility by passing bonds with proceeds earmarked for new schools, demolition of 1917 and 1920s buildings, and improvements upon and renovations of other school buildings.

Superintendent Masters was impressed and secretly ecstatic with the grass-roots effort. The most difficult part of passing a bond levy, she knew, was in identifying a wellrespected community member to take the lead. She did not want anyone to think that she wanted to build schools based on a conceited effort instead of a concerted effort. Passing a bond was not about her but about what was best for the community and the children of District \#2. Her job was to make sure others took the lead and received the credit for the 
work that they did. She would place her efforts behind the scenes. The discussion topic changed to wondering when the Task Force would become the Bond Campaign Committee. Superintendent Masters thoughtfully approached the topic. The longer the Task Force could delay the actual bond campaign, she stated, the better. Elections laws would activate as soon as the District \#2 board passed a resolution to approve a bond campaign. She suggested building a calendar of events leading to the board's passage of the bond resolution. In the meantime, she would develop her own communications' calendar to begin communicating specific information to the public and to the press. It was important that the community build its faith in and support of the school district first. Only then would bond passage be possible. The next Task Force meetings were scheduled. Superintendent Masters would explore ethics, campaign, and elections laws so the Task Force would become thoroughly educated. The campaign must be entirely free of any ethics or elections violations or public complaints. A clean campaign-to honor the ideals of the community-was imperative.

Young Dr. Samuels was a go-getter. He wanted to start the campaign immediately. In each Task Force meeting he wanted to begin fundraising or ordering campaign flyers and posters. The superintendent held multiple conversations with him explaining how easy it is for campaign managers to get burned out. The strategy would be to work on the plans now that would be implemented later. If the board passed a resolution in February to hold a May bond, that would then be the appropriate time period to unleash all the campaign strategies. In the meantime, the Facilities Task Force would lay plans for a bond campaign but be discreet about the district plans to hold a bond 
election. The superintendent still wanted to collaborate with both internal and external constituents about the district's vision, mission, and goals to gain their support, trust, and respect.

In November and December, Dr. Samuels and several volunteers began to collect contributions for the bond campaign. While the Task Force members knew the district had made deep cuts to its budget recently because of the economic recession, they also knew that the community was becoming more supportive of the school district. The community perceptions from a comprehensive survey provided those data. Large landowners vocally supported the new superintendent, who managed to gain their confidence. It also helped that each school board member was fully dedicated to passing the bond and often communicated such convictions with friends, neighbors, and church parishioners. The superintendent had been attending retirees' coffees and business professionals' luncheons, Chamber events, and club meetings. She held community forums to provide information about the district, the budget and financial picture, and her vision for the children of the district to all parents and community leaders at each of the elementary schools, middle schools, and high school. She met with the staff from each school multiple times to provide transparent two-way conversations that all the teachers and staff craved.

At the January board meeting, the board listened to a presentation from Dr. Samuels asking the board to approve a bond election of $\$ 45$ million, exactly the amount that had not passed in the previous bond election. 
Two weeks before the board meeting, in an intense discussion with Dr. Samuels, the superintendent held her ground in support of not changing the $\$ 45$ million bond. Dr. Samuels was considering raising the amount, maybe by just $\$ 5$ million, "for a little padding" to the construction budget.

The superintendent countered: "The amount of the bond must remain unchanged. Public support depends on trust. If the amount is changed without a significant reason, why would voters support it?" Voters would certainly use any modification as an excuse to reject the bond.

"Voters are fickle," she continued. "They are looking for any excuse to save money."

After the discussion with Superintendent Masters, Dr. Samuels agreed: No changes to the $\$ 45$ million.

The board approved the May bond election at its February board meeting. Immediately following the February board meeting, campaign signs popped up across the city, posted in several private yards, public lots, and in business windows. Campaign literature was distributed according to law; letters to the editor were strategically planned; the newspaper published an editorial in support of the bond; and the city council passed a resolution in support of the school bond. The Facilities Task Force was now the Campaign Committee.

Early in February Superintendent Masters received a call from the state education department. One of the district's schools was identified in the bottom 5\% in achievement in the state. While this was truly negative news and a black eye on the school district, the 
designation also brought with it several million dollars to turn the school around. Again, not missing a beat, the superintendent turned a negative into a positive and immediately planned how to share this information with the media, staff, parents, community, and voters. Being transparent was one of her qualities and one of the reasons the community supported her.

Superintendent Masters continued her circuit of disseminating clear information to the public. Spanish-speaking Campaign Committee members visited the churches where Latino parishioners attended and provided them with accurate information about the bond. More than $60 \%$ of the children in the district were of Latino heritage. They were recognized as an important part of the community, and targeted parent meetings with Spanish-speakers leading the meetings were also scheduled to keep parents fully informed. Other members of the Campaign Committee had frequent and ongoing discussions with friends, neighbors, and relatives. Voters were promised a Citizens' Oversight Committee to monitor bond expenditures once the bond was passed and construction begun. That requirement would be embedded into the election language on the ballot.

The third Tuesday of the third week in May arrived and the Campaign Committee met at a local Mexican restaurant. No one was very hungry, yet chips, salsa, nachos, and other snacks littered the tables in the private banquet room. What would be the next steps if the bond did not pass? Everyone waited for the polls to close and ballots to be officially counted. Eight o'clock came and went; 9:30 brought no word. At 10:07 p.m. an announcement was made. The bond was passing by a wide margin. Instead of cheers, a 
collective sigh of relief and air of disbelief filled the room. The strategic campaign paid off. Then the excitement and noise rose. "Now, the work will really begin," Superintendent Masters reflected. "Selling the bonds, selecting participants for the citizens' oversight committee, and hiring the construction management company, architects, and engineers," she thought, as she began her mental list. But most important on the list was thanking the community for its overwhelming support.

The newspaper, the next day, proudly featured a headline: "Over 65 percent of voters say 'Yes' to District \#2." 


\section{CHAPTER I}

\section{INTRODUCTION}

Seventy percent of public schools in the United States are in need of major repairs and remodeling (Picus, n.d.). The nation's children are being educated in substandard buildings with less than adequate heating, ventilation, and air conditioning. School districts' energy costs are escalating because of inadequate insulation, single-pane windows, and poor lighting. How can students learn when classrooms are too hot or too cold, when lighting flickers, hums, or gives off harmful rays, or when ceiling and floor tiles crumble, releasing harmful particles of asbestos into the air? How can children be safe in case of fire, earthquake, or other disaster? How do they receive an adequate education without the technological infrastructure and upgraded electrical systems? In most states, the school district is responsible for school upgrades through general obligation bonds. In other words, the school district must hold a bond campaign to gain voter support and trust that stakeholders vote yes at the polls. What often occurs is a "hit or miss" approach to gaining voter support. Districts attempt a bond campaign without a long-range plan or short-term campaign strategy. Districts campaign in an attempt to garner support, but in Oregon only about $60 \%$ of the districts are successful (Oregon School Boards Association [OSBA], 2012). What do successful districts do to gain the support of their constituents in bond levies?

Attaining voter support for a $\$ 4$ million or $\$ 400$ million bond requires a thorough understanding of school and community issues, including the need for capital 
improvements and new construction, the complexity of bond campaigns, reputations of schools and districts, voters and the composition of the electorate, the sluggish economy and bond costs, citizen campaign members, school and district communications, the shift in school and community demographics, and the skill set of district leaders.

\section{Statement of the Problem}

When the polls close and the ballots are counted, the best sound is the roar of ecstatic cheering from delighted but exhausted campaign committee members. A bond campaign takes an inordinate amount of work, but the results are worth the effort when the campaign is managed strategically. Districts can be successful bond recipients when they effectively market their schools to gain the support of their constituents.

\section{Need for Capital Improvements and New Construction}

School districts across the United States are in dire need of repairing, rebuilding, and remodeling aging school buildings and facilities. Some call the need a nationwide crisis (Long, 2011). Rebuild America’s Schools (2011), a federal plan that earmarked \$25 billion toward modernization of 35,000 aging schools, only touched the surface of the need. In Oregon's 197 school districts, a typical scenario is similar to the Eugene School District. Aging and dilapidated schools, some dating to the 1920s, are in need of millions of dollars' worth of repair and refurbishing in the coming years at an estimated cost of \$244 million (Palmer, 2012). Portland Public Schools (2014) geared up in the fall of 2012 for its second attempt at passing a bond for $\$ 482$ million "to keep students warm, safe and dry, save energy and support learning at each building" (para. 7). The previous 
attempt to pass a $\$ 548$ million bond in May 2011 was narrowly defeated by $51 \%$ of the voters. As one parent in support of Portland's bond described:

Our children are learning under Third World conditions...toilets not replaced since the 1950s, asbestos, poor temperature control, peeling paint, old furnaces, dirty windows and brown water...cracked floors, 30 adults using two telephones, poor ventilation, outdated electronics... right now our schools are crumbling" (McKim-Bell, 2012, p. 9A)

The description of Portland Public Schools is typical of the need in most districts.

Modernization, upgrades, and safety are necessities to provide children with school environments conducive to learning. Fortunately, for Portland Public and its children, the November 2012 bond passed by a wide margin, with 66\% voting in favor (OSBA, 2012).

No matter the district's size or location, modernization of school buildings and new construction are immediate needs. Ontario School District in eastern Oregon, for example, maintains buildings dating to the 1920s. A successful campaign led to passage of a bond levy in May 2010 for $\$ 18.5$ million but only covered about $20 \%$ of the total remodeling and replacement requirements identified in the long-range facilities plan. It is also the first bond to pass in more than 30 years.

Bend-LaPine School District reveals a different story. The district seemingly has a tradition of passing bonds, the most recent ones in 2013 for $\$ 96$ million and 2006 for \$119 million. Although Bend is considered an affluent central Oregon tourist spot, it made national news in 2007 when Donald Trump mentioned it as the place to buy real estate. Even with Bend's notoriety, Bend-LaPine School District still has its share of aging buildings. The community has supported new schools; but unlike many other districts, it also supports remodeling such as the remodeling of Old Bend High School. 
Old Bend High School was constructed in 1924 and was listed on the National Register of Historic Places in 1993. Since 1979, administrative offices, district-level programs and departments, and some student programs are housed there. The building has seen numerous remodels through the years, including the most recent work in 2006. The threestory building holds its historic grandeur intact while upgrades attempt to mask its age. Few school districts hold claim to such a supportive constituency especially for remodeling administrative offices.

\section{Complexity of Bond Campaigns}

Why do some districts enjoy successful passage of bond elections while other districts struggle to pass one? Campaigns are complex, and there is little research or literature to help guide superintendents through the complicated process. In their study of 695 Texas bond elections, Theobald and Meier (2002) examined five questions to determine which ones, if any, contributed to passage of a bond election:

1. Does the school district have pressing needs?

2. What will the bond issue cost?

3. Can the district afford the bond issue?

4. Has the district performed well with the money it has?

5. What is in the self-interest of the individual voter? (pp. 2-3)

While bond election success is shown to be "sensitive" to the district's needs, costs, resources, and the voting history of the community, the study was inclusive as to any direct correlation between the authors' findings and a successful bond election. They did find that information presented during a campaign plays a "critical role" in the success of a bond election. 
In the past five years, of the 42 Oregon districts that attempted to pass a bond, 31 school districts held successful elections, a 62\% success rate (OSBA, 2012). While the figure sounds somewhat impressive, how do $38 \%$ of the districts with defeated bond elections pick up the pieces and try again or make do with the facilities they have? Gervais School District suffered several defeated bond elections over the past several years: May 1997, \$18 million; March 1998, \$9.8 million; May 1998, \$9.8 million; May 2003, \$17 million; and November 2005, \$4 million (OSBA, 2012). Ontario School District with a similar demographic constituency passed its bond levy in 2012 .

Why do some districts pass bond elections while others cannot? The entire process is multifaceted and thus complicated. Most superintendents, school boards, and campaign committee members do not have the skills, understanding, or experience to take the lead. Bond processes, election laws, and communication strategies, for example, are not likely to be on a course list for university programs in administrative licensure. Most guides to passing a bond provide simplified tips without the essential detail for novice leaders' understanding. Meador (2013), who is typical of many authors' articles, provided a skeletal plan: Build a Foundation, Organize and Plan, Establish a Need, Be Honest, Campaign, Campaign, Campaign, and Focus on Uncertainty. Without additional guidance, district leaders are in a quandary in understanding how to proceed with the complicated task of a bond campaign. Superintendents and others require practical steps in the planning and execution of a bond election. Thus, the inexperience of leadership and lack of substantive information or materials about bond campaigns may be the primary reasons for the high failure rate of school districts passing bond elections. 


\section{School and District Reputation}

Schools and districts have reputations. When district leaders make the commitment to hold a bond campaign, they must be fully educated about their district's status in the community. Perception is the reality. Phi Delta Kappa/Gallup Poll of the Public's Attitudes Toward the Public Schools (Bushaw \& Lopez, 2012) identified the public as being supportive of local schools. Community members view their local schools more favorably than schools outside their district, which is consistent with other Phi Delta Kappa polls. About half of Americans give the schools in their community a letter grade of $\mathrm{A}$ or $\mathrm{B}$, while almost $50 \%$ give a $\mathrm{C}$ to the nation's schools. These positive perceptions, however, may not be sustained when a bond is involved. Voters are much more skeptical about their districts when their personal finances are involved.

A district should conduct its own opinion survey or opinion poll to learn how the public rates the district well in advance of a bond election. Surveys and polls also provide valuable feedback to districts to determine how much the public is willing to spend on capital projects and what district communications will need to be developed to clear up any misperceptions.

District reputations are legitimately earned whether the reputation is positive or negative. Lake Oswego School District (LOSD), for example, holds the reputation of a high-performing school district. It is also located in a highly affluent part of Oregon. Even when the board and superintendent closed schools in 2012 as a cost-saving measure for the district causing a public outcry, the reputation of the district remained unharmed. According to one resident whose job as realtor connects him with many incoming and 
exiting families, the school district is the number one reason for people to locate to Lake Oswego (Costello, 2012). The district has been well managed and led. The superintendent has served the district for more than 25 years and kept it fiscally solvent. Schools have earned the highest student achievement ratings on the Oregon Department of Education report cards over the past 4 years, and the high schools' SAT and ACT scores lead the state (Costello, 2012). In 2010 the mean SAT score of LOSD students was 1,751 , compared to 1,546 for the state. When finances became tough, the community pitched in: LOSD Foundation raised money each year for the purpose of funding teaching jobs (LOSD Foundation, 2011). In 2008 voters renewed a 5-year local option levy to supplement state funding. Not many school districts can compete with the LOSD reputation.

Reynolds School District, on the other hand, has experienced its share of negative press in recent years. Four superintendents served in a 5-year period. District office administrators, including a superintendent, were fined for ethics violations for misuse of medical benefits. Incompetent accounting practices nearly bankrupted the district. A volatile five-day teacher strike brought chaos to the district and community. Termination of a principal who allowed his license to lapse and who misused student body money hit the headlines for months. Years of lack of oversight led to mediocre student achievement scores. These negative events and actions have contributed to a poor perception of the school district. With such negative press, attempting a bond levy would not be in the best interest of the district. Yet Reynolds requires hundreds of millions of dollars in deferred 
maintenance and remodeling costs to upgrade and replace old school buildings that are literally crumbling away.

School district reputations are not required to be at an outstanding rating on surveys to pass a bond levy (Holt, 2002). The public, however, must perceive the district as having systems in place that demonstrate strong organizational behaviors in its responsiveness to the needs of children and families, a commitment to high achievement, fiscal accountability, trustworthiness, ethical and cultural values, community loyalty, and strong communication practices (Holt, 2002). The public will not support a district that is floundering. While ethical leadership, strong organizational behaviors, fiscal responsibility, and high student achievement are important, they all must be communicated satisfactorily to the public.

\section{Voting and the Composition of the Electorate}

A simple majority, or $50 \%$ plus one, is required to pass a bond election in Oregon in the May and November elections. A simple majority was not always the legal requirement to decide a taxation measure in Oregon. Before 2008, a school bond election proved to be more difficult to pass because a double majority vote was required: First, a majority of registered voters needed to cast its ballots; then, the measure itself had to pass by a majority of votes. Oregon Ballot Measure 56, which passed in the November 2008 election, changed the constitutional amendment allowing property tax elections to be decided by a simple majority of voters at the May and November elections (Brown, 2012a). Passage of this measure supposedly made it less difficult for districts to pass a 
bond levy. However, this relatively recent change has not yet shown a positive effect on districts passing bonds (OSBA, 2012).

A significant challenge of holding a successful bond campaign is in understanding the composition of the electorate, including its race or ethnicity, age of the voter, and whether the voter has school-aged children. According to the Census 2010, the Latino population is the largest minority in Oregon at $12 \%$ (U.S. Census Bureau, 2010). Oregon Common Cause 2005 data show $41.4 \%$ of the Latino population is unregistered, compared to $24.8 \%$ of the entire statewide voting-eligible population who are not registered (Thompson, 2009). When every vote counts, school districts must reach out to all the various groups despite the research indicating that those who vote tend to be "white, more affluent, better educated, older, and longer in residence than those who do not vote" (Thompson, 2009, para. 8).

Kirby and Kawashima-Ginsberg (2009) reported that an estimated 22 million young Americans under the age of 30 voted in the 2008 presidential election, two million more voters than in the 2004 election. Nationally, the youth voter turnout increased to $51 \%$ across the nation; but in Oregon the youth vote increased to $59 \%$ in the 2008 election and $69.5 \%$ for the 30 and older group.

Attracting the youth vote makes sense for bond campaigns. Some young voters in the 18 to 30 age group may still attend high school or may be recent graduates who value their experiences and investment in the school system. Some young voters may have started families, and their children will attend schools in the near future. Tanden and Johnson (2013) recognized the urgency to include this group: 
Indeed, our country's future demands that we embrace our next generation of leaders-the often-underestimated Millennials-who are the largest, most diverse, and most progressive generation the country has ever seen. And it's an electoral imperative as well-by 2020, they will make up nearly 40 percent of voters. (para. 4)

Knowing how to hook these younger voters' interest and support in schools will increase the likelihood of a successful bond.

Another group with positive perceptions of schools is parents of school-aged children. Parents are generally supportive of bond elections because their children will benefit from attending the new or remodeled school. Nationally, only $33.5 \%$ of a school district's population is comprised of families who have children aged 18 or under (El Nasser \& Overberg, 2011). In Oregon it is still lower. Just 30\% of households in Oregon have children, the lowest rate among all but seven states, according to 2010 U.S. Census Bureau data (Hannah-Jones, 2011). The picture is even starker in Portland, where only one in four homes includes a child 17 or younger. How voters perceive this gap can create additional challenges in passing a bond levy (Hannah-Jones, 2011). That means the parent voting group is perilously in the minority of overall voters. Although this group may be the most supportive of a bond levy, it alone does not have the numbers to ensure a successful bond election. In closer analysis, the parent group is also divided. Some parents may send their children to charter schools, private schools, faith-based schools, and online schools, while others may choose to home-school their children. How does the district secure support from a divided parent group?

Senior citizens are much more likely to vote than younger voters (Brandon, 2012). Nationwide, $61 \%$ of people aged 65 and older voted in the 2010 election, compared to 
$46 \%$ of all citizens. The oldest Oregon residents are the most likely to vote, with a $71 \%$ turnout among the state's 75 -and-older population. Less than half or $44 \%$ of citizens aged 25 to 44 and only a third of residents aged 18 to 24 cast a ballot (Brandon, 2012). Corresponding to the aging of America, the estimated citizen voting age in Oregon in 2010 was 53.9 (United States Election Assistance Commission, 2010).

Voters without children in school are often those voters who oppose school bonds. A 3-year study in Charlotte County, Florida, found that retirees often vote against education issues because they no longer have school-aged children, they live on fixed incomes and fear new taxes, or they are migrants with no attachments to their new communities ("Study Finds," 1991). They may feel disconnected from the schools in their community because they are not involved. If non-parents are retired and have no grandchildren or relatives in the local schools, they may not vote favorably for school bonds. Senior citizen voters also may be on a tight or fixed income. Gradstein and Kaganovich (2004) found that retirees prefer a decrease in the amount of spending on education because they will not live to see the benefits. MacManus (1995) found that although senior citizens were adverse to increases in property taxes, they were generally in favor of raising revenue for schools if they had a connection to the schools. In a Texas study conducted by Bowers and Lee (2013), the senior citizen population was found to be relatively unsupportive of new school debt. The study found that the percentage of the population over age 65 was negative and significant on the probability of passing a bond. Age of the voter weighs heavily on election outcomes. 
Whatever the voter age group, the current economy and costs of the bond are also issues that must be considered in a successful bond campaign and have a direct effect on the outcome of the bond election.

\section{Sluggish Economy and Bond Cost}

When people lose their jobs and their homes, they are not in an economic position to vote for a bond levy. The financial crisis beginning in 2008 has burdened school districts in several budgetary areas. Cutting millions of dollars out of their budgets, districts have laid off teachers and instructional aides; decreased instructional materials such as textbooks, supplementary materials, and supplies; decreased instructional hours; and decreased budgets in maintenance, technology, and transportation. In turn, districts have placed more of the burden on parents and community organizations to help. Portland City Council, for example, passed an ordinance in August 2012 for more than \$5.5 million to offset school district cuts (C. Hanson, 2012); foundations helped to rehire teachers to help lower class sizes. Some districts passed local option levies that added back revenue to their insufficient general fund. Districts have been forced to increase fees on elective classes, activities, and pay-to-play sports. Despite the poor economy, districts still need new schools, funding for deferred maintenance projects, electrical and technology infrastructures, and upgrades to existing structures.

School districts today face agonizing internal decisions because district revenue needs are so vast and varied while monetary resources for capital projects are so scarce. A local option levy, for example, is a voter-supported tax increase that would raise much needed revenue for a district to supplement its general fund budget and would be used to 
pay for employee salaries and benefits, textbooks, and technology. Raising student fees for elective classes, activities, and pay-to-play sports would mean additional school revenue, but parents would be required to open their wallets for students to participate in these extra or co-curriculum sports and activities.

School foundations and other school-focused community organizations often solicit local residents and businesses for larger quantities of money to fund certain targeted projects. If community stakeholders support a district through local option levies, pay-to-play or participation fees, or through community organizations, how can the district also ask voters for additional revenue by funding a capital construction bond, and why would parents and community members support it?

There are scarce resources and limited competing dollars. The district therefore must prioritize what is most important and evaluate what its true needs are: additional teachers to lower class size or new and remodeled buildings for children to attend? Culver School District passed a bond in 1997, in part, because the school board promised voters that students would not canvass the community with fundraisers (S. Garber, personal communication, August 2005). Voters were annoyed at the district for allowing children to peddle cheap products to raise money for every seemingly minor classroom project or field trip.

Districts seeking these community-funded opportunities may cause voters to believe that they are already solving the district's funding problems. In reality, they are simply filling the increasing number of reductions caused by the declining economy. 
However, in the perceptions of the voters, these may just be reason enough not to float a bond.

Regardless of the economy, the overall cost of the bond influences voter support. In Texas and Michigan studies, the bond amount was crucial to passage. The studies suggested that voters may have "sticker shock" if the bond calls for a large increase in taxes (Bowers, Metzger, \& Militello, 2010; Holt, Wendt, \& Smith, 2006). Voters instead tend to favor "neutral" taxation, which extends current taxes if one bond is paid off, and is seen as an acceptable way to fund needed facilities (Bowers et al., 2010).

\section{Citizen Campaign Members}

The bond is set up for failure if $100 \%$ of the board is not supportive of a bond measure (Holt et al., 2006). If 100\% board approval is first, then citizen participation comes in as number two (Holt, 2002). Holt's (2002) study of bond elections determined that the citizen campaign groups should be comprised of all segments of the community. Inclusionary district practices gave citizens a personal stake in the results of the election, and these districts saw the greatest margins of victory.

Citizen participation is a critical component of a successful bond election, but recruiting already busy leaders as volunteers to take on such a significant task is a challenge. Several different citizen groups are needed in a bond election. A facilities task force, pre-campaign citizens' group, and campaign advocacy committee, when spearheaded by leaders in the community, will lead to success at the polls (Carroll \& Carroll, 2000). Community leaders are highly respected and trusted individuals of the community. A local, well-respected Ontario dentist, who graduated from Ontario High 
School and chaired both the Ontario School District facilities task force and the bond campaign committee, helped clinch the deal. The Ontario task force and campaign committee were comprised of several prominent business leaders and land owners who were determined to pass the bond. Holt (2002) recognized that citizen participation and community leaders help to pass a bond when members take strong leadership roles in the campaign. The problem arises when these important and influential community leaders do not step forward to lead the campaign. Chance of success at the polls is highly diminished.

\section{School and District Communications}

Since the film Cool Hand Luke (Rosenberg, 1967), an often quoted wisecrack, attributed to two different characters, declares: "What we've got here is failure to communicate." So it is with school districts. Communication is generally the number one complaint from internal staff and external constituents. It is also central to the success of all challenging issues in a district (Bagin, Gallagher, \& Moore, 2008). A key component of an effective bond campaign hinges on a strong communication plan. The plan, however, must be implemented well in advance of any public announcement of a bond campaign. Open, honest, transparent communication builds public confidence and trust in the district. In the absence of trust, so is an absence of supportive voters. The importance of communication cannot be underestimated: It makes or breaks a bond campaign. Bagin et al. (2008) described the vulnerability of school districts in communicating with the public on finance issues: "If a school district does not maintain ongoing and clear 
communications with its parents and taxpayers on finance and budget issues, confusion and distrust can develop" (p. 297).

Internal communication. To prevent confusion and distrust, both internal and external communications must be employed to reduce or prevent negative perceptions of school districts before a bond campaign becomes public. An internal communication plan sets its targets on employees of the district. Often dismissed by the administration as unimportant in a communication plan, internal communication is likely to be the most important communication strategy to improve the district's image in the community and in gaining support of constituents in a bond campaign (Bagin et al., 2008). The public sees district employees as ambassadors of the district. The public instinctively believes what employees say about the district, whether the employee is a teacher, secretary, bus driver, or cook. The public believes that working in the district means employees have the most accurate information and the most accurate perceptions of the district. In short, employees are trusted (Hughes \& Hooper, 2000). To impact community relations and to impact the district's image, the communication plan must emphasize building a strong relationship with its internal constituents. Employees are the frontrunners of the district who candidly talk with friends, neighbors, relatives, and business representatives about the schools and are likewise potential voters if they live in the district. A district's internal constituents should be strong advocates of the district and schools who spread accurate and positive messages about the district to the general public and be considered dependable yes voters. E. M. Hanson (2003) cited difficulties associated with internal communication as a result of institutional climate. A lack of shared values and beliefs, 
social behaviors, a lack of resources, and a flawed organizational design can all lead to poor internal communications.

External communication. Communicating with external constituents, those individuals or groups not employed by the district, is of equal importance. Stover (2012) termed a bond a "tough sell" to the public. That "sale" takes place at least a year in advance of the bond election by the superintendent, school board members, and others through the building of strong relationships with key external constituents. Stover identified five external groups to help convey the district message: key communicators, advisory councils, partnerships, focus groups, parent groups, and "blut und bod" or blood and body, which are special interest groups literally rooted in ethnic or racial heritage such as Latino and Russian groups in the Portland metropolitan areas. How to meet and greet these diverse groups and begin meaningful conversations must be established by using the most appropriate action or media.

Just as Barack Obama used key Internet-based strategies to set him in a position to win the 2008 presidential election, strategic social media communication tools such as Facebook, Twitter, and blogs are equally useful to gain public support in a bond campaign. Harfoush (2009) detailed how effective the Internet and social media strategies were to the 2008 Obama campaign. Use of the Internet captured the vote and support of younger citizens and raised valuable campaign dollars. The extent of using the Internet as a communication tool in the Obama campaign was groundbreaking. When Ontario School District decided to conduct a bond campaign during the 2009-2010 school year, several younger teachers and parents volunteered to serve on the campaign committee 
and began planning Internet-based campaign strategies. A Facebook page and Twitter account were developed. The Facebook page provided ongoing updates about the campaign, requested campaign contributions, and gave instructions on how to become involved. An online list showed hundreds of hits in support of the bond. Tweets were sent to encourage 18-year-old students to register to vote. Bloggers followed the local newspaper blogs and interjected when more accurate information was needed.

Strategically-placed bloggers prevented negative comments about the district to spread. YouTube videos delivered personal accounts of the facilities and need for voters to support the bond. Ontario's bond campaign was truly a contemporary technological effort.

One-way communication. Traditional forms of one-way communication such as letters to the editor, flyers, advertising, and yard and store signs are still important to a bond campaign. However, the type of communication literature, targeted to specific age groups or audiences, must be examined to ensure the greatest impact. Likewise, campaign literature must also be closely scrutinized to convey the intended message. In Ontario School District a sub-committee of the campaign committee distributed literature to internal and external stakeholders that detailed certain construction projects that would be completed at each school in the district. The information shared, however, conflicted with the ballot message. Fortunately, the problem was discovered and resolved after the successful election. While campaign literature can provide important key points of the bond projects, the campaign committee must examine the literature and materials 
carefully before distribution. Does the information correspond to the intended message? Is there any misinformation? Or is there too much information?

Two-way communication. For both internal and external constituents, the greatest impact is face-to-face, two-way communication. While this form of communication is time consuming, it is the most effective because it develops trust and can be accomplished in question-and-answer meetings, focus groups, advisory teams, coffees with groups, and speaking engagements (DeBruyn, \& DeBruyn, 1987). A Redmond superintendent said she felt like a "prostitute" hustling votes when the school district was in the middle of its bond campaign. She visited downtown businesses, spoke about the bond with the owners, and received their feedback. She talked with people on the street and customers in the stores. As a result, nearly all businesses supported the bond and placed campaign signs in their business windows to broadcast their support. The Redmond School District passed the $\$ 110$ million bond in the May 2008 election with $58.8 \%$ of the voters casting yes ballots (V. Fleming, personal communication, February 8, 2014).

Communication must be personalized for the audience by using campaign literature, media, and multiple venues to reach diverse audiences. This does not often happen. It must be planned for and developed in a comprehensive communication plan. Communication is a massive undertaking but is a requirement in order to experience a successful bond campaign. District leaders must identify the different groups comprising the school district communities, provide accurate and objective information to both 
internal and external constituents, and win the confidence and trust of the district's constituents so that they vote yes in the bond election.

\section{Changing District Demographics}

Important demographic information to consider in a bond election includes race and ethnicity, social-economic status, and age of voters. Districts in high poverty and highly diverse communities may have more difficulty passing bond elections if each of the groups is not included in the communication plan. Sometimes key groups are ignored because of language barriers, and then they do not receive important information. Leaders of the bond election need to be strategic in understanding the composition of their communities. For example, statistics on poverty indicate that $15.8 \%$ of the Gervais School District community is in poverty (Proximity Resources, 2012b). The school district community is comprised of $40 \%$ Latino, $1 \%$ Asian, $0.4 \%$ Black, and $0.7 \%$ American Indian (U.S. Department of Education, 2010). Gervais has not passed a bond election in the past 20 years although district leaders have attempted five elections (OSBA, 2012). How have leaders reached out to each of the groups during the various campaigns? How were they included in the communication plans and the campaign committee?

A high poverty rate and ethic and cultural diversity, however, are not necessarily contributing factors to failure of a bond election in Oregon or a factor at all. The residents of the Ontario School District community, for example, have a $19.4 \%$ poverty rate, and are comprised of 31\% Latino, 2\% Black, 1\% Asian, 1\% American Indian, and 0.2\% Hawaiian/Pacific Islander (Proximity Resources, 2012c). Ontario passed a bond election 
in 2010. Ontario's demographic composition and its passage of a bond election are not the national norm. A study completed by the 21st Century School Fund with Building Educational Success Together (as cited in Filardo, Cheng, Allen, Bar, \& Ulsoy, 2010) discovered disparity in spending by school districts to provide healthy, safe, and educationally adequate school facilities. During the period from 1995-2004, the lowest income communities had by far the least amount of spending to improve facilities. Overall, Oregon ranked 39th in the U.S. in per-student spending for capital projects (Filardo et al., 2010).

In the 2003-2004 school year Ontario School District's demographics changed to reflect conditions that had been predicted in the late 1990s for urban school districts. Racial and ethnic minority groups would become the majority. In a Census 2010 report, minority groups were identified as the majority in 22 of the nation's 100-largest metro areas (Frey, 2011). By the year 2023, minority youth in America will become the majority youth in America (Oregon University System, 2012). In several Oregon districts, minority groups comprise the majority: David Douglas, Forest Grove, Gervais, Hood River County, Jefferson County, Morrow County, Nyssa, Ontario, Parkrose, Reynolds, Umatilla, and Woodburn (Oregon Department of Education, 2013). While a few districts have held this status for several years, other districts have acquired the status more recently such as Forest Grove in 2011-2012.

While a majority of students who are racially and culturally diverse may make up the majority of students in the district, the surrounding community does not often parallel the diversity of the schools. According to 2010 Census, community demographics of 
Ontario School District in eastern Oregon stands at 35\% overall minority rate; however, the school district demographics changed to a minority-majority status during the 20032004 school year (U.S. Census Bureau, 2010). The general public, however, was unaware that minority groups comprised $60 \%$ of the total school district population until 2010 , while I served as the superintendent. That year I reported the conditions of the school district while speaking to the Ontario Chamber of Commerce in August. The school district had passed a bond levy the May. Would the bond have been in jeopardy of passing if the general public had been aware of this demographic shift?

While this question may be unsettling to some, it had to be asked. At different meetings that I would regularly attend, stakeholders would inquire why the school district would offer an education to "those Mexicans." I would have to explain that in the United States we offer a free education to all children. A common retort was to send them back. "It isn't right that our tax dollars go to those kids." The question of passing a bond is a valid one when clearly so much racism still exists in the $21{ }^{\text {st }}$ Century. Two studies affirm this. Tedin, Matland, and Weiher (2001) and Theobald and Meier (2002) suggested that a high level of racial resentment leads to a negative vote on school bonds. Theobald and Meier called it self-interest while Tedin et al. called it racism.

David Douglas School District, located in east Portland, passed a $\$ 49$ million bond levy in May 2012. Over the past 10 years, it too experienced changing demographics. In $2002,70 \%$ of the school district students were white; in 2012, minority groups made up the majority. In contrast the David Douglas external community is comprised of 73\% White, 6\% Black, 2.1\% American Indian, 10\% Asian/Pacific Islander, 
and $4.2 \%$ other (Proximity Resources, 2012a). Despite the demographic variance between the David Douglas community and David Douglas School District, it passed a bond levy with $60 \%$ approval rate. Is demographic disparity a factor in whether a bond is passed? Passage of bonds in Ontario and David Douglas seem to challenge the assumption that changing demographics could be a factor in a district not passing a bond election. Research does point to poverty as a key factor and not the racial composition of the district. In a Michigan research study of 789 bond elections, Bowers et al. (2010) found the general socioeconomic status of the district to be significant in predicting bond passage, citing the higher the number of students living in poverty, the lower the chances of a district passing a bond election. Nonetheless, community and school district demographic data must be seriously considered as a potential challenge in the bond election process. A strong communication plan that targets each of the community groups may be the game changer.

\section{Skill Set of District Leadership}

Who are the leaders, what are their functions, and what leadership qualities are essential? In a bond campaign, several different leaders are essential, but the most important leaders of the campaign are the superintendent, school board members, and school principals. The superintendent is expected to rally the troops, understand the bond process, teach the bond process, keep everyone focused on the goals and objectives of the bond, and obey campaign and elections laws-not a simple undertaking.

The skill set of the superintendent. A major caveat of the bond campaign process is the expectation that the superintendent is knowledgeable and experienced in 
bond campaigns. Most superintendents, however, are amateurs and will often learn from the experiences of their past failed bond elections. Boards and, to some extent, the public expect the superintendent to lead the bond process and be well informed and capable in election procedures, especially in smaller school districts. However, few universities offer administrative coursework to accomplish the task of passing a bond (Holt, 2002). When essential coursework is missing, then expertise falls onto the inherent leadership skills of the superintendent. Hoy and Miskel (2001) classified key traits associated with strong leadership effectiveness under the categories of personality, motivation, and skill, and these key traits may be sorely lacking in a superintendent's skill set. Thus, the outcome of the bond campaign is tenuous.

Skill set of the school board. The bond is set up for failure if $100 \%$ of the board is not supportive of a bond proposal (Holt et al., 2006). Board members must agree unanimously to support a bond. If individual members of the board cannot agree to support a bond, then the board should not approve taking those next steps. Holt (2002) maintained that the "failure of the board to reach a consensus appears to doom the results of the election" (p. 23).

Any negative vote from a board member about the bond is cause for public alarm. For example, when I served as superintendent of Culver School District, two board members publicly opposed the bond levy at a school board meeting because they did not want their own taxes to be increased during a difficult economic period. This public announcement guaranteed an unfavorable election: Only $38.1 \%$ of the voters supported the bond in the November 2006 election (OSBA, 2012). 
Skill set of school principals. While it is important for the board to be in full agreement, the board should not attempt to lead the campaign. Often, the results are negative (Holt et al., 2006). The same is true for the principals of the various schools in the district. Elections laws also prevent too much rallying of the troops. Members of the staff and principals of schools can and should advocate for new construction and upgrades with community partners, parents, and staff, but not during work hours. During work hours, public employees must provide only factually-based school bond election information to satisfy the guidelines of the elections laws. School principals must be careful that their staffs fully follow the elections laws. However, board members are allowed to advocate fully for passage of levies; elections laws do not apply to elected officials.

A caveat that can turn an election is in personnel issues. Some disgruntled administrators may try to undermine the process by publically criticizing the bond or the projects. Such personnel issues can disrupt a campaign. Negotiations, grievances, plans of assistance, employee discipline issues, and even votes of "no confidence" can impact the outcome of a bond campaign. In case of such events, they must be planned for in the district's communication plan.

\section{Purpose and Significance of the Study}

Superintendents are generally unprepared for leading a bond campaign. While they have ample academic preparation to take on the work of the school district, they often are ill prepared for understanding the process of a bond campaign because of a lack of practical field experience (Holt, 2002). Most leaders gain this experience through trial 
and error. As a result of my observations and experiences, I developed a handbook for superintendents and other district leaders to use so they would better understand the campaign process and apply the key strategies essential to operate a successful bond election. The handbook informed and guided superintendents and other district leaders through a bond campaign process and election. Testing of the handbook, Holding Successful Bond Campaigns: Not for Dummies, answered my major research questions:

1. How useful is the handbook to district leaders embarking on a school bond election?

2. How effective is the handbook to district leaders embarking on a school bond election?

3. How important is the handbook to district leaders embarking on a school bond election?

Many school buildings are in such disrepair that they are literally falling down. In my research, I found a picture of a large brick chimney that fell through the roof of a middle school and into the classroom (Holt, 2002). Fortunately, no one was hurt. An interesting side note is that I taught in this building during the 1983-1984 school year when the West Central School District in South Dakota attempted a bond. It did not pass at the time because the Humboldt community still resented the Hartford community. A district merger forced the Humboldt middle and high school children to travel 15 miles into Hartford to attend school. That merger took place in the early 1960s. A bond was finally approved in the early 2000s. Institutional memory persists and is not easily forgotten in school district communities, and those rigid memories can be overwhelming obstacles for any district attempting a bond. 
School districts across the United States are in dire need of repairing, rebuilding, and remodeling aging school buildings and facilities. Some call the need for new buildings and remodeled facilities a national crisis (Long, 2011). Aging and dilapidated schools require millions of dollars' worth of repair and refurbishing (Palmer, 2012). Yet, school districts are not funded adequately to remodel their schools. Districts must instead rely on voters to pay the bill. This is a distinct disadvantage for most district leaders who have had little to no experience in working with their communities to pass a bond.

Workshops on holding bond campaigns are limited or nonexistent; the literature is also insufficient for guaranteeing districts a win at the polls. The OSBA offered the Bonds and Ballots workshops annually; but the economic decline in 2008 forced OSBA to discontinue its 1- to 2-day event. In the winter of 2013, three firms-a securities company that sells bonds for school districts, a communications company, and an opinion research company-held their version of a finance campaign workshop under the sponsorship of OSBA (2013b), but the agenda was restricted to each company's function and operated like a prolonged TV infomercial or high-pressured real estate tactics. This is just one example of why the handbook is so essential for school districts struggling to pass a bond election. District leaders need to know the strategies that successful districts employ to gain public support in bond elections without the added burden of a sales pitch.

\section{Research Methodology}

My work is theoretically grounded in problem-based learning as defined by Bridges and Hallinger (1995). I used this model to address a real problem in the practice of school districts' inability to pass bond levies. As superintendent, I was fortunate to 
pass a bond levy in Ontario School District. However, I also have experienced a number of failed bond elections, once as a superintendent and several times as an administrator working in other school districts. The importance of having successful strategies published in a useful handbook will help to fill a void for other superintendents attempting a construction bond election. Most school districts in Oregon do not have the resources to hire outside consultants to run a bond campaign. That leaves superintendents to their own individual skills and knowledge.

My dissertation followed the research and development (R\&D) cycle to create and field test the handbook for school district leaders (Borg \& Gall, 1989):

Steps in the R\&D Cycle

1. Research and information collecting

2. Planning objectives, learning activities, and small-scale testing

3. Develop preliminary form of the product

4. Preliminary field testing

5. Main product revision

6. Main field testing

7. Operational product revision

8. Operational field testing

9. Final product revision

10. Dissemination and implementation. (pp. 784-785)

Step 1, "Research and information collecting" generates as much information about the problem as is available. In this step I researched the existing literature and developed a review of the research and literature on the topic. I prepared questions for conducting a small-scale research in Step 2. This helped me to develop a broad and deeper understanding of the problem and begin an outline of the essential strategies needed in the handbook. I started a draft of the handbook. 
Step 2, "Planning objectives, learning activities, and small-scale testing" broadened my understanding of problem, identified my audience, and initiated a rough draft of the handbook. In Step 2, I conducted the small-scale testing and interviewed two superintendents, one communication director, and one finance/operations director whose districts recently passed bond elections.

Step 3, "Develop preliminary form of the product" is the culmination of the planning in Steps 1 and 2. In this step I revised and expanded the handbook based on the interview results of the small-scale testing in Step 2.

Steps 4 and 5 are "Preliminary field testing" and "Main product revision." These steps involved obtaining "an initial qualitative evaluation of the new educational product" (Borg \& Gall, 1989, p. 790), similar to a rehearsal for the Main field test. In this step I prepared a mini workshop of 3.5 hours for five district leaders (three superintendents, one communications director, and one principal) who were contemplating a bond campaign in the next one to two years. The handbook was the main text. Surveys were administered as a pretest and posttest to determine the participants' learning. Surveys were also administered to determine the efficacy of both the handbook and the workshop. Results of the surveys were used in Step 5 to revise the handbook and workshop in preparation of Step 6.

Steps 6 and 7 are "Main field testing and Operational product revision." These steps required implementation of the handbook and collection of key data relating to the handbook's efficacy. Main field testing took the form of a full-day workshop for superintendents and other district leaders who were planning a bond election in the next 
one to two years. The handbook was used as the main tool. The same surveys were used in the Preliminary field testing. Feedback from participants provided a summative and formative evaluation of the usefulness, effectiveness, and importance of the handbook and the workshop.

Steps 8,9 , and 10 require the researcher to determine whether the product can stand on its own merits and whether it is of publishable quality. In Steps 8 and 9, Operational field testing and Final product revision, the product is used in a variety of natural settings and data is then collected from others who are using the product as well as from their participants. Step 10, Dissemination and implementation makes others aware of the product through publications, presentations, or articles published about the product.

Bridges and Hallinger (1995) recommended Steps 1 through 7 for students designing dissertation projects. Steps 8, 9 and10 are left to the students' own discretion. Therefore, for the purposes of this study, consideration for these last steps is discussed in chapter 5.

\section{Chapter Summary}

The 17th Annual School Construction Report (Abramson, 2012) described school construction across the U.S. as averaging more than $\$ 20$ billion annually from 2000 through 2008. In 2010, however, as an effect of the recession, construction fell to $\$ 14.5$ billion. This downward trend continued in 2011 to $\$ 12.4$ billion with total construction in 2012 to be even less, in the $\$ 10$-billion range, half of what it was before the recession. Economics has had a serious impact on whether a district passes a bond, but numerous 
other factors also influence whether a district experiences a successful campaign.

Attaining voter support requires a thorough understanding of school and community

issues. Passage of a bond in one school district does not guarantee that a bond will pass in another even if all tools and tactics are replicated. Demographics, the district's internal and external constituents, and the leadership team, for example, are often disparate from one district to the next.

A successful bond campaign, however, is grounded in certain key processes that are related: Assessing the need for capital improvements and new construction, determining the complexity of the bond campaign, judging school and district reputation, investigating voters and the composition of the electorate, assessing the sluggish economy and bond costs, describing effective citizen campaign members, rating school and district communications, evaluating the shift in school and community demographics, and appraising the skill set of district leaders.

Once the processes of a bond campaign are fully explored, developed, and analyzed, the district will then be equipped to operate a successful bond campaign.

\section{Definition of Terms}

Bond Measure. A bond measure is a public school district election to finance a new construction or other capital projects. District school boards place these measures on the ballot to be approved or defeated by the voting public. Under Oregon law, all ballot measures must have a caption of not more than 10 words to headline the measure, a question of no more than 20 words that lists the purpose of the ballot question, a concise 
and impartial statement of not more than 175 words summarizing the measure and its major effect, along with a response of "I Vote Yes" or "I vote No."

Bond Campaign Committee. The bond campaign committee, a political action group, is a collection of devoted citizens who manage the school district bond campaign. The committee's mission is to advocate for new construction and/or capital improvements, gain the support of yes voters, and help pass the bond levy. Campaign committee members, as long as they are not employees of the district, are not restricted by Oregon ethics laws and can openly promote the bond election.

Bond Cost. The bond cost is the dollar amount assessed to the taxpayers to repay the district's indebtedness. It is based on payment of the principal plus interest as applied to the total property valuation in the school district. Interest rates are determined not only by the current interest rate but also the district's credit rating as determined by rating companies such as Moody's Investors Service and Standard and Poors Corporation. The rating is similar to an individual's credit score when purchasing a house or vehicle. The higher the rating, the lower the total cost. The taxpayer typically sees school district language about bond costs as represented in the following example: The proposed $\$ 195$ million in bonds would cost property taxpayers an estimated average of 51 cents per $\$ 1,000$ of assessed value per year over the life of the bonds, generally twenty years. This tax would begin no sooner than the 2013-2014 fiscal year. For example, a taxpayer who owns a $\$ 250,000$ home would pay an estimated $\$ 127.50$ per year or $\$ 10.63$ per month. 
Bond Levy. A bond levy is an amount of money a district asks voters to approve in an election in order for the district to sell bonds to purchase land, build new schools, renovate existing facilities, purchase technology, and furnish and equip new construction.

Capital Projects/Capital Construction. Capital Projects/Capital Construction includes the acquisition of land or buildings, renovation of existing buildings, improvements to district facilities, and new construction.

Communications. Communications is the overall formal or informal exchange or transmission of information.

Community Partners. Community partners are individuals, businesses, or organizations who provide time, resources, or financial support to schools. Some business or organization partnerships may also be contractual in exchange for services provided to students.

Constituents. Constituents are the people whom the organization serves, advocates, or organizes.

Deferred Maintenance. Deferred maintenance is the upkeep, repairs, and preventive maintenance of buildings that are often put on hold, neglected, or ignored because of limited resources.

Electorate. The electorate is the voting public.

Elections Law Violations. Oregon's constitutional and statutory provisions of elections laws are located in chapters 246 through 260 from the Oregon Revised Statutes (ORS). Election law, ORS 260.432, provides restrictions on any political campaigning by public employees. Specifically, for schools districts and school personnel, elections laws 
prohibit the use of taxpayer dollars to support a bond campaign. For example, school district employees would be in violation if, while on district time, they wrote, edited, and published a brochure that would be considered a political ad. A comprehensive memorandum on ORS 260.432, "Restrictions on Political Campaigning by Public Employees," is available upon request from the Secretary of State's office.

Ethics Laws. Provisions of Ethics Law prohibit any public official from using the position or office held for financial gain. For example, public officials who authorize or have a significant role in a contract while acting in an official capacity may not have a direct, beneficial, financial interest in the public contract in their current capacity or for two years after leaving the official position. Likewise, a member of a board or committee of the board or other governing body who participates in the authorization of a public contract may not have a direct, beneficial, and financial interest (ORS 244.047). Members of a citizens' oversight committee, appointed by the school board, for example, are considered a committee of the board and are legally bound by the ethics law.

External Communication. External communication is the formal or informal exchange or transmission of information between a school or district and other organizations, groups, or individuals outside its formal structure.

General Obligation Bond. A general obligation bond or municipal bond is backed by the credit and taxing power of the issuing school district rather than the revenue from a given project. General obligation bonds are issued with the assurance that the school district will be able to repay its debt obligation through taxation. No assets are used as collateral. 
Internal Communication. Internal communication is the formal or informal exchange or transmission of information within a school or district and other schools or individuals inside the school's or district's formal structure. It is the flow of information between or among employees or departments and across all levels or divisions of an organization.

Marketing. Marketing for a school district is creating or offering services that are perceived as valuable to others. Are children receiving the best education possible? Are parents satisfied with school district services? Do potential taxpayers and businesses want to relocate into the school district boundaries? The district markets its programs or creates services based on the perceptions and needs of the consumer. In this case, the consumer is defined as students, parents, taxpayers, and the greater community.

Modernization. Modernization refers to remodeling, upgrading, and/or renovating existing structures.

New Construction. New construction refers to site preparation and construction of an entirely new structure and/or significant extension to an existing building, whether or not the site was previously occupied.

School and Community Relations. School and community relations is the relationship that the school district develops with its external stakeholders and constituents through one-way and two-way, formal or informal, information flow, communication, and dialogue.

School Bonds. School bonds, also called general obligation bonds, are bonds a school district sells to fund capital construction projects. School bonds are a cost to 
taxpayers in addition to school taxes and must be approved by the district's voters. When the bond election passes, the district sells bonds to investors who will then be paid principal and interest during a period of not more than 40 years.

Stakeholders. Stakeholders are the people who care about an organization and consider it their own. They are the school board, employees, volunteers, parents, business partners, and contracted businesses, groups, and/or individuals.

Successful Bond Campaign. A successful bond campaign is a culmination of events and the united efforts of the school board, superintendent, parents, citizens, and school district employees, coupled with a well-developed strategic plan, to attract voters to support a school district's construction bond levy, which ends in an election victory. 


\section{CHAPTER II}

\section{LITERATURE REVIEW}

Salem-Keizer School District passed the largest K-12 bond in Oregon state history in 2008. Fifty-eight percent of the voters supported the $\$ 241.1$ million bond. Fast forward to 2012. Portland Public School District passed the largest K-12 bond in state history when voters approved a $\$ 482$ million bond. What do successful bond campaigns have in common? Effective communications. "Effective communication is the key to a successful campaign," Stephanie Curtis, Redmond School District's communications director, said after Redmond passed its 2008 bond levy for \$110 million (OSBA, 2008). Curtis has the belief that a "clear, concise, and consistent message" builds strong relationships and trust with the community and is pivotal in operating a successful bond campaign. Construction bond elections are often seen by school boards and superintendents as a "necessary evil" because passing a bond election is a massive undertaking in order to finance the remodeling or rebuilding of outdated and crumbling schools (Johnson \& Ingle, 2008).

While a bond campaign does take the focus away from the academics, an additional problem arises. Specific guidance in holding bond elections is not readily available. The OSBA used to offer a Bonds and Ballots workshop annually; but in recent years, as a result of the downturn in the economy, the organization has not hosted the full-day event. In the winter of 2013 three firms-a securities company that sells bonds for school districts, a communications company, and an opinion research company-held their 
version of a finance campaign workshop under the sponsorship of OSBA (2013b), but the agenda was restricted to each company's function. Obviously, the companies promoted the 4-hour workshop (with pizza) in anticipation of acquiring additional business, much like a prolonged TV infomercial. That is one reason why that a handbook is developed for school districts struggling to pass a bond. District leaders need to know the strategies that successful districts employ to gain public support in bond elections without the added burden of a sales pitch.

While workshops on holding bond campaigns are limited or nonexistent in this economically depressed period of history, the literature for holding successful school bond campaigns is also insufficient for guaranteeing districts a win at the polls. Ample literature and research have been published in the past century that describe effective leaders and leadership qualities and skills necessary for top school district positions (Leithwood, Jantzi, \& Steinbach, 2000). Typical administrator and superintendent licensure programs all require courses in leadership; and while research has linked qualities and skills to increased academic performance (Darling-Hammond, LaPointe, Meyerson, Orr, \& Cohen, 2007), little evidence has linked these same qualities and skills to passing a bond levy. In practice, however, the communication skills of the school district leaders and the district's strategic communication plan, which include precampaign, during the campaign, and post-campaign activities, seem to be the leading indicators of whether the district will realize a successful election outcome. How districts communicate with their numerous and varied constituents is tantamount to gaining public support in construction bond levies. This literature review describes the communication 
strategies that are most important in garnering district support, which, in turn, would lead to a successful outcome in a bond campaign. This review describes the communication strategies in three areas: organizational communication, public relations, and marketing.

\section{Organizational Communication}

Why is communication important? First and foremost, communication develops trust. Covey (1989) introduced the concept as an emotional bank account "that describes the amount of trust that is built up in a relationship" (p. 188). Just as with any bank account, people can make deposits and withdrawals. However, instead of dealing with units of monetary value, people deal with emotional units, and these are, according to Covey, units of trust. If a positive reserve is kept in relationships by making regular deposits, there is greater tolerance for mistakes; and open communication is the result. However, when withdrawals are made and the balance becomes low or maybe “overdrawn," then bitterness, mistrust, and discord develop. If a relationship is to be salvaged, a conscious effort to make regular deposits must be employed. So it is with communication. Ongoing communication, when planned appropriately, will develop that high level of trust so that if a withdrawal is made, it will hardly be noticed. Covey said that people would know you, understand, and not worry about the withdrawal.

Broadening Covey's (1989) definition of trust, Bowman (n.d.) added five key actions to building trust: possessing personal integrity, communicating the vision and values, treating employees as partners, focusing on shared goals, and doing what is right. Gunther, McGowan, and Donegan (2011) built further on the definition of trust with specificity of actions such as being transparent with financial records, giving stakeholders 
a voice, being open and honest, and valuing and acting on feedback. Trust was an integral part of how I passed the bond in Ontario School District. When I began my position as superintendent in July 2009, I found that the community was eager for open, honest communication from the school district, which I immediately provided by publicly announcing my vision for the district with the new mission, goals, and action plan. Achievement and financial data that I provided had not been shared so transparently previously without being manipulated to appear more positive than it actually was. District and community trust developed rapidly. These communications are what Covey describes as regular deposits. When the high school was found to be in the bottom 5\% of the schools in Oregon 8 months later, that negative news-or withdrawal-did not create a setback. The community seemed content that the superintendent would take care of the problem. Community support was ultimately demonstrated about three months later in a positive voter response to the bond election.

Communication is the glue that holds organizations together. Effective communication builds support for schools and the district (Hoyle, English, \& Steffy, 1994; Porterfield \& Carnes, 2008). Understanding organizational communication is important for school leaders to be able to convey the district's many messages to a variety of constituents and conversely have a means for the constituents to respond. To fulfill that purpose, communication can thus be described as a strategy that allows a free exchange of ideas in defined settings such as formal and informal communication, oneway communication, two-way communication, and internal and external communication. 
Furthermore, it can be described as a leadership skill. In turn, a high degree of trust in the organization is developed when used intentionally.

\section{Formal and Informal Communication}

Formal communication, as represented in Table 1, is a deliberate interaction and flow of information from one person to another or one organization to another. Bagin and Gallagher (2001, p. 73) called it "a mutual sharing of ideas" and "a cooperative enterprise" that draws people and their viewpoints closer together. Generally, formal communication lines could be illustrated on a flow chart or in a plan of action.

Understanding the formal communication lines is advantageous for a district to communicate important events or news to gain public confidence and trust. However, most external communications from districts are directed to parents, which may be only $20 \%$ of the school community. Part of the formal process needs to include communication to the remaining $80 \%$ who are not parents if a bond levy is in the district's future. Porterfield and Carnes (2008) called this situation one of the "greatest ironies": The vast majority of people who pay taxes do not have children in schools.

Comprehensive formal communication processes help districts read the pulse of the community. Fiore (2011) said the first step is in knowing the community leaders and being involved in community organizations. Bagin et al. (2008) called it taking a "sociological inventory" of the community, which would be a formal process of understanding the entire school community's characteristics through formally understanding all communication channels and power structures. While these processes may apply to more metropolitan and urban school districts, smaller districts do not have 
the personnel, financial resources, or time to conduct such formal steps. In small school districts, the districts' fixed resources do not allow for nonessential expenditures for civic clubs' dues or for the additional personnel that it might require to engage with many organizations. The superintendent's time may be entirely consumed with district business by also being responsible for duties as the principal of the elementary school, as curriculum director, and/or as personnel director. In small districts the superintendent might meet the mayor informally for coffee but skip attending Rotary in a town 30 or more miles away.

Table 1

Formal and Informal Communication

\begin{tabular}{|l|l|l|}
\hline & \multicolumn{1}{|c|}{ Formal } & \multicolumn{1}{c|}{ Informal } \\
\hline Descriptors & Planned, Intentional, Controlled & $\begin{array}{l}\text { Unplanned, Unintentional, Not } \\
\text { Controlled, Brief }\end{array}$ \\
\hline Structures & $\begin{array}{l}\text { Organizational Chart, Communication } \\
\text { Plan, Mailing Lists }\end{array}$ & $\begin{array}{l}\text { Random, List of Community Leaders, } \\
\text { Parents, Students, School and District } \\
\text { Employees }\end{array}$ \\
\hline Types & $\begin{array}{l}\text { Speeches, Documents, Newsletters, } \\
\text { Meetings }\end{array}$ & $\begin{array}{l}\text { Conversations, Brief Meetings/ } \\
\text { Encounters, Emails, Notes }\end{array}$ \\
\hline $\begin{array}{l}\text { School Collaboratives, Partnerships, } \\
\text { PTA/PTO, Key Communicators, } \\
\text { Teacher/Staff Associations, Leadership } \\
\text { Teams, Government Agencies, Civic } \\
\text { Clubs/Organizations, Special Events, } \\
\text { Forums }\end{array}$ & $\begin{array}{l}\text { Grocery Store, School/District Offices, } \\
\text { Church, Civic Clubs/Organizations, } \\
\text { Schools, Before/After Meetings/Events, } \\
\text { Social/Neighborhood/Family Gatherings, } \\
\text { Athletics/Activities }\end{array}$ \\
\hline
\end{tabular}

In a formal communication process, certain school and community groups such as non-English speakers or senior citizens are sometimes ignored or overlooked and do not receive campaign literature. Like the Novato School District example, districts omit 
groups from communication because these constituents may not be registered voters or they may vote against the election. Therefore, some groups are excluded in the formal communication process. Bagin et al. (2008) cautioned about stereotyping people and groups. Failure to develop a school culture "respectful and representable of the community's culture can doom a school for failure" (Fiore, 2011, p. 39). Not all senior citizens are poor or opposed to school bond elections and not all second-language speakers should be stereotyped as nonvoters. Instead, in my experience, seniors have more free time to devote to a bond campaign and will gladly volunteer to take the lead and rally more seniors to support the passage of bond. Moreover, the district has much to gain by inviting its culturally diverse community groups into the communication processes. They too want what is best for their children and will advocate for the district if given the opportunity.

Communications must reach the right people and carry the right message. "If not, your district, at best, can't demonstrate that it's using taxpayers' money wisely and at worst, is wasting it" (Gunther et al., 2011, pp. 97-98). While it may take time and district human and financial resources to develop and maintain a formal communication process and plan, the formality of taking a systematic approach to communication will ensure that all the various community groups are welcomed, supported, and highly informed.

Conversely, informal communication is not controlled, structured, or systematic as noted in Table 1. How would a school district leader know, for example, that a group of citizens was not supportive of a bond or some parents were dissatisfied with the district? It is often through informal structures such as during the wait time before a 
meeting or event. Informal communication builds relationships. Porterfield and Carnes (2008) provide this example:

...we know of a superintendent in a small school district who shakes the hand of each staff member at the beginning of the year and again at the end of the year. And rather than asking staff members to come to him, he goes to them. Walking the hallways, moving in and out of classrooms, pressing flesh, he makes a point of calling staff members by name. And if he doesn't know a name, he asks. (p. 183)

Informal communication may be unplanned, but it is time that must be planned for. There is a difference. The superintendent in the Porterfield and Carnes' (2008) example knew that, by being courteous, on staff turf, and available, he was creating a positive culture and making deposits to his bank account. Informal communication, such as this example, opens more opportunities for staff and community input. Kowalski, Petersen, and Fusarelli (2007) called this informal communication "social interaction." According to the authors, "Superintendents and principals who view social interaction as being important are likely to shape formal networks" (p. 151). That personalized approach has been studied in other literature. In a study of rural superintendents by Forner, Bierlein-Palmer, and Reeves (2012), several effective leadership practices were identified. However, direct, personal conversations helped to personalize the superintendents' approach and gain support of their communities. I have found that the personal approach thrives in both rural and urban areas. As superintendent with experience in both types of locales, I find that while I am shopping, a staff member, parent, or community member will introduce himself or herself to me. Often, these informal occasions are appropriate times for my "grocery store checkout line," one- to two-minute conversations. Because these informal communication exchanges are 
foreseeable, I plan for them. For example, knowing current facts about each school or sharing my experiences about recent school and classroom visitations, I am able to demonstrate my commitment to the district. Whether answering an email with a quick, informal response or communicating briefly one-on-one before meetings, these informal exchanges strengthen community trust in and support of the schools and district. By being prepared for informal communication situations, the superintendent is then perceived as friendly, approachable, and knowledgeable.

Both formal and informal communication is necessary to gain support of the community in a bond election. While formal communication is planned and systematic, the informal communication structure is loose and often not controllable. Being prepared to present a speech before 100 city chamber members or being prepared for those random conversations at the grocery store, a well-informed superintendent will be alert to the pulse of the community.

\section{One-Way and Two-Way Communication}

Any communication plan should include both one-way and two-way

communication. One-way communication can be defined as information out to a receiver, which tends to be the most prevalent type in schools and districts. One-way communication is linear, unilateral, but limited because it occurs in a straight line from sender to receiver and serves to inform, persuade, or dictate as noted in Figure 1. Hoy and Miskel (2001) argued the advantages of one-way communication:

First, it emphasizes the skills of the message sender and encourages administrators and teachers to think through their ideas, accurately articulate them, and prove specificity in their instructions, explanations, and descriptions. Second, one-way strategies typically imply strong linkages between 
communication behavior and action....It conveys a strong emphasis on efficiency and goal achievement. (p. 360)

Bagin et al. (2008) contended that educators have relied extensively on one-way communication to get the school story to the community. "Often this has served to make citizens aware of some activities in the school without fully understanding them" (p. 119). Fiore (2011) called this the knowledge stage in communicating information about a bond. The public becomes aware of the bond through one-way communication by reading a press release in the newspaper, hearing a radio announcement, or reading a newsletter. David Douglas School District in Oregon provided the public with one-way communication to convey its message about the bond election in the spring of 2012 . D. McCue (personal communication, February 15, 2013), communication director for David Douglas School District, said there were two messages the public received: one was the bond title and message and the other was the list of projects the bond would cover, including the price of each project on the list. Both were simple, but the district sent them out often in school newsletters and district flyers. Keeping messages simple and direct helped David Douglas pass the bond in May 2012.

\section{One-Way Communication}

SCHOOL (Sender)

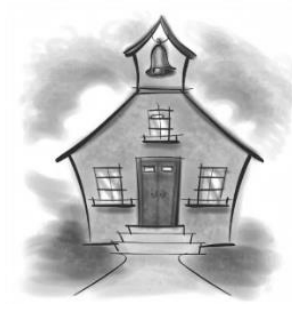

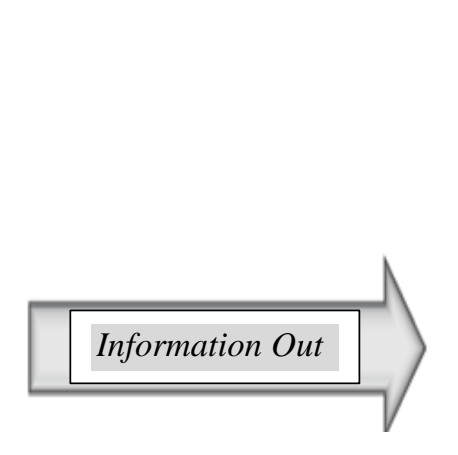

HOME (Receiver)

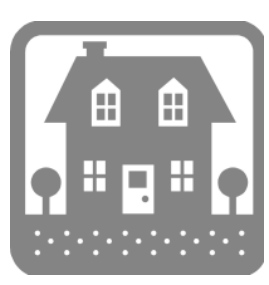

Figure 1. One-way communication. 
Two-way communication is different from one-way because it includes feedback from the receiver back to the sender (see Figure 2). Two-way communication is negotiated, meaning that both the sender and receiver listen to each other and gather information they need before responding. They are also willing to make changes to work together as in a dialogue.

\section{Two-Way Communication}

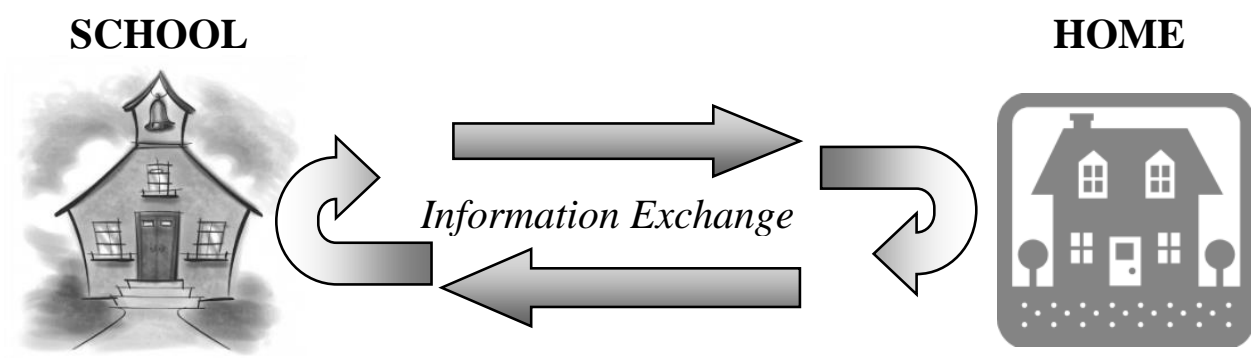

Figure 2. Two-way communication.

Hoy and Miskel (2001) approached the definition of two-way communication as "a reciprocal, interactive process directed toward discovery and new understandings through speaking and listening" (p. 262). Fiore (2011) cautioned about only communicating during bond elections. Strong two-way communication should be a consistent practice. "The twenty-first century demands that school leaders communicate regularly and purposefully with all stakeholder groups. This communication...must be two-way with the school leader listening as much or more than he or she speaks" (p. 222). Collins (2001), in his book Good to Great, discussed making organizations better: "A primary task in taking a company from good to great is to create a culture wherein people have a tremendous opportunity to be heard" (p. 88). Most leaders in the 
corporate world know that clear two-way communication is vital to the success of any organization (Porterfield \& Carnes, 2008). Two-way communication is more beneficial than one-way because the ongoing feedback develops strong relationships and trust in advance of seeking a bond election. Once that trust is established, stakeholders tend to be more supportive when they cast their ballots. I developed a communication plan (see Table 2) when I became superintendent in Ontario. The district's communication coordinator ensured that everyone followed the protocol. I also had my own communication plan to meet personally with every group and organization and share the vision of the district and receive feedback from our constituents. We passed a bond that first year.

Both one-way and two-way communication are essential to passing a bond. Twoway communication provides better results, but both are necessary to develop strong relationships with stakeholders. During the bond campaign, however, election laws prohibit district information from being more than factual and words in brochures or campaign flyers sent from the district must be scrutinized (Brown, 2012b). Taxpayer money cannot, in any way, contribute to a bond campaign. School districts are encouraged to submit all publications to the Secretary of State's Office for approval before being distributed or published. Any "persuasive" types of campaign literature or forums must be delivered by the campaign committee members. Districts cannot advocate for their own bond election. 
Table 2

Strategic Communications Plan Outline

$$
\text { Strategic Communications Plan Outline }
$$

Mission: The reason for the plan.

Example: To communicate in an ongoing dialogue with the district communities in order to pass a bond levy

Goals: General guidelines of what must be accomplished.

Example: Enhance and improve community relations.

Objectives: The actions necessary to achieve the goals.

Example:

Objective 1: Compile a list internal and external stakeholders

Objective 2: Create, administer, and evaluate survey of perceptions of school district

Objective 3: Target each stakeholder group with the appropriate communication venue, tactic, and/or tool

Action Plan: The actions necessary to achieve the goals; the timeline to accomplish the actions; the outcomes anticipated; the evaluation of outcomes; person or department responsible; budget/costs associated with the action.

The actions would include the following types of communication:

- Communication with Internal/External Stakeholders

- One-way Communication

- Two-way Communication

\section{Communication With Internal and External Publics}

A communication plan that strategically targets the key internal and external stakeholders and provides open, honest, accurate, timely, and two-way communication is a district setting itself up for continued public support (Gunther et al., 2011). Boards and administrators cannot enlist the public's support alone. "They must enlist the help of employees, and in doing so, it requires a structured internal communication program" 
(Bagin \& Gallagher, 2001; Bagin et al., 2008). Bagin et al. (2008) provided three reasons for a strong internal communication program:

(1) A good external communication program cannot survive without it; (2) constructive ideas will be suggested by employees because someone is listening and informing them; and (3) human needs, such as recognition and sense of belonging, will be met, thus making employees more productive. (p. 90)

In my experience, internal communication from the district level is often superficial at best. Even one-way communication is nearly nonexistent. During the 6 years when I served as principal of one district, no newsletter or communication from the district to its employees as a whole was ever sent. The only district-wide meetings that employees attended were board meetings during negotiations or budget meetings when a reduction in force was announced. Thus staff morale was low. If a bond is pending, the internal stakeholders must not only be informed but must also be part of the planning process. A district has a variety of internal stakeholders as demonstrated in Figure 3. Each of the internal stakeholders listed could also have subgroups creating even more groups. This is why communication must be thoughtfully planned. While all may be employees of the district (with the exception of the volunteers and students), their needs may be very different. For example, Bagin et al. (2008) and Fiore (2011) described a study, conducted by Frederick Herzberg, of internal communications and staff morale. The outcome of the study found managers and administrators mistakenly assumed what each employee wanted from his or her job. They predicted that good pay, job security, and promotion and growth would be at the top of their desires, while the employees, when surveyed, placed them in the middle of the list. Instead, the employees listed at the top interesting 


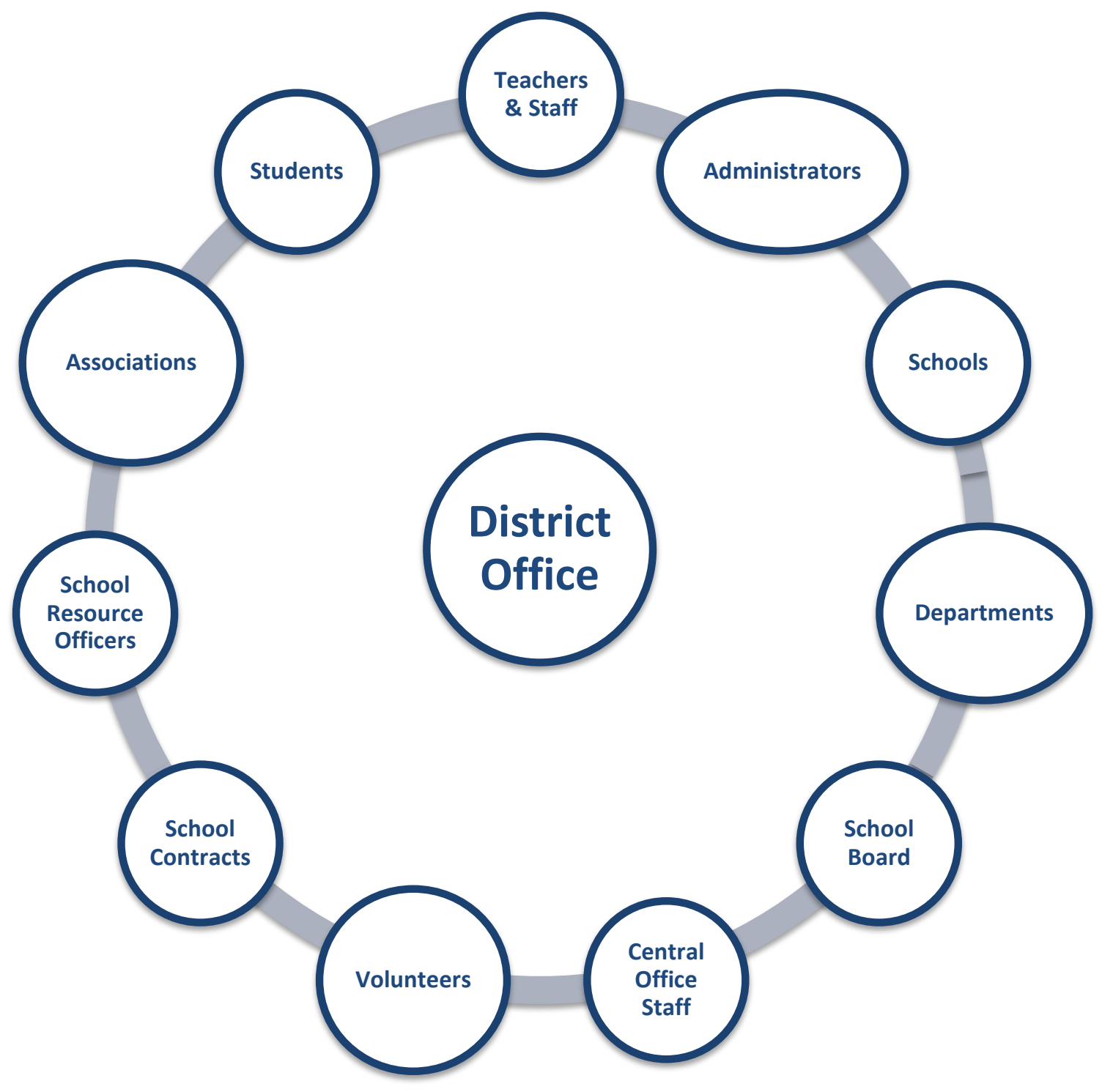

Figure 3. District communication with internal stakeholders. 
work, being appreciated when work was completed, and feeling in the know (through communication) as their top choices. When I interviewed recently for a new position, I also interviewed with different employee groups besides the school board. The classified group, which included instructional assistants, custodians, bus drivers, and secretaries, was mainly concerned about being recognized for their work. The interview was more like a dialogue. They shared with me their belief that managers or supervisors did not genuinely care about the work they accomplished. In a comprehensive communication plan, time would certainly be designated to receive such important feedback through surveys or focus groups. Strategies then could be developed for next steps on ways to show application toward all employees.

Why is internal communications important to a bond campaign? Employees are visible members of the community (Fiore, 2011). Because they live in the community and vote in the school district as well, they take on an important role as messenger of what is happening in the district, schools, and departments. The information they receive daily from the district is communicated to their friends, neighbors, and family daily. If they do not receive accurate information, they will share inaccurate information. If they do not feel positive about the district, they will most assuredly communicate their negative views. Hughes and Hooper (2000) shared, "If internal stakeholders are valued and engaged, they will assist in promoting positive and effective communications" (p. 87).

With a plan targeting internal communications solidly in place, the next step is to plan for external communications (see Figure 4). While a district has some control over 


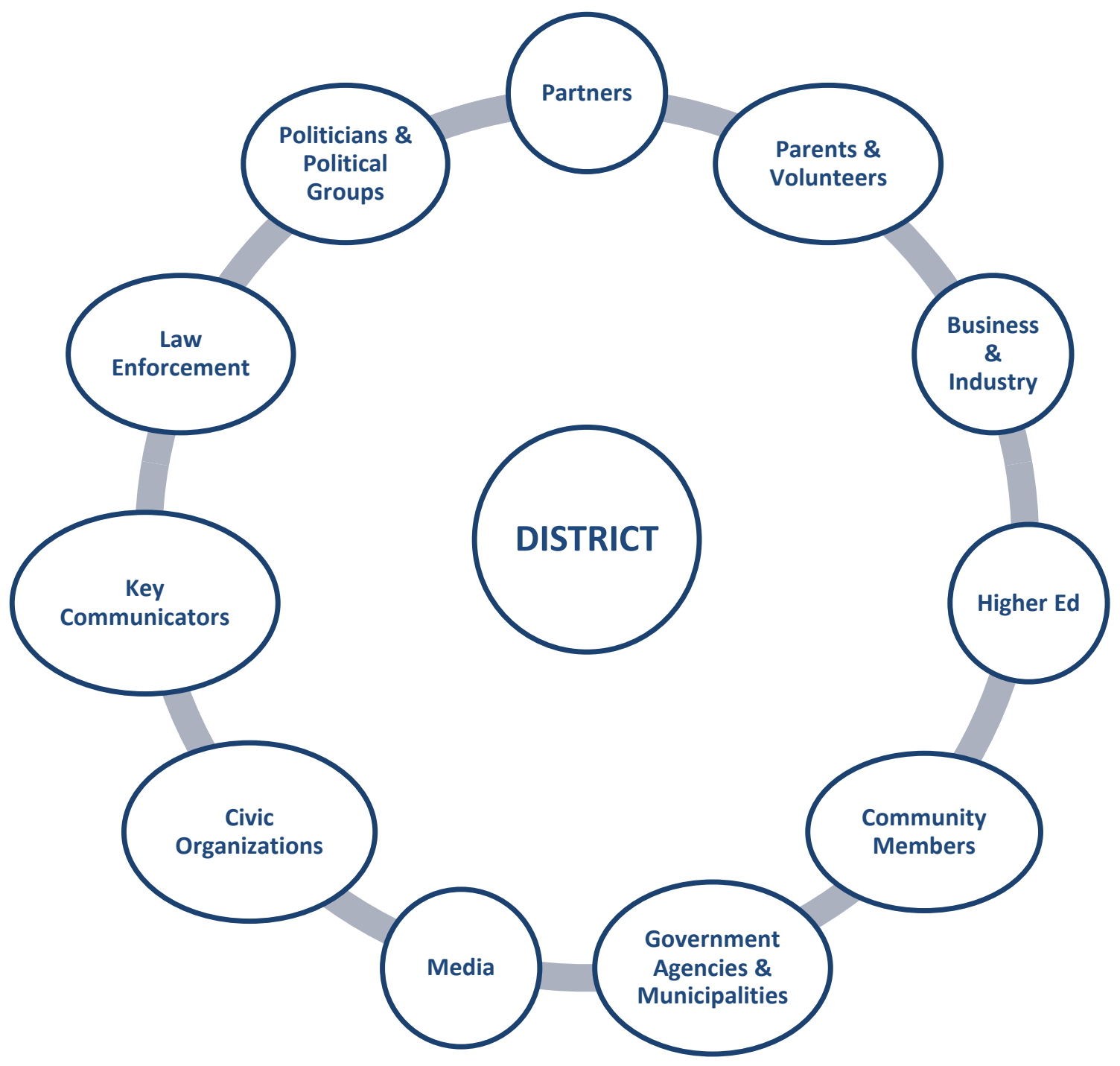

Figure 4. District communication with external stakeholders. 
its internal stakeholders, the external stakeholders are continually changing. Specifically about school community demographic changes, Carr (2010) addressed possible communication issues:

Unprecedented demographic shifts in the U.S. are creating a communications gap between teachers, principals, and the students and families they serve, forcing educators to rethink their school communication strategies. Minorities will become the majority of children under 18 by 2023 , according to the U.S. Census Bureau. Educators and school communicators, on the other hand, are predominately non-Hispanic white females.

The gap is also socioeconomic in nature, because children of color are often poor as well, while teachers and other school officials are solidly middle to uppermiddle class....In terms of education, the gap widens even further, with educators holding more advanced degrees than most other American workers haveincluding their students' parents.

All these trends will require profound changes in parent engagement and school communication, as well as classroom instruction. Tried-and-true school communication methods, such as fliers, memos, teacher notes, eMail messages, and newsletters - typically written in college-level English-aren't going to reach parents who struggle to read or who might not be literate in their own native language. (para. 1-3)

Most districts in Oregon have already experienced the changing demographics. Many are or will soon be minority-majority districts in the next few years, with possibly 40 or more different languages spoken. Urban school districts such as Salem-Keizer, Reynolds, Portland, Beaverton, and Hillsboro boast about having the most languages spoken. Portland Public has the largest number with 94 home languages for its 46,836 student body (Portland Public Schools, 2013). In these districts, communicating with the external publics takes additional time and financial resources.

There are no quick and easy guides to work with such diverse populations, and the literature reviewed often reflects a 1950s model of communication. Bagin et al. 
(2008) do, however, provide a list of suggestions in communicating with diverse school communities, a new feature from the authors' previous editions of their books. Mainly, the authors advise listing all the ethnic groups in the district; learning who each group's key communicators are; creating an advisory committee within each group, if possible; training teachers in working with diverse families; printing publications in the language spoken; providing transportation to conferences and other school activities for parents; teaching students to respect all languages; learning the most effective strategies to communicate with the parent groups; believing that all students can succeed; and using resources of public and government agencies and organizations who serve minority groups. While these are valuable suggestions, districts in Multnomah County and elsewhere are exceeding these expectations. In Reynolds School District, for example, the district is in its third year of equity training using Courageous Conversations about Race; Portland Public is in its fourth year. Training in the first year targets administration; the second year, administration and teachers; and the third year, administration, teachers, and parents. During the past 2 years, Reynolds has also offered the "Educate and Inspire" curriculum for Latino parents through Salem-Keizer Coalition for Equality. The curriculum has 16 units of study that focuses on such topics as student achievement, dropout prevention, effective communication, and discipline of children. These classes as well as monthly Latino parent nights held at each school have greatly improved two-way, external communication in the district. The communication model is inclusive of all groups. 
Parents are just one small faction in a school district's external stakeholders; they only comprise about $30 \%$ of Oregon households (U.S. Census Bureau, 2010). Other external constituents must also be addressed in the communication plan. Figure 4 lists several external stakeholder groups in school districts. By no means is this an exhaustive list. While these total 11 entities, other districts may have more or less. Gunther et al. (2011) planned for communication outcomes that involve these varied audiences: All groups should feel engaged and involved in the schools; they should feel community pride in the schools; and they should want to support the schools. This can be accomplished through "collaboration, commitments, values, and engagement" (pp. 113114). Collaboration involves the district in a dialogue with its internal and external stakeholders to maintain a flow of communication about the district's vision and mission, finances, or curriculum and instruction. Commitments are the district's promises or obligations to its community. A commitment to speak to and listen to the community and carry out promises establishes a strong, lasting relationship. What the district chooses to emphasize and publicize are directly related to its values. If the district focuses on a commitment to two-way communication in words and deeds, then the community will know communication is a priority. Engagement seeks to open doors by being transparent and welcoming to the external community. When the community members feel engaged, they, in turn, feel ownership and pride in their schools. Several Multnomah and Clackamas school districts held education forums during 2012-2013 school year. These forums encompassed the four of Gunther et al.'s strategies. With ongoing emphasis of the four strategies, the external communities will feel a part of the school community and 
talk about our schools, not the schools. Likewise, they will also be more inclined to vote favorably in bond measures.

Engaging with the district's external publics is a process. Porterfield and Carnes (2008) cautioned districts not to attempt anything big in the beginning such as developing a strategic plan or mission and vision. They propose the process should start small. Bagin et al. (2008), conversely, see communication as a "cooperative enterprise," a process that requires a "mutual interchange of ideas and information" (p. 119). According to the authors, once communication policies are adopted, the next step would be to move toward a strategic plan with goals and actions, just the opposite of Porterfield and Carnes, who cautioned to take it slowly. Gunther et al. (2011) added that communication must be aligned with the district goals and values so these must be established first. Having served three districts as superintendent, I find the fastest way to unite the school community and maintain that support is through community involvement in strategic planning. Unlike advice from Porterfield and Carnes, I like to draw from the ideas of all the different stakeholders into a common vision, mission, values and beliefs for the district. When the various community stakeholders, as identified on that long list of external publics, are brought to the table to determine a common vision for the district, a cooperative and collaborative effort such as this helps to dispel myths about the district. It builds relationships necessary to pass a bond and provides the avenue for long-term, twoway communication between the district and its external stakeholder groups. GreshamBarlow School District, for example, started the strategic planning process with its community about two years before the school board approved placing a bond on the 
ballot. As a result of these ongoing community meetings, district leaders and the school board developed a positive relationship with community stakeholders. In fall of 2012 the district held an education summit with the community. By spring of 2013, the district offered six more community meetings that focused solely on the election message. Gresham-Barlow developed and nurtured community input and feedback well in advance of the November 2013 bond election by following an inclusive communication plan (J. Schlachter, personal communication, February 8, 2013).

Both internal and external communications are important to successfully build community support and trust in a school district. A comprehensive communication plan provides open, honest, accurate, and timely information structured for both one-way and two-way communication with the many and varied internal and the external stakeholders. Employees are the voice of the district in the community. These internal stakeholders must feel supported by having the most accurate information available to share with the public. External stakeholder groups must be evaluated so that each group is provided with the communication that best fits its particular needs. Successful external communication results in stakeholders who have a sense of pride and ownership for the district and its schools. According to Gunther et al. (2011), "Those who feel that sense of ownership volunteer, attend school events, nod affirmatively when you describe your new initiatives, vote for your budgets and tax increases, and give you the benefit of the doubt when there's bad news" (p. 115). These responses would be the ultimate endorsement for a successful communications plan. 


\section{Communication as a Leadership Skill}

"Building public support for school is not something an effective school administrator does on the side. It should, in fact, be the first act of survival" (Hoyle et al., 1994, p. 49). Guenther et al. (2011) said that "leaders must be judged on their commitment to communicate, their skill in doing so, and the extent to which they can bring their stakeholders together through communication" (pp. 115-116). Bagin et al. (2008) added further advice to these skills by describing the superintendent's role as an “educational diplomat” (p. 58). Top leadership skills for communicating have gone beyond simply writing, speaking, and listening well. While these skills remain necessary to any school leadership position, leading a school system requires much more. In smaller districts, the superintendent may assume additional responsibilities for curriculum, personnel, and public relations. In larger school districts the superintendent may supervise and direct others to do this work but have further responsibilities in building relationships with the external community. The skills needed to conduct school business are multiple. If a construction bond is well planned, excellent communication skills are vital to the election's success.

Bagin et al. (2008) reported that superintendents may be excellent instructional leaders or financial wizards but fail to communicate well with the board, staff, or taxpayers. Fiore (2011) stated that administrators must be role models who exhibit honesty, integrity, care, and understanding; be flexible and adaptable; develop listening skills; and practice humility. They must possess effective human relations skills. In other words, they must have the skills known to improve employee satisfaction and enhance 
community perceptions of the schools. Superintendents are responsible for keeping internal and external groups informed by establishing, maintaining, and nurturing open communication channels both internally and externally; developing and championing policies created to enhance school and community relations; always keeping the school board, staff, and general public informed of school matters; ensuring that the school and community relationship is assessed and evaluated regularly and that the outcomes are reported to the school board; and by making sure that influential groups and community leaders are provided with factual information that will cause them to act on behalf of the school children and their education (Fiore, 2011).

Superintendents must be highly skilled in writing, speaking, and listening. These communication skills are necessary for the top job as well as the skills to plan, assess, and evaluate the pulse of the community and to work with a variety of stakeholders. Skilled communicators understand that there is not one "public," and the superintendent must be savvy in knowing how to communicate with each of the different external groups as well as with the various internal groups (Hoyle et al., 1994). The message or the type of communication cannot be the same. Holding a meeting about a possible school bond needs to be entirely different when planned for the city chamber, the boosters club, a teachers' meeting, or for a Latino parent night.

\section{School and Community Relations}

The most important work in winning elections occurs long before a measure is placed on the ballot (Campbell \& Magmer, 2007). One to two years in advance of a bond election, district leaders must learn how the community perceives their schools. Are 
parents satisfied with their children's education? Do community leaders support the schools? Are newspaper articles favorable? Are teachers and staff highly motivated? Is morale high? If the answer to these questions is affirmative, chances are the district has an active school and community relations program. School and community relations can be defined as formal or informal interactions between an educational institution and the surrounding community while public relations can be defined as the professional maintenance of a favorable public image by an organization. Porterfield and Carnes (2008) warned: "You can’t market a poor product. No amount of marketing will help. Sooner or later, everyone recognizes lipstick on a pig" (p. 102). While a communications plan and public relations program are of utmost importance, a district must first assess its public image. Using the feedback tactically will create a stronger plan.

If a strong communications plan is absent, community support is also likely missing. Fiore (2011) cautioned, "Failure to plan for school-community relations is an invitation for disaster" (p. 13). Instead of school and district leaders "thinking on their toes," a planned school and community reactions program will prepare leaders for nearly any circumstance. Relating to the larger community as issues arise in a knowledgeable, organized, and methodical manner prevents mistakes that can blemish the leader, the school, or district.

Winning at the polls will mean evaluating and analyzing the current perceptions and conditions of the district and then, if needed, making strategic changes to transform those perceptions. The first step in determining community support is to evaluate public perceptions of the district as a whole. Next is the development of public relations 
strategies for effective internal and external communication as well as ideas for improving media relations.

\section{Perceptions of the Schools}

Both internal and external stakeholder perceptions of the schools should be assessed and evaluated. Hughes and Hooper (2000) suggested determining the general impressions of the districts from parents, community, and staff through surveys developed for each key public relations audience. Bagin et al. (2008) related how indispensable a survey is when the public is asked for its opinion. For example, a survey can determine how the public might react to purposed district changes, learn how citizens judge the quality of the schools, ascertain how staff will react to a proposed curriculum, or discover how willing the public would be to support a proposed bond. An added bonus, according to Bagin et al. is how opinion research actually stimulates individuals who are contacted to form opinions:

Individuals who have not thought seriously about the schools and the school programs for some years are forced to do some thinking about them when their opinions are being sought in a research study. Moreover, they feel important for being asked their opinions. (p. 27)

In my experience I have observed a negative side to opinion surveys. In Culver School

District, for example, the board spent about $\$ 8,000$ to contract with a well-known opinion research company to survey the Culver community about various tax measure scenarios under consideration to determine what the voters might be willing to support. Rather than the community feeling important, they were outraged. They misunderstood the survey questions and were frustrated with the pollsters. Phone connections were sometimes not good; and, in some instances, more than one person was polled from the same household. 
No amount of information afterward would change people's misperceptions.

Unfortunately, a local realtor sent flyers to voters urging them to vote no on the tax measure. She also included voters' individual property tax estimates, which showed their taxes as being more than double of what the actual cost would be.

In another district, the facilities task force conducted a grassroots community survey to determine what the community would support in a bond levy. Besides surveying for a tax measure, the task force also developed additional questions on perceptions of the district and schools. When the task force tabulated more than 3,000 results, some comments on the surveys indicated dissatisfaction with certain administrators in the district. Instead of redacting the names of those personal attacks, the board members on the task force decided to "clean house" and took action to fire the administrators named in the survey.

While surveys may occasionally have adverse outcomes, the information gleaned from surveys far outweighs the negatives. Survey results determine perceptions of various groups including parents, senior citizens, business people, community members, and district employees (Campbell \& Magmer, 2007). Fiore (2011) concurred that the effectiveness of a school organization cannot be determined through feelings and observations. Formal opinion surveys, questionnaires, rating scales, and telephone surveys provide effective feedback on community perceptions. Survey Monkey, Fluid Survey, Zoomerang, and InstantSurvey are all free and simple-to-use online surveys. After every workshop, training, or community meeting in Reynolds School District, 
participants are asked to participate in an online survey so planners can receive feedback on how to improve next time. As a result, administrators have received praise for being open to feedback.

While online surveys have reduced costs or no cost and a quick turnaround associated with them, Hughes and Hooper (2000) also suggested other more in-depth methods to understand the community's attitudes and beliefs about the district. Focus groups, public meetings, town halls, panel discussions, and advisory committees provide face-to-face venues. Hoyle et al. (1994) concurred: "Face-to face communications is still the most effective of all 'other means." Figure 5 illustrates Hoy and Miskel's (2001, p. 55) representation of the communication continuum, depicting face-to-face rating highest in richness because it provides immediate feedback through verbal and visual cues. Bagin et al. (2008) added to the context of face-to-face communication with key communicators and group conferences while Carroll and Carroll (2000) emphasized a more comprehensive key communicator program that disaggregates participants into internal and external stakeholders. Instead of one key communicator group, the district establishes as many as necessary to reach the influencers and audiences as identified in the communication plan. 


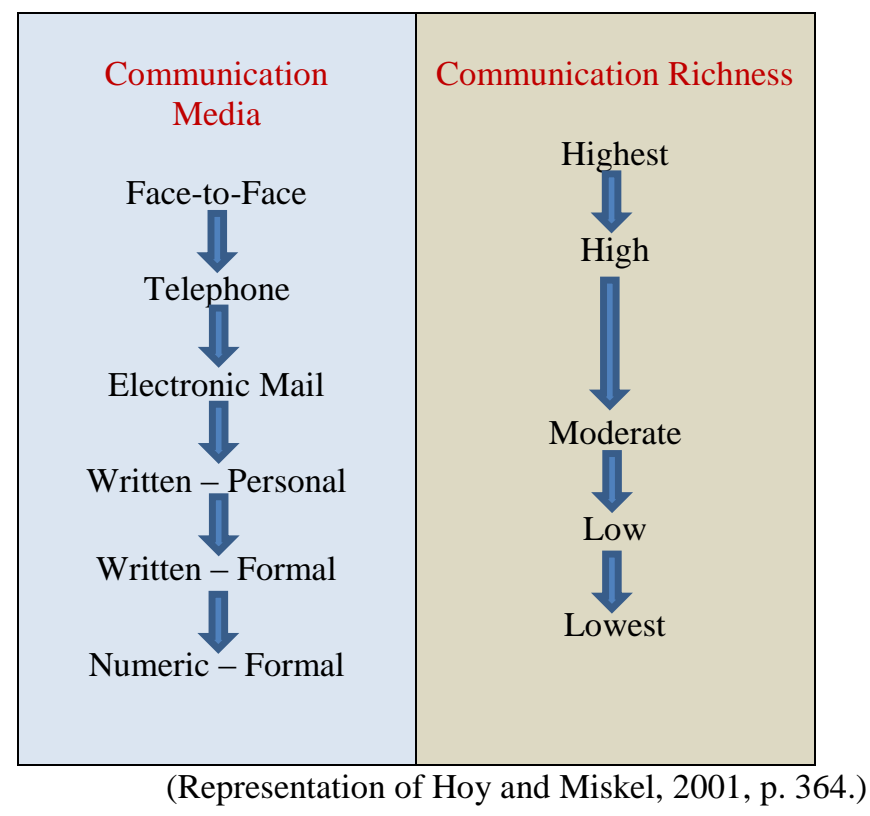

Figure 5. Continuum for communication media and richness.

Face-to-face communication provides the best venue for me in providing information to the community and receiving the feedback in district decision-making. More time and planning is involved, but the results are much richer. For example, before the Ontario School Board approved its bond election, I scheduled meetings with every group that routinely gathered whether they met at the Steak and Pancake, McDonald's, or Matsy's. Some were retired teacher's groups; others were workers who took morning breaks. Business owners and workers who did not meet regularly were invited to attend a lunch in which I was the guest speaker. As a result, I developed relationships with many different leaders and voices in the community. They received factual information about the district, and they asked me some difficult questions. In one meeting with about 25 local business executives and owners, I started out with a formal presentation, but the formality ended when we sat down and engaged in a one-to-one dialogue. The results 
were staggering. Not only were people talking about the school district, but they were also talking about the district using positive language. A business executive's wife later shared with me that her husband found the conversation so informative and felt that I was so transparent that he would vote yes for the bond. He had a record of never voting yes for school district tax measures. Face-to-face communication is the best communication because it is two-way; it promotes sharing and feedback; it can build trust; and it can clear up misconceptions of the district.

To establish and maintain positive community perceptions, Fiore (2011) focused on eight areas of attention:

1. Focus energies on the overall climate of your school

2. Pay similar attention to the exterior of your school facility.

3. Remind all staff members that they are the best spokespersons for the school.

4. The above item is less of an issue when employees are glad they work at the school.

5. Recruit and retain the best teachers you can find.

6. Communicate with external groups as effectively as you possibly can.

7. Inform the press of every good thing that happens in your school.

8. Focus on the students. (pp. 284-285)

Including these areas of attention in a compressive communication plan will ensure community perceptions on surveys or in face-to-face meetings will improve.

\section{Strategies for Internal and External Communication}

Campbell and Magmer (2007) provided insight in enhancing community relations:

Community support is built with an effective researched-based, strategically planned, year-round communication program that engages people from all segments of a community. Trying to pass a finance referendum without a formal plan in place is like hiring a carpenter to frame a house without first constructing the foundation. (p. 13) 
The first step in developing a communication program is identifying the internal and external stakeholders. Hoyle et al. (1994) reported that part of the planning effort is not just in identifying the specific public to be targeted but in identifying the specific communication method and determining how to get that message to hit home. "The more focused a message is, the more effective it can be. Conversely, the more universal a message is, the less impact it will have on any one recipient" (p. 57). Bagin et al. (2008) said to keep it simple, "This mean to eliminate educational gobbledygook and long polysyllabic sentences" (p. 308). While Hoyle's et al. proposal seems reasonable, David Douglas School District provided a more universal message by not targeting the school district's many audiences. Partly due to state elections law of only allowing districts to send factual, non-promotional information, David Douglas simply sent out two main communications about the bond message to all external constituents (D. McCue, personal communication, February 15, 2013). The district sent a list of projects with itemized costs and a variation of the bond election message multiple times. They chose not to offer informational meetings to focus groups or community forums. The communications director kept the messages simple. While the message on both flyers was translated into two other languages, Russian and Spanish, it maintained a focus toward a general group. Surprisingly to surrounding districts, the bond passed by a wide margin. However, the David Douglas School District has benefited from a history of favorable elections, and that consistent community support is its main selling point.

Bagin et al. (2008) and Bagin and Gallagher (2001) suggested that a key strategy for enhancing internal relations is offering both a general advisory committee and special 
advisory committees. A general advisory committee, as the name implies, would be comprised of membership from all constituencies in the school system. It would be designed to hear from the internal community but also to receive information from the school district. Special advisory committees would be formed representing the different employee groups in the district such as a licensed committee and classified committee. Members on the committees would then serve to communicate information back to their buildings or departments and, likewise, communicate to the superintendent about concerns or questions from the buildings and departments. Most districts offer similar committees for their employees. Generally, rather than advisory, they are employee association groups such as the licensed and classified association leadership teams that meet with the superintendent or superintendent and human resources director regularly. Whatever is chosen, advisory or contract management, these groups are important in building positive and lasting relationships with teachers and staff and administration.

New staff, new teacher, and new administrator orientation programs help transition new employees into the culture of the school district. Bagin et al. (2008) and Bagin and Gallagher (2001) maintained that employees new to a school can become "bitter and resentful" if they are not properly familiarized with the school or do not know what is expected of them. Most districts offer orientation programs, which are a great way to meet and greet new employees. This year I presented my vision for the district with talking points to the 51 new staff at the August orientation. Being the first to meet and train new staff about district requirements is advantageous because district administration helps to set the expectations and guide them in the district's vision, 
mission, and goals. For new administrators, I offer monthly "dinners with the superintendent" that include one to two significant workshop topics such as human resources, budget, and curriculum and instruction. There is also ample time allotted for new administrators to ask questions and collaborate with each other on their experiences of being new to the district. In the fall of 2012 the district hired a retired administrator to fill an opening from a late resignation. In feedback following a dinner meeting, she stated that she learned so much more about the functions and processes of our district than she had while serving several years in her former district.

Taking time to employ two-way communication strategies helps to build strong relationships with internal stakeholders. Porterfield and Carnes (2008) provided a rationale:

Two-way communication with your employees is fundamental to the smooth operation of your organization. Employees help make change happen. They can be a powerful marketing arm. They can provide good customer service to parents and community members. But before they offer their help, your staff members must feel engaged in the mission of the school and the school division. Your job as leader is to make them feel part of the team. (p. 81)

When the district leaders plan to hold a bond election, the internal constituents will be ready to support the district in its efforts even if it is just to speak positively about what is happening in the district.

Where are the external stakeholders? Porterfield and Carnes (2012) said they have developed into an online community. School districts communicating with their external constituents may need to update their communications plans and use blogs, Twitter, message boards, and Facebook. Most districts and schools now have a Facebook page, and many often use Twitter. But some school board policies remain antiquated, and 
leaders fear using social networks to convey district news and information. Yet using these strategies will make connections to parents and younger stakeholders. Gunther et al. (2011) offered these strategies:

Based on your experience and knowledge of your community, you already have a sense of what information your parents need. But do you know how many prefer getting newsletters in the mail rather than online? What percentage of your parents or larger community expects to hear from you on the Web, via email, or via Twitter? (p. 43)

To communicate well with the different school groups, the district must continually assess its publics and determine its choice of communication as stakeholders get older or younger and speak different languages. These changes seem to take place on a yearly basis in most districts. Gunther et al. added, "To communicate well your district must respond appropriately" (p. 43). More traditional forms of communication strategies must still be utilized for parents who do not have technology. However, no one should make any assumptions about who has Internet access. Many families in poverty make Internet a priority, whether on computer or smart phone. The point of using Twitter or a paper newsletter is dependent on the intended audience, the identified outcome to be achieved, and the best medium in which to make that happen.

Other strategies continue to see face-to-face communication as the most important strategy. Both the National School Public Relations Association (Campbell \& Magmer, 2007) and Department of Defense Education Activity (2007) provided a Hierarchy of Effective Communication, based on a Washington University at St. Louis study. Listed below, from most important and most effective to least important and least effective, are the communication strategies that districts should consider: 
- One-to-one, face-to-face

- Small group discussion or meeting

- Speaking before a large group

- Phone conversation

- Hand-written, personal note

- Typewritten, personal letter, not a form letter or e-mail

- Personal "form letter"

- Mass-produced, non-personal letter

- Brochure or pamphlet sent out as a direct mail piece

- Articles in organizational newsletter, magazine, tabloid

- News carried in popular press

- Advertising in newspaper, radio, television, magazines, posters, etc.

- Others-billboards, pens, give-aways, etc. (p. 19)

The district must make the determination of which strategies hold the most cost-tobenefit ratio. The National School Public Relations Association offered additional examples of strategies such as announcements, brochures, fliers, or memos. These are considered mass communications. However, dialogues, discussions, receptions, workshops, and telephone calls are considered interpersonal communications. The first provides information; the second changes attitudes. While both are important, in a bond levy meeting, for example, providing informational documents in combination with a meeting or forum would increase the value of the written communication.

The most important strategy is in knowing and understanding the different internal and external publics in the school community and determining the best method and forum to communicate. Districts must assess those publics and know which forms of communication best serve each group. Making certain, for example, that documents are translated into the language the group uses or making sure translators are scheduled for meetings will create an environment that is accepting of all groups and demonstrates that the district values, respects, and appreciates its stakeholders. 


\section{Media Relations}

According to Kowalski et al. (2007), school administrators have historically approached media relations as either "wounded and bloody" or "naively optimistic" (p. 187). In many cases reporters are often thought to be the enemy. District administrators often fear the press because they have not been trained to work with the print or broadcast media. The adage, "Never argue with a man who buys ink by the barrel” (attributed to former Indiana Congressman Charles Bruce Brownson in 1964), evokes fear. Additional embellishments add, "paper by the ton.” Unfortunately, these symbolic scare tactics do not build positive relationships, and that is the first step to resolve the mystery of media relations.

Porterfield and Carnes (2008) called working with the media an investment. As with any school community group, the district leaders would take the first step to build positive relationships through face-to-face meetings. Hughes and Hooper (2000) and Porterfield and Carnes advocated for information meetings to discuss working together. Reporters are often on deadline. Deadlines mean reporters need a fast turnaround; so when they contact the district communications director, school administrator, or superintendent, those calls should be answered or returned promptly. Informal meetings will help establish the protocol of how the reporter will work with the district and vice versa. The communication director and I generally meet with a reporter from each local paper about once a month for coffee and alert the reporters to any newsworthy events in the district. The communication director provides the reporters with regular news releases in between those meetings, provides them with a calendar, and invites them to major 
school events. I also have met with the managing editor and publisher from one local paper just to share some frustrations the district was having with one reporter. The reporter had been absent from executive sessions and therefore was not privy to the district's side of a story. The reporter took the complainant's side, and subsequent news articles were biased. I shared this and the fact that the reporter said he would glean articles from our website and would not need to speak with any district officials. At first the managing editor was defensive. When I cautiously added that my husband used to be an executive editor of the largest newspaper corporation in the United States and that I understood newspaper philosophy well, I acquired their full attention. The meeting resulted in a very positive outcome. The reporter was assigned a new beat, and I have since sent complimentary emails to the editor and publisher for articles published.

Often, superintendents learn how to deal with the media through experience. I have been fortunate to be around newspaper companies for many years. But I also learned what not to do from a superintendent of a large school district a number of years ago when the she cut off all communication with the local newspaper because she did not like how it reported an event. This symbolized her drawing a line in the sand. Those affected reporters were quickly out for blood because the superintendent did not handle media relations well. Reporters were relentless in their coverage of events, often making unfavorable remarks to characterize the superintendent as a buffoon or completely incompetent. It was brutal and, in my opinion, uncalled for. But the battle between the district and the newspaper continued until a new superintendent was hired. Years after the 
superintendent left the district, the paper still continued its criticisms about that superintendent.

Despite the best efforts of members of the media and school administration, there will be times when errors are made. According to Fiore (2011) these are not the times to think that the media or the reporters are out to get anyone. Making a personal contact to inform, but not belittle, the reporter increases the likelihood that the error will be corrected, future errors will be avoided, and the district and media relations remain positive.

Kowalski et al. (2007) offered a few tips on working with media and building positive relationships with them:

- Understand the reporter's job, roles and timelines;

- Realize that the media is a business with the goal of attracting viewers and readers;

- Acknowledge that the school and media relationship is more of a marathon than a sprint;

- Being proactive rather than reactive when it comes to media coverage; and

- Being willing to take the bad news with the good. (p. 191)

Fiore (2011) and Hughes and Hooper (2000) added to this list that "nothing is ever off the record" (p. 149; p. 127). The best way to work with the media is always to be prepared-to be proactive. When news events occur that are media worthy, a plan should be developed and a press release sent. That way the district is primed for the unexpected. When speaking to a reporter, caution should be taken not to share more than the question asks. When a story is written or aired, will the statement hold up and still be accurate even if it is taken out of context? A final caveat from Hughes and Hooper: No comment is never without an implication. Fiore urged giving the reason you cannot comment, for example, 
by using phrases as the following: "This is a privacy issue"; "You know that I cannot release that information because of confidentiality or state law"; or "What I can say is..." (p. 137). I have offered advice to my communication director to approach answers in other ways without divulging confidential information. Simply explaining that personnel issues are confidential and protected by law is preferable over no comment.

The school district's reputation relies on good media relations. The public is always interested in news about the district because schools are responsible for two prized possessions: their children and their tax dollars (Hughes \& Hooper, 2000). Leaders must be prepared to share the news of the district. In working with the media, a strong relationship must be developed as a proactive step. Reporters find it difficult to write something malicious about someone whom they like and respect.

\section{Marketing Strategies}

Educators are often fearful of using marketing strategies to tell the school or district story because it sounds too commercial and cheapens the genuine mission of educating students. Yet districts must tell their story. Porterfield and Carnes (2008) quipped, "If you don't manage your reputation, someone else will" (p. 102). Marketing assists in doing that. Bagin et al. (2008) defined marketing as "the process of discovering, defining and delivering what people need and want. Marketing also has to do with helping people see things that they haven't seen before" (p. 323). With charter schools, online schools, private schools, parochial schools, and the option to transfer to other districts, families have multiple choices for their children's education. While this is good news for families with children, it presents a challenge to public education. Public 
education is no longer the Mercedes in an empty parking garage. Instead, it is now one of many choices in a car lot filled with similar-priced vehicles. Even so, education leaders have avoided thinking of schools in a competitive sense because they have essentially refused to acknowledge any connection between business and education (Kotler, 2000). Educators do not want to be viewed as used car dealers. Nevertheless, in today's competitive education market, using marketing strategies has become a necessity to enhance a school district's public image.

Image matters. Only one poorly handled crisis could permanently damage the reputation of a school or district. Carroll and Carroll (2000) recounted that marketing experts believe image to be more important than reality because "image-the sum of perceptions, aptitudes, beliefs, ideas, and feelings held about an object-makes people act in certain ways and shapes attitudes toward a product, service, business, corporation, organization, or public school system" (p. 69). Closing a deal with the public in a bond election takes a thorough understanding of which marketing strategies will influence a yes vote.

\section{Marketing Techniques, Tools, and Publications}

As Porterfield and Carnes (2008) cleverly described, putting lipstick on a pig will not cover up the underlying problem. Underneath the lipstick the pig remains. No matter how leaders try to frame their districts, if a district is not progressing toward its strategic education goals, no amount of marketing will enhance the district's image. The district must show progress toward its goals and then share the improvements and outcomes with its stakeholders. 
Carroll and Carroll (2002) offered several marketing strategies to communicate effectively with a district's stakeholders:

1. Seize all opportunities that communicate quality to the customer.

2. Use word-of-mouth marketing to spread good news about your school system.

3. Use repetition to make your message memorable.

4. Develop a solid relationship with the media.

5. Name an EdMarketing coordinator.

6. Issue press releases and PSAs [public service announcements].

7. Start building an arsenal in writing and in pictures.

8. Develop your marketing communication with senior citizens in mind.

9. Develop and maintain a website. (p. 129)

These nine strategies can be developed into a marketing plan of action for the district and I would add one more. In districts where I have served as superintendent, I have employed a word-of-mouth marketing technique called "positive gossip" to foster and grow a collective body of good news stories about the district. Built on the premise that destructive rumors and gossip often hit the communication wires faster than Twitter, at the end of each Cabinet or Leadership Team meeting, team members would develop a few pieces of positive information to be shared with teachers, staff, parents, and community members. I anticipated the positive information would smother the negative. The positive gossip campaign operated well because it compelled district leaders to make positive information a priority, whether in a staff meeting or supermarket checkout line. What is overlooked in Carroll and Carroll's marketing communication plan is describing special communication with other groups in the external community who are not senior citizens. The authors do not address techniques for marketing to diverse cultural groups and these should be targeted, priority groups in every district. 
Holt (2002) also offered marketing techniques appropriate to employ for routine communications or during a bond campaign. First, the district leaders or campaign committee members should provide information to voters with honest facts about the issues. Second, they should identify their varied audiences and provide the information that best suits the needs of each group. For example, Holt offered special communication for senior citizens who may be out of touch with schools and need additional information about the schools that parents would not need because of their familiarity with their neighborhood schools. In other words, the district and campaign committee would target each audience with materials specific to each group's identified needs. Third, the information medium chosen would also match the audience. Holt described a 1994 study prepared for the American Association of School Administrators (AASA):

The Mellman-Lazarus-Lake polling firm determined that most people believe they get a majority of their information about the schools from newspapers, friends, and children. The interesting result is that those surveyed placed one-onone sources much higher than all media in terms of the quality of information they provide. (p. 117)

Participants in the study rated principals highest in the "very good" category at $37 \%$ and superintendents lowest in the "very good" category at 29\%. When both "good" and "very good" were added together, parents came out in the lead as the best medium for information at $80 \%$. Newspapers were rated lower in "good" and "very good" at $63 \%$. What the data indicates is that one-to-one communication is the favored medium to receive information; and the farther up the organizational chart an individual is, the less trusted he or she becomes. In my experience, this is generally the case for parents and teachers in communication with their local principal. The principal has developed a 
relationship built on trust and respect with the staff and parents; thus parents value and support the principal's information. At the district level, however, most community members, especially external stakeholders without children in school, would probably rate the superintendent higher in terms of quality of information if there have been opportunities for two-way communication or one-to-one communication with the public versus one-way communication.

General marketing tools, implemented months in advance of a bond campaign and others tools during the bond campaign, include a variety of communication tools as described in Table 3. While several are considered one-way communication, which tends to be the least effective form of communication, one-way communication becomes more effective the more often it is repeated (Campbell \& Magmer, 2007; Carroll \& Carroll, 2000). This was the case in David Douglas School District. The district circulated mass communications of two informational brochures: one containing a variation of the bond message that would appear on the ballot and the other including a list of construction projects with estimated cost for each project. These were scheduled to be sent several times to the entire community. All David Douglas School District publications abided by restrictions of the Oregon elections laws, which prohibit districts from promoting a bond election; however, these restrictions do not apply to the campaign advocacy committee. The campaign committee members can advertise and market using any of the marketing tools listed in Table 3. 
Table 3

Marketing Tools, Definition, and Characteristics

\begin{tabular}{|c|c|c|}
\hline Tools & Definition & Characteristics \\
\hline Direct Mail & $\begin{array}{l}\text { Flyers, brochures, } \\
\text { information sheets }\end{array}$ & $\begin{array}{l}\text { - One-way communication } \\
\text { - Impersonal } \\
\text { - Persuasive (Holt, 2002) } \\
\text { - Informs no voters (Campbell \& Magmer, 2007) } \\
\text { - Effectiveness greatly increases through repeated } \\
\text { contact (Carroll \& Carroll, 2000) }\end{array}$ \\
\hline Free Media & $\begin{array}{l}\text { Video presentations, } \\
\text { Facebook. Twitter, } \\
\text { blogs, public } \\
\text { announcements, press } \\
\text { conferences }\end{array}$ & $\begin{array}{l}\text { - One-way, two-way, and repeated communication } \\
\text { - Detailed information } \\
\text { - Can reach large numbers and various audiences } \\
\text { - Online requires continual updates and monitoring } \\
\text { (Porterfield \& Carnes, 2012) } \\
\text { - Low financial impact }\end{array}$ \\
\hline $\begin{array}{l}\text { Letters to the } \\
\text { Editor }\end{array}$ & $\begin{array}{l}\text { Letters written to editors } \\
\text { of print media to express } \\
\text { support of the school } \\
\text { district or bond election }\end{array}$ & $\begin{array}{l}\text { - One-way, external communication } \\
\text { - Can be persuasive } \\
\text { - Effectiveness greatly increases through repeated } \\
\text { contacts from several writers (Carroll \& Carroll, 2000) }\end{array}$ \\
\hline Material Drops & $\begin{array}{l}\text { Distribution to homes by } \\
\text { teams of volunteers }\end{array}$ & $\begin{array}{l}\text { - One-way communication } \\
\text { - Impersonal contact with voters } \\
\text { - Detailed communication } \\
\text { - Can target supporters } \\
\text { - Fewer voters targeted than other tools }\end{array}$ \\
\hline Paid Advertising & $\begin{array}{l}\text { Billboards, yard signs, } \\
\text { bumper stickers }\end{array}$ & $\begin{array}{l}\text { - Specific to a bond campaign } \\
\text { - Impersonal } \\
\text { - Can reach large numbers } \\
\text { - No targeted customers } \\
\text { - Effectiveness contingent on saturation placement } \\
\text { (Carroll \& Carroll, 2000) } \\
\text { - Informs no voters (Campbell \& Magmer, 2007) }\end{array}$ \\
\hline $\begin{array}{l}\text { Print and } \\
\text { Broadcast Media }\end{array}$ & $\begin{array}{l}\text { Paid political } \\
\text { announcements on radio, } \\
\mathrm{TV} \text {, newspapers }\end{array}$ & $\begin{array}{l}\text { - One-way communication } \\
\text { - Impersonal } \\
\text { - High cost } \\
\text { - Effectiveness greatly increases through repeated } \\
\text { contacts (Carroll \& Carroll, 2000) } \\
\text { - Can be persuasive and dramatic (Carroll \& Carroll, } \\
\text { 2000) }\end{array}$ \\
\hline
\end{tabular}


Table 3 (continued)

\begin{tabular}{|l|l|l|}
\hline \multicolumn{1}{|c|}{ Tools } & \multicolumn{1}{|c|}{ Definition } & \multicolumn{1}{c|}{ Characteristics } \\
\hline Public Speaking & $\begin{array}{l}\text { Formal presentations to } \\
\text { civic clubs, parent } \\
\text { groups, forums }\end{array}$ & $\begin{array}{l}\text { - Special events (Superintendent and board should not } \\
\text { consistently take the lead during a bond campaign) } \\
\text { (Holt, 2002) } \\
\text { - Speakers must be thoroughly familiar with all aspects } \\
\text { of the bond (Bagin et al., 2008) }\end{array}$ \\
\hline Telephone Banks & $\begin{array}{l}\text { Personal phone calls to } \\
\text { targeted yes voters }\end{array}$ & $\begin{array}{l}\text { - Specific to a bond campaign } \\
\text { - Can be very persuasive (Campbell \& Magmer, 2007) } \\
\text { - High degree of control over message } \\
\text { - General information } \\
\text { - Reaches fewer voters than advertising }\end{array}$ \\
\hline $\begin{array}{l}\text { Meet and } \\
\text { Greet/Canvassing }\end{array}$ & $\begin{array}{l}\text { Face-to-face contact with } \\
\text { voters by walking to } \\
\text { homes in targeted } \\
\text { neighborhoods }\end{array}$ & $\begin{array}{l}\text { - Specific to a bond campaign } \\
\text { - Highly personal, one-to-one contact } \\
\text { - Detailed information } \\
\text { - Can be very persuasive (Carroll \& Carroll, 2000) }\end{array}$ \\
\hline
\end{tabular}

Direct mail, free media, letters to the editor, material drops, paid advertising, and print and broadcast media are all one-way communication tactics. Free media, Facebook, blogs, or Twitter may contain both one-way and two-way communication. Public speaking telephone banks and meet-and-greet are two-way communication, which are more persuasive marketing tools (Campbell \& Magmer, 2007). While all these can be effective marketing tools, the district would have to determine which are most cost effective, which target the intended audiences, and which provide the most appropriate information to that audience.

School and district leaders often do not do a good job of self-promotion. Whether knowledge, time, or cost factors are inhibiting the utilization of marketing tools, publicizing the district's successes is essential. Marketing techniques, tools, and publications all help to create a positive image to internal and external school district 
stakeholders. Carroll and Carroll (2002) listed several advantages for districts that

monitor their image and work toward improving it:

1. They are more likely to be more effective in securing community support for school projects and instituting changes sought by teachers, administrators, and boards of directors.

2. "Them-us" attitudes are minimized.

3. They experience increased parental support and involvement.

4. They have greater staff morale because the staff feels it is part of a winning team. (p. 78)

Marketing the district's accomplishments in tandem with a strategic improvement plan will ensure that the public does not see "lipstick on a pig," but instead will see a district achieving its goals and stated actions.

\section{Social Media}

The 2008 presidential election was a social media success. Barack Obama won nearly $70 \%$ of the vote among Americans under age 25-the highest percentage since U.S. exit polling began in 1976, according to U.S. News (Fraser \& Dutta, 2008). In 2008 about 140 million members were actively using Facebook each month (Smith, 2008). In 2012, Businessweek reported Facebook hitting one billion active monthly users in September (Vance, 2012), while the median age of a Facebook user had actually fallen from 26 in 2008 to 22 in fall of 2012 (Grandoni, 2012). Still, this social medium can help win elections, whether presidential or district bond elections and can swiftly and effectively provide information about the district to its stakeholders. Many school districts have developed a Facebook page to post events and to keep in touch with constituents and other institutions, but many districts still fear social media and continue to adhere to antiquated school board policies that forbid usage of these special communication tools. 
Many school boards worry about the liability of students and staff using social media.

The occasional news story that garners national attention about online improprieties between students and teachers has many rural board members apprehensive.

Still, times have changed. Porterfield and Carnes (2012) explained that educators must do more than educate students. They must build relationships with the students' families and the taxpayers in the communities they serve:

School leaders have the responsibility to reach out to the larger community-to listen to their stakeholders and include them in new ways, to provide information more quickly than ever before, and, ultimately, to build stakeholder trust. To do this, leaders must develop new communication skills that utilize new technologies. (pp. 1-2)

Using social media such as Facebook, Twitter, blogs, and message boards can serve that purpose. Gagne (2012), CEO of Allerton Hill Consulting, a communications firm that works with school districts, concurred:

I'm convinced that if schools want to improve their image with taxpayers, they must begin to use social media. The benefits are just too great, and as more of the taxpaying community ties into social media through mobile devices, "traditional" public schools have to become non-traditional, and join the conversation. (para. 2)

Just like email and websites, which eventually became the norm in every school district, school leaders will ultimately need to embrace social media. Gagne described school districts thriving if they use social media to engage their community and to aggressively enhance and protect their reputation. The ones who do not will "find themselves playing defense with an unengaged public and a healthy number of skeptics who may question the value of public education in their community" (Gagne, 2012, para. 5). Before I became superintendent in Ontario School District, the district technology-use policies were rigid and outdated. These were promptly revised to be more flexible, yet safe for 
students, staff, and district. As a result, the district passed its bond in 2010, in part, by developing and using Facebook, Twitter, and YouTube to communicate to the public, especially to younger audiences. After the successful campaign, Facebook was then used to update the public on the construction projects and other major events occurring in the district.

Marketing the school district has several advantages, but two rise to the top: First, marketing enhances the district's image by providing the public with specific information about the district. Second, it specifically develops a communication tool to target an intended audience. Bagin et al. (2008) defined marketing as "the process of discovering, defining, and delivering what people need and want" (p. 323). Districts are finding themselves in survival mode. On a daily basis, students transfer out of the K-12 public school system to online charter schools, alternative schools, or private schools. The K-12 system, apparently, is not "delivering what people want." This dissatisfaction is then spread throughout the greater school communities. In a competitive marketplace, it is critical that districts investigate what the public wants, develop the programs that fit the needs of the students and community, and then inform the public of those changes through meaningful two-way, face-to-face communication. Using marketing strategies has become a necessity in order to enhance a school district's image.

Likewise, when a bond election draws near, the district's image shapes the public's attitudes toward the public school system. Closing a deal with the public in a bond election takes a thorough understanding of which marketing strategies will influence a yes vote. 


\section{Chapter Summary}

Communication alone does not guarantee the support of different constituencies.

One of the great ironies today is that you can do a great job of educating students and communicating with parents and still miss 78 to 80 percent of the people upon whose support public education-and your livelihood-depends. That is because the vast majority of people who pay taxes in most communities small and large, do not have school-aged children. This means that we have to start paying more attention to school public relations and marketing, or pay the consequences. (Carr as cited in Porterfield \& Carnes, 2008, p. 3)

According to the 2010 U.S. Census, 12 to $50 \%$ of taxpayers in Oregon communities have school-aged children (Hannah-Jones, 2011). The average for Oregon is 30\% with children under the age of 18 . That means districts must be thoughtful, intentional, and strategic about communications with all stakeholders and constituencies by systematically assessing the school district demographics. Open, honest, and transparent communication builds public confidence and trust in the district, but that communication must intentionally target every group of stakeholders.

The importance of an effective communications program cannot be underestimated: It can enhance a school district's image and reputation and be the impetus to passing a bond campaign. While Bagin et al. (2008) described the vulnerability of school districts in their communication to the public on finance issues, it can also apply to any topic of school communication: "If a school district does not maintain ongoing and clear communications with its parents and taxpayers on finance and budget issues, confusion and distrust can develop" (p. 297). Erickson (2011) warned that whether answers to public questions are positive or negative, people should see that 
district leaders are transparent. Communication ultimately builds trust and confidence in the school district.

Chapter 2 reviewed the literature that described the communication strategies considered most important in garnering district support and the communication strategies that would lead to a successful outcome in a bond campaign. As the literature described, most district leaders are not experts in communication strategies to attain public support in bond levy elections. In practice, however, the communication skills of the school district leaders and the district's strategic communication plan, which include precampaign, during the campaign, and post-campaign activities, seem to be the leading indicators of whether the district will realize a successful election outcome. How districts communicate with their numerous and varied constituents is tantamount to gaining public support in construction bond levies. District leaders consequently need to be aware of communication strategies and practices that best elicit a positive response from the district stakeholders. That is why it is urgent that a handbook is developed for districts and district leaders who are struggling to pass a bond.

This review described the communication strategies and practices essential to districts strengthening their relationships with their internal and external stakeholders. As a result of those strengthened relationships, districts leaders would also find the public prepared to support the district and schools at the polls in construction bond elections. Communication strategies were reviewed in three categories: Organizational Communication, School and Community Relations, and Marketing Strategies. 


\section{CHAPTER III \\ RESEARCH METHODOLOGY}

School districts across the United States are in dire need of repairing, rebuilding, and remodeling aging school buildings and facilities. Some call the need for new buildings and remodeled facilities a nationwide crisis (Long, 2011). These aging and dilapidated schools are in dire need of millions of dollars' worth of repair and refurbishing (Palmer, 2012). Yet school districts are not funded to repair or rebuild their schools. They must instead ask voters to finance the costs. Voter-dependent support presents an obvious disadvantage for most district leaders who have had little or no experience in passing a bond. Their preparatory coursework typically concentrates on curriculum, instruction, leadership, and management with no training centered on voters or the election system. In recent years, because of the economic shortfall, workshops on holding bond campaigns are limited or nonexistent. Published materials and literature are also insufficient for guaranteeing districts a win at the polls. They are often bound in rhetoric and theory with little practical value. As a result, school leaders engage in a haphazard approach to campaigns with little guidance. No wonder school construction bond elections are successful only about $60 \%$ of the time (OSBA, 2012).

The failure of districts to pass bond measures is a costly problem worth hundreds of millions in untapped dollars to school districts. I have personal experience dating back two decades. Early in my career as a principal, I witnessed superintendents working an excessive number of hours to pass a bond but to no avail. As a superintendent I have 
experienced one failed bond measure. However, having learned from mistakes of the past, I have also experienced a successful bond levy.

The key to a successful bond campaign is a systematic approach. That is why I developed the handbook Holding Successful School Bond Campaigns: Not for Dummies. It describes 17 strategies that successful districts have used to gain public support in school district construction bond elections. The strategies can be easily replicated in other school districts. As the main tool of this research project, the handbook was also the main text used in a workshop for superintendents and other district leaders who were embarking on a bond election in the next year or two. I shared the effective strategies and measured the handbook's usefulness, effectiveness, and importance as it applies to school bond elections.

Chapter 3 focuses on five sections. The first two sections discuss the research design and research questions that were used to evaluate the efficacy of the handbook in school districts. The third section describes the data collection procedures that I used to justify my data. The data analysis section clarifies how I safeguarded the study against bias and defended the validity of the study. The last section examines the action plan that managed the field-testing of the handbook.

\section{Research Design}

The Problem-Based Learning (PBL) approach that employs R\&D as the method and design structure is most beneficial for collecting the qualitative data for my study (Borg \& Gall, 1989; Bridges \& Hallinger, 1995). Bridges and Hallinger (1995) contended that the PBL option is different from other research options because the research includes 
a set of steps that result in the development of a PBL project. Borg and Gall (1989), furthermore, provided the list of steps as shown in Table 4. According to Bridges and Hallinger, the project involved the exploration of a "salient research question or set of questions in the context of implementing a self-authored PBL project" (p. 124).

Table 4

Borg and Gall's R\&D Cycle

Steps in the Research and Development Cycle

1. Research and information collecting

2. Planning objectives, learning activities, and small-scale testing

3. Develop preliminary form of the product

4. Preliminary field testing

5. Main product revision

6. Main field testing

7. Operational product revision

8. Operational field testing

9. Final product revision

10. Dissemination and implementation

(Borg \& Gall, 1989, pp. 784-85)

For my study, I incorporated Bridges and Hallinger's (1995) work by using PBL as my research method. PBL adheres to an $R \& D$ process that supports my overall research goal of creating a useful tool for superintendents embarking on a school bond election. Borg and Gall (1989) depicted educational R\&D as "a process used to develop and validate educational products" (p. 782). Borg and Gall contended that students working in an R\&D environment must demonstrate their own understanding of the 
problem through the development of a product that reflects their own learning by adhering to these guiding questions:

1. Does the proposed product meet an important educational need?

2. Is the state of the art sufficiently advanced that there is a reasonable probability that a successful product can be built?

3. Are personnel available who have the skills, knowledge, and experience necessary to build this product?

4. Can the product be developed within a reasonable period of time? (p. 785)

Beginning with the end in mind, I developed the preliminary form of the product or handbook, which affirmatively answered these questions. The problem of passing bond elections was explored and defined in chapter 1 . The literature review in chapter 2 discussed the essential effects of communication on school bond elections. My years of experience, skills, and knowledge in passing-or not passing-a bond campaign assisted in the development of the handbook. PBL following an R\&D process was an applicable research methodology to conduct my study.

The $R \& D$ process tests products, such as my handbook, that are ready to be implemented in school settings. Borg and Gall's (1989) research has supported the R\&D cycle as an effective way to develop, field test, and refine a product so that the product is ready to help or support the work of practitioners. This R\&D cycle assisted me in developing and field testing a handbook for superintendents and other district leaders who were planning a bond election in the next one to two years. This study provided school leaders with a tested product that is ready for operational use in districts. In creating this handbook, I was guided by the following questions:

- How useful is the handbook to district leaders embarking on a school bond election? 
- How effective is the handbook to district leaders embarking on a school bond election?

- How important is the handbook to district leaders embarking on a school bond election?

School superintendents and other district leaders were equipped with a handbook to provide them with a knowledge base to successfully manage a bond campaign. This study provided both theoretical and practical solutions for school leaders in their planning of a bond campaign.

Borg and Gall's (1989) R\&D Cycle offers researchers 10 steps to adhere to in conducting a study. Bridges and Hallinger (1995) stated, "These steps reflect a systematic plan of inquiry designed for product development and testing" (p. 119). I followed Steps 1-7 in my study as discussed below.

Step 1, Research and information collecting. I have had a passion for nearly two decades in understanding why some bond elections pass while others fail. I seriously began my quest for understanding by researching and collecting data while serving as superintendent in three school districts from 2005 to present, but my experience goes back to 1995 as principal of the Atwood High School (pseudonym) in a rural school district. The district at that time attempted three different bond elections with all three being soundly defeated. As superintendent of Seven Mountains School District (pseudonym), I held a bond election in November 2006, which was sorely defeated with 38.1\% voting yes (OSBA, 2012). In May 2010, Pioneer School District (pseudonym), a medium-sized, rural district, held a bond election and won with $58.2 \%$ voting yes (OSBA, 2012). 
It took many defeated efforts, research, and discussions with other successful districts before I developed a list of strategies that worked in 2010. Now that I am serving as superintendent in Twin Rivers School District (pseudonym), an urban district, I systematically and formally developed a detailed list of strategies compiled in a handbook, not only to be used in my district but also to be used in other districts embarking on a bond campaign.

To prepare for this project, I took three marketing classes in the masters of business administration program as part of my doctoral coursework. I also interviewed recent successful colleagues in surrounding school districts. I spoke with communication directors and campaign committee chairs. My chapter 2 Literature Review focused on communication, which is a fundamental requirement to pass a bond. Learning more about these key strategies continued throughout my dissertation research and in the R\&D process.

In this first step, I outlined the main points of the handbook by citing the key strategies that districts use to pass a bond election. I first created a template of the handbook to be updated; and as I learned more about each strategy through my research, I added the new strategies. I soon found that the majority of the key strategies in passing a bond were dependent on firmly established communication techniques and practices. These findings drove my planning and research in Step 2.

Step 2, Planning objectives, learning activities and small-scale testing. My advisor suggested that I draft my product early in my dissertation work so it would drive my problem statement and literature review. Conversely, what I learned from my research in 
chapters 1 and 2 further helped me to define and develop the product. I developed an initial draft of the product or handbook and received feedback from my advisor and Oregon superintendents and other district leaders whose districts recently passed a bond election. This is referred to as Small-scale testing. As a result of the feedback, I was able to revise and add several sections to the first draft of the handbook. The handbook or product was developed to be used as a guiding tool in a workshop for superintendents and other district leaders who are planning a bond election in the next one to two years. The handbook included activities to be completed during the workshop in Steps 4 and 6 .

Step 3, Develop preliminary form of the product. As a result of Steps 1 and 2, I crafted a fully developed model of the product. The handbook is called Holding Successful School Bond Campaigns: Not for Dummies. I chose this title because passing a bond campaign is not an easy task for a superintendent no matter what advice is shared by others, literature researched and collected, or special training received. Successful skills to pass a bond are often acquired through the experiences of failing to win the support of the public or by successfully passing a bond election. The context reversal in the title of the handbook Not for Dummies also adds a glimmer of humor. The work of superintendents to pass a bond is painfully intense. While still leading and managing the school district, they work long hours to convince a diverse mix of stakeholders to vote in support of a bond that raises taxes. A sense of humor must be at the core of these communication efforts.

The handbook included the rationale, introduction, anecdotes, objectives, activities, and next steps to be used in the workshop. It was divided into three sections: 
Pre-Bond Campaign, During the Bond Campaign, and Post-Bond Campaign. I divided the handbook into sections when I realized that most of the work of the district must be accomplished before the board approves the bond election, and I wanted to demonstrate that in the handbook itself. More than $90 \%$ of the handbook identifies pre-campaign strategies; less than $10 \%$ of the handbook describes during and post-campaign topics. Once the school board approves holding an election, Oregon elections law prohibits the superintendent and employees from campaigning during work hours or with school district resources. Feedback from Small-scale testing identified communication as a key component of passing a bond election so I added a lengthy section on communication theory and practice to the handbook.

While Step 3 developed the preliminary product, the product is still considered in its infancy. In Step 3 I revised and expanded the handbook after the Small-scale testing. Preliminary field testing would deliver a more formal assessment and evaluation of the handbook and thus produce substantive improvements and revisions.

Step 4, Preliminary field testing. "The purpose of the preliminary field test is to obtain an initial qualitative evaluation of the new educational product" (Borg \& Gall, 1989, p. 790). An audience of five practitioners were invited to a scaled-down workshop to provide critical, formative, and systematic feedback about the product. I presented the handbook to three superintendents, one principal, and one communications director who were contemplating a bond campaign in the next one to two years. The formative-evaluation feedback from the preliminary field test advanced the improvement of several areas of the handbook's key strategies and activities. 
Assessment of participants' learning from their use of the handbook and participation in the workshop was in the form a pretest and posttest of communication theory and the campaign strategies. A follow-up survey conducted on SurveyMonkey provided me with formative and summative feedback to determine the efficacy of the handbook and the workshop.

Step 5, Main product revision. After Step 4 and my analysis of the formative and summative feedback, I revised the product based on survey data, written comments, and personal observation. The feedback helped me to revise the handbook further. The surveys administered on SurveyMonkey ensured that participants were able to provide clear and honest feedback. As a result of the feedback, I added a new section to the handbook on teaching and learning. Bridges and Hallinger (1995) cautioned, "In cases where the preliminary field-test data do not suggest a need for revision, there is likely to be a flaw in the procedures used to generate the formative evaluation data" (p. 122).

I encountered a flaw similar to this during my Step 1 and 2 investigations when I interviewed a communications director from a nearby school district. The superintendent did not have the time to meet and assigned the communicators director to speak with me. The communications director provided a wealth of information about his district passing the bond, but he did not provide feedback on the specific strategies in the handbook. He had received the handbook in advance of the meeting, but he did not have time to read it. He confessed that his district only conducted one-way communication, but the campaign committee was responsible for everything else. My interpretation of this event is that the interview was considered unimportant. My task after this incident was to safeguard my procedures so that I would receive more reliable data from interviewees and other 
participants would provide valid and conscientious feedback to help me improve my product.

Step 6: Main field testing. The main field test involved implementation of the new product and collection of data concerning its application. It is at this stage that I collected the key data in relation to the product's efficacy. Main field testing was conducted with superintendents and other school district leaders such as communications' directors, directors of operations, business managers and school board members. Sixteen district leaders participated in a full-day workshop, sponsored by the Confederation of Oregon School Administrators (COSA). The handbook or product was the guiding document for the September 27, 2013, workshop. The workshop used a pretest and posttest to determine participants' learning of communication theory and the campaign strategies. A survey was then administered at the end of the workshop to determine the efficacy of the handbook and the workshop. It provided both summative and formative feedback with written comments and suggestions.

Step 7, Operational product revision. After the Main field testing, I studied the formative and summative data and determined "whether the educational product was fully ready for use in schools" (Borg \& Gall 1989, p. 793). After the necessary revisions, the handbook was then ready to be professionally edited, bound, and ready to implement in a variety of natural settings.

Steps 8, 9, and 10, Operational field testing; Final product revision; Dissemination and implementation. These steps are designed more for specific professional publications and dissemination. I do not plan to conduct these last three steps for this research study. 
Bridges and Hallinger (1995) recommended Steps 1 through 7 for students designing dissertation projects. Step 10 is left to students' own discretion. Therefore, considerations for Steps 8-10 are discussed in chapter 5 .

\section{Research Questions}

Since the mid 1990s, I have been interested in knowing what strategies help prepare districts to pass bond elections. I have attended several OSBA Bonds and Ballots workshops. I have researched other districts' efforts by meeting with superintendents, campaign managers, and district operations directors. Published materials on passing bond levies are limited and often do not meet the needs of individual school districts. That is why I have been so eager to develop a handbook to help superintendents and other district leaders who may be attempting a bond for the first time. My intent is for the handbook to be used as a guiding tool by helping districts to take the appropriate steps and apply the successful strategies identified in the handbook.

The following research questions helped to guide the effectiveness of the handbook and workshop, Holding Successful School Bond Campaigns: Not for Dummies.

Primary Research Questions

1. What is the usefulness of the handbook to district leaders embarking on a school bond election? Usefulness is defined as practical information for district leaders initiating a bond. Is the content fully developed with necessary details and examples?

2. How effective is the handbook to district leaders embarking on a school bond election? Effectiveness is defined as being able to apply the information. Can this information be applied in school districts?

3. How important is the handbook to district leaders embarking in a school bond election? Importance is defined as meeting school district's needs at this time. Is this strategy important to the needs of the district?

4. What is the perceived impression of the handbook's format and style? Format and style are defined by the way the contents are presented: structure, method, and form. 
5. What are the participants' perceptions of the workshop's content, design, facilitator, results, and presentation?

Secondary Questions

Communications Theory and Practices

1. How familiar are participants with communications theory and practices? Level of Familiarity would include participants' knowledge, understanding, and application of the communication theory and strategies related to the greater organization and personal communication skills.

2. How comfortable are participants in applying the communication strategies? Level of Comfort would describe the participants' ease of understanding and ability to apply the communication strategies related to the greater organization and personal communication skills.

3. Which communication strategies do participants perceive needing the most help?

\section{Campaign Strategies}

1. How familiar are participants with school bond campaign strategies? Level of Familiarity would include participants' knowledge, understanding, and application of Pre-Bond Campaign Strategies, During-the-Bond Campaign Strategies, After-the-Bond Campaign Strategies.

2. How comfortable are participants with school bond campaign strategies? Level of Comfort would describe participants' ease of understanding and ability to apply the Pre-Bond Campaign Strategies, During-the-Bond Campaign Strategies, After-the-Bond Campaign Strategies in their district.

3. Which campaign strategies do participants perceive needing the most help?

General

1. Can the handbook stand alone on its own merits without a workshop?

I used these questions to further my research on the effectiveness of the handbook by gathering feedback from a variety of school district leaders. The feedback was used to improve and revise the product so the handbook would become a useful, effective, and important tool for districts to follow when planning a construction bond election. 


\section{Data Collection Procedures}

The development of the strategies used in the handbook is based on research, observations, and personal experience. However, my research, observations, and personal experiences alone cannot provide a complete representation of the efficacy of the handbook. Therefore, in a PBL model and R\&D study (Borg \& Gall, 1989; Bridges \& Hallinger, 1995), I enlisted the expertise and feedback of others in the field to fill in any gaps in the handbook.

Feedback and revisions were accomplished in multiple settings and data collection sources and techniques: initial interviews about the product's effectiveness from district leaders who have recently passed a bond election (Step 2 in the R\&D Cycle: Small-scale testing); feedback from a small group of superintendents and other district leaders in a mini workshop held on September 12, 2013 (Step 4 in the R\&D Cycle: Preliminary field testing); and Main field testing of the handbook with 16 district leaders in a workshop environment with initial and follow-up surveys and open-ended questions (Step 6 in the R\&D Cycle: Main field testing). I conducted Step 6, Main field testing, on September 27, 2013, which was sponsored by COSA.

To accomplish these tasks, I first invited superintendents of school districts near Twin Rivers School District, who recently passed a bond election, to conduct an initial review of the handbook and provide feedback. Scheduled participants in the interviews were provided a copy of the handbook at least two weeks in advance of the interview. Interviews were scheduled, one-on-one, with four superintendents or their designee. They each signed a consent form assuring that the study would be entirely confidential. 
Questions were general and open-ended except for district demographic information. Districts and participants were identified by a pseudonym. An interview protocol or form was developed that contained information about the process of the interview such as purpose for the study, individuals and sources of data being collected, protection of confidentiality of the interviewee, length of the interview, questions to be asked, and space to take notes on interviewee's responses. These protocols are fully described in chapter 4 . All interviews were recorded and later transcribed into a data file for analysis. Interviews included the following steps as identified by Creswell (2002):

1. Identify the interviewees.

2. Determine the type of interview you will use.

3. During the interview, audio-tape the questions and responses.

4. Take brief notes during the interview.

5. Locate a quiet suitable place for conducting the interview.

6. Obtain consent from the interviewee to participate in the study.

7. Have a plan, but be flexible.

8. Use probes to obtain additional information.

9. Be courteous and professional when the interview is over. (pp. 207-208)

Anderson, Herr, and Nihlen (1994) stated, "Interviews are a good tool to use when one wishes to know how a person feels about events that have happened or are happening. They are also important in gaining a perspective on how others understand and interpret their reality" (p. 115).

In a classic model of coding, I followed the basic coding steps:

Step 1: Read the transcripts

Step 2: Label relevant pieces

Step 3: Decide which codes are the most important, and create categories by bringing several codes together

Step 4: Label categories and decide which are the most relevant. How are they connected to each other? 
Step 5: Additional options

- Decide if there is a hierarchy among the categories.

- Decide if one category is more important than the other. (Lofgren, 2013)

After reading and rereading the transcripts several times, I labeled the relevant pieces. This covered the first two steps of the coding steps. I then decided which codes seemed to be most important, mainly by the number of comments or pieces of information, which were then coded. At this point in Step 5 of the classic coding model, I could easily ascertain the emerging themes and labeled them as such. Twenty main themes emerged. Step 3 of the R\&D process develops the preliminary form of the product. I had already prepared the first draft of the handbook in Step 2, so I revised the handbook in Step 3 in preparation for the Step 4, Preliminary field testing.

The second assessment of the handbook or Step 4 of the R\&D Cycle was generated from a small group of participants. This was the Preliminary field testing of the R\&D process. Three superintendents, one communication director, and one principal, all of whom were planning a bond election in the next one to two years, were invited. Districts and participants in the study were identified using pseudonyms. Participants were provided with the revised handbook at the workshop because they were assessed on their learning by a pretest and posttest on communication theory and practices and the strategies in the handbook. Afterward, participants were also assessed on their perceptions of the usefulness, effectiveness, and importance of both the handbook and workshop through a Likert-like scale survey, which also allowed open-ended responses. General demographic information about each participant's school district was also gathered using SurveyMonkey. 
The last assessment, Step 6, Main field testing, was a summative and formative evaluation. The Main field test consisted of inviting Oregon superintendents, who are planning a bond election in the next one to two years, to participate in a gratis workshop, sponsored by COSA. Participants were administered a pretest and posttest of their learning about communication theory and practices and the strategies in the handbook. Afterward, participants assessed the usefulness, effectiveness and importance of the handbook and workshop through Likert-scale surveys, open-ended responses, and general demographic information about the school district using SurveyMonkey.

Although I attempted two times to facilitate a workshop using the handbook at the OSBA Summer Conference and Fall Convention, this idea did not come to fruition. Both times my request was rejected. This would be Step 8 in the R\&D Cycle or the Operational field test. I would need to continue these R\&D steps if the final result is to publish the handbook. These last steps, 8,9 , and 10, are described in more detail in chapter 5 and are not be part of this research study.

\section{Data Analysis Strategies}

Creswell (1998) defined data analysis as the "process of systematically searching and arranging the interview transcripts, field notes, and other material you accumulate to increase your own understanding of them and to enable you to present what you have discovered to others" (p. 157). In this study, I analyzed formative and summative data from interviews, surveys, observations, and comments about the handbook Holding Successful School bond Campaigns: Not for Dummies to improve my product. 
A generally accepted research practice is for researchers not to "rely on any single source of data, interview, observation, or instrument” (Mills, 2003, p. 52). Golafshani (2003) pointed out, that in qualitative research, reliability and validity are replaced by the idea of trustworthiness; he recommends triangulation as a way to establish this trustworthiness in the results of a study.

Triangulation can be a mix of techniques (Anderson et al., 1994) or a collection of data from several sources or subjects (Bogdan \& Biklen, 1998). Triangulation is a method used by qualitative researchers to check and establish validity in their studies by analyzing a research question from multiple perspectives to reduce or remove bias from a study (Creswell, 1998). Thus, multiple sources, methods, investigators, and theories help to ensure the credibility of a study. I included interviews, surveys, observations, and participant comments in at least three different settings to provide feedback on the handbook.

The first setting was Step 2 of the R\&D Cycle. I interviewed key district leaders, one-on-one, who recently passed a bond. The second setting was Step 4 of the R\&D Cycle or the Preliminary field test. I held a workshop, using the handbook, with three superintendents, one communications director, and one principal, who were planning a bond election in the next one to two years. The third setting was Step 6 of the R\&D Cycle or the Main field test. This workshop invited 16 Oregon superintendents and other district leaders, who were planning a bond election in the next one to two years, to participate in a gratis workshop, sponsored by COSA. 
Interviews were digitally recorded to minimize any personal bias in the research. The recordings were burned to a $\mathrm{CD}$ for transcription. I then transcribed, coded the notes, and analyzed them. Two superintendents, one communication director, and one business/operations director, who recently passed a bond election, reviewed and scrutinized the handbook and participated in the interviews. After their review of the handbook, I interviewed them to receive feedback on the handbook.

Creswell (2005) described data analysis requiring the researcher to be comfortable in developing ideas and making comparison and contrasts. "It also requires that the researcher be open to possibilities and see contrary or alternative explanations for the findings" (p. 152). Being open to multiple ideas and differing ideas was important to improve the handbook and to prepare it for use in the Preliminary and Main Field tests, Steps 4-7. The interviews conducted fall into the first two steps of the R\&D Cycle when information and data gathering are required to improve the product. Using valid research methods was central to collecting the information needed to conduct a reliable study.

In the Preliminary and Main field tests, workshop participants, comprised of superintendents and other district leaders, used the handbook not only to guide them through a bond campaign but also to examine its practicality. When they arrived at the workshop, participants were administered a pretest and posttest of communication theory and practices and campaign strategies using SurveyMonkey. After the workshop, participants also took a survey evaluating the handbook and workshop. This provided both summative and formative feedback to improve the handbook and the workshop. Bridges and Hallinger (1995) noted, "The researcher will gather formative and 
summative evaluation data about how the project can be improved and its efficacy" (p. 127).

In my analyses of survey data, I used SurveyMonkey. This Internet-based program has several features of analyses such as filtering responses, cross tabulation, and text analysis. Filtering responses allowed me to view only the comments from respondents who answered a particular question. Cross tabulation allowed me to see a side-by-side comparison of two or more questions to determine how they were interrelated. The text analysis allowed me take open-ended responses and comments and turn them into data that I could easily categorize and analyze.

\section{Work Plan}

My work plan began with the end in mind and working backward. Since I was reinstated into the doctoral program in October 2012, I had aimed for completion of my dissertation draft by the end of November 2013 with the defense in February or March. However, because of some unanticipated scheduling setbacks, completion of the dissertation instead ended in January 2014 with the defense scheduled for the end of February.

When I first became a superintendent in 2005, I often considered the necessity of having a single document with the strategies described to pass a bond. I instead depended on attending the yearly OSBA Bonds and Ballots workshops. The workshops included practitioners who recently passed a bond levy and a majority of presenters who were market researchers, architects, construction management, and municipal security corporations and companies vying for new business. All of them made passing a bond 
sound easy-as long as their company was hired. Districts that passed a bond optimistically told their stories and shared their communication brochures. It looked easy. All a district had to do was replicate some communication strategies. Millions of dollars could be in any district's future-just for the asking.

My first superintendent position was in Seven Mountains School District (pseudonym). The district was growing fast and the buildings were old and crowded. The district had a culture of passing bond elections. As superintendent I became the leader of the campaign. The problem was that I did not have a clear understanding of what the process needed to be. I talked often with the leaders of larger school districts that recently passed their bond elections. But because I had no experience, the messages shared did not have much meaning. The information fell on ignorant ears.

The idea of a handbook to lead districts through bond campaign strategies came to me after passing a bond election in Pioneer School District (pseudonym). When I was named superintendent of my current district and I considered the continuation of my doctorate program, the idea of a handbook to help districts pass a bond election was obvious. My district was gearing for a campaign beginning in 2015 for a May or November election. That is why I intended to complete the handbook and dissertation by March 2014. The handbook has a legitimate purpose.

The work plan (see Table 5) followed the R\&D Cycle of Steps 1-10. My proposal was approved in August 2013. Afterward, I prepared the Preliminary and Main field tests and product revisions. These steps ensured the product would ready for public use. 
Table 5

\section{$R \& D$ Timeline and Activities}

\begin{tabular}{|c|c|c|}
\hline \multicolumn{3}{|c|}{ WORK PLAN } \\
\hline Timeline & $\begin{array}{l}\text { Step in Product } \\
\text { Development }\end{array}$ & Activity \\
\hline $\begin{array}{l}\text { October-December } \\
2012\end{array}$ & $\begin{array}{l}\text { Step } 1 \text { in the R\&D Cycle } \\
\text { Research and information } \\
\text { collecting }\end{array}$ & $\begin{array}{l}\text { - Research existing literature } \\
\text { - Develop \& review research/ literature on } \\
\text { specific community engagement strategies } \\
\text { - Organize \& outline essential strategies for the } \\
\text { handbook } \\
\text { - Draft the statement of problem (chapter 1) } \\
\text { - Compose chapter on communication (chapter } \\
\text { 2) }\end{array}$ \\
\hline $\begin{array}{c}\text { January-May } \\
2013\end{array}$ & $\begin{array}{l}\text { Step } 2 \text { in the R\&D Cycle } \\
\text { Planning objectives, } \\
\text { learning activities, and } \\
\text { small-scale testing }\end{array}$ & $\begin{array}{l}\text { - Broaden understanding of problem } \\
\text { - Identify audience intended for the handbook } \\
\text { - Compose draft of the handbook including } \\
\text { multiple proven strategies \& activities } \\
\text { - Schedule interviews with various local district } \\
\text { leaders who recently passed a bond levy } \\
\text { - Develop open-ended \& closed interview } \\
\text { questions } \\
\text { - Record \& transcribe interviews }\end{array}$ \\
\hline $\begin{array}{c}\text { May-September } \\
2013\end{array}$ & $\begin{array}{c}\text { Step } 3 \text { in the R\&D Cycle } \\
\text { Develop preliminary form } \\
\text { of the product }\end{array}$ & $\begin{array}{l}\text { - Complete preliminary form of the handbook } \\
\text { and revise from formative Small-scale testing } \\
\text { - Organize and schedule small group } \\
\text { Preliminary field testing (Step 4) } \\
\text { - Set September date of Main field testing }\end{array}$ \\
\hline $\begin{array}{l}\text { August-September } \\
2013\end{array}$ & $\begin{array}{l}\text { Step } 4 \text { in the R\&D Cycle } \\
\text { Preliminary field testing }\end{array}$ & $\begin{array}{l}\text { Invite five district leaders to participate in the } \\
\text { Preliminary testing of the handbook, } \\
\text { September } 12,2013 \\
\text { Prepare survey questions for handbook and } \\
\text { workshop }\end{array}$ \\
\hline $\begin{array}{c}\text { September } \\
2013\end{array}$ & $\begin{array}{l}\text { Step } 5 \text { in the R\&D Cycle } \\
\text { Main Product Revision }\end{array}$ & $\begin{array}{l}\text { - Invite superintendents and others to Main field } \\
\text { test workshop, September } 28,2013 \\
\text { - Revise handbook based on outcomes of the } \\
\text { survey } \\
\text { - Prepare/revise workshop agenda, syllabus } \\
\text { - Revise survey questions (SurveyMonkey). }\end{array}$ \\
\hline $\begin{array}{c}\text { September-October } \\
2013\end{array}$ & $\begin{array}{c}\text { Step } 6 \text { in the R\&D Cycle } \\
\text { Main field testing }\end{array}$ & $\begin{array}{l}\text { - Facilitate a workshop sponsored by COSA to } \\
15 \text { to } 20 \text { district leaders seeking a bond } \\
\text { - Conduct pretest and posttest surveys of } \\
\text { communication theory and campaign strategies } \\
\text { - Conduct survey after the workshop to } \\
\text { determine the effectiveness of the workshop } \\
\text { and the degree of the handbook's efficacy } \\
\text { (SurveyMonkey) }\end{array}$ \\
\hline
\end{tabular}


Table 5 (continued)

\begin{tabular}{|c|c|c|}
\hline \multicolumn{3}{|c|}{ WORK PLAN } \\
\hline Timeline & $\begin{array}{l}\text { Step in Product } \\
\text { Development }\end{array}$ & Activity \\
\hline $\begin{array}{l}\text { October-December } \\
\qquad 2013\end{array}$ & $\begin{array}{c}\text { Step } 7 \text { in the R\&D Cycle } \\
\text { Operational product } \\
\text { revision }\end{array}$ & $\begin{array}{l}\text { Evaluate results of formative and summative } \\
\text { feedback for the handbook and workshop's } \\
\text { usefulness, effectiveness, and importance } \\
\text { - Determine if further revisions to the handbook } \\
\text { are necessary } \\
\text { - Revise handbook and workshop }\end{array}$ \\
\hline $\begin{array}{c}\text { June-November } \\
2014\end{array}$ & $\begin{array}{c}\text { Steps } 8,9, \& 10 \\
\text { Operational field testing } \\
\text { Final product revision } \\
\text { Dissemination and } \\
\text { implementation }\end{array}$ & $\begin{array}{l}\text { Steps } 8,9 \text {, and } 10 \text { require the researcher to } \\
\text { determine whether the product can stand on its } \\
\text { own merits and whether it is of publishable } \\
\text { quality. In Steps } 8 \text { and 9, Operational field test } \\
\text { and Final product revision, the product is used in } \\
\text { a variety of natural settings and data is then } \\
\text { collected from others who are using the product } \\
\text { as well as from their participants. } \\
\text { Step 10, Dissemination and implementation, } \\
\text { makes others aware of the product through } \\
\text { publications, presentations, or articles published } \\
\text { about the product. } \\
\text { Bridges and Hallinger (1995) recommend Steps } 1 \\
\text { through } 7 \text { for students designing dissertation } \\
\text { projects. For the purposes of this study, Step } 7 \\
\text { will be the last step. } \\
\text { Steps } 8-10 \text { are thus left to their own discretion. } \\
\text { Therefore, consideration for these last steps will } \\
\text { be discussed in chapter } 5 \text {. }\end{array}$ \\
\hline
\end{tabular}

Step 1, Research and information collecting, generates as much information about

the problem as available. In this step, I researched the existing literature and developed a

review of the research and literature on the topic. This helped me to discern a broad and

deeper understanding of the problem and begin an outline of the essential strategies

needed in the handbook. 
Step 2, Planning objectives, learning activities, and small-scale testing, broadened my understanding of problem, identified my audience, and initiated a rough draft of the handbook. I interviewed four practitioners: two superintendents, one communication director, and one business/operations director.

Step 3, Develop preliminary form of the product is the culmination of the planning in Steps 1 and 2. I produced the preliminary form of the handbook. However, for my study, I revised the handbook and added a communication section as determined through the formative feedback of Step 2.

Steps 4 and 5 are Preliminary field testing and Main product revision. These steps involve obtaining "an initial qualitative evaluation of the new educational product" (Borg $\&$ Gall, 1989, p. 790), similar to a rehearsal for the Main field test. I presented the handbook to a small group of practitioners in a workshop. The workshop included three superintendents, one communication director, and one principal all of whom were contemplating a bond campaign in the next one to two years. The formative-evaluation feedback from the Step 4, Preliminary field test, revised and improved several of the handbook's components. From the formative evaluation results of Step 4, I added another section to the handbook on teaching and learning in Step 5 and increased the length of time for the workshop.

Steps 6 and 7 are Main field testing and Operational product revision. These steps require implementation of the handbook and collection of key data relating to the handbook's efficacy. Main field testing took the form of a workshop for 16 district 
leaders planning a bond election, in which the handbook was used as the main tool. The

primary feedback from participants was a summative assessment of the usefulness, effectiveness, and importance of the handbook and workshop and formative assessment data to revise and improve the product.

Steps 8,9 , and 10 require the researcher to determine whether the product can stand on its own merits and whether it is of publishable quality. In Steps 8 and 9, Operational field test and Final product revision, the product is used in a variety of natural settings, and the data are then collected from others who are using the product as well as from their participants. Step 10, Dissemination and implementation, makes others aware of the product through publications, presentations, or articles published about the product. Bridges and Hallinger (1995) recommended Steps 1 through 7 for students designing dissertation projects. Step 10 is left to the students' own discretion. While these last steps are not part of my research study, these steps are addressed in chapter 5.

\section{Chapter Summary}

The purpose of this study is to determine how useful, effective, and important the handbook, Holding Successful School Bond Campaigns: Not for Dummies, is for district leaders embarking on a school bond election. The study determined how effective the accompanying workshop was for district leaders embarking on a school bond election.

Attaining voter support requires a thorough understanding of school and community issues. Passage of a bond in one school district does not guarantee that a bond will pass in another even if all tools are replicated. Demographics, the district's internal 
and external constituents, and the leadership team, for example, are unique to each school district and can affect the success of an election. However, successful campaigns are grounded in certain key processes and strategies; hence, the necessity for the handbook to guide superintendents and other district leaders through the complicated process of a construction bond campaign. As one parent described: "Our children are learning under Third World conditions...toilets not replaced since the 1950s, asbestos, poor temperature control, peeling paint, old furnaces, dirty windows and brown water...cracked floors, 30 adults using two telephones, poor ventilation, outdated electronics... right now our schools are crumbling" (McKim-Bell, 2012, p. 9A). The importance of sharing effective strategies cannot be underestimated. It means millions of dollars in resources to districts' outdated and often unsafe schools.

Chapter 3 focused on the research methodology of this study. The first two sections discussed the research design and research questions that were used to evaluate the effectiveness, usefulness, and importance of the handbook, Holding Successful School Bond Campaigns: Not for Dummies, in school districts. The research design adhered to Bridges and Hallinger's (1995) PBL Model and Borg and Gall's (1989) R\&D Cycle. The third section described the data collection procedures such as interviews, surveys, observations, and comments. The data analysis section clarified how I safeguarded the study against bias and defended the validity of the study through proven research practices such as triangulation. The last section examined the work plan and timeline that managed the field-testing of the handbook. 


\title{
CHAPTER IV
}

\begin{abstract}
ANALYSIS
This research study is based on the handbook Holding Successful Bond Campaigns: Not for Dummies. I developed the handbook because school district leaders have a need for a means to lead them through the process of passing a school bond. For example, in the November 2013 Oregon election only three school districts passed their construction bond elections out of the 12 that attempted a bond. More than $\$ 74$ million was approved by voters, well short of the $\$ 565$ million total requested by districts attempting a bond election (OSBA, 2013a). District leaders need to know what strategies work and which do not.

Since 1996 I began informally compiling a list of campaign strategies that seemed to generate an impact on bond elections, both positive and negative. Through the years, I attended annual workshops sponsored by the OSBA on Bonds and Ballots and conferred often with colleagues in successful districts. As a principal of a high school, I worked in districts that had successful results and districts that had disastrous results; but I did not fully understand what strategies led to a successful election. As superintendent of my first district, I experienced a failing bond attempt and learned a great deal from those efforts. In my second district, I experienced a successful bond. I thought that I was onto something. Presently, I serve in a large school district that will need to pass a construction bond in the near future. What better way to prepare for my district's election
\end{abstract}


than to compile a handbook with the strategies necessary to be successful! Furthermore, the handbook will benefit my colleagues in other districts who also need to pass bonds.

Holding Successful Bond Campaigns: Not for Dummies was developed for district leaders to conduct successful bond elections. The study is theoretically grounded in PBL as defined by Bridges and Hallinger (1995) and Borg and Gall's (1989) R\&D. The R\&D process for doctoral students of education ends after Step 7, but further speculation of Steps, 8, 9, and 10 will be reviewed in chapter 5 .

The purpose of this study is to determine how useful, effective, and important the handbook and the workshop are for district leaders to build their capacity and confidence to pass a school bond election. My analysis follows Steps 1-7 of the R\&D process. The process includes a series of steps that initiate involvement from key participants in order to improve the product, both the handbook and the workshop. The following is a brief overview of the study's R\&D process that includes Steps 1 through Step 7.

Step 1: In Step1, I researched and collected information and drafted the handbook.

Step 2: In Step 2, the handbook first was tested using Small-scale testing.

Participants were asked to review the handbook. Small-scale testing consisted of interviewing four district leaders who recently passed a bond election.

Step 3: After I interviewed participants, I used their feedback to further develop the handbook, which is Step 3, Develop preliminary form of the product.

Step 4: In Step 4, I conducted a preliminary field test. In the Preliminary field test, I invited district leaders to participate in a half-day mini workshop. The handbook was used extensively. Five participants were surveyed before and after the workshop in a self- 
assessment of their learning. After the workshop, participants were also surveyed on the usefulness, effectiveness, and importance of both the handbook and workshop.

Step 5: Observation and survey data were used for product revision, which is Step 5 of the R\&D cycle. These data were used to improve the product to prepare for the final step of my research, Step 6, Main field testing.

Step 6: In Step 6, I offered a full-day workshop for district leaders that included superintendents, district-level administrators, and school board members to use the handbook. Again, as in Step 4, I surveyed participants before and after the workshop in a self-assessment of their learning and again after the workshop on the usefulness, effectiveness, and importance of both the workshop and the handbook.

Step 7: I used the formative assessment data from Step 6 Main field test for the final editing and revisions to the handbook and workshop, which is Step 7. Step 7 is discussed in chapter 5 .

Chapter 4 analyzes the first six steps in the R\&D cycle that I used to develop, field test, and revise the handbook Holding Successful Bond Campaigns: Not for Dummies and the workshop. This chapter is divided into three major sections. The first section of chapter 4 reviews the research questions and goals considered in conducting the research, and it describes the general design of the project. The second section describes my experience through Step 6 of the R\&D process, including the development and implementation or field testing of the PBL project. The third section is a summative evaluation of the results of the field testing. The formative assessment of the evaluation results is discussed in chapter 5 . 


\section{Review of the Research Questions and Goals}

This study is theoretically grounded in Bridges and Hallinger's (1995) PBL and Borg and Gall's (1989) R\&D process. The purpose of this study is to determine the usefulness, effectiveness, and importance of the handbook, Holding Successful School Bond Campaigns: Not for Dummies and the workshop. My analysis follows Steps 1 through 7 of the R\&D process. The process includes a series of steps that initiates feedback from key participants in order to improve the product or handbook.

I used Steps 1 through 7 of the R\&D Cycle to test and revise the handbook. Borg and Gall's (1989) research supports the R\&D cycle as an effective way to develop, field test, and refine a product so that the product is ready to help or support the work of practitioners. This R\&D cycle assisted me in the development and field testing of the handbook so that the handbook is ready for superintendents and other district leaders who are planning a bond election in the next one to two years. This study provides school leaders with a tested product that is ready for operational use in their districts.

\section{Research Questions}

The development of the handbook in Steps 1 through 7 was guided by the following primary research questions:

1. How useful is the handbook to district leaders embarking on a school bond election?

2. How effective is the handbook to district leaders embarking on a school bond election?

3. How important is the handbook to district leaders embarking on a school bond election? 
Useful is defined as practical information for district leaders initiating a bond. Is the content fully developed with necessary details and examples? Effective is defined as the ability to apply the information. Can the handbook's information be applied to the participant's school district? Important is defined as meeting school districts' current needs. Is this strategy important to the needs of the participant's district?

Step 1: Research and information collecting. Step 1 is research and information collecting, which is what I have accomplished since 1996 but more deeply continued when I began researching, outlining, and developing strategies for the handbook in the fall of 2012 .

Step 2: Planning objectives, learning activities, and small-scale testing. Step 2, according to Bridges and Hallinger (1995), conducts small-scale research such as interviews with practitioners who are knowledgeable about the problem. These interviews provide the researcher with a deeper understanding of the problem and how it will be addressed by the product. "This is the stage during which the student develops a formal research proposal. The researcher must formulate not only a plan for development of the product, but also for its assessment" (p. 121). In this step of the R\&D cycle, I interviewed four practitioners, one-on-one, who recently passed bond elections: two superintendents, a communications director, and a business/operations director from rural and urban districts.

My questions were initially rudimentary, so the quality of the feedback, from two interviews, was not as helpful as I anticipated. Therefore, I revised the questions to prompt more substantive feedback. The initial questions simply asked the first participant 
to identify the strengths and weaknesses of the handbook and to identify missing information such as the strategies the district used that were not listed. These questions may have been too open-ended. While this first participant provided some essential information that I used to improve the handbook, the depth of the interview was fairly shallow.

My second interview was improved, but I soon found that the questions still did not produce the information that I sought. The main issue was the participant himself had not reviewed the handbook before the interview. The participant's lack of preparation caused the interview to take a different route. However, the participant provided information that I used to make revisions to the handbook.

Finally, the third and fourth interview participants adhered to the initial interview questions, and the participants had familiarized themselves with the handbook before the scheduled interview. As a result these interviews took on a more formal and thus valuable interview process (see Table 6). The outcome proved to be substantially productive. While I was planning ahead for the workshop that would accompany the handbook, I did not remove question Number 2 from the interview: 2 . How useful and effective is the workshop to district leaders embarking on a school bond election? In hindsight, that question should have been omitted because it did not apply to the interview and caused some confusion. It became a discussion distraction for two participants because they wanted to know more information about the impending workshop. 
Table 6

Interview Questions Used in Steps 2 and 3 of the R\&D Cycle

$$
\text { Interview Questions }
$$

Primary Research Questions

1. How useful and effective is the handbook to district leaders embarking on a school bond election?

2. How useful and effective is the workshop to district leaders embarking on a school bond election?

Secondary Research Questions

1. What effective strategies do districts employ to gain public support in school district construction bond elections?

2. What strategies are missing in the handbook?

3. What strategies should be deleted for the handbook?

4. What are the current processes districts use to conduct a campaign?

5. Which strategies in the handbook are new to school districts? Which are commonly used?

6. How will the strategies in the handbook help districts plan a more focused and organized campaign?

7. Which pre-campaign strategies are most important to districts? (During the campaign; post campaign strategies?)

8. What strategies are considered innovative?

9. What strategies are considered common knowledge?

10. What campaign strategies are most effective for the particular needs each school district?

11. What communication strategies are most important to districts seeking a bond?

12. How does the handbook compare to other materials or information used by school districts to prepare for a bond election?

13. What improvements would district leaders make to the handbook?

\section{Step 3: Develop preliminary form of the product. Results of the interviews}

helped to improve the initial draft of the handbook. While the R\&D cycle does not require a first draft of the product in Step 2, I did initiate a draft that was used in the interviews. A preliminary form of the product is more commonly produced in Step 3.

Step 3, which develops a prototype of the product, was then used as a step to revise the handbook from the interview feedback.

Step 4: Preliminary field testing. During Step 4, I revised the primary research questions. The original research questions read 
1. How useful and effective is the handbook to district leaders embarking on a school bond election?

2. How useful and effective is the workshop to district leaders embarking on a school bond election?

I could not test useful and effective together; I needed to separate them. I also added a third question about importance and defined each one, useful, effective, and important, as noted in Table 7. The first three research questions covered the content of the handbook. I was neglecting format and style of the handbook and questions about the workshop. I then added two more primary research questions, one specific to the handbook's format and style and another research question specific to the workshop.

Survey questions were administered using the web-based survey tool, SurveyMonkey, for both the Preliminary and Main field tests. "The purpose of the preliminary field test is to obtain an initial qualitative evaluation of the new educational product” (Borg \& Gall, 1989, p. 790). Specific survey questions for each research question are noted in Table 7.

According to Bridges and Hallinger (1995), "Prior to any full administration of the product, the developer should schedule a 'dry run' with a group of 'students' that is representative of the target audience" (p. 121). Participants in the Preliminary field test were asked to take a pretest and posttest which was a self-assessment of their understanding of communications theory and bond campaign strategies. This assessment helped to determine whether participants learned new information as a result of the handbook and the workshop and if they perceived themselves to be better prepared to conduct a bond campaign. 


\section{Table 7}

\section{Primary and Secondary Research Questions}

\section{Primary Research Questions}

1. What is the usefulness of the handbook to district leaders embarking on a school bond election? Usefulness is defined as practical information for district leaders initiating a bond. Is the content fully developed with necessary details and examples?

2. How effective is the handbook to district leaders embarking on a school bond election? Effectiveness is defined as being able to apply the information. Can this information be applied in school districts?

3. How important is the handbook to district leaders embarking in a school bond election? Importance is defined as meeting school district's needs at this time. Is this strategy important to the needs of the district?

4. What is the perceived impression of the handbook's format and style? Format and style are defined by the way the contents are presented: structure, method, and form.

5. What are the participants' perceptions of the workshop's content, design, facilitator, results, and presentation?

\section{Secondary Questions}

Communications Theory and Practices

6. How familiar are participants with communications theory and practices? Level of Familiarity would include participants' knowledge, understanding, and application of the communication theory and strategies related to the greater organization and personal communication skills.

7. How comfortable are participants in applying the communication strategies? Level of Comfort would describe the participants' ease of understanding and ability to apply the communication strategies related to the greater organization and personal communication skills.

8. Which communication strategies do participants perceive needing the most help?

Campaign Strategies

9. How familiar are participants with school bond campaign strategies? Level of Familiarity would include participants' knowledge, understanding, and application of Pre-Bond Campaign Strategies, During-the-Bond Campaign Strategies, After-the-Bond Campaign Strategies.

10. How comfortable are participants with school bond campaign strategies? Level of Comfort would describe participants' ease of understanding and ability to apply the Pre-Bond Campaign Strategies, During-the-Bond Campaign Strategies, After-the-Bond Campaign Strategies in their district.

11. Which campaign strategies do participants perceive needing the most help?

General

12. Can the handbook stand alone on its own merits without a workshop? 
Another survey focused on the usefulness, effectiveness, and importance of the handbook and the effectiveness of the workshop. The outcomes of these surveys and participants' comments provided the feedback for the next step.

Step 5: Main product revision. As a result of the surveys, participants' comments, and my observations, Step 5 provided me with the feedback to revise the handbook and workshop. After revisions to the handbook, I also revised the survey by adding specific questions about the new section, Foundation: Teaching and Learning Connection.

Step 6: Main field testing. The Main field test focused on the revised research questions, as shown in Table 7, with the addition of the new section on teaching and learning in the handbook. However, the primary and secondary research questions remained the same as the ones in the Preliminary field test.

\section{Research Goals}

This study provides both theoretical and practical solutions for school leaders in their planning of a bond campaign. The overarching goal of the study was to produce a field-tested handbook for superintendents or other district leaders to use that provides them with an essential knowledge base to successfully manage a bond election. Secondly, the workshop provided an environment in which to learn about the strategies and begin planning for a bond election. Both of these goals were substantially accomplished.

\section{Development and Implementation: Field Testing the PBL Project}

In the PBL, the student explores a set of salient research questions in the context of implementing a self-authored PBL project (Bridges \& Hallinger, 1995). Holding 
Successful Bond Campaigns: Not for Dummies is the PBL project or handbook that I developed because of the ongoing problems superintendents and school district leaders have faced for decades: not passing bond elections. The handbook satisfies an important educational need.

Bridges and Hallinger's (1995) PBL relies on Borg and Gall's (1989) 10 Steps in the R\&D Cycle. Step 1 is Research and information collecting; Step 2 is Planning objectives, learning activities and small-scale testing; Step 3 is Develop preliminary form of the product; Step 4 is Preliminary field testing; Step 5 is Main product revision; Step 6 is Main Field testing; and Step 7 is Operational product revision (pp. 784-785). Bridges and Hallinger recommended Steps 1 through 7 for students designing dissertation projects for PBL. Steps 8, 9, and10 are left to the student's own discretion. A discussion of these last three steps is presented in chapter 5 .

Most steps in the R\&D process are either testing or revisions to the product. Step 1 is collecting information and researching the problem. Step 2 is planning objectives and small-scale testing. Step 2 can also develop a draft form of the product, which is the step I took with the small-scale testing; Step 3 develops a preliminary form of the product or makes revisions to the product after small-scale testing. Step 4 is preliminary field testing. Step 5 is revising the product after the Step 4 testing. Step 6 is main field testing, and Step 7 is operational product revision after the Main field testing. This section describes the field testing used in Steps 2, 4, and 6 for the development and implementation of the PBL project, the handbook Holding Successful School Bond Campaigns: Not for Dummies. 


\section{Step 2: Small-Scale Testing}

While I conducted research and information collecting in Step 1, I also developed a draft of the handbook with a majority of the campaign strategies already described. Personally experiencing a number of bond elections (some failures, some successes), campaigns, and workshops on bond elections provided me with a rich background on which to base the handbook, Holding Successful Bond Campaigns: Not for Dummies. Therefore, in Step 2, I performed small-scale testing of the draft product by conducting interviews. The purpose of the interviews was to gain additional insights into the successful districts' election campaigns and processes. I wanted to ensure that the strategies I drafted corresponded with strategies used in districts that passed their bond elections.

Interview questions were mostly broad, open-ended questions with some closedended questions for clarification. I used the one-on-one approach to interviewing because I limited the interviews to four participants in small-scale testing. One-on-one is considered the most time-consuming and costly approach to conduct individual interviews (Creswell, 2002). In a one-on-one approach, only one participant is interviewed at a time.

I interviewed four school leaders who recently passed bond elections in their districts, as depicted in Table 8. Two participants were superintendents; one was a communication director; and one was a director of business and operations. One district is a medium-sized, rural district of approximately 3,700 students; one is a suburban district of 5,500 students; another is an urban district of 11,000 students; and another is a 
suburban district of 13,000 . Three are considered high poverty districts, and minority groups comprise the majority of the students. All four, however, had passed bond elections in recent years.

Table 8

Small-Scale Testing: Interview Participant Demographic Information

\begin{tabular}{|l|l|l|l|l|}
\hline Participant & 1. Thomas & 2. Robert & 3. Kathy & 4 Joyce \\
\hline Date of Interview & $2-19-13$ & $3-15-13$ & $5-29-13$ & $6-4-13$ \\
\hline Position & Superintendent & $\begin{array}{l}\text { Communications } \\
\text { Director }\end{array}$ & Superintendent & $\begin{array}{l}\text { CFO/ } \\
\text { Operations } \\
\text { Director }\end{array}$ \\
\hline District Description & Suburban & Urban & Suburban & Rural \\
\hline Demographics & & & & 3,700 \\
\hline Enrollment & 13,000 & 11,000 & 5,500 & $68 \%$ \\
\hline Poverty & $44 \%$ & $80 \%$ & $75 \%$ & $60 \%$ \\
\hline Students of Color & $\begin{array}{l}37 \% \text { Minority } \\
23 \% \text { Hispanic }\end{array}$ & $\begin{array}{l}\text { Minority/ } \\
\text { Majority District }\end{array}$ & $60 \%$ & $\begin{array}{l}\text { Mostly } \\
\text { Spanish/English }\end{array}$ \\
\hline \# of Languages & $\begin{array}{l}13 \% \text { English } \\
\text { Language } \\
\text { Learners }\end{array}$ & No Response & 50 & \\
\hline
\end{tabular}

Note. Pseudonyms were used to protect participants' identities.

Interviews were conducted during a four-month period in the spring of 2013 in each participant's office. Interviews were digitally taped, but I also took notes during each interview. Each participant signed a consent form agreeing to the interview (Appendix A). While this study is not about human subjects, anonymity and confidentiality of participants are still central to ethical research practice. I assured participants that every effort would be made to safeguard the data that they shared about the handbook and workshop so that the information would not be traced back to them. "The primary method researchers use to preserve anonymity and confidentiality is to use pseudonyms for participants and the location of the research" (Crow \& Wiles, 2008). 
Therefore, I used pseudonyms for participants in this study and for the school districts in which they work. My research focused on participants' perceptions of the handbook and its improvement, and not on the participants themselves.

The first interview that I conducted with Thomas was less formal and of a short duration because of time constraints of the superintendent. The second interview was scheduled with the superintendent; but when I arrived for the interview, the superintendent scheduled Robert, the communications director, to meet with me in his place. The third interview took place with Kathy, the superintendent, during a scheduled 90-minute interview. The fourth interview was with a chief financial officer/operations director, Joyce. The superintendent who passed the bond in that district had moved to a new position in another school district. However, this was the longest interview and lasted two hours.

I developed an interview protocol modeled after Asmussen and Creswell's (1995) protocol, which I used to structure the interviews (see Appendix B). I provided the demographic information, the interview questions, and a reminder to thank participants for their time.

Interviews were captured on a digital recorder and burned to a $\mathrm{CD}$. From the $\mathrm{CD}$, I transcribed the interviews, verbatim, in a Word document. Then, in a classic model of coding, I followed the basic coding steps:

Step 1: Read the transcripts

Step 2: Label relevant pieces

Step 3: Decide which codes are the most important, and create categories by bringing several codes together

Step 4: Label categories and decide which are the most relevant. How are they connected to each other? 
Step 5: Additional options

- Decide if there is a hierarchy among the categories.

- Decide if one category is more important than the other. (Lofgren, 2013)

After reading and rereading the transcripts several times, I labeled the relevant pieces. This covered the first two steps of the coding steps. I then decided which codes seemed to be most important, mainly by the number of comments or pieces of information, which were then coded. At this point in Step 5, I could easily ascertain the emerging themes and labeled them (see Table 9).

While all the major themes are important, themes that sparked the most discussion during the interviews (represented in parentheses by the number of times participants repeated the topic) focused on the need for the Handbook (88), construction bond Cost (60), Facilities Plan (46), Timeline (45), Communication (42) and campaign Strategies (40). When all communication topics such as Community Relations, Marketing, and Advertising are added to Communication, then there are 72 pieces of information centered on the theme of communication. District leaders consider communication a key component in passing a bond election.

Interview participants praised the handbook and the need for it in the education field. Although the interview was brief, Thomas did say the handbook was "very well done and informative." In comparing the handbook to a public relations consultant's materials, Kathy said, "This is more down to earth. It is more Oregonian. That is important, not because it is specific to Oregon, because it is not. But it is practical and useable." Joyce could not remember seeing any publications or handbooks that were used in the bond when her district passed the election. She said, "I don't know what is 
available, but I haven't seen any publications. This is a very complete and easy-to-follow guide." Kathy was impressed and thought the handbook would make a great addition, especially for superintendents who had not passed a bond election previously. She said:

This handbook would be very helpful. Extremely helpful. The next thing you should do is market it. Charge money for it. Charge $\$ 50$ a notebook and then market the dang thing. This is generic enough that it could go anywhere in the nation. There aren't a lot of materials out there at all. I think you get a lot of advice, free advice, but this is a step-by-step guide. I wish I had something like this when I went for my first bond.

Table 9

Major Themes That Emerged From Four Combined, Coded Interviews

\begin{tabular}{|l|c|}
\hline \multicolumn{1}{|c|}{ Themes } & $\begin{array}{c}\text { Number of Pieces of } \\
\text { Information Coded }\end{array}$ \\
\hline Advocacy/Support & 15 \\
\hline After Bond & 9 \\
\hline Contractors/Consultants & 30 \\
\hline Communication & 42 \\
\hline Community Relations & 14 \\
\hline Cost & 60 \\
\hline Election & 36 \\
\hline Experience & 10 \\
\hline Facilities Plan & 46 \\
\hline Future & 10 \\
\hline Handbook & 88 \\
\hline History & 21 \\
\hline Leadership & 15 \\
\hline Marketing/Advertising & 16 \\
\hline Organization/Order/Sequence & 20 \\
\hline PAC & 21 \\
\hline Strategies & 40 \\
\hline Survey/Polling/Feedback & 23 \\
\hline Teaching and Learning/Vision and Mission & 9 \\
\hline Timeline & 45 \\
\hline
\end{tabular}


All four interviews provided rich formative feedback of the handbook as presented in Table 10. Thomas provided constructive feedback in his observations and ideas about the initial draft of the handbook. While Thomas said that he did not have much to offer in his assessment of the handbook, the information he shared was embraced and adjustments were immediately made to the handbook. He provided the valuable critical eye to catch flaws in the handbook such as school board members' ability to campaign and other essential information about Oregon elections law.

Step 3 of R\&D cycle is to develop the preliminary form of the product. As I had already accomplished drafting the handbook earlier in the process, I revised the handbook from the feedback collected from the interviews in Step 3. After review and analysis of the interview data, I expanded the handbook by adding a major section on communication that included marketing strategies, community relations, and leadership skills in communication. A communication self-assessment was also designed for users to determine their current understanding of communication theory and practice and to assess what they learned after reviewing the section on communication.

I corrected the faulty information that Thomas identified, added information about elections and a link to Oregon elections law from Robert, and developed a section on celebrating the win and public relations plan for future bond elections from Joyce. The order of the strategies could possibly be different for each person who uses it, so I made no changes to the order. The order seems to be based more on personal preference than an actual necessity. 
Table 10

Formative Interview Feedback: Primary Handbook Improvement Areas/Advice

\begin{tabular}{|c|c|}
\hline & Primary Handbook Improvement Areas/Advice \\
\hline \multirow[t]{5}{*}{ Thomas } & $\begin{array}{l}\text { The limits on the school board members, as elected members, are few. I think they } \\
\text { can actively campaign. }\end{array}$ \\
\hline & $\begin{array}{l}\text { If the non-profit citizens group pays for the survey/polling, then it is not public } \\
\text { information for any opposition groups to ask for. }\end{array}$ \\
\hline & $\begin{array}{l}\text { Page 30: You might list here and elsewhere ORS } 195-110 \text { as the statute that guides } \\
\text { long range planning. }\end{array}$ \\
\hline & $\begin{array}{l}\text { Page 36: A note on polls. If they are funded by district funds, the data can be } \\
\text { requested by public-possibly those who would oppose the bond. If the non-profit } \\
\text { group pays for the survey, they get to control the data. }\end{array}$ \\
\hline & $\begin{array}{l}\text { Page } 49 \text { and 73: A description of a District Owners Team is mentioned on page } 73 \text {. It } \\
\text { might be helpful to define this team on page } 49 \text { where the team is also listed. }\end{array}$ \\
\hline \multirow[t]{5}{*}{ Robert } & Conduct a full facilities survey: building per building \\
\hline & Prioritize the list and chose top projects. \\
\hline & Communicate project list with the dollar amount and priorities \\
\hline & $\begin{array}{l}\text { Communicate: Brief summary of the projects: very simple and nonstop: in school } \\
\text { newsletters, district publications, and community wide. }\end{array}$ \\
\hline & $\begin{array}{l}\text { Caveat: Election Law complaints. Anyone can file a complaint. By the time it is final, } \\
\text { the filing of a complaint is what kills you. Bad PR. }\end{array}$ \\
\hline Kathy & $\begin{array}{l}\text { I don't know that you garner support before you create the communication plan. } \\
\text { Don't you create the communication plan and then garner support? I would flip } \\
\text { those. }\end{array}$ \\
\hline \multirow[t]{2}{*}{ Joyce } & $\begin{array}{l}\text { I was surprised about all the pomp and circumstance that the district wanted to } \\
\text { "market" the schools after the construction started. They wanted to celebrate the win. } \\
\text { They knew that in five years they wanted the voters to support another bond so they } \\
\text { put a lot of emphasis on getting the voters into all the celebrations of construction: } \\
\text { ground breaking, essentially marketing for the next bond. Who is in charge of the } \\
\text { celebrations? It would be good to identify early on who is in charge of celebrations } \\
\text { and other responsibilities. }\end{array}$ \\
\hline & $\begin{array}{l}\text { Facilities planning should come first. I come from operations land. Depending on } \\
\text { your messaging, if building relationships, engaging the key communicators, and } \\
\text { helping them to know the district are what you want, then they need to be part of } \\
\text { facilities planning. They need to know the deficiencies in the facilities while also } \\
\text { building relationships with the district. If this is the direction, it needs to be done } \\
\text { alongside or on the same timeline that you are doing this other work. You can set up } \\
\text { these community members on the facilities planning committee who will help the } \\
\text { district communicate and share this info to the greater community and organizations } \\
\text { that they belong to. }\end{array}$ \\
\hline
\end{tabular}




\section{Step 4: Preliminary Field Testing}

Borg and Gall (1989) explained the purpose of the preliminary field test as obtaining "an initial qualitative evaluation of the new educational product" (p. 790). It is a dry run with a group of "students" who represent the product's target audience (Bridges \& Hallinger, 1995).

I felt confident that my handbook included the information that was necessary to fully inform readers or participants about the strategies needed to ensure a successful outcome at the polls. The importance of districts having the handbook as a tool to use to pass a bond election was clearly evident from the interviews conducted in the Step 2, Small-scale testing. The Step 4. Preliminary field testing, however, brought with it additional challenges besides collecting feedback on the handbook. I would be conducting a mini-workshop using the handbook.

The workshop meant that I would be required to assess the workshop's impact on participants as well as test the actual product, the handbook itself. Multiple surveys would need to be administered to participants. Data from Step 2 confirmed that district leaders must be fully knowledgeable and skilled in communication theory and practices to pass a bond election. It would be important to assess what knowledge and skills participants currently held in communication theory and practice and in their knowledge of the campaign strategies.

In all I developed three separate surveys administered through SurveyMonkey:

1. Pretest: Section 1-Self-assessment of communications theory and Section 2Strategies and self-assessment of the handbook's 17 campaign strategies.

2. Posttest: Self-assessment of communications theory and Section 2-Strategies and self-assessment of the handbook's 16 campaign strategies. 
3. Survey of the Handbook: Section 1-Participant and District Information; Section 2-Handbook's Strategies; Section 3-Handbook's Format and Style; Section 4-Workshop

This section describes the instruments used, the workshop materials, the participants, the workshop, and the summative and formative data collected.

Self-assessment pretest and posttest. The pretest and posttest assessed identical items. The administration of the pretest was scheduled before the workshop and the posttest was scheduled after the workshop. The results measured what participants learned. Using a Likert-style rating scale of 1 to 4 with 1 as Least Familiar and 4 as Most Familiar, participants rated how familiar they were with listed examples of communications theory and practices in Section 1 and school bond campaign strategies in Section 2 (see Table 11).

Using the same communication examples and school bond campaign strategies, participants were then asked to rate how comfortable they were with the listed examples. Level of Comfort described their ease of understanding and ability to apply the listed communication strategies in Section 1 and school bond campaign strategies in Section 2. Participants then were asked to identify which school bond strategy(s) that they perceive that they need the most help in understanding and/or application of the strategy. They could check all that applied. 
Table 11

Pretest and Posttest: Communication and Campaign Strategies Self-Assessment

\begin{tabular}{|rl|}
\hline \multicolumn{1}{|c|}{ Section 1: Communication Theory Self-Assessment } \\
\hline 1. & Formal Communication-Planned, intentional, controlled \\
\hline 2. & Informal Communication-Unplanned, unintentional, brief \\
\hline 3. & One-Way Communication-Information out to receiver \\
\hline 4. & Two-Way Communication-Information exchange between sender and receiver \\
\hline 5. & Strategic Communications Planning-Systematic, formal plan of community-wide approach \\
to communication
\end{tabular}


Table 11 (continued)

\begin{tabular}{|r|}
\hline \multicolumn{1}{|c|}{$\begin{array}{l}\text { Section 2: School Bond Campaign Strategies } \\
\text { Self-Assessment }\end{array}$} \\
\hline Pre-Bond Campaign Strategies \\
\hline 1. $\quad$ Evaluate School \& Community Relations-Survey methods and feedback to assess \\
community perceptions
\end{tabular}

Survey of the handbook. The survey of the handbook, administered at the end of the mini-workshop, was comprised of four major sections:

- Section 1: Participant and District Information

- Section 2: Survey of the Usefulness, Effectiveness, and Importance of the Handbook

- Section 3: Format and Style

- Section 4: Workshop 
Section 1: Participant and district information. The first section invited

participants to provide information about themselves and their districts. Participants were asked to

1. Describe your title.

2. Identify the number of years you have been in your current position in your district counting this school year as one of the years.

3. Identify the total number of years you have been in your current position in all districts in which you worked.

4. Identify the number of students in your school district.

5. Describe your district's locale.

6. Describe your district's economic status as defined by students' free and reduced lunch percentages.

7. Describe the district's total racial/ethnic minority percentages.

Titles included Superintendent, Business Manager/CFO, Operations/Facilities

Management, Communications, and other, which participants were asked to identify by filling in the blank.

Choices for number of years in participants' current district included first year, 23 years, 4-5 years, 6-10 years, 11-15, 16 or over. These were delineated in 5-year ranges with the exception of the first two choices. First-year district leaders would have the least experience and skill in passing a bond election and 2-3 year district leaders may still be in their probationary period. The 4-5 year range would also identify more veteran leaders, especially for superintendents whose tenure statistically has the least stability. In a 2010 study by Council of Great City Schools (CGCS), the average tenure of urban superintendents is 3.64 years. Sixty-three percent of superintendents are in their positions between one and five years. Only $29 \%$ of superintendents held their positions for five or more years (CGCS, 2010). For all superintendents the mean is higher at 5-6 years (AASA, 2010). 


\section{Section 2: Survey of the usefulness, effectiveness, and importance of the}

handbook. The second section included three subsections that posed three different questions about each section of the handbook. Sections comprised 22 areas of the handbook including the 16 strategies. Question 1 asked participants to rate the usefulness of the handbook. Participants were directed to rate the usefulness of the handbook's content in the Introductory Sections, Communication Section, Pre-, During-, PostCampaign Strategies, and Supplemental Information using a 1 to 4 scale for usefulness of content information with 1 being the Least Useful and 4 being the Most Useful. Usefulness was defined as practical information for district leaders initiating a bond. Is the content fully developed with necessary details and examples?

Question 2 asked participants to rate the effectiveness of the handbook. Participants were directed to rate the Handbook's Introductory Sections, Communication Section, Pre-, During-, Post-Campaign Strategies, and Supplemental Information using a 1 to 4 scale for effectiveness of content with 1 being the Least Effective and 4 being the Most Effective. Effectiveness was defined as being able to apply the information. Can this information be applied in the participant's district?

Question 3 asked participants to rate the importance of the handbook. Participants were directed to rate the Handbook's Introductory Sections, Communication Section, Pre-, During-, Post-Campaign Strategies, and Supplemental Information on a 1 to 4 scale for importance of the district's needs with 1 being the Least Important for the district's needs and 4 being the Most Important for the district's needs. Importance was defined as 
meeting the participant's district's needs at this time. Is this strategy important to the needs of the district?

Section 3: Format and style. Format and Style is the way the contents are presented: structure, method, and form. Structure, method, and form, while interrelated, aim to answer these questions:

- Is the information well-structured, organized, and easy to find?

- Is the text readable?

- Are illustrations and layout used well?

- Is the user involved? How is the manual introduced? (Folmer, Moynihan, \& Schothorst, n.d., pp. 12-14)

Structure has to do with the order of the contents. The order of the contents must be logical, and users must be able to quickly find the section they need. Method has to do with readability and whether the text is readable. Are the contents presented in a way so that the user can easily read and understand the information? Form has to do with the presentation of the contents. The contents and pictures must be attractive and the text should be presented in a way that involves the reader.

Section 3: Format and Style of the survey rated the participant's level of agreement to the following statements about the Format and Style of the handbook. Level of agreement used a 1 to 4 scale with 1 in strong disagreement and 4 in strong agreement with the statement.

1. The title of the handbook captures my interest.

2. The title reflects the contents of the handbook.

3. The introduction compels me to read further.

4. The "Tale of Two Districts" adds humor.

5. The "Tale of Two Districts" introduces important concepts. 
6. Information is in the right order.

7. Information is easy to find.

8. The text is easy read.

9. Illustrations/visuals make sense.

10. Illustrations/visuals add interest.

11. Titles and subtitles help the reader understand the text.

12. Quotes support the content.

13. The table of contents is arranged in the right order.

14. The table of contents is easy to use.

15. The language of the handbook is simple enough for all users.

16. The language of the handbook is advanced enough to keep readers' interested.

17. The vocabulary aligns with the abilities of the reader.

18. Sentences are short and clear.

19. The writing style is similar to everyday reading in newspapers, magazines, or books.

20. Layout is designed well.

21. Layout is visually pleasing.

22. Adequate space is available for the reader to plan or take notes.

23. Reflection pages help the reader to process the material.

24. The handbook's contents are understood without a workshop.

Section 4: Workshop. Section 4 asked participants to rate their perception of the workshop content, design, facilitator, results, and presentation (see Table 12). The questions were based, in part, on workshop surveys developed for professional development activities in Reynolds School District. The Workshop survey rated the participant's level of agreement to the following statements about the workshop. Level of agreement used a 1 to 4 scale with 1 signifying Strongly Disagree and 4 signifying Strongly Agree. A list of statements in the last section of the workshop survey asked participates to check all statements that would apply about ways the workshop could be improved. 
Table 12

Section 4: Survey of the Workshop

\begin{tabular}{|c|}
\hline Workshop \\
\hline Workshop Content \\
\hline 1. I was well informed about the objectives of this workshop. \\
\hline 2. This workshop lived up to my expectations. \\
\hline 3. The content is relevant to my job. \\
\hline Workshop Design \\
\hline 4. The workshop objectives were clear to me. \\
\hline 5. The workshop activities stimulated my learning. \\
\hline 6. The activities in this workshop gave me sufficient practice and feedback. \\
\hline 7. The difficulty level of this workshop was appropriate. \\
\hline 8. The pace of this workshop was appropriate. \\
\hline Workshop Facilitator \\
\hline 1. The facilitator was well prepared. \\
\hline 2. The facilitator was helpful. \\
\hline 3. The facilitator was knowledgeable. \\
\hline Workshop Results \\
\hline 4. I accomplished the objectives of this workshop. \\
\hline 5. I will be able to use what I learned in this workshop. \\
\hline Content Presentation \\
\hline 6. The workshop was a good way for me to learn this content. \\
\hline 7. The content is best learned through the workshop. \\
\hline 8. I would like to learn more about this topic. \\
\hline 9. I would attend another workshop on this topic. \\
\hline $\begin{array}{l}\text { How would you improve this workshop? } \\
\text { Check all that apply. }\end{array}$ \\
\hline __Provide more information before the workshop. \\
\hline Clarify the workshop objectives. \\
\hline Reduce the content covered in the workshop. \\
\hline Increase the content covered in the workshop. \\
\hline Update the content covered in the workshop. \\
\hline Improve the presentation format. \\
\hline Make workshop activities more collaborative. \\
\hline Make workshop activities less collaborative. \\
\hline Improve workshop organization. \\
\hline Slow down the pace of the workshop. \\
\hline Speed up the pace of the workshop. \\
\hline Increase time for the workshop. \\
\hline Shorten the time for the workshop. \\
\hline Provide follow-up information after the workshop. \\
\hline
\end{tabular}


Preliminary field test materials. In preparation for the workshop, I created a syllabus or curriculum that included the goals, learning objectives, and activities (See Appendix C). According to the syllabus,

The goal of the workshop was to prepare district leaders for the multiple challenges of a school construction bond election. Today's school leaders are faced with a multitude of daily decisions and challenges. They do not have time to research requirements of a bond election. Yet a construction bond election is necessary for the maintenance of school buildings, upgrading and remodeling of buildings, and for new construction. The workshop and handbook will help district leaders become more knowledgeable in the bond election process and they will understand and be able to apply what is needed to pass a bond.

Participants would assess their current knowledge and skills, understand and apply new vocabulary of school bond elections, know and apply pre-, during- and post-bond activities, understand the value of surveys to learn school-community perceptions, construct a calendar of events, plan a communications strategy, and evaluate the usefulness, effectiveness, and importance of the handbook as a tool for passing a construction bond election. The handbook Holding Successful Bond Campaigns: Not for Dummies was the main source of information for participants.

As a way to organize the workshop, I developed a PowerPoint presentation (see Appendix D), "School District Bond Campaigns: Strategies That Ensure Successful Outcomes." It explained the informed consent form and confidentiality of participants' information. It included the agenda, objectives of the workshop, information about SurveyMonkey, and accessing the workshop surveys online. It included my personal journey with bond campaigns, the goals of the workshop, the problem of passing bonds, and the need for new construction and remodeling. These topics led into communication 
theory and practices, the pre-bond, during the bond, and after the bond campaign strategies.

Preliminary field test participants. The preliminary field test was scheduled as a half-day, mini-workshop held in my district office conference room. It was scheduled for 3.5 hours. I called this small group of practitioners my talented-and-gifted group because participants were expected to move through the workshop activities at a rapid pace. Participants were apprised of this condition before they consented to participate. Because it was such a small group, I anticipated that the number of questions and length of discussion would be easily controlled.

I invited five district leaders who planned to lead or participate in a bond election in the near future and who represented different geographic and demographic districts (see Table 13). The district leaders invited to participate in the workshop were comprised of four superintendents and one communication's director. However, on the day of the workshop, one superintendent canceled, but he sent a school principal as a replacement.

All three superintendents and the principal served in their jobs for two to three years. Superintendents' years of service information correlates to the CGCS (2010) and AASA (2010) statistics on superintendent tenure. The district-level communications director was the veteran among the group, serving in her current position for 6-10 years. Most participants had no experience with bond elections in their current districts; however, one had participated in a successful bond election in a previous district. 
Table 13

Preliminary Field Test Demographic Data

\begin{tabular}{|c|c|c|c|c|c|}
\hline \multicolumn{6}{|c|}{$\begin{array}{c}\text { Preliminary Field Test 9-12-13 } \\
\text { Demographic Data }\end{array}$} \\
\hline & 1. Pete & 2. Todd & 3. Sean & 4. Ray & 5. Amy \\
\hline 1. Describe your title & Supt & Supt & Supt & Principal & $\begin{array}{l}\text { Communi- } \\
\text { cation }\end{array}$ \\
\hline $\begin{array}{l}\text { 2. Identify the number of years you have } \\
\text { been in your current position in your } \\
\text { district counting this school year as one } \\
\text { of the years. }\end{array}$ & $2-3$ years & $2-3$ years & $2-3$ years & $2-3$ years & $6-10$ years \\
\hline $\begin{array}{l}\text { 3. Identify the total number of years you } \\
\text { have been in your current position in all } \\
\text { districts in which you worked. }\end{array}$ & $1-3$ years & $1-3$ years & $1-3$ years & $1-3$ years & $\begin{array}{l}11-15 \\
\text { Years }\end{array}$ \\
\hline $\begin{array}{l}\text { 4. Identify the number of students in } \\
\text { your school district. }\end{array}$ & $\begin{array}{l}500- \\
1,499 \\
\text { ADM }\end{array}$ & $\begin{array}{l}1,500- \\
3,999 \\
\text { ADM }\end{array}$ & $\begin{array}{l}4,000 \text { or } \\
\text { more } \\
\text { ADM }\end{array}$ & $\begin{array}{l}500- \\
1,499 \\
\text { ADM }\end{array}$ & $\begin{array}{l}4,000 \text { or } \\
\text { more } \\
\text { ADM }\end{array}$ \\
\hline 5. Describe your district's locale. & Rural & Suburban & Suburban & Rural & Suburban \\
\hline $\begin{array}{l}\text { 6. Describe your district's economic } \\
\text { status as defined by students' free and } \\
\text { reduced lunch percentages. }\end{array}$ & $\begin{array}{l}\text { More } \\
\text { than } \\
30 \% \text { but } \\
\text { less than } \\
50 \%\end{array}$ & $\begin{array}{l}50 \% \text { or } \\
\text { more but } \\
\text { less than } \\
70 \%\end{array}$ & $\begin{array}{l}50 \% \text { or } \\
\text { more but } \\
\text { less than } \\
70 \%\end{array}$ & $\begin{array}{l}\text { More } \\
\text { than } 30 \% \\
\text { but less } \\
\text { than } 50 \%\end{array}$ & $\begin{array}{l}\text { More than } \\
70 \%\end{array}$ \\
\hline $\begin{array}{l}\text { 7. Describe the district's total } \\
\text { racial/ethnic minority percentages }\end{array}$ & $\begin{array}{l}\text { Less } \\
\text { than } \\
10 \%\end{array}$ & $\begin{array}{l}10 \% \text { or } \\
\text { more but } \\
\text { less than } \\
30 \%\end{array}$ & $\begin{array}{l}50 \% \text { or } \\
\text { more but } \\
\text { less than } \\
70 \%\end{array}$ & $\begin{array}{l}\text { Less than } \\
10 \%\end{array}$ & $\begin{array}{l}50 \% \text { or } \\
\text { more but } \\
\text { less than } \\
70 \%\end{array}$ \\
\hline $\begin{array}{l}\text { 8. Have you ever attempted a bond in } \\
\text { your district before? If your answer is } \\
\text { Yes, please answer Number } 9 \text {. If your } \\
\text { answer is No, skip Number } 9 \text { and go to } \\
\text { Number } 10 \text {. }\end{array}$ & No & No & No & Yes & Yes \\
\hline 9. Was the bond election successful? & na & na & $\mathrm{Na}$ & No & No \\
\hline $\begin{array}{l}\text { 10. Have you attempted a bond in a } \\
\text { previous school district? If your answer } \\
\text { is Yes, please answer Number } 11 \text {. If } \\
\text { your answer is No, skip Number } 11 \text { and } \\
\text { go to Number } 12 \text {. }\end{array}$ & Yes & No & No & No & Yes \\
\hline 11. Was the bond election successful? & Yes & na & $\mathrm{Na}$ & na & No \\
\hline
\end{tabular}

Note: Pseudonyms were used to protect participants' identities.

District demographics were varied in district size, locale, economic status, and in racial composition. The district size key was based on the COSA Survey of Administrative Salary and Benefits handbook. In the COSA handbook district size is 
categorized by enrollment, based on average daily membership (ADM), in four categories: 4,000 or more ADM; 1,500-3,999 ADM; 500-1,499 ADM; 499 or less ADM. Enrollment of 4,000 or more is considered a large school district; 1,500-3,999 ADM is considered medium-sized; and 500-1,499 ADM and less is a small school district. Workshop participants represented two large school districts, one medium-sized school district, and two small school districts located in two rural and three suburban areas. Each district's economic status was defined as the percentage of students who received free and/or reduced lunch. No participants identified their districts as A, 0-10\% free and reduced lunch or B, more than $10 \%$ but less than $30 \%$. Two districts identified themselves as $\mathrm{C}, 50 \%$ or more but less than $70 \%$; two as $\mathrm{D}, 50 \%$ or more but less than 70\%; and one as E, more than $70 \%$ free and reduced lunch.

Two participants described their districts' total racial/ethnic minority percentages as less than $10 \%$; one as $10 \%$ or more but less than $30 \%$; and two as $50 \%$ or more but less than $70 \%$. These five participants represented a varied cross section of Oregon school districts.

Preliminary field test workshop. Participants were required to bring a laptop or iPad to access the surveys on SurveyMonkey. I allowed 30 minutes for participants to take the three separate surveys: the pretest and posttest of the self-assessment of communication theory/practices and campaign strategies and the survey of the handbook and workshop. When participants arrived, they were instructed to log into the district's wireless access and to access the survey. I provided them with an agenda and a copy of the syllabus for the workshop. After participants took the pretest self-assessment of 
communication theory/practices and campaign strategies, they received a copy of the handbook and were asked to scan through the introductory sections of the handbook and read the "Tale of Two Districts."

After all participants had taken the pretest self-assessment, participants were asked to follow along in the communication section of the handbook while I presented the main points of communication theory and practice as outlined in the PowerPoint presentation. This would be a massive quantity of information to digest, but my assumption was that most administrators are knowledgeable in communication theory from their administrative licensure programs and from their experiences in their districts. The presentation would serve as review.

The major portion of the mini-workshop focused on the 17 campaign strategies. In this shortened version of the workshop, minimal time was scheduled for discussion or sharing as the participants studied the information. The focus was on the handbook, the examination of the efficacy of the strategies, and, in Step 5, improving the handbook through revising the product.

Preliminary field test: Pretest and posttest. The pretest and posttest focused on communication theory and practices. The first question assessed Level of Familiarity with listed examples. The five participants rated their familiarity with the listed examples of communication theory and practices before the workshop and before and after the workshop. Level of Familiarity includes knowledge, understanding, and application of the communication listed strategies. Questions 1 through 13 focused on communication in the context of the greater organization. Questions 14 through 25 focused on personal 
communication skills. Ratings are based on a 1-4 Likert-style scale with 1 being Not Familiar and 4 being Extremely Familiar.

After reviewing the handbook and after participating in the workshop, participants rated their level of familiarity as depicted in Table 14. The participants' ratings were averaged. Comparing the results of the pretest and posttest indicates that, after review of the handbook and participation in the workshop, growth was exhibited in nearly all areas. Administrative programs usually offer a course in communication. Communication theory then would be review. How communication related to passing a bond election would be new. Numbers 2, 15, 16, and 20 remained the same. However, the pretest average was already high and therefore not much change would be expected. Numbers 15 and 16 were about writing and speaking skills that administrators probably already possessed, considering the positions they have. Number 18. building relationships with teachers and staff dropped from 3.75 to 3.50 . Sometimes when participants learn more about a topic, they may find their understanding is less than first anticipated.

The second question assessed Level of Comfort. Participants rated their comfort with the listed examples of communication theory and practices before the workshop and before they received their copy of the handbook Holding Successful Bond Campaigns: Not for Dummies. Level of Comfort would describe participants' ease of understanding and ability to apply the listed communication strategies. 
Table 14

Preliminary Field Test: Familiarity of Communication Theory and Practices

\begin{tabular}{|c|c|c|}
\hline Level of Familiarity: Communication Self-Assessment & Pre & Post \\
\hline 1. Formal Communication-Planned, intentional, controlled & 3.25 & 3.50 \\
\hline 2. Informal Communication-Unplanned, unintentional, brief & 3.50 & 3.50 \\
\hline 3. One-Way Communication-Information out to receiver & 3.00 & 3.25 \\
\hline $\begin{array}{l}\text { 4. Two-Way Communication-Information exchange between sender and } \\
\text { receiver }\end{array}$ & 3.00 & 3.25 \\
\hline $\begin{array}{l}\text { 5. Strategic Communications Planning-Systematic, formal plan of } \\
\text { community-wide approach to communication }\end{array}$ & 2.50 & 3.50 \\
\hline 6. Communication with Internal Publics-Employees, volunteers, students & 3.00 & 3.25 \\
\hline $\begin{array}{l}\text { 7. Communication with External Publics-Parents, business partners, } \\
\text { contractors }\end{array}$ & 3.25 & 3.50 \\
\hline $\begin{array}{l}\text { 8. School Community Relations-Understanding and responding to } \\
\text { community perceptions of the school district }\end{array}$ & 3.00 & 3.50 \\
\hline $\begin{array}{l}\text { 9. Communications Strategies-Face to face, telephone, electronic, written, } \\
\text { numeric }\end{array}$ & 2.75 & 3.25 \\
\hline 10. Media Relations-Building positive relationships with reporters & 2.25 & 3.25 \\
\hline 11. Marketing Strategies-Managing the district's image & 2.25 & 3.00 \\
\hline $\begin{array}{l}\text { 12. Marketing Techniques, Tools, and Publications-Direct mail, free media, } \\
\text { material drops, print/broadcast media, meet and greet }\end{array}$ & 2.25 & 3.00 \\
\hline 13. Social Media-Facebook, Twitter, blogs, message boards & 2.50 & 3.00 \\
\hline \multicolumn{3}{|l|}{ Communication as a Leadership Skill by } \\
\hline 14. being a good listener & 3.25 & 3.50 \\
\hline 15. being a good writer & 3.75 & 3.75 \\
\hline 16. being a prepared speaker & 3.75 & 3.75 \\
\hline 17. building relationships with board members & 3.00 & 3.25 \\
\hline 18. building relationships with teachers and staff & 3.75 & 3.50 \\
\hline 19. building relationships with taxpayers & 2.75 & 3.25 \\
\hline 20. keeping internal and external groups informed & 3.50 & 3.50 \\
\hline 21. establishing, maintaining, and nurturing open communication channels & 3.25 & 3.75 \\
\hline $\begin{array}{l}\text { 22. developing and championing policies created to enhance school and } \\
\text { community relations }\end{array}$ & 2.50 & 3.25 \\
\hline $\begin{array}{l}\text { 23. always keeping the school board, staff, and general public informed of } \\
\text { school matters }\end{array}$ & 3.25 & 3.75 \\
\hline $\begin{array}{l}\text { 24. ensuring the school and community relationship is assessed and evaluated } \\
\text { regularly }\end{array}$ & 2.25 & 3.25 \\
\hline $\begin{array}{l}\text { 25. making sure that influential groups and community leaders are provided } \\
\text { with factual information }\end{array}$ & 3.25 & 3.75 \\
\hline
\end{tabular}


After reviewing the handbook and after participating in the workshop, participants rated their level of comfort as depicted in Table 15. Growth was exhibited in nearly every area. Numbers $6,8,15$, and 16 show no change. Number 2: Informal Communication dropped from 3.75 to 3.50 . Informal communication is often underestimated, and that may be why Number 2 decreased. Informal communication opens more opportunities for staff and community input. Kowalski et al. (2007) called these social interactions. Administrators who see social interaction as being important and understand how to work in informal communication settings are likely to shape formal networks. Participants learned that informal communication was more complex than they first thought. However, the pretest average was already at a high level, and not much change would be expected.

The third question asked: In what areas do you perceive that you need the most help? Participants were instructed to place a check mark next to the listed communication strategies that they perceived to need the most help in understanding and/or application of the strategy. 
Table 15

Preliminary Field Test: Comfort of Communication Theory and Practices

\begin{tabular}{|c|c|c|}
\hline Level of Comfort: Communication Self-Assessment & Pre & Post \\
\hline 1. Formal Communication-Planned, intentional, controlled & 3.75 & 4.00 \\
\hline 2. Informal Communication-Unplanned, unintentional, brief & 3.50 & 3.75 \\
\hline 3. One-Way Communication-Information out to receiver & 3.75 & 3.50 \\
\hline $\begin{array}{l}\text { 4. Two-Way Communication-Information exchange between sender and } \\
\text { receiver }\end{array}$ & 3.25 & 3.50 \\
\hline $\begin{array}{l}\text { 5. Strategic Communications Planning-Systematic, formal plan of } \\
\text { community-wide approach to communication }\end{array}$ & 3.25 & 3.50 \\
\hline 6. Communication with Internal Publics-Employees, volunteers, students & 3.75 & 3.75 \\
\hline $\begin{array}{l}\text { 7. Communication with External Publics-Parents, business partners, } \\
\text { contractors }\end{array}$ & 3.00 & 3.50 \\
\hline $\begin{array}{l}\text { 8. School Community Relations-Understanding and responding to } \\
\text { community perceptions of the school district }\end{array}$ & 3.00 & 3.00 \\
\hline $\begin{array}{l}\text { 9. Communications Strategies-Face to face, telephone, electronic, } \\
\text { written, numeric }\end{array}$ & 3.25 & 3.50 \\
\hline 10. Media Relations-Building positive relationships with reporters & 2.25 & 3.25 \\
\hline 11. Marketing Strategies-Managing the district's image & 2.25 & 2.75 \\
\hline $\begin{array}{l}\text { 12. Marketing Techniques, Tools, and Publications-Direct mail, free } \\
\text { media, material drops, print/broadcast media, meet and greet }\end{array}$ & 2.50 & 2.75 \\
\hline 13. Social Media-Facebook, Twitter, blogs, message boards & 2.00 & 3.00 \\
\hline \multicolumn{3}{|l|}{ Communication as a Leadership Skill by } \\
\hline 14. being a good listener & 3.50 & 3.75 \\
\hline 15. being a good writer & 4.00 & 4.00 \\
\hline 16. being a prepared speaker & 4.00 & 4.00 \\
\hline 17. building relationships with board members & 2.75 & 3.25 \\
\hline 18. building relationships with teachers and staff & 3.50 & 3.75 \\
\hline 19. building relationships with taxpayers & 2.75 & 3.25 \\
\hline 20. keeping internal and external groups informed & 2.75 & 3.50 \\
\hline 21. establishing, maintaining, and nurturing open communication channels & 3.50 & 3.75 \\
\hline $\begin{array}{l}\text { 22. developing and championing policies created to enhance school and } \\
\text { community relations }\end{array}$ & 2.75 & 3.00 \\
\hline $\begin{array}{l}\text { 23. always keeping the school board, staff, and general public informed of } \\
\text { school matters }\end{array}$ & 2.75 & 3.25 \\
\hline $\begin{array}{l}\text { 24. ensuring the school and community relationship is assessed and } \\
\text { evaluated regularly }\end{array}$ & 2.25 & 3.25 \\
\hline $\begin{array}{l}\text { 25. making sure that influential groups and community leaders are } \\
\text { provided with factual information }\end{array}$ & 2.50 & 3.25 \\
\hline
\end{tabular}


In the pretest, two or more participants needed the most help with several

examples of communication as shown in Table 16:

5. Strategic Communications Planning

7. Communication with External Publics

10. Media Relations

11. Marketing Strategies

12. Marketing Techniques, Tools, and Publications

13. Social Media

19. building relationships with taxpayers

22. developing and championing policies created to enhance school and community relations

24. ensuring the school and community relationship is assessed and evaluated regularly

25. making sure that influential groups and community leaders are provided with factual information

The posttest saw mixed improvement, some change, or no change. Numbers 2,7 , $8,10,11,12,13,21,22$, and 23 decreased from the pretest to the posttest. However, 11. Marketing Strategies remained the same with four responding needing the most help. 13. Social Media dropped from four to three checks, which indicated that a need continued to exist in that example. 9. Communications Strategies, 17. building relationships with board members, and 19. building relationships with taxpayers increased in number from the pretest. Again, sometimes when participants learn more about a topic, they may find their knowledge of that topic is less than first anticipated.

Number 11. Marketing strategies, that manage the district's image, are complex. These strategies are difficult to understand when given unlimited time and much more difficult to understand in workshop addressing the topic in a few minutes. Changing the district's image takes more than a few minutes. With four of the five participants still perceiving that they need the most help with marketing strategies in the posttest, I see this 
as an area in which the district might contract with a public relations firm to help manage or improve the district's image. "If you don't manage your reputation, someone else will" (Porterfield \& Carnes, 2008, p. 102). That is an alarming thought and a good reason why superintendents and other district administrators should contract with professionals.

Table 16

Preliminary Field Test: Communication Topics-Participants Needing the Most Help

\begin{tabular}{|c|c|c|}
\hline \multicolumn{1}{|c|}{ Need the Most help: Communication Self-Assessment } & Pre & Post \\
\hline 1. Formal Communication-Planned, intentional, controlled & 0 & 0 \\
\hline 2. Informal Communication-Unplanned, unintentional, brief & 0 & 0 \\
\hline 3. One-Way Communication-Information out to receiver & 0 & 0 \\
\hline 4. Two-Way Communication-Information exchange between sender and receiver & 1 & 0 \\
\hline $\begin{array}{l}\text { 5. Strategic Communications Planning-Systematic, formal plan of community-wide } \\
\text { approach to communication }\end{array}$ & 2 & 2 \\
\hline 6. Communication with Internal Publics-Employees, volunteers, students & 0 & 0 \\
\hline 7. Communication with External Publics-Parents, business partners, contractors & 2 & 1 \\
\hline $\begin{array}{l}\text { 8. School Community Relations-Understanding and responding to community } \\
\text { perceptions of the school district }\end{array}$ & 1 & 0 \\
\hline 9. Communications Strategies-Face to face, telephone, electronic, written, numeric & 1 & 2 \\
\hline 10. Media Relations-Building positive relationships with reporters & 2 & 0 \\
\hline 11. Marketing Strategies-Managing the district's image & 4 & 4 \\
\hline $\begin{array}{l}\text { 12. Marketing Techniques, Tools, and Publications-Direct mail, free media, material } \\
\text { drops, print/broadcast media, meet and greet }\end{array}$ & 3 & 2 \\
\hline 13. Social Media-Facebook, Twitter, blogs, message boards & 4 & 3 \\
\hline $\begin{array}{l}\text { Communication as a Leadership Skill by } \\
\text { 14. being a good listener }\end{array}$ & 1 & 1 \\
\hline 15. being a good writer & 0 & 0 \\
\hline 16. being a prepared speaker & 0 & 0 \\
\hline 17. building relationships with board members & 1 & 2 \\
\hline 18. building relationships with teachers and staff & 2 & 3 \\
\hline 19. building relationships with taxpayers & 1 & 0 \\
\hline 20. keeping internal and external groups informed & 1 & 0 \\
\hline 21. establishing, maintaining, and nurturing open communication channels & 2 & 1 \\
\hline $\begin{array}{l}\text { 22. developing and championing policies created to enhance school and community } \\
\text { relations }\end{array}$ & 2 & 0 \\
\hline $\begin{array}{l}\text { 23. always keeping the school board, staff, and general public informed of school } \\
\text { matters }\end{array}$ & 1 \\
\hline $\begin{array}{l}\text { 24. ensuring the school and community relationship is assessed and evaluated } \\
\text { regularly } \\
\text { factual information }\end{array}$ & 0 \\
\hline 25. making sure that influential groups and community leaders are provided with & 3 \\
\hline
\end{tabular}


The pretest and posttest of school bond campaign strategies was administered at the same time as the pretest and posttest of the communication examples. To describe the results more clearly, I divided the test sections results.

The first question of school bond campaign strategies assessed Level of Familiarity. Participants rated their familiarity with the listed examples of school bond campaign strategies before the workshop and before they received their copy of the handbook Holding Successful Bond Campaigns: Not for Dummies. Level of Familiarity includesd knowledge, understanding, and application of the listed school bond campaign strategies. Ratings were based on a 1-4 Likert-style scale with 1 being Not at all Familiar and 4 being Extremely Familiar.

After reviewing the handbook and after participating in the workshop, participants rated their level of familiarity as presented in Table 17. The five participants' ratings were averaged. Comparing the results of the pretest and posttest shows that, after review of the handbook and participation in the workshop, growth is exhibited in every area.

The second question assessed Level of Comfort. Participants rated their comfort with the listed examples of school bond campaign strategies before the workshop and before they received their copy of the handbook Holding Successful Bond Campaigns: Not for Dummies. Level of Comfort would describe participants' ease of understanding and ability to apply the listed communication strategies. Ratings were based on a 1-4 Likert scale with 1 being not at all comfortable and 4 being extremely comfortable. 
Table 17

Preliminary Field Test: Familiarity of Campaign Strategies

\begin{tabular}{|c|c|c|}
\hline Level of Familiarity: Campaign Strategies Self-Assessment & & \\
\hline Pre-Bond Campaign Strategies & Pre & Post \\
\hline $\begin{array}{l}\text { 1. Evaluate School \& Community Relations-Survey methods and feedback to } \\
\text { assess community perceptions }\end{array}$ & 2.50 & 3.75 \\
\hline 2. Garner Support-Strategies to gain community support & 2.75 & 3.25 \\
\hline $\begin{array}{l}\text { 3. Create the Communications Plan-Systematic, formal plan for } \\
\text { communications with internal and external stakeholders }\end{array}$ & 2.75 & 3.25 \\
\hline $\begin{array}{l}\text { 4. Enlist Key Community Leaders-Identification and commitment of internal } \\
\text { and external stakeholders }\end{array}$ & 2.50 & 3.25 \\
\hline 5. $\quad$ Develop \& Publish the Long-Range Facilities Plan & 2.50 & 3.00 \\
\hline 6. Identify Construction Projects \& Costs & 1.50 & 2.50 \\
\hline 7. Conduct a Survey-Knowing what the public is willing to support & 2.50 & 3.25 \\
\hline $\begin{array}{l}\text { 8. Prepare for the Bond Campaign-Brainstorming and preparing for bond } \\
\text { activities }\end{array}$ & 2.50 & 2.75 \\
\hline 9. Select Consultants-e.g., architects, construction management, engineers & 2.0 & 2.25 \\
\hline 10. Develop the Bond Calendar & 2.00 & 3.00 \\
\hline 11. Create Campaign Literature \& Organize Activities & 2.00 & 2.75 \\
\hline 12. Communicate with Media & 2.00 & 3.00 \\
\hline $\begin{array}{l}\text { 13. Utilize Contemporary Marketing Strategies-Facebook, Twitter, blogs, } \\
\text { gamification, YouTube videos }\end{array}$ & 2.00 & 3.00 \\
\hline \multicolumn{3}{|l|}{ During-the-Bond Campaign Strategies } \\
\hline $\begin{array}{l}\text { 14. Count Down to Election Day-Scheduled of events during a } 60 \text { or 90-day } \\
\text { period }\end{array}$ & 2.00 & 2.75 \\
\hline 15. Celebrate the Win-Key media releases & 2.00 & 3.00 \\
\hline \multicolumn{3}{|l|}{ After-the-Bond Campaign Strategies } \\
\hline 16. Next Steps-Strategies to insure another win in 5-10 years & 1.75 & 2.50 \\
\hline
\end{tabular}

After reviewing the handbook and after participating in the workshop, participants rated their level of comfort as presented in Table 18. Growth was exhibited in all areas except 1. Evaluate School \& Community Relations, which remained unchanged. The greatest growth with an increase of one or more from the pretest to the posttest occurred in several areas:

2. Garner Support

3. Create the Communications Plan 
5. Develop \& Publish the Long-Range Facilities Plan

10. Develop the Bond Calendar

11. Create Campaign Literature \& Organize Activities

15. Celebrate the Win

16. Next Steps

While these clearly show better understanding of the strategies, the posttest scores still

stayed in a 2.25 to 2.75 range. Number 6. Identify Construction Projects \& Costs, and 9.

Select Consultants remained low at 2.25. Number 1. Evaluate School \& Community

Relations stayed unchanged at 2.25 for both the pretest and posttest.

Table 18

Preliminary Field Test: Comfort of Campaign Strategies

\begin{tabular}{|c|c|c|}
\hline $\begin{array}{l}\text { Level of Comfort: } \\
\text { School Bond Campaign Strategies Self-Assessment }\end{array}$ & & \\
\hline Pre-Bond Campaign Strategies & Pre & Post \\
\hline $\begin{array}{l}\text { 1. Evaluate School \& Community Relations-Survey methods and feedback to } \\
\text { assess community perceptions }\end{array}$ & 2.25 & 2.25 \\
\hline 2. Garner Support-Strategies to gain community support & 2.25 & 3.50 \\
\hline $\begin{array}{l}\text { 3. Create the Communications Plan-Systematic, formal plan for communications } \\
\text { with internal and external stakeholders }\end{array}$ & 2.50 & 3.50 \\
\hline $\begin{array}{l}\text { 4. Enlist Key Community Leaders-Identification and commitment of internal and } \\
\text { external stakeholders }\end{array}$ & 2.50 & 3.00 \\
\hline 5. $\quad$ Develop \& Publish the Long-Range Facilities Plan & 1.75 & 2.75 \\
\hline 6. Identify Construction Projects \& Costs & 1.50 & 2.25 \\
\hline 7. Conduct a Survey-Knowing what the public is willing to support & 2.00 & 2.75 \\
\hline $\begin{array}{l}\text { 8. Prepare for the Bond Campaign-Brainstorming and preparing for bond } \\
\text { activities }\end{array}$ & 2.00 & 2.75 \\
\hline 9. Select Consultants-e.g., architects, construction management, engineers & 1.75 & 2.25 \\
\hline 10. Develop the Bond Calendar & 1.50 & 2.75 \\
\hline 11. Create Campaign Literature \& Organize Activities & 1.75 & 2.75 \\
\hline 12. Communicate with Media & 2.25 & 3.00 \\
\hline $\begin{array}{l}\text { 13. Utilize Contemporary Marketing Strategies-Facebook, Twitter, blogs, } \\
\text { gamification, YouTube videos }\end{array}$ & 2.25 & 2.75 \\
\hline \multicolumn{3}{|l|}{ During-the-Bond Campaign Strategies } \\
\hline $\begin{array}{l}\text { 14. Count Down to Election Day-Scheduled of events during a } 60 \text { or 90-day } \\
\text { period }\end{array}$ & 2.00 & 2.75 \\
\hline 15. Celebrate the Win-Key media releases & 2.00 & 3.00 \\
\hline \multicolumn{3}{|l|}{ After-the-Bond Campaign Strategies } \\
\hline 16. Next Steps-Strategies to insure another win in 5-10 years & 1.50 & 2.50 \\
\hline
\end{tabular}


The third question asked: In what areas do you perceive that you need the most help? Participants were instructed to place a check mark next to the listed campaign strategies that they perceived to need the most help in understanding and/or application of the strategy. The two or more participants needed the most help with the following strategies as shown in Table 19:

4. Enlist Key Community Leaders

5. Develop \& Publish the Long-Range Facilities Plan

6. Identify Construction Projects \& Costs

8. Prepare for the Bond Campaign

9. Select Consultants

13. Utilize Contemporary Marketing Strategies

14. Count Down to Election Day

In the posttest two or more participates still needed the most help with 6 . Identify Construction Projects \& Costs, 10. Develop the Bond Calendar, and 11. Create Campaign Literature \& Organize Activities. No participants checked Number 10 in the pretest but two marked 10. Develop the Bond Calendar in the posttest. One participant remarked: "I am registering for the full-day workshop. This is complicated." 
Table 19

Preliminary Field Test: Campaign Strategies Participants Need the Most Help

\begin{tabular}{|c|c|c|}
\hline $\begin{array}{l}\text { Need the Most Help: School Bond Campaign Strategies } \\
\text { Self-Assessment }\end{array}$ & & \\
\hline Pre-Bond Campaign Strategies & Pre & Post \\
\hline $\begin{array}{l}\text { 1. Evaluate School \& Community Relations-Survey methods and feedback to } \\
\text { assess community perceptions }\end{array}$ & 0 & 0 \\
\hline 2. Garner Support-Strategies to gain community support & 1 & 1 \\
\hline $\begin{array}{l}\text { 3. Create the Communications Plan-Systematic, formal plan for communications } \\
\text { with internal and external stakeholders }\end{array}$ & 1 & 0 \\
\hline $\begin{array}{l}\text { 4. Enlist Key Community Leaders-Identification and commitment of internal and } \\
\text { external stakeholders }\end{array}$ & 2 & 1 \\
\hline 5. $\quad$ Develop \& Publish the Long-Range Facilities Plan & 2 & 1 \\
\hline 6. Identify Construction Projects \& Costs & 2 & 2 \\
\hline 7. Conduct a Survey-Knowing what the public is willing to support & 1 & 0 \\
\hline $\begin{array}{l}\text { 8. Prepare for the Bond Campaign-Brainstorming and preparing for bond } \\
\text { activities }\end{array}$ & 2 & 1 \\
\hline 9. Select Consultants-e.g., architects, construction management, engineers & 2 & 1 \\
\hline 10. Develop the Bond Calendar & 0 & 2 \\
\hline 11. Create Campaign Literature \& Organize Activities & 1 & 2 \\
\hline 12. Communicate with Media & 1 & 1 \\
\hline $\begin{array}{l}\text { 13. Utilize Contemporary Marketing Strategies-Facebook, Twitter, blogs, } \\
\text { gamification, YouTube videos }\end{array}$ & 2 & 1 \\
\hline \multicolumn{3}{|l|}{ During-the-Bond Campaign Strategies } \\
\hline $\begin{array}{l}\text { 14. Count Down to Election Day-Scheduled of events during a } 60 \text { or } 90 \text {-day } \\
\text { period }\end{array}$ & 3 & 1 \\
\hline 15. Celebrate the Win-Key media releases & 2 & 0 \\
\hline \multicolumn{3}{|l|}{ After-the-Bond Campaign Strategies } \\
\hline 16. Next Steps-Strategies to insure another win in 5-10 y & 0 & 0 \\
\hline
\end{tabular}

Preliminary field test: Usefulness, effectiveness, and importance. The majority

of the participants perceived the handbook to be Useful or Most Useful in practical

information with content fully developed with necessary details and examples.

Comments from participants' supported the usefulness of the handbook (see Table 20).

"The handbook is great!

"The handbook is a useful and practical tool." 
One participant marked five areas or strategies as Not Useful: 1. Introduction, 9. Identify Construction Projects \& Costs, 20. Epilogue, and 21. Artifacts. No strategies were considered Least Useful. In response, I did revise the material in the Epilogue. To improve these areas, the section on Artifacts became Appendices with added links and information.

The next section of the survey assessed effectiveness. Effectiveness was defined as being able to apply the information. Can this information be applied in your district? Participants assessed the handbook by rating the effectiveness of the handbook's content in the Introductory Sections, Communication Section, Pre-, During-, Post-Campaign Strategies, and Supplemental Information on a 1 to 4 scale for Effectiveness of Applying the handbook's information. Ratings were based on a 1-4 Likert-style scale with 1 being Least Effective and 4 being Most Effective. After reviewing the handbook and after participating in the workshop, participants rated the effectiveness of the handbook as presented in Table 21.

The majority of the participants perceived the handbook to be Effective or Most Effective in participants' ability to apply the handbook's information in their school districts. Three commented on the efficacy of the handbook:

"The handbook is a useful and practical tool."

"This is an excellent resource for superintendents to use in the planning and implementation for a bond."

"You need to publish this document as a book. Present your final document at OSBA Conference or COSA Conference." 
Table 20

Preliminary Field Test: Usefulness of the Handbook

\begin{tabular}{|c|c|c|c|c|}
\hline \multicolumn{5}{|l|}{ Usefulness: School Bond Campaign Strategies } \\
\hline Handbook's Introductory Sections & $\begin{array}{c}\text { Least } \\
\text { Useful }\end{array}$ & $\begin{array}{c}\text { Not } \\
\text { Useful }\end{array}$ & Useful & $\begin{array}{c}\text { Most } \\
\text { Useful }\end{array}$ \\
\hline 1. Introduction & & 1 & 4 & \\
\hline 2. Tale of Two Districts & & & 2 & 3 \\
\hline 3. Review Communication Theory \& Practices & & & 2 & 3 \\
\hline Pre-Bond Campaign Strategies & & & & \\
\hline $\begin{array}{l}\text { 4. Evaluate School \& Community Relations-Survey methods } \\
\text { and feedback to assess community perceptions }\end{array}$ & & & 4 & 1 \\
\hline 5. Garner Support-Strategies to gain community support & & & 5 & \\
\hline $\begin{array}{l}\text { 6. Create the Communications Plan-Systematic, formal plan } \\
\text { for communications with internal and external } \\
\text { stakeholders }\end{array}$ & & & 5 & \\
\hline $\begin{array}{l}\text { 7. Enlist Key Community Leaders-Identification and } \\
\text { commitment of internal and external stakeholders }\end{array}$ & & & 4 & 1 \\
\hline 8. Develop \& Publish the Long-Range Facilities Plan & & & 3 & 2 \\
\hline 9. Identify Construction Projects \& Costs & & 1 & 3 & 1 \\
\hline $\begin{array}{l}\text { 10. Conduct a Survey-Knowing what the public is willing to } \\
\text { support }\end{array}$ & & & 4 & 1 \\
\hline $\begin{array}{l}\text { 11. Prepare for the Bond Campaign-Brainstorming and } \\
\text { preparing for bond activities }\end{array}$ & & & 5 & \\
\hline $\begin{array}{l}\text { 12. Select Consultants-e.g., architects, construction } \\
\text { management, engineers }\end{array}$ & & 1 & 3 & 1 \\
\hline 13. Develop the Bond Calendar & & & 2 & 3 \\
\hline 14. Create Campaign Literature \& Organize Activities & & & 4 & 1 \\
\hline 15. Communicate with Media & & & 3 & 2 \\
\hline $\begin{array}{l}\text { 16. Utilize Contemporary Marketing Strategies-Facebook, } \\
\text { Twitter, blogs, gamification, YouTube videos }\end{array}$ & & & 3 & 2 \\
\hline During-the-Bond Campaign Strategies & & & & \\
\hline $\begin{array}{l}\text { 17. Count Down to Election Day-Scheduled of events during } \\
\text { a } 60 \text { or 90-day period }\end{array}$ & & & 3 & 2 \\
\hline 18. Celebrate the Win-Key media releases & & & 5 & \\
\hline After-the-Bond Campaign Strategies & & & & \\
\hline 19. Next Steps-Strategies to insure another win in 5-10 years & & & 3 & 2 \\
\hline Supplemental Information & & & & \\
\hline 20. Epilogue & & 1 & 4 & \\
\hline 21. Artifacts & & 1 & 3 & 1 \\
\hline 22. School Bond Campaign Links & & & 3 & 2 \\
\hline
\end{tabular}


Table 21

Preliminary Field Test: Effectiveness of the Handbook

\begin{tabular}{|c|c|c|c|c|}
\hline \multicolumn{5}{|l|}{ Effectiveness: School Bond Campaign Strategies } \\
\hline Handbook's Introductory Sections & $\begin{array}{c}\text { Least } \\
\text { Effective }\end{array}$ & $\begin{array}{c}\text { Not } \\
\text { Effective }\end{array}$ & Effective & $\begin{array}{c}\text { Most } \\
\text { Effective }\end{array}$ \\
\hline 1. Introduction & & 1 & 3 & 1 \\
\hline 2. Tale of Two Districts & & & 1 & 4 \\
\hline 3. Review Communication Theory \& Practices & & & 2 & 3 \\
\hline \multicolumn{5}{|l|}{ Pre-Bond Campaign Strategies } \\
\hline $\begin{array}{l}\text { 4. Evaluate School \& Community Relations-- } \\
\text { Survey methods and feedback to assess } \\
\text { community perceptions }\end{array}$ & & & 3 & 2 \\
\hline $\begin{array}{l}\text { 5. Garner Support-Strategies to gain community } \\
\text { support }\end{array}$ & & & 3 & 2 \\
\hline $\begin{array}{l}\text { 6reate the Communications Plan-Systematic, } \\
\text { formal plan for communications with internal } \\
\text { and external stakeholders }\end{array}$ & & & 2 & 3 \\
\hline $\begin{array}{l}\text { 7. Enlist Key Community Leaders-Identification } \\
\text { and commitment of internal and external } \\
\text { stakeholders }\end{array}$ & & & 2 & 3 \\
\hline $\begin{array}{l}\text { 8. Develop \& Publish the Long-Range Facilities } \\
\text { Plan }\end{array}$ & & & 3 & 2 \\
\hline 9. $\quad$ Identify Construction Projects \& Costs & & 1 & 2 & 2 \\
\hline $\begin{array}{l}\text { 10. Conduct a Survey-Knowing what the public is } \\
\text { willing to support }\end{array}$ & & & 3 & 2 \\
\hline $\begin{array}{l}\text { 11. Prepare for the Bond Campaign-Brainstorming } \\
\text { and preparing for bond activities }\end{array}$ & & & 3 & 2 \\
\hline $\begin{array}{l}\text { 12. Select Consultants-e.g., architects, construction } \\
\text { management, engineers }\end{array}$ & & 1 & 1 & 3 \\
\hline 13. Develop the Bond Calendar & & & 4 & 1 \\
\hline $\begin{array}{l}\text { 14. Create Campaign Literature \& Organize } \\
\text { Activities }\end{array}$ & & & 3 & 2 \\
\hline 15. Communicate with Media & & & 3 & 2 \\
\hline $\begin{array}{l}\text { 16. Utilize Contemporary Marketing Strategies- } \\
\text { Facebook, Twitter, blogs, gamification, } \\
\text { YouTube videos }\end{array}$ & & & 4 & 1 \\
\hline \multicolumn{5}{|l|}{ During-the-Bond Campaign Strategies } \\
\hline $\begin{array}{l}\text { 17. Count Down to Election Day-Scheduled of } \\
\text { events during a } 60 \text { or } 90 \text {-day period }\end{array}$ & & & 2 & 2 \\
\hline 18. Celebrate the Win-Key media releases & & & 4 & \\
\hline \multicolumn{5}{|l|}{ After-the-Bond Campaign Strategies } \\
\hline $\begin{array}{l}\text { 19. Next Steps-Strategies to insure another win in } \\
5-10 \text { years }\end{array}$ & & & 3 & 2 \\
\hline \multicolumn{5}{|l|}{ Supplemental Information } \\
\hline 20. Epilogue & & 1 & 4 & \\
\hline 21. Artifacts & & 1 & 2 & 2 \\
\hline 22. School Bond Campaign Links & & & 1 & 4 \\
\hline
\end{tabular}


One participant marked five areas or strategies as Not Effective: 1. Introduction, 9. Identify Construction Projects \& Costs, 12. Select Consultants 20. Epilogue, and 21. Artifacts. No strategies were considered Least Effective. Comments included recommendations to the handbook:

"How do you elicit money from donors for the campaign?"

"Include more, 'Research says."”

"Include more information on dynamics of board communication or role of superintendent in passing a bond."

"In Tale of Two Districts, use more examples of effective/ineffective two-way communication with stakeholders."

"The check lists and lists of resources were more valuable to me than the narrative."

As a result of these comments, I made some additions to the handbook in the form of graphic representations of quotes from my research to support the different sections of the handbook. I also added the section on Foundation: Teaching and Learning Connection.

The third section of the survey assessed the handbook's importance. Importance is defined as meeting your district's needs at this time. Is this strategy important to the needs of your district? Participants assessed the handbook by rating the importance of the handbook's content in the Introductory Sections, Communication Section, Pre-, During-, Post-Campaign Strategies, and Supplemental Information on a 1 to 4 scale for Importance of the participants' district needs. Ratings are based on a 1-4 Likert-style scale with 1 being Least Important and 4 being Most Important. After reviewing the 
handbook and after participating in the workshop, participants rated the importance of the

handbook to the needs of their district as shown in Table 22.

Table 22

Preliminary Field Test: Importance of the Handbook

\begin{tabular}{|c|c|c|c|c|}
\hline \multicolumn{5}{|c|}{ Importance: School Bond Campaign Strategies } \\
\hline Handbook's Introductory Sections & $\begin{array}{c}\text { Least } \\
\text { Important }\end{array}$ & $\begin{array}{c}\text { Not } \\
\text { Important }\end{array}$ & Important & $\begin{array}{c}\text { Most } \\
\text { Important }\end{array}$ \\
\hline 1. Introduction & & 2 & 2 & 1 \\
\hline 2. Tale of Two Districts & & & 2 & 3 \\
\hline $\begin{array}{l}\text { 3. Review Communication Theory \& } \\
\text { Practices }\end{array}$ & & & 2 & 3 \\
\hline Pre-Bond Campaign Strategies & & & & \\
\hline $\begin{array}{l}\text { Evaluate School \& Community } \\
\text { Relations-Survey methods and feedback } \\
\text { to assess community perceptions }\end{array}$ & & & & 5 \\
\hline $\begin{array}{l}\text { 5. Garner Support-Strategies to gain } \\
\text { community support }\end{array}$ & & & 1 & 4 \\
\hline $\begin{array}{l}\text { 6reate the Communications Plan- } \\
\text { Systematic, formal plan for } \\
\text { communications with internal and } \\
\text { external stakeholders }\end{array}$ & & & 1 & 4 \\
\hline $\begin{array}{l}\text { 7. Enlist Key Community Leaders- } \\
\text { Identification and commitment of } \\
\text { internal and external stakeholders }\end{array}$ & & & 1 & 4 \\
\hline $\begin{array}{l}\text { 8. Develop \& Publish the Long-Range } \\
\text { Facilities Plan }\end{array}$ & & & 1 & 4 \\
\hline 9. $\quad$ Identify Construction Projects \& Costs & & & 2 & 3 \\
\hline $\begin{array}{l}\text { 10. Conduct a Survey-Knowing what the } \\
\text { public is willing to support }\end{array}$ & & 1 & 2 & 2 \\
\hline $\begin{array}{l}\text { 11. Prepare for the Bond Campaign-- } \\
\text { Brainstorming and preparing for bond } \\
\text { activities }\end{array}$ & & & 3 & 2 \\
\hline $\begin{array}{l}\text { 12. Select Consultants-e.g., architects, } \\
\text { construction management, engineers }\end{array}$ & & 1 & 1 & 3 \\
\hline 13. Develop the Bond Calendar & & & 3 & 2 \\
\hline $\begin{array}{l}\text { 14. Create Campaign Literature \& Organize } \\
\text { Activities }\end{array}$ & & & 2 & 3 \\
\hline 15. Communicate with Media & & & 2 & 3 \\
\hline $\begin{array}{l}\text { 16. Utilize Contemporary Marketing } \\
\text { Strategies-Facebook, Twitter, blogs, } \\
\text { gamification, YouTube videos }\end{array}$ & & & 2 & 3 \\
\hline
\end{tabular}


Table 22 (continued)

\begin{tabular}{|c|c|c|c|c|}
\hline \multicolumn{5}{|c|}{ Importance: School Bond Campaign Strategies } \\
\hline Handbook's Introductory Sections & $\begin{array}{c}\text { Least } \\
\text { Important }\end{array}$ & $\begin{array}{c}\text { Not } \\
\text { Important }\end{array}$ & Important & $\begin{array}{c}\text { Most } \\
\text { Important }\end{array}$ \\
\hline \multicolumn{5}{|l|}{ During-the-Bond Campaign Strategies } \\
\hline $\begin{array}{l}\text { 17. Count Down to Election Day- } \\
\text { Scheduled of events during a } 60 \text { or } 90- \\
\text { day period }\end{array}$ & & & 2 & 3 \\
\hline 18. Celebrate the Win-Key media releases & & & 3 & 2 \\
\hline \multicolumn{5}{|l|}{ After-the-Bond Campaign Strategies } \\
\hline $\begin{array}{l}\text { 19. Next Steps-Strategies to insure another } \\
\text { win in } 5-10 \text { years }\end{array}$ & & & 2 & 3 \\
\hline \multicolumn{5}{|l|}{ Supplemental Information } \\
\hline 20. Epilogue & & 1 & 3 & 1 \\
\hline 21. Artifacts & & 1 & 1 & 3 \\
\hline 22. School Bond Campaign Links & & & 1 & 4 \\
\hline
\end{tabular}

The majority of the participants again perceived the handbook to be Important or Most Important to their district's needs. One participant said: "This handbook is such an important tool for district leaders."

Two participants marked the Introduction as Not Important. Four other areas were marked as Not Important: 10. Conduct a Survey; 12. Select Consultants; 20. Epilogue; and 21. Artifacts. Number 10 and 12 are actual strategies that would aid a district in passing a bond election, but they may not be important to the district at this time if the district is not planning a bond.

What is not represented in the data or in the comments is the discussion that took place during the mini workshop. Selling a bond to the public must focus on the district's vision and mission and on teaching and learning. The structure of the buildings, whether remodels or new construction, need to reflect that vision and direction of the district. As a result of that discussion, I added another section to the handbook-Foundation: Teaching 
and Learning Connection. This new section in the handbook provides research on the positive connection between new and/or upgraded school facilities and improved teaching and learning. For example, Bullock (2007) found students performed better in newer or recently renovated buildings than they did in older buildings.

Results of the survey on format and style. In this section of the survey, participants were instructed to rate their level of agreement to the survey statements about the Format and Style of the handbook as shown in Table 23. Format and style are defined as the way the contents are presented: structure, method, and form. Structure has to do with the order of the contents. The order of the contents must be logical, and users must be able to quickly find the section they need. Method has to do with readability and whether the text is readable. Are the contents presented in a way so that the user can easily read and understand the information? Form has to do with the presentation of the contents. The contents and pictures must be attractive and the text should be presented in a way that involves the reader.

Participants were asked to rate their level of agreement to a series of statements about the handbook's format and style. Ratings were based on a 1-4 Likert-style scale with 1 being Strongly Disagree and 4 being Strongly Agree. After reviewing the handbook and after participating in the workshop, participants rated their level of agreement to the statements about the format and style of the handbook. 
Table 23

Preliminary Field Test: Format and Style of the Handbook

\begin{tabular}{|c|c|c|c|c|}
\hline Format \& Style of the Handbook & $\begin{array}{l}\text { Strongly } \\
\text { Disagree }\end{array}$ & Disagree & Agree & $\begin{array}{l}\text { Strongly } \\
\text { Agree }\end{array}$ \\
\hline 1. The title of the handbook captures my interest. & & & 2 & 3 \\
\hline 2. The title reflects the contents of the handbook. & & & 1 & 4 \\
\hline 3. The introduction compels me to read further. & & & 3 & 2 \\
\hline 4. The "Tale of Two Districts" adds humor. & & & 3 & 2 \\
\hline $\begin{array}{l}\text { 5. The "Tale of Two Districts" introduces } \\
\text { important concepts. }\end{array}$ & & & & 5 \\
\hline 6. Information is in the right order. & & & 2 & 3 \\
\hline 7. Information is easy to find. & & & 1 & 4 \\
\hline 8. The text is easy read. & & & 2 & 3 \\
\hline 9. Illustrations/visuals make sense. & & & 3 & 2 \\
\hline 10. Illustrations/visuals add interest. & & & 4 & 1 \\
\hline $\begin{array}{l}\text { 11. Titles and subtitles help the reader understand } \\
\text { the text. }\end{array}$ & & & 4 & 1 \\
\hline 12. Quotes support the content. & & & 3 & 2 \\
\hline $\begin{array}{l}\text { 13. The table of contents is arranged in the right } \\
\text { order. }\end{array}$ & & & 3 & 2 \\
\hline 14. The table of contents is easy to use. & & & 3 & 2 \\
\hline $\begin{array}{l}\text { 15. The language of the handbook is simple } \\
\text { enough for all users. }\end{array}$ & & & 2 & 3 \\
\hline $\begin{array}{l}\text { 16. The language of the handbook is advanced } \\
\text { enough to keep readers' interested. }\end{array}$ & & & 2 & 3 \\
\hline $\begin{array}{l}\text { 17. The vocabulary aligns with the abilities of the } \\
\text { reader. }\end{array}$ & & & 2 & 3 \\
\hline 18. Sentences are short and clear. & & & 2 & 3 \\
\hline $\begin{array}{l}\text { 19. The writing style is similar to everyday } \\
\text { reading in newspapers, magazines, or books. }\end{array}$ & & & 2 & 3 \\
\hline 20.Layout is designed well. & & & 2 & 3 \\
\hline 21.Layout is visually pleasing. & & & 1 & 4 \\
\hline $\begin{array}{l}\text { 22. Adequate space is available for the reader to } \\
\text { plan or take notes. }\end{array}$ & & 1 & 2 & 2 \\
\hline $\begin{array}{l}\text { 23. Reflection pages help the reader to process the } \\
\text { material. }\end{array}$ & & & 2 & 3 \\
\hline $\begin{array}{l}\text { 24. The handbook's contents are understood } \\
\text { without a workshop. }\end{array}$ & & 1 & 2 & 2 \\
\hline
\end{tabular}


Nearly every participant agreed or strongly agreed to the survey statements. One participant disagreed with two statements: Number 22. Adequate space is available for the reader to plan or take notes, and 24. The handbook's contents are understood without a workshop. I added more space to each section of the handbook for participants to take notes. Of interest is that later in the Main field test, some participants thought there was too much space in the handbook for notes and reflection. An important statement for me is 24. It answers the research question, "Can the handbook stand alone as a viable source?" Only one participant disagreed out of five who took the survey. I also understand that some participants have different learning styles and may need a more hands-on approach to learn. A workshop provides a kinesthetic, collaborative format instead of reading the handbook in isolation to learn.

Results of the survey of the workshop. In this section of the survey, participants were instructed to rate their level of agreement to the survey statements about the workshop as shown in Table 24. Statements were categorized under workshop content, design, facilitator, results, and presentation. A separate section asked participants how they would improve the workshop.

Participants were asked to rate their level of agreement to a series of statements in each section. Ratings are based on a 1-4 Likert-style scale with 1 being Strongly Disagree and 4 being Strongly Agree with each statement. After participating in the workshop, participants rated their level of agreement to the survey statements about the workshop. 
Table 24

Preliminary Field Test: Evaluation of the Workshop

\begin{tabular}{|c|c|c|c|c|}
\hline Workshop & $\begin{array}{l}\text { Strongly } \\
\text { Disagree }\end{array}$ & Disagree & Agree & $\begin{array}{l}\text { Strongly } \\
\text { Agree }\end{array}$ \\
\hline \multicolumn{5}{|l|}{ Workshop Content } \\
\hline $\begin{array}{l}\text { 1. I was well informed about the objectives of } \\
\text { this workshop. }\end{array}$ & & 1 & 2 & 2 \\
\hline 2. This workshop lived up to my expectations. & & & 2 & 3 \\
\hline 3. The content is relevant to my job. & & & 2 & 3 \\
\hline \multicolumn{5}{|l|}{ Workshop Design } \\
\hline 4. The workshop objectives were clear to me. & & & 2 & 3 \\
\hline $\begin{array}{l}\text { 5. The workshop activities stimulated my } \\
\text { learning. }\end{array}$ & & & 3 & 1 \\
\hline $\begin{array}{l}\text { 6. The activities in this workshop gave me } \\
\text { sufficient practice and feedback. }\end{array}$ & & & 5 & \\
\hline $\begin{array}{l}\text { 7. The difficulty level of this workshop was } \\
\text { appropriate. }\end{array}$ & & & 2 & 3 \\
\hline 8. The pace of this workshop was appropriate. & & 2 & 3 & \\
\hline \multicolumn{5}{|l|}{ Workshop Facilitator } \\
\hline 9. The facilitator was well prepared. & & & 1 & 4 \\
\hline 10. The facilitator was helpful. & & & 1 & 4 \\
\hline 11. The facilitator was knowledgeable. & & & 1 & 4 \\
\hline \multicolumn{5}{|l|}{ Workshop Results } \\
\hline $\begin{array}{l}\text { 12. I accomplished the objectives of this } \\
\text { workshop. }\end{array}$ & & & 2 & 3 \\
\hline $\begin{array}{l}\text { 13. I will be able to use what I learned in this } \\
\text { workshop. }\end{array}$ & & & 2 & 3 \\
\hline \multicolumn{5}{|l|}{ Content Presentation } \\
\hline $\begin{array}{l}\text { 14. The workshop was a good way for me to } \\
\text { learn this content. }\end{array}$ & & & 2 & 3 \\
\hline $\begin{array}{l}\text { 15. The content is best learned through the } \\
\text { workshop. }\end{array}$ & & & 3 & 2 \\
\hline 16. I would like to learn more about this topic. & & & 2 & 3 \\
\hline $\begin{array}{l}\text { 17. I would attend another workshop on this } \\
\text { topic. }\end{array}$ & & & 2 & 3 \\
\hline
\end{tabular}

One participant disagreed with Number 1 . I was well informed about the objectives of this workshop. The rating for Number 1 could be attributed a superintendent 
who found a last-minute replacement for him, and the replacement participant had not reviewed the syllabus. The replacement also arrived 30 minutes late and did not participate in the introductory materials. However, all participants agreed or strongly agreed to 12. The workshop objectives were clear to me.

Two participants disagreed with 16 . The pace of this workshop was appropriate. This surprised me. I thought that all participants would mark this in disagreement. The workshop was run at a very fast pace. One commented on this phenomenon: "The handbook is great. I would like more time to read it before providing specific feedback. In the speed version, there was not enough time to really compare elements." Others may have enjoyed the fast pace. They received a lot of information in a short amount of time, obtained a handbook, and were done in time to go back to the office. Another participant saw the value of more time: "Workshop time with dialogue and changes to steal ideas from other smart folks will help most participants."

Participants agreed or strongly agreed with all statements under Workshop Facilitator and Workshop Results. One participant commented: "I appreciate your clear writing style. This handbook is an excellent resource." Another enjoyed the content of the handbook: "A good guide. It will be useful for novice and veterans alike."

The last section of the survey asked participants how they would improve the workshop (see Table 25). Participants could check all that applied. Four areas were checked. One participant checked, "Provide more information before the workshop." Because this workshop helped to fulfill the requirements of my dissertation and research study, I had some restrictions on the amount of information that I could share before the 
workshop. The pretest/posttest prevented me from sharing content or the results of the surveys and self-assessment would have been biased. I can see the major sections such as Tale of Two Districts, communication theory, and later in my study, the teaching and learning section, assigned before the workshop.

Table 25

Preliminary Field Test: Formative Results

\begin{tabular}{|l|l|}
\hline $\begin{array}{l}\text { How would you improve this workshop? } \\
\text { Check all that apply. }\end{array}$ & \\
\hline Provide more information before the workshop. & 1 \\
\hline Clarify the workshop objectives. & 0 \\
\hline Reduce the content covered in the workshop. & 0 \\
\hline Increase the content covered in the workshop. & 0 \\
\hline Update the content covered in the workshop. & 0 \\
\hline Improve the presentation format. & 0 \\
\hline Make workshop activities more collaborative. & 3 \\
\hline M Make workshop activities less collaborative. & 0 \\
\hline Improve workshop organization. & 0 \\
\hline Slow down the pace of the workshop. & 3 \\
\hline S Speed up the pace of the workshop. & 0 \\
\hline Increase time for the workshop. & 2 \\
\hline S Shorten the time for the workshop. & 0 \\
\hline Provide follow-up information after the workshop. & 0 \\
\hline
\end{tabular}

The other three comments have to do with the amount of time and the amount of information imparted. Three checked, "Make workshop activities more collaborative," "Slow down the pace of the workshop," and "Increase time for the workshop." I packed six hours' worth of material into three-and-a-half hours. There was not much time for discussion, sharing anecdotes, working in groups, and learning from each other. The workshop for the Step 6, Main field test included time for all those activities. 
Summary of the preliminary field testing. Overall, Step 4, Preliminary field testing, provided positive results in all areas. This project was a huge undertaking, which is reflected in number and length of the surveys to test both the handbook and the workshop. Table 26 illustrates a visual depiction of the surveys' complexities in administration, collection, and analysis of the data. The three surveys covered all sections of the handbook and workshop. For the Main field test an additional survey question was added to correspond to the new section Foundation: Teaching and Learning Connection. Instead of the 16 campaign strategies in the Preliminary field testing, there were 17 in the Main field testing.

\section{Step 6: Main Field Testing}

Bridges and Hallinger (1995) explained that the Main field test's purpose "involves implementation of the new product and the collection of data concerning its application" (p. 122). While Step 4 is considered the "dry run" or practice step, Step 6 is at the completion or implementation stage. The product or handbook is revised in the Step 5, Main product revision and is now considered a functional product in Step 6, Main field testing. How the product performs is what is assessed at this stage. Product revision at Step 7 is based on the analysis of data collected during the Main field test. "In practice the researcher assesses the product using both formative and summative evaluation methods" (p. 122). Summative methods are discussed later in the third section of this chapter, Summative Evaluation of the Results. Formative Assessment of the Evaluation Results is discussed in chapter 5. 
Table 26

Preliminary Field Test Surveys, Topics Covered, and Number of Questions

\begin{tabular}{|c|c|c|c|c|}
\hline & Survey Questions & Topic/Strategy & Topic/Strategy & $\begin{array}{c}\text { \# of } \\
\text { Questions }\end{array}$ \\
\hline \multicolumn{5}{|l|}{$\begin{array}{l}\text { Survey 1- } \\
\text { Pretest: Self- } \\
\text { Assessment }\end{array}$} \\
\hline & Level of Familiarity & $\begin{array}{l}\text { Communication } \\
\text { Theory }\end{array}$ & $\begin{array}{l}\text { Communication as a } \\
\text { Leadership Skill }\end{array}$ & 24 \\
\hline & Level of Comfort & $\begin{array}{l}\text { Communication } \\
\text { Theory }\end{array}$ & $\begin{array}{l}\text { Communication as a } \\
\text { Leadership Skill }\end{array}$ & 24 \\
\hline & Need the Most Help & $\begin{array}{l}\text { Communication } \\
\text { Theory }\end{array}$ & $\begin{array}{l}\text { Communication as a } \\
\text { Leadership Skill }\end{array}$ & 24 \\
\hline & Level of Familiarity & Campaign Strategies & & 16 \\
\hline & Level of Comfort & Campaign Strategies & & 16 \\
\hline & Need the Most Help & Campaign Strategies & & 16 \\
\hline \multicolumn{5}{|l|}{$\begin{array}{l}\text { Survey 2- } \\
\text { Posttest: Self- } \\
\text { Assessment }\end{array}$} \\
\hline & Level of Familiarity & $\begin{array}{l}\text { Communication } \\
\text { Theory }\end{array}$ & $\begin{array}{l}\text { Communication as a } \\
\text { Leadership Skill }\end{array}$ & 24 \\
\hline & Level of Comfort & $\begin{array}{l}\text { Communication } \\
\text { Theory }\end{array}$ & $\begin{array}{l}\text { Communication as a } \\
\text { Leadership Skill }\end{array}$ & 24 \\
\hline & Need the Most Help & $\begin{array}{l}\text { Communication } \\
\text { Theory }\end{array}$ & $\begin{array}{l}\text { Communication as a } \\
\text { Leadership Skill }\end{array}$ & 24 \\
\hline & Level of Familiarity & Campaign Strategies & & 16 \\
\hline & Level of Comfort & Campaign Strategies & & 16 \\
\hline & Need the Most Help & Campaign Strategies & & 16 \\
\hline \multicolumn{5}{|l|}{$\begin{array}{l}\text { Survey 3- } \\
\text { Testing of } \\
\text { Handbook }\end{array}$} \\
\hline & Level of Usefulness & Campaign Strategies & & 22 \\
\hline & Level of Effectiveness & Campaign Strategies & & 22 \\
\hline & Level of Importance & Campaign Strategies & & 22 \\
\hline & Format and Style & $\begin{array}{l}\text { Structure, Method, } \\
\text { Form }\end{array}$ & & 24 \\
\hline \multicolumn{5}{|l|}{$\begin{array}{l}\text { Survey 4- } \\
\text { Testing of } \\
\text { Workshop }\end{array}$} \\
\hline & Level of Agreement & $\begin{array}{l}\text { Content, Design, } \\
\text { Facilitator, Results, } \\
\text { Presentation }\end{array}$ & & 17 \\
\hline & $\begin{array}{l}\text { How could workshop } \\
\text { be improved }\end{array}$ & $\begin{array}{l}\text { Content, Design, } \\
\text { Facilitator, Results, } \\
\text { Presentation }\end{array}$ & & 14 \\
\hline
\end{tabular}


Data results from Steps 2 and 4 confirmed the need for the handbook. District leaders do not have the tools to begin such a complicated task. The handbook Holding Successful School Bond Campaigns: Not for Dummies fills superintendents and other district leaders' toolbox.

As developed in Step 4, I used the same three separate surveys administered through SurveyMonkey:

1. Pretest: Section 1-Self-assessment of communications theory and Section 2-Strategies and self-assessment of the handbook's 17 campaign strategies.

2. Posttest: Self-assessment of communications theory and Section 2Strategies and self-assessment of the handbook's 16 campaign strategies.

3. Survey of the Handbook: Section1-Participant and District Information; Section 2-Handbook's Strategies; Section 3-Handbook's Format and Style; Section 4-Workshop

This section describes the Step 6 instruments used, the workshop materials, the participants, and the workshop. However, because I used most of the same materials and workshop set up, I will be brief in those areas.

Self-assessment pretest and posttest. Participants were administered the same self-assessment of communication theory and practices and campaign strategies as the Step 4 pretest and posttest. Participants rated their level of familiarity and their level of comfort with communication theory and practices and campaign strategies on a Likertstyle scale. Participants then identified which school bond strategy(s) that they perceive that they need the most help in understanding and/or application of the strategy. They could check all that applied.

Survey of the handbook. As in Step 4, at the end of the workshop, participants were administered the survey of the handbook with four major sections: 
Section 1: Participant and District Information

Section 2: Survey of the Usefulness, Effectiveness, and Importance of the Handbook

Section 3: Format and Style

Section 4: Workshop

Section 1 invites participants to provide information about themselves and their districts. Participants were asked to

1. Describe your title.

2. Identify the number of years you have been in your current position in your district counting this school year as one of the years.

3. Identify the total number of years you have been in your current position in all districts in which you worked.

4. Identify the number of students in your school district.

5. Describe your district's locale.

6. Describe your district's economic status as defined by students' free and reduced lunch percentages.

7. Describe the district's total racial/ethnic minority percentages.

Section 2 of the survey was divided into three subsections that examined participants' perception of the handbook in three different ways. Participants rated each area using a Likert-type scale. One represented, for example, the least useful and 4 represented the most useful.

The subsections comprised 22 areas of the handbook including the 17 campaign strategies (see Table 27). Question 1 asked participants to rate the usefulness of the handbook using all 22 areas. Usefulness was defined as practical information for district leaders initiating a bond. Is the content fully developed with necessary details and examples? Question 2 asked participants to rate the effectiveness of the handbook. Effectiveness was defined as being able to apply the information. Can this information be applied in the participant's district? Question 3 asked participants to rate the importance 
of the handbook. Importance was defined as meeting the participant's district's needs at this time. Is this strategy important to the needs of his or her district? Participants rated each of the 22 areas of the handbook for each question.

Table 27

Areas of the Handbook Evaluated for Usefulness, Effectiveness, and Importance

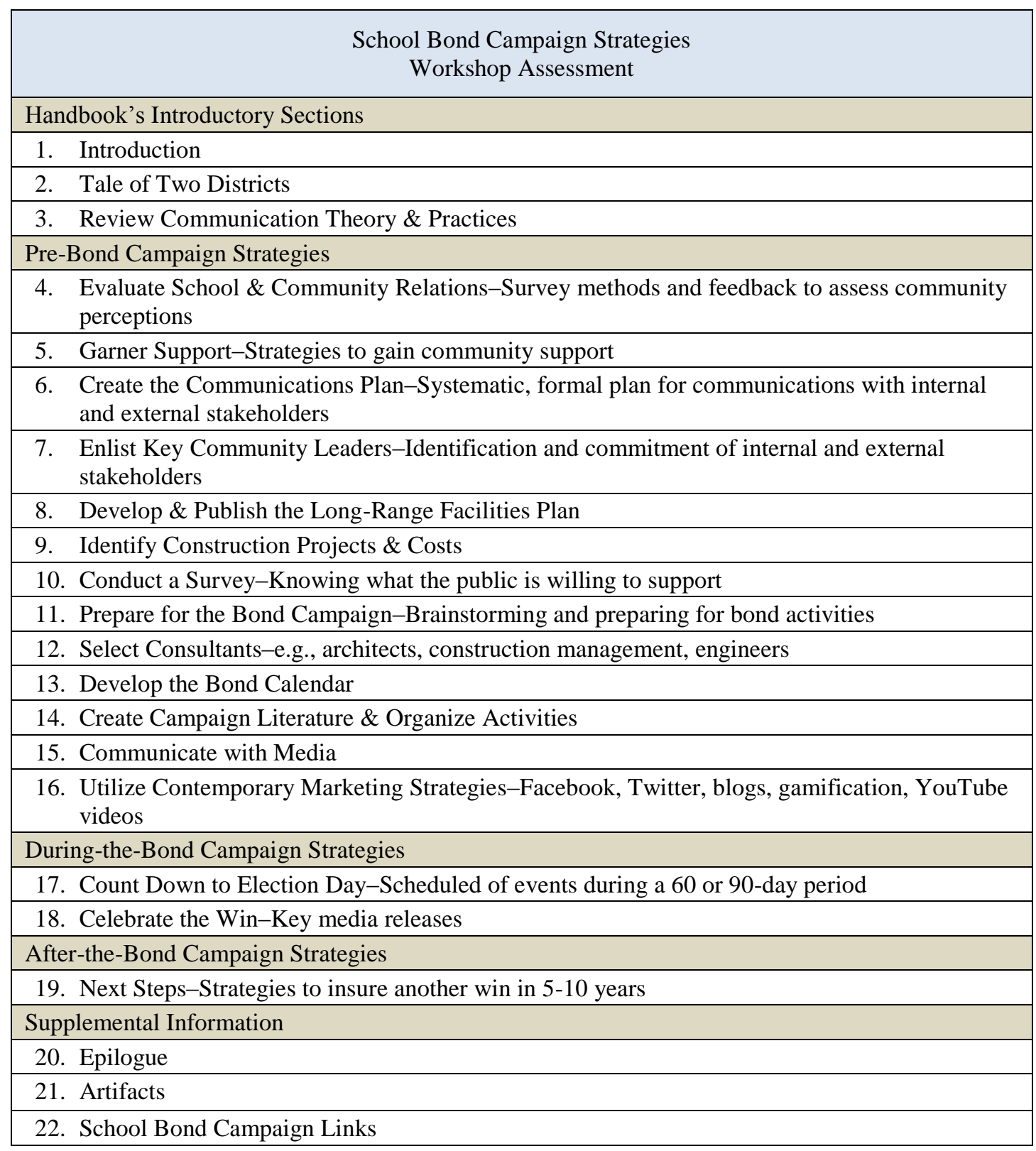


Section 3: Format and style. Format \& Style is the way the contents are

presented: structure, method, and form. Structure, method, and form, while interrelated, aimed to answer these questions:

- Is the information well-structured, organized, and easy to find?

- Is the text readable?

- Are illustrations and layout used well?

- Is the user involved? How is the manual introduced? (Folmer et al., n.d., pp. 12-14)

Structure has to do with the order of the contents. The order of the contents must be logical, and users must be able to quickly find the section they need. Method has to do with readability and whether the text is readable. Are the contents presented in a way so that the user can easily read and understand the information? Form has to do with the presentation of the contents. The contents and pictures must be attractive, and the text should be presented in a way that involves the reader.

Section 3: Format and Style of the survey rated the participant's level of agreement to the following statements about the Format and Style of the handbook. Level of agreement uses a 1 to 4 scale with 1 strongly disagree and 4 strongly agree with the statement.

1. The title of the handbook captures my interest.

2. The title reflects the contents of the handbook.

3. The introduction compels me to read further.

4. The "Tale of Two Districts" adds humor.

5. The "Tale of Two Districts" introduces important concepts.

6. Information is in the right order.

7. Information is easy to find.

8. The text is easy read.

9. Illustrations/visuals make sense.

10. Illustrations/visuals add interest.

11. Titles and subtitles help the reader understand the text.

12. Quotes support the content. 
13. The table of contents is arranged in the right order.

14. The table of contents is easy to use.

15. The language of the handbook is simple enough for all users.

16. The language of the handbook is advanced enough to keep readers' interested.

17. The vocabulary aligns with the abilities of the reader.

18. Sentences are short and clear.

19. The writing style is similar to everyday reading in newspapers, magazines, or books.

20. Layout is designed well.

21 . Layout is visually pleasing.

22. Adequate space is available for the reader to plan or take notes.

23. Reflection pages help the reader to process the material.

24. The handbook's contents are understood without a workshop.

Section 4: Workshop. Section 4 of the survey asked participants to rate their perception of the workshop content, design, facilitator, results, and presentation (see Table 11). The questions were based, in part, on workshop surveys developed for professional development activities in Reynolds School District. The Workshop survey rated the participant's level of agreement to the following statements about the workshop. Level of agreement used a 1 to 4 scale with 1 signifying strongly disagree and 4 signifying strongly agree with the survey statement. A list of statements in the last section of the workshop survey asked participates to check all statements that would apply about ways the workshop could be improved.

Main field test: Materials. In preparation for the workshop for the Preliminary field test, I created a syllabus or curriculum that included the goals, learning objectives, and activities (Appendix C). I also used the syllabus for the Step 6, Main field test. According to the syllabus,

The goal of the workshop is to prepare district leaders for the multiple challenges of a school construction bond election. Today's school leaders are faced with a multitude of daily decisions and challenges. They do not have time to research requirements of a bond election. Yet a construction bond election is necessary for 
the maintenance of school buildings, upgrading and remodeling of buildings, and for new construction. The workshop and handbook will help district leaders become more knowledgeable in the bond election process and they will understand and be able to apply what is needed to pass a bond.

Participants would assess their current knowledge and skills, understand and apply new vocabulary of school bond elections, know and apply pre-, during- and post-bond activities, understand the value of surveys to learn school-community perceptions, construct a calendar of events, plan a communications strategy, and evaluate the usefulness, effectiveness, and importance of the handbook as a tool for passing a construction bond election. The handbook Holding Successful Bond Campaigns: Not for Dummies was the main source of information for participants.

Originally, I intended to email a copy of the handbook to participants before the workshop so that they would have time to review the handbook, but I was advised that this would not be a good idea for two reasons. First, if workshop participants received the handbook in advance, they might not attend the workshop. Second, a requirement to receive a copy of the handbook would be to complete all surveys. The handbook would be the carrot to lure participants to the workshop and to complete the testing of the product.

A month before the workshop, I crafted a brochure announcing the workshop and emailed Oregon superintendents information about workshop with the brochure attached (see Appendix E). The brochure included information about the workshop; registration; a description of participants who would most benefit; a description of the handbook; importance of the workshop for districts seeking a bond; and location, date, and time of the workshop. A section about me as the presenter described the testing the handbook in 
the form of surveys as a requirement of my dissertation. I continued to email the brochure each week to attract the greatest number of participants.

As in Step 4, I again used a PowerPoint presentation, "School District Bond Campaigns: Strategies That Ensure Successful Outcomes" (see Appendix D). It explained the informed consent form and confidentiality of participants. It included the agenda, objectives of the workshop, information about SurveyMonkey, and accessing the workshop surveys online. It included an outline of my personal journey with bond campaigns, the goals of the workshop, the problem of passing bonds, and the need for new construction and remodeling. These topics led into communication theory and practices, the pre-bond, during the bond, and after the bond campaign strategies.

Main field test: Participants. Step 4, Preliminary field test was scheduled as a half-day mini-workshop conducted in my district office conference room. But the Step 6, Main field test was scheduled as a full-day workshop at the COSA conference room in Salem, Oregon, beginning at 8:30 in the morning and ending at 3:30 in the afternoon, a seven-hour workshop. I anticipated having ample time for questions and small-group discussions.

Seventeen district leaders registered, but 16 attended. Participants identified themselves as seven superintendents, five school board members, and four district office administrators. District office administrators were identified as business managers/financial officers, operations/facilities management, and communication (see Table 28). 
Table 28

Main Field Test Participant Demographic Data

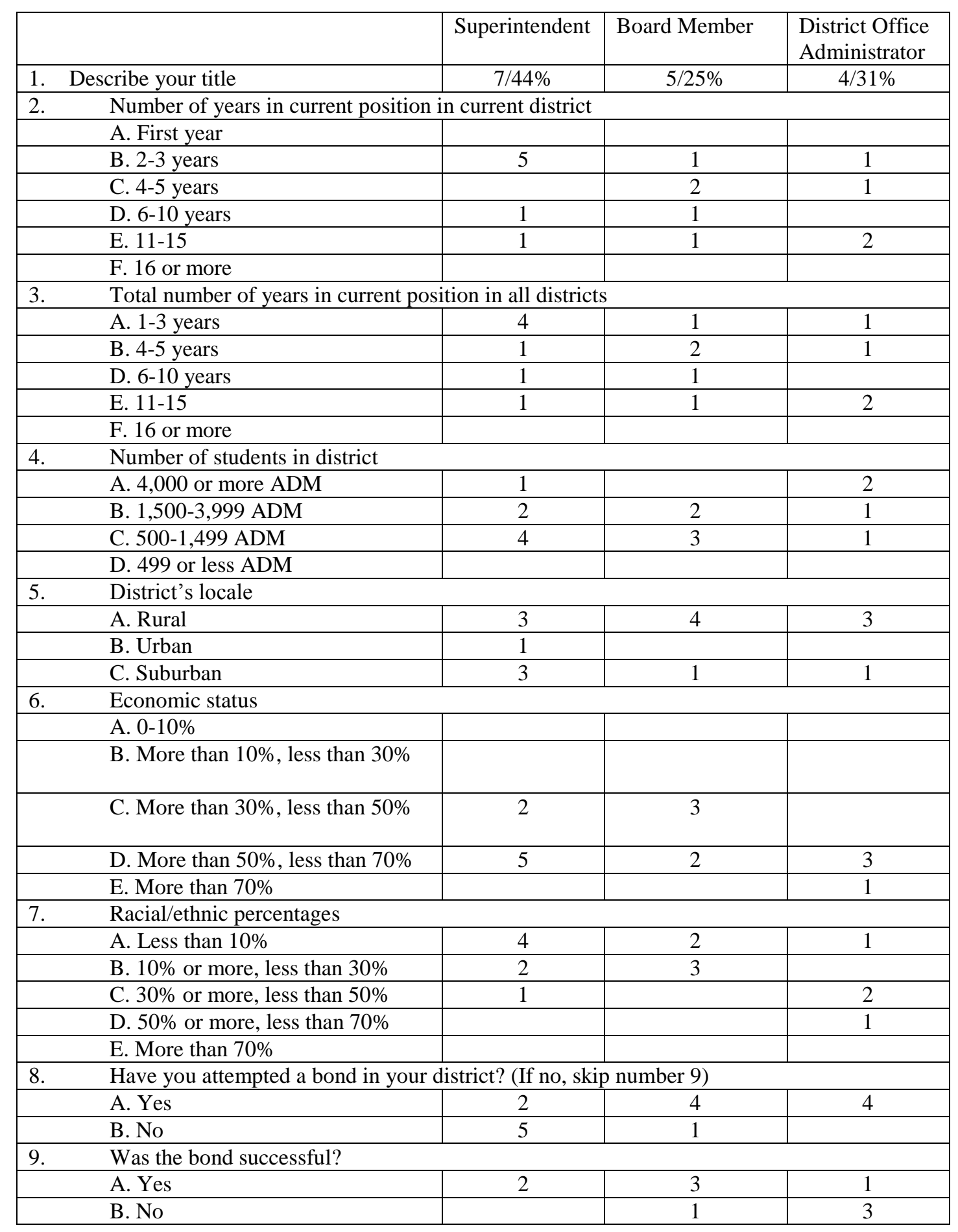


Table 28 (continued)

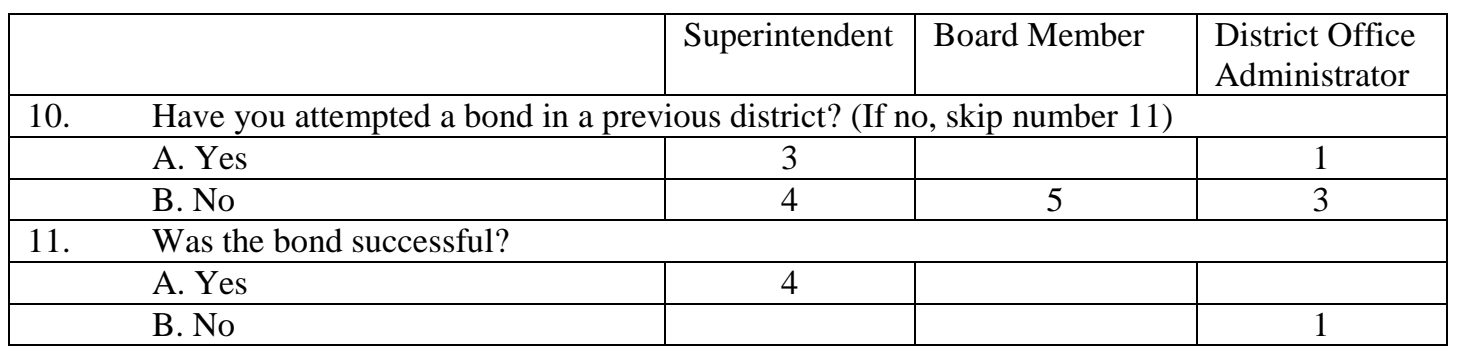

Five of the seven superintendents served in their positions for two to three years. Superintendents' years of service data correlate with the CGCS (2010) and AASA (2010) statistics on superintendent tenure. Sixty-three percent of superintendents have served in their positions between one and five years with the average tenure of urban superintendents as 3.64 years (CGCS, 2010). For all superintendents, nationally, the mean is higher at 5-6 years (AASA, 2010).

As with the participants in Step 4, Preliminary field test, the District demographics of Step 6, Main field test, are also varied in district size, locale, economic status, and in racial composition. Workshop participants represented three large school districts, five medium-sized districts, and eight small school districts located in 10 rural, one urban, and three suburban settings.

Each district's economic status is defined as the percentage of students who receive free and/or reduced lunch. No participants identified their districts as A, 0-10\% free and reduced lunch or B, more than $10 \%$ but less than $30 \%$. Five districts identified themselves as C, $50 \%$ or more but less than $70 \%$; 10 as D, $50 \%$ or more but less than $70 \%$, and one as E, more than $70 \%$ free and reduced lunch. 
Five participants described their districts' total racial/ethnic minority percentages as less than $10 \%$; 10 participants identified their districts as $10 \%$ or more but less than $30 \%$; and one as $50 \%$ or more but less than $70 \%$. These 16 workshop participants represented a varied cross section of Oregon school districts.

Main field test: Workshop. The Main field test took place September 28, 2013, at the COSA building in Salem, Oregon. I chose this location because COSA is a credible association that supports the work of administrators. It is fairly centrally located in the state and is considered a neutral site. COSA executives provided me with the email addresses of superintendents, the COSA list serve, and allowed me to use the conference room suite without a charge. The room can comfortably hold 20 to 25 people and still have space for breakfast and lunch set up.

Two people accompanied me to help with set up. In case some participants' forgot, we brought an additional six iPads. During the preliminary field test workshop, two of the participants had difficulty accessing the survey on SurveyMonkey or had questions about the survey as they were taking it. Knowing I had a much wider audience and perhaps several novice technology users participating, I asked my workshop assistants to attend the workshop to help participants enjoy trouble-free survey access. I knew that I would be too occupied in facilitating the workshop.

Participants were required to bring a laptop or iPad to access the surveys on SurveyMonkey. However, all six of the iPads we brought plus one laptop were used by participants because they did not bring the required technology. I had allowed 45 minutes for participants to take the three separate surveys: the pretest and posttest of the self- 
assessment of communication theory/practices and campaign strategies, and the survey of the handbook and workshop.

When participants arrived, they were instructed to log into COSA's wireless access and access the survey. Each participant had a name plate (see Appendix F), nametag (see Appendix G), an agenda (see Appendix H), specially designed notepads (see Appendix I), and a copy of the workshop syllabus. During this time they also received the informed consent form, just as participants had in the preliminary field test. The form stated that the study was both anonymous and confidential and participants' identities would be kept private. The information collected during the workshop could not be traced back to individual participants because participants would be identified by numbers or pseudonyms and not by names or districts. No original participant names or districts would be needed in the written report after the workshop. I asked them to sign an informed consent form as part of the requirements of research at Portland State University.

After participants took the pretest self-assessment of communications theory and practices and campaign strategies, they received a copy of the handbook and were asked to speed read through the introductory sections of the handbook and the "Tale of Two Districts."

Some participants arrived late. I did not want to begin the workshop until all participants were in attendance. That way, when they took the posttest at the end of the workshop, everyone would have received the same information. We started about 15 
minutes late, not just because of those who arrived late but because some participants were slower readers.

The room was set up in a large U-shape facing the screen where I projected the PowerPoint presentation. When everyone finished reading the "Tale of Two Districts," I welcomed them, and we introduced ourselves.

The PowerPoint provided the framework and outline for my presentation. I described my background and why I developed the handbook. I also gave some background on the problem of passing bond elections. Then I gave an overview of communication theory and practice and had them follow along in the handbook. This was a massive amount of information to digest in a short period of time, but most administrators had some knowledge of communication theory from their administrative licensure programs and from their experiences in their districts. The five board members probably did not. For most participants, the presentation served as review.

The major portion of the workshop focused on the 17 campaign strategies. After each strategy was presented, time was allotted to discuss the section in their groups-or with another participant nearby-and to strategize what they could do in their districts. The focus remained on the handbook and the evaluation of the efficacy of the strategies. Throughout the presentation, I answered questions, shared anecdotes, and allowed participates to share their stories. At the end of the workshop, participants were asked to take the posttest and the survey of the handbook and workshop. These surveys served to provide the summative and formative feedback to determine the efficacy of the handbook and workshop and to make improvements and revisions to them in Step 7. When the 
workshop ended, all participants received a thank-you card with a coffee gift card (see Appendix J).

\section{Evaluation of Results}

Borg and Gall's (1989) Step 6 of the R\&D cycle involves implementation of the new product and the collection of data concerning its application. The Main field test of the product took place during a workshop for superintendents and other district leaders who were planning a construction bond election in the near future. Participants took part in a workshop that used the product, the handbook, Holding Successful Bond Campaigns: Not for Dummies. Both the product and the workshop were assessed as well as what the participants learned during the workshop.

This section first describes the summative evaluation results of the field test. Formative evaluation results are discussed in chapter 5. The summative evaluation focuses on the efficacy or usefulness of the product, the handbook, and the workshop. Formative assessment focuses on the improvement of the product and workshop.

\section{Summative Evaluation of the Results}

Three surveys were administered. The first two consisted of a pretest and posttest to assess the learning of the workshop participants in communication theory and practices and campaign strategies. The pretest and posttest was a self-assessment of participants'

level of familiarity and level of comfort with communication and campaign strategies and which strategies the participants needed the most help. The third survey evaluated the usefulness, effectiveness, and importance of the handbook; the handbook's format and 
style; and the workshop. I separated the third survey into three separate subheadings because they focus on different topics of the survey.

\section{Summative evaluation of the results of pretest and posttest. Comparing} participants' posttest scores to their pretest scores enabled me to see whether the handbook and training were successful in increasing participant knowledge of the content. The pretest and posttest included two sections: Section 1: Communication Theory and Practices and Section 2: School bond Campaign Strategies.

Pretest and posttest: Section 1-Communication. The first question assessed Level of Familiarity. Participants rated their familiarity with the listed examples of communication theory and practices before the workshop and before they received their copy of the handbook Holding Successful Bond Campaigns: Not for Dummies. Level of Familiarity includes knowledge, understanding, and application of the listed communication strategies. Questions 1-13 focused on communication in the context of the greater organization. Questions 14-25 focused on personal communication skills. Ratings were based on a 1-4 Likert-style scale with 1 being not familiar and 4 being extremely familiar.

After reviewing the handbook and after participating in the workshop, participants rated their level of familiarity as depicted in Table 29. The 16 participants' ratings were averaged. Comparing the results of the pretest and posttest indicated that, after review of the handbook and participation in the workshop, growth was exhibited in every area. 
Table 29

Participants' Level of Familiarity of Communication Theory and Practices

\begin{tabular}{|c|c|c|}
\hline Level of Familiarity: Communication Self-Assessment & Pretest & Posttest \\
\hline 1. Formal Communication-Planned, intentional, controlled & 2.69 & 3.25 \\
\hline 2. Informal Communication-Unplanned, unintentional, brief & 2.69 & 3.31 \\
\hline 3. One-Way Communication-Information out to receiver & 2.63 & 3.38 \\
\hline $\begin{array}{l}\text { 4. Two-Way Communication-Information exchange between sender and } \\
\text { receiver }\end{array}$ & 2.63 & 3.31 \\
\hline $\begin{array}{l}\text { 5. Strategic Communications Planning-Systematic, formal plan of } \\
\text { community-wide approach to communication }\end{array}$ & 2.38 & 3.13 \\
\hline 6. Communication with Internal Publics-Employees, volunteers, students & 2.63 & 3.38 \\
\hline $\begin{array}{l}\text { 7. Communication with External Publics-Parents, business partners, } \\
\text { contractors }\end{array}$ & 2.31 & 3.38 \\
\hline $\begin{array}{l}\text { 8. School Community Relations-Understanding and responding to } \\
\text { community perceptions of the school district }\end{array}$ & 2.69 & 3.19 \\
\hline $\begin{array}{l}\text { 9. Communications Strategies-Face to face, telephone, electronic, written, } \\
\text { numeric }\end{array}$ & 2.75 & 3.38 \\
\hline 10. Media Relations-Building positive relationships with reporters & 2.31 & 3.50 \\
\hline 11. Marketing Strategies-Managing the district's image & 2.38 & 3.25 \\
\hline $\begin{array}{l}\text { 12. Marketing Techniques, Tools, and Publications-Direct mail, free media, } \\
\text { material drops, print/broadcast media, meet and greet }\end{array}$ & 2.00 & 3.25 \\
\hline 13. Social Media-Facebook, Twitter, blogs, message boards & 1.88 & 2.88 \\
\hline \multicolumn{3}{|l|}{ Communication as a Leadership Skill by } \\
\hline 14. being a good listener & 3.13 & 3.44 \\
\hline 15. being a good writer & 2.88 & 3.13 \\
\hline 16. being a prepared speaker & 3.00 & 3.44 \\
\hline 17. building relationships with board members & 2.94 & 3.38 \\
\hline 18. building relationships with teachers and staff & 3.06 & 3.50 \\
\hline 19. building relationships with taxpayers & 2.31 & 3.25 \\
\hline 20. keeping internal and external groups informed & 2.56 & 3.38 \\
\hline 21. establishing, maintaining, and nurturing open communication channels & 2.75 & 3.44 \\
\hline $\begin{array}{l}\text { 22. developing and championing policies created to enhance school and } \\
\text { community relations }\end{array}$ & 2.75 & 3.13 \\
\hline $\begin{array}{l}\text { 23. always keeping the school board, staff, and general public informed of } \\
\text { school matters }\end{array}$ & 2.75 & 3.50 \\
\hline $\begin{array}{l}\text { 24. ensuring the school and community relationship is assessed and } \\
\text { evaluated regularly }\end{array}$ & 2.31 & 3.00 \\
\hline $\begin{array}{l}\text { 25. making sure that influential groups and community leaders are provided } \\
\text { with factual information }\end{array}$ & 2.63 & 3.63 \\
\hline
\end{tabular}


Greatest growth from the pretest to the posttest of one full point or more was achieved in five areas:

7. Communication with External Publics

10. Media Relations

12. Marketing Techniques, Tools, and Publications

13. Social Media

25. making sure that influential groups and community leaders are provided with factual information

Number 7, Communication with External Publics level of familiarity increased from 2.31 to 3.38. Participants had not considered the depth and breadth of their district's constituents when identifying the different groups that comprised their external publics. For example, Bagin et al. (2008) advise listing all ethnic groups, learning about each group, identifying each group's key communicators, training teachers to work with diverse families, and printing publications in each group's home language. Participants had not considered the scope of working with the entire external community.

Number 10, Media Relations level of familiarity increased from 2.31 to 3.50. One superintendent showed a great deal of interest in this communication strategy. She shared that her district was planning a bond. She and her team spent a year and six months researching what the district needed to do to pass a bond without the aid of my handbook. Media Relations was of high interest to her because she had not considered meeting with the local newspaper's editorial board to discuss the bond. She saw this strategy as one of the gaps in the campaign and intended to meet with the local paper if it was not already too late.

Participants made great gains from the pretest to posttest in numbers 12 and 13. Participants' level of familiarity in Marketing Techniques, Tools, and Publications 
increased significantly from 2.00 to 3.25. Likewise, Social Media increased significantly from 2.63 to 3.63. Participants in the Preliminary field test did not show as much growth. In the Preliminary field test, participants' level of familiarity increased from 2.25 to 2.75 in Marketing Techniques and from 2.00 to 3.00 in Social Media. The additional workshop time allotted for discussion and planning seemed to facilitate participants' improved learning about the topics.

As a leadership skill, participants' level of familiarity with number 25 , making sure that influential groups and community leaders are provided with factual information, also increased significantly from 2.63 to 3.63 .

The second question assessed Level of Comfort. Participants rated their comfort with the listed examples of communication theory and practices before the workshop and before they received their copy of the handbook Holding Successful Bond Campaigns: Not for Dummies. Level of Comfort would describe participants' ease of understanding and ability to apply the listed communication strategies. Ratings were based on a 1-4 Likert-style scale with 1 being not at all comfortable and 4 being extremely comfortable.

After reviewing the handbook and after participating in the workshop, participants rated their level of comfort as depicted in Table 30. Growth was exhibited in every area, but not to the extent as described in the level of familiarity. The least growth in participants' level of comfort occurred in 14. Being a good listener, and 15. Being a good writer. Application of these skills is a higher level of understanding than the level of familiarity, which may account for a lower increase. 
Table 30

Participants' Level of Comfort of Communication Theory and Practices

\begin{tabular}{|c|c|c|}
\hline Level of Comfort: Communication Self-Assessment & Pretest & Posttest \\
\hline 1. Formal Communication-Planned, intentional, controlled & 2.94 & 3.38 \\
\hline 2. Informal Communication-Unplanned, unintentional, brief & 2.94 & 3.44 \\
\hline 3. One-Way Communication-Information out to receiver & 3.07 & 3.44 \\
\hline $\begin{array}{l}\text { 4. Two-Way Communication-Information exchange between sender and } \\
\text { receiver }\end{array}$ & 2.94 & 3.31 \\
\hline $\begin{array}{l}\text { 5. Strategic Communications Planning-Systematic, formal plan of } \\
\text { community-wide approach to communication }\end{array}$ & 2.50 & 3.25 \\
\hline 6. Communication with Internal Publics-Employees, volunteers, students & 2.94 & 3.53 \\
\hline $\begin{array}{l}\text { 7. Communication with External Publics-Parents, business partners, } \\
\text { contractors }\end{array}$ & 2.75 & 3.38 \\
\hline $\begin{array}{l}\text { 8. School Community Relations-Understanding and responding to } \\
\text { community perceptions of the school district }\end{array}$ & 2.81 & 3.31 \\
\hline $\begin{array}{l}\text { 9. Communications Strategies-Face to face, telephone, electronic, written, } \\
\text { numeric }\end{array}$ & 2.88 & 3.50 \\
\hline 10. Media Relations-Building positive relationships with reporters & 2.38 & 3.44 \\
\hline 11. Marketing Strategies-Managing the district's image & 2.44 & 3.27 \\
\hline $\begin{array}{l}\text { 12. Marketing Techniques, Tools, and Publications-Direct mail, free media, } \\
\text { material drops, print/broadcast media, meet and greet }\end{array}$ & 2.31 & 3.31 \\
\hline 13. Social Media-Facebook, Twitter, blogs, message boards & 1.94 & 2.88 \\
\hline \multicolumn{3}{|l|}{ Communication as a Leadership Skill by } \\
\hline 14. being a good listener & 3.38 & 3.47 \\
\hline 15. being a good writer & 2.94 & 3.13 \\
\hline 16. being a prepared speaker & 2.88 & 3.13 \\
\hline 17. building relationships with board members & 3.19 & 3.47 \\
\hline 18. building relationships with teachers and staff & 3.38 & 3.47 \\
\hline 19. building relationships with taxpayers & 2.38 & 3.20 \\
\hline 20. keeping internal and external groups informed & 2.63 & 3.33 \\
\hline 21. establishing, maintaining, and nurturing open communication channels & 2.94 & 3.33 \\
\hline $\begin{array}{l}\text { 22. developing and championing policies created to enhance school and } \\
\text { community relations }\end{array}$ & 2.63 & 3.00 \\
\hline $\begin{array}{l}\text { 23. always keeping the school board, staff, and general public informed of } \\
\text { school matters }\end{array}$ & 3.00 & 3.38 \\
\hline $\begin{array}{l}\text { 24. ensuring the school and community relationship is assessed and evaluated } \\
\text { regularly }\end{array}$ & 2.50 & 3.13 \\
\hline $\begin{array}{l}\text { 25. making sure that influential groups and community leaders are provided } \\
\text { with factual information }\end{array}$ & 3.00 & 3.38 \\
\hline
\end{tabular}


Greatest growth in level of comfort from the pretest to the posttest was achieved in five areas:

10. Media Relations

11. Marketing Strategies

12. Marketing Techniques

13. Social Media

19. Building relationships with taxpayers

Participants' level of comfort of Media Relations increased from 2.38 to 3.44; Marketing Strategies increased from 2.44 to 3.27; Marketing Techniques increased from 2.31 to 3.31; Social Media increased from 1.94 to 2.88; and Building relationships with taxpayers increased from 2.38 to 3.20 . Learning about and discussing the ways in which districts and campaign committees can work with these practices help to bridge a perceived gap in applying communication skills to important planning events associated with a bond campaign. The handbook and workshop informed participants of essential practices and raised their level of comfort in applying these practices in districts.

The third question asked: In what areas do you perceive that you need the most help? Participants were instructed to place a check mark next to the listed communication strategies that they perceived to need the most help in understanding and/or application of the strategy (see Table 31). In the pretest, half to most of participants marked the following areas where they needed the most help:

3. Formal Communication, 8 participants

5. Strategic Communications Planning, 13 participants

7. Communication with External Publics, 9 participants

8. School Community Relations, 10 participants

11. Marketing Strategies, 14 participants

12. Marketing Techniques, 12 participants

13. Social Media, 11 participants

19. building relationships with taxpayers, 13 participants

22. developing and championing policies created to enhance school and community relations, 10 participants

24. ensuring the school and community relationship is assessed and evaluated regularly, 10 participants 
Table 31

Communication Topics Participants Perceive They Need the Most Help

\begin{tabular}{|c|c|c|}
\hline Need the Most Help: Communication Self-Assessment & $\begin{array}{l}\text { Pretest } \\
\text { Number }\end{array}$ & $\begin{array}{l}\text { Posttest } \\
\text { Number }\end{array}$ \\
\hline 1. Formal Communication-Planned, intentional, controlled & 8 & 1 \\
\hline 2. Informal Communication-Unplanned, unintentional, brief & 3 & 1 \\
\hline 3. One-Way Communication-Information out to receiver & 1 & 0 \\
\hline $\begin{array}{l}\text { 4. Two-Way Communication-Information exchange between sender } \\
\text { and receiver }\end{array}$ & 3 & 3 \\
\hline $\begin{array}{l}\text { 5. Strategic Communications Planning-Systematic, formal plan of } \\
\text { community-wide approach to communication }\end{array}$ & 13 & 8 \\
\hline $\begin{array}{l}\text { 6. Communication with Internal Publics-Employees, volunteers, } \\
\text { students }\end{array}$ & 1 & 0 \\
\hline $\begin{array}{l}\text { 7. Communication with External Publics-Parents, business partners, } \\
\text { contractors }\end{array}$ & 9 & 3 \\
\hline $\begin{array}{l}\text { 8. School Community Relations-Understanding and responding to } \\
\text { community perceptions of the school district }\end{array}$ & 10 & 7 \\
\hline $\begin{array}{l}\text { 9. Communications Strategies-Face to face, telephone, electronic, } \\
\text { written, numeric }\end{array}$ & 3 & 5 \\
\hline 10. Media Relations-Building positive relationships with reporters & 5 & 4 \\
\hline 11. Marketing Strategies-Managing the district's image & 14 & 7 \\
\hline $\begin{array}{l}\text { 12. Marketing Techniques, Tools, and Publications-Direct mail, free } \\
\text { media, material drops, print/broadcast media, meet and greet }\end{array}$ & 12 & 8 \\
\hline 13. Social Media-Facebook, Twitter, blogs, message boards & 11 & 12 \\
\hline \multicolumn{3}{|l|}{ Communication as a Leadership Skill by } \\
\hline 14. being a good listener & 1 & 2 \\
\hline 15. being a good writer & 2 & 3 \\
\hline 16. being a prepared speaker & 5 & 4 \\
\hline 17. building relationships with board members & 2 & 1 \\
\hline 18. building relationships with teachers and staff & 0 & 0 \\
\hline 19. building relationships with taxpayers & 13 & 6 \\
\hline 20. keeping internal and external groups informed & 4 & 1 \\
\hline $\begin{array}{l}\text { 21. establishing, maintaining, and nurturing open communication } \\
\text { channels }\end{array}$ & 5 & 5 \\
\hline $\begin{array}{l}\text { 22. developing and championing policies created to enhance school and } \\
\text { community relations }\end{array}$ & 10 & 8 \\
\hline $\begin{array}{l}\text { 23. always keeping the school board, staff, and general public informed } \\
\text { of school matters }\end{array}$ & 3 & 3 \\
\hline $\begin{array}{l}\text { 24. ensuring the school and community relationship is assessed and } \\
\text { evaluated regularly }\end{array}$ & 10 & 8 \\
\hline $\begin{array}{l}\text { 25. making sure that influential groups and community leaders are } \\
\text { provided with factual information }\end{array}$ & 4 & 4 \\
\hline
\end{tabular}

In the posttest, a majority of participates still needed the most help in one area, 13.

Social Media. The pretest indicated that 11 participants needed the most help with social 
media and posttest indicated that 12 needed the most help in this area. This may be the result of how fast technology changes. In my handbook and workshop, I presented a number of ways to use technology. Participants were unaware of how to use contemporary media such as blogs, gamification, ideation, podcasts, social networks, Twitter, and wikis. They were mostly familiar with using videos and Facebook in campaigns. Another possibility is that as participants learn more about a topic, they find that they actually know less about it than they first perceived.

Many district leaders fear the use of social media because of the speed and distance that information travels (Porterfield \& Carnes, 2012). Everyone has a story about emailing the wrong information to an unintended receiver, and social media has a much wider audience. Neither are district leaders fully informed and knowledgeable about the best communication strategies using the latest technologies. While Facebook and Twitter are typical household words, in practice they usually are not so typical. Porterfield and Carnes (2008) said the power of technology provides us with a "set of tools that offer the ability to reach stakeholders and influence community discussion like never before. Social media are simply another way to communicate like a newsletter, an email, or website" (p. 205). Having a majority of participants who need the most help with social media seems to be the norm and the reason social media are addressed in the handbook and workshop.

Pretest and posttest: Section 2-School bond campaign strategies. The first question assessed Level of Familiarity. Participants rated their familiarity with the listed examples of school bond campaign strategies before the workshop and before they received their copy of the handbook Holding Successful Bond Campaigns: Not for 
Dummies. Level of Familiarity included knowledge, understanding, and application of the listed school bond campaign strategies. Ratings were based on a 1-4 Likert-style scale with 1 being not familiar and 4 being extremely familiar.

After reviewing the handbook and after participating in the workshop, participants rated their level of familiarity as presented in Table 32 . The 16 participants' ratings were averaged. Comparing the results of the pretest and posttest indicated that, after review of the handbook and participation in the workshop, growth was exhibited in every area.

Table 32

Participants' Level of Familiarity of Campaign Strategies

\begin{tabular}{|c|c|c|}
\hline Level of Familiarity: Campaign Strategies Self-Assessment & & \\
\hline Pre-Bond Campaign Strategies & Pretest & Posttest \\
\hline $\begin{array}{l}\text { 1. Foundation: Teaching and Learning Connection-Connect construction } \\
\text { improvements to teaching and learning }\end{array}$ & 2.31 & 3.25 \\
\hline $\begin{array}{l}\text { 2. Evaluate School \& Community Relations-Survey methods and } \\
\text { feedback to assess community perceptions }\end{array}$ & 2.19 & 3.13 \\
\hline 3. $\quad$ Garner Support-Strategies to gain community support & 2.00 & 3.31 \\
\hline $\begin{array}{l}\text { 4. Create the Communications Plan-Systematic, formal plan for } \\
\text { communications with internal and external stakeholders }\end{array}$ & 1.94 & 3.25 \\
\hline $\begin{array}{l}\text { 5. Enlist Key Community Leaders-Identification and commitment of } \\
\text { internal and external stakeholders }\end{array}$ & 2.50 & 3.50 \\
\hline 6. Develop \& Publish the Long-Range Facilities Plan & 2.56 & 3.38 \\
\hline 7. Identify Construction Projects \& Costs & 2.44 & 3.27 \\
\hline 8. Conduct a Survey-Knowing what the public is willing to support & 2.20 & 2.94 \\
\hline $\begin{array}{l}\text { 9. Prepare for the Bond Campaign-Brainstorming and preparing for bond } \\
\text { activities }\end{array}$ & 2.19 & 3.38 \\
\hline $\begin{array}{l}\text { 10. Select Consultants-e.g., architects, construction management, } \\
\text { engineers }\end{array}$ & 2.38 & 3.25 \\
\hline 11. Develop the Bond Calendar & 2.38 & 3.38 \\
\hline 12. Create Campaign Literature \& Organize Activities & 2.13 & 3.31 \\
\hline 13. Communicate with Media & 2.13 & 3.31 \\
\hline $\begin{array}{l}\text { 14. Utilize Contemporary Marketing Strategies-Facebook, Twitter, blogs, } \\
\text { gamification, YouTube videos }\end{array}$ & 1.69 & 2.88 \\
\hline \multicolumn{3}{|l|}{ During-the-Bond Campaign Strategies } \\
\hline $\begin{array}{l}\text { 15. Count Down to Election Day-Scheduled of events during a } 60 \text { or } 90- \\
\text { day period }\end{array}$ & 1.94 & 3.31 \\
\hline 16. Celebrate the Win-Key media releases & 1.75 & 3.19 \\
\hline \multicolumn{3}{|l|}{ After-the-Bond Campaign Strategies } \\
\hline 17. Next Steps-Strategies to insure another win in 5-10 years & 1.63 & 3.06 \\
\hline
\end{tabular}


Greatest growth occurred in 10 areas, averaging a full point to 1.43 increases.

2. Evaluate School \& Community Relations

3. Garner Support

4. Create the Communications Plan

5. Enlist Key Community Leaders

9. Prepare for the Bond Campaign

12. Create Campaign Literature \& Organize Activities

13. Communicate with Media

14. Utilize Contemporary Marketing Strategies

15. Count Down to Election Day

16. Celebrate the Win

17. Next Steps

Four strategies stood out, exhibiting the most growth overall: 3. Garner Support; 4. Create the Communications Plan; 16. Celebrate the Win; and 17. Next Steps. Garner support and Create the Communication Plan each increased by 1.31. Celebrate the Win and Next Steps each increased by 1.43. In my observations during the workshop, several participants remarked that they had not considered the value of celebrations. Their main focus was in winning the campaign. They did not have the foresight to determine what their plans would be if they won the election. This strategy then became important for them.

Similar to Celebrate the Win, Next Steps provided the steps to be taken after a win at the polls. Again, the workshop discussions pointed to many participants not recognizing the value of planning in advance of the win to be prepared after the win. As a result, their learning took a steep increase in their level of familiarity of campaign strategies.

The second question assessed Level of Comfort. Participants rated their comfort with the listed examples of school bond campaign strategies before the workshop and 
before they received their copy of the handbook Holding Successful Bond Campaigns: Not for Dummies. Level of Comfort would describe participants' ease of understanding and ability to apply the listed communication strategies. Ratings were based on a 1-4 Likert-style scale with 1 being not at all comfortable and 4 being extremely comfortable. After reviewing the handbook and after participating in the workshop, participants rated their level of comfort as presented in Table 33. Growth was again exhibited in every area. Greatest growth in comfort, increasing by 1 point or more, occurred in 1 . Foundation: Teaching and Learning Connection; 9. Prepare for the Bond Campaign; 12. Create Campaign Literature \& Organize Activities; 13. Communicate with the Media; 14. Utilize Contemporary Marketing Strategies; 15. Count Down to Election Day; 16. Celebrate the Win; and 17. Next Steps.

The third question asked: In what areas do you perceive that you need the most help? Participants were instructed to place a check mark next to the listed campaign strategies that they perceived to need the most help in understanding and/or application of the strategy. In the pretest as shown in Table 34, the majority of participants needed the most help with 3. Garner Support; 4. Create the Communications Plan; 12. Create Campaign Literature \& Organize Activities; 14. Utilize Contemporary Marketing Strategies; 15. Count Down to Election Day; 16. Celebrate the Win; and 17. Next Steps. In the posttest, the majority of participates, or 10 out of the 16 participants, still needed the most help with 14. Utilize Contemporary Marketing Strategies. 
Table 33

Participants' Level of Comfort of Campaign Strategies

\begin{tabular}{|c|c|c|}
\hline Level of Comfort: Campaign Strategies Self-Assessment & & \\
\hline Pre-Bond Campaign Strategies & Pretest & Posttest \\
\hline $\begin{array}{l}\text { 1. Foundation: Teaching and Learning Connection-Connect construction } \\
\text { improvements to teaching and learning }\end{array}$ & 2.13 & 3.13 \\
\hline $\begin{array}{l}\text { 2. Evaluate School \& Community Relations-Survey methods and feedback } \\
\text { to assess community perceptions }\end{array}$ & 2.25 & 3.19 \\
\hline 3. Garner Support-Strategies to gain community support & 2.19 & 3.07 \\
\hline $\begin{array}{l}\text { 4. Create the Communications Plan-Systematic, formal plan for } \\
\text { communications with internal and external stakeholders }\end{array}$ & 2.13 & 3.06 \\
\hline $\begin{array}{l}\text { 5. Enlist Key Community Leaders-Identification and commitment of } \\
\text { internal and external stakeholders }\end{array}$ & 2.50 & 3.38 \\
\hline 6. Develop \& Publish the Long-Range Facilities Plan & 2.38 & 3.19 \\
\hline 7. Identify Construction Projects \& Costs & 2.25 & 3.00 \\
\hline 8. Conduct a Survey-Knowing what the public is willing to support & 2.13 & 3.06 \\
\hline $\begin{array}{l}\text { 9. Prepare for the Bond Campaign-Brainstorming and preparing for bond } \\
\text { activities }\end{array}$ & 2.31 & 3.50 \\
\hline 10. Select Consultants-e.g., architects, construction management, engineers & 2.31 & 3.31 \\
\hline 11. Develop the Bond Calendar & 2.31 & 3.25 \\
\hline 12. Create Campaign Literature \& Organize Activities & 2.06 & 3.25 \\
\hline 13. Communicate with Media & 2.13 & 3.13 \\
\hline $\begin{array}{l}\text { 14. Utilize Contemporary Marketing Strategies-Facebook, Twitter, blogs, } \\
\text { gamification, YouTube videos }\end{array}$ & 1.75 & 2.88 \\
\hline \multicolumn{3}{|l|}{ During-the-Bond Campaign Strategies } \\
\hline $\begin{array}{l}\text { 15. Count Down to Election Day-Scheduled of events during a } 60 \text { or } 90 \text {-day } \\
\text { period }\end{array}$ & 2.00 & 3.25 \\
\hline 16. Celebrate the Win-Key media releases & 1.88 & 3.29 \\
\hline \multicolumn{3}{|l|}{ After-the-Bond Campaign Strategies } \\
\hline 17. Next Steps-Strategies to insure another win in $5-10$ years & 1.69 & 3.00 \\
\hline
\end{tabular}


Table 34

Campaign Strategies Participants Perceive They Need the Most Help

\begin{tabular}{|c|c|c|}
\hline Need the Most Help: Campaign Strategies Self-Assessment & & \\
\hline Pre-Bond Campaign Strategies & $\begin{array}{c}\text { Pretest } \\
\text { Number }\end{array}$ & $\begin{array}{l}\text { Posttest } \\
\text { Number }\end{array}$ \\
\hline $\begin{array}{l}\text { Foundation: Teaching and Learning Connection-Connect } \\
\text { construction improvements to teaching and learning }\end{array}$ & 4 & 1 \\
\hline $\begin{array}{l}\text { 2. Evaluate School \& Community Relations-Survey methods and } \\
\text { feedback to assess community perceptions }\end{array}$ & 7 & 4 \\
\hline 3. Garner Support-Strategies to gain community support & 11 & 4 \\
\hline $\begin{array}{l}\text { 4. Create the Communications Plan-Systematic, formal plan for } \\
\text { communications with internal and external stakeholders }\end{array}$ & 9 & 5 \\
\hline $\begin{array}{l}\text { 5. Enlist Key Community Leaders-Identification and } \\
\text { commitment of internal and external stakeholders }\end{array}$ & 2 & 2 \\
\hline 6. Develop \& Publish the Long-Range Facilities Plan & 6 & 4 \\
\hline 7. Identify Construction Projects \& Costs & 5 & 3 \\
\hline $\begin{array}{l}\text { 8. Conduct a Survey-Knowing what the public is willing to } \\
\text { support }\end{array}$ & 8 & 6 \\
\hline $\begin{array}{l}\text { 9. Prepare for the Bond Campaign-Brainstorming and preparing } \\
\text { for bond activities }\end{array}$ & 6 & 1 \\
\hline $\begin{array}{l}\text { 10. Select Consultants-e.g., architects, construction management, } \\
\text { engineers }\end{array}$ & 7 & 4 \\
\hline 11. Develop the Bond Calendar & 5 & 2 \\
\hline 12. Create Campaign Literature \& Organize Activities & 11 & 5 \\
\hline 13. Communicate with Media & 6 & 3 \\
\hline $\begin{array}{l}\text { 14. Utilize Contemporary Marketing Strategies-Facebook, Twitter, } \\
\text { blogs, gamification, YouTube videos }\end{array}$ & 11 & 10 \\
\hline \multicolumn{3}{|l|}{ During-the-Bond Campaign Strategies } \\
\hline $\begin{array}{l}\text { 15. Count Down to Election Day-Scheduled of events during a } 60 \\
\text { or } 90 \text {-day period }\end{array}$ & 10 & 3 \\
\hline 16. Celebrate the Win-Key media releases & 9 & 2 \\
\hline \multicolumn{3}{|l|}{ After-the-Bond Campaign Strategies } \\
\hline 17. Next Steps-Strategies to insure another win in 5-10 years & 12 & 2 \\
\hline
\end{tabular}

Contemporary marketing strategies consist of using social media and other

contemporary communication strategies in a communication plan targeting voters. Like the communication pretest and posttest, participants are not familiar with, or comfortable using, and need the most help with social media and contemporary marketing strategies. 
This correlates with findings of a 2010 AASA. Superintendents in focus groups said they wanted nothing to do with social media. They perceived social media as being potentially dangerous (as cited in Porterfield \& Carnes, 2012). Yet Twitter, Facebook, Pinterest, Flickr, Instagram, and Tumblr, for example, helped President Obama win the presidential re-election in 2012. At stake for school districts are potential "votes from citizens, particularly younger ones, who may not watch television or read the paper but spend plenty of time on the social Web" (Wortham, 2012, para. 3). Contemporary marketing strategies are important in passing a bond election.

\section{Summative evaluation of the results of the handbook's usefulness,}

effectiveness, and importance. After the review of the handbook Holding Successful School Bond Campaigns: Not for Dummies and participation in the workshop, participants' took the last survey, comprised of three areas, an evaluation of the handbook's usefulness, effectiveness, and importance. This was the second section of a four-section survey. In the first section, participants described their personal and school district demographic information (see Table 28).

Results of the handbook's usefulness. After review of the handbook and their participation in the workshop, participants assessed the usefulness of the handbook Holding Successful Bond Campaigns: Not for Dummies. Usefulness was defined as practical information for district leaders initiating a bond. Is the content fully developed with necessary details and examples?

Participants assessed the handbook by rating the usefulness of the handbook's content in the Introductory Sections, Communication Section, Pre-, During-, Post- 
Campaign Strategies, and Supplemental Information on a 1 to 4 scale for Usefulness of Content Information. After reviewing the handbook and after participating in the workshop, participants rated the usefulness of the handbook as presented in Table 35 . The majority of the participants perceived the handbook to be Useful or Most Useful in practical information with content fully developed with necessary details and examples. Comments from participants' supported the usefulness of the handbook, for example:

"The handbook is very useful for superintendents, board members, community bond leaders, and business managers."

"The handbook's content is well written with relevant examples and practical advice."

Three of the 16 participants marked 11. Conduct a Survey as not useful. Two of the 16 participants marked 2. Tale of Two Districts; 19. Celebrate the Win; and 24. References as not useful. No strategies were considered least useful.

Conducting a survey is an integral part of understanding what the community will support before a bond is placed on a ballot. Surveys should be part of the communication plan to always gauge what the public is thinking. If three participants' still believe that administering a survey is not useful, that may explain why so many districts are not successful in passing bond elections. They are not listening to their voters. A survey is the quickest and least expensive method of learning about the attitudes and beliefs of community members (Hughes \& Hooper, 2000). Fiore (2011) maintained that surveys should be conducted regularly to compare results from one year to the next as part of the district's communication plan to determine the image of the organization. Polling or 
survey data provide districts with important insights into the opinions of voters. Good polling data allow the superintendents and other district leaders to determine the ballot issue that will meet the needs of the district, while also addressing voter concerns about how much the bond will cost them (Fairbank, 2006).

“The Tale of Two Districts," while fictional, still provides a setting for the strategies described in the handbook. It not only introduces the struggles of passing a bond, but it also provides the solutions to passing a bond in an amusing manner. Only two participants out of 16 did not find it useful. However, a significant majority of 14 participants did find it useful.

References were also perceived as not useful by two participants. References are required to prevent academic violations such as plagiarism. References are also important to readers who would like to conduct additional research.

Table 35

Evaluation of the Usefulness of the Handbook

\begin{tabular}{|c|c|c|c|c|}
\hline \multicolumn{5}{|c|}{ School Bond Campaign Strategies } \\
Usefulness \\
\hline Handbook's Introductory Sections & $\begin{array}{c}\text { Least } \\
\text { Useful }\end{array}$ & $\begin{array}{c}\text { Not } \\
\text { Useful }\end{array}$ & Useful & $\begin{array}{c}\text { Most } \\
\text { Useful }\end{array}$ \\
\hline 1. Introduction & & 1 & 13 & 2 \\
\hline 2. Tale of Two Districts & & 2 & 11 & 3 \\
\hline 3. Review Communication Theory \& Practices & & & 9 & 7 \\
\hline $\begin{array}{l}\text { Pre-Bond Campaign Strategies } \\
\text { Foundation: Teaching and Learning } \\
\text { Connection-Connect construction } \\
\text { improvements to teaching and learning }\end{array}$ & & & & 6 \\
\hline $\begin{array}{l}\text { Evaluate School \& Community Relations- } \\
\text { Survey methods and feedback to assess } \\
\text { community perceptions }\end{array}$ & & & 9 & 6 \\
\hline 6. $\begin{array}{l}\text { Garner Support-Strategies to gain community } \\
\text { support }\end{array}$ & & 1 & & \\
\hline
\end{tabular}


Table 35 (continued)

\begin{tabular}{|c|c|c|c|c|}
\hline \multicolumn{5}{|c|}{$\begin{array}{l}\text { School Bond Campaign Strategies } \\
\text { Usefulness }\end{array}$} \\
\hline Handbook's Introductory Sections & $\begin{array}{l}\text { Least } \\
\text { Useful }\end{array}$ & $\begin{array}{c}\text { Not } \\
\text { Useful }\end{array}$ & Useful & $\begin{array}{l}\text { Most } \\
\text { Useful }\end{array}$ \\
\hline $\begin{array}{l}\text { 7. Create the Communications Plan-Systematic, } \\
\text { formal plan for communications with internal } \\
\text { and external stakeholders }\end{array}$ & & & 7 & 9 \\
\hline $\begin{array}{l}\text { 8. Enlist Key Community Leaders-Identification } \\
\text { and commitment of internal and external } \\
\text { stakeholders }\end{array}$ & & 1 & 8 & 7 \\
\hline $\begin{array}{l}\text { 9. Develop \& Publish the Long-Range Facilities } \\
\text { Plan }\end{array}$ & & & 9 & 6 \\
\hline 10. Identify Construction Projects \& Costs & & & 10 & 5 \\
\hline $\begin{array}{l}\text { 11. Conduct a Survey-Knowing what the public is } \\
\text { willing to support }\end{array}$ & & 3 & 8 & 5 \\
\hline $\begin{array}{l}\text { 12. Prepare for the Bond Campaign-Brainstorming } \\
\text { and preparing for bond activities }\end{array}$ & & 1 & 5 & 10 \\
\hline $\begin{array}{l}\text { 13. Select Consultants-e.g., architects, construction } \\
\text { management, engineers }\end{array}$ & & 1 & 9 & 5 \\
\hline 14. Develop the Bond Calendar & & & 10 & 6 \\
\hline $\begin{array}{l}\text { 15. Create Campaign Literature \& Organize } \\
\text { Activities }\end{array}$ & & & 10 & 6 \\
\hline 16. Communicate with Media & & & 11 & 5 \\
\hline $\begin{array}{l}\text { 17. Utilize Contemporary Marketing Strategies- } \\
\text { Facebook, Twitter, blogs, gamification, } \\
\text { YouTube videos }\end{array}$ & & & 7 & 7 \\
\hline \multicolumn{5}{|l|}{ During-the-Bond Campaign Strategies } \\
\hline $\begin{array}{l}\text { 18. Count Down to Election Day-Scheduled of } \\
\text { events during a } 60 \text { or } 90 \text {-day period }\end{array}$ & & 1 & 11 & 4 \\
\hline 19. Celebrate the Win-Key media releases & & 2 & 10 & 4 \\
\hline \multicolumn{5}{|l|}{ After-the-Bond Campaign Strategies } \\
\hline $\begin{array}{l}\text { 20. Next Steps-Strategies to insure another win in } \\
5-10 \text { years }\end{array}$ & & 1 & 11 & 4 \\
\hline \multicolumn{5}{|l|}{ Supplemental Information } \\
\hline 21. Epilogue & & 1 & 12 & 2 \\
\hline 22. Appendices & & & 6 & 10 \\
\hline 23. School Bond Campaign Links & & & 2 & 14 \\
\hline 24. References & & 2 & 9 & 5 \\
\hline
\end{tabular}

Results of the handbook's effectiveness. After review of the handbook and their

participation in the workshop, the same participants rated the effectiveness of the

handbook Holding Successful Bond Campaigns: Not for Dummies. Effectiveness was 
defined as being able to apply the information. Can this information be applied in your district?

Participants assessed the handbook by rating the effectiveness of the handbook's content in the Introductory Sections, Communication Section, Pre-, During-, PostCampaign Strategies, and Supplemental Information on a 1 to 4 scale for Effectiveness of Applying the handbook's information. Ratings were based on a 1-4 Likert-style scale with 1 being least effective and 4 being most effective. After reviewing the handbook and after participating in the workshop, participants rated the effectiveness of the handbook as presented in Table 36 .

The majority of the participants perceived the handbook to be Effective or Most Effective in participants' ability to apply the handbook's information in their school districts. Three commented on the efficacy of the handbook:

"Overall, the handbook is well done."

"A very well put together manual."

"Your range of topics and the step-by step nature of the handbook's organization are well done."

During the workshop one participant shared with me her district's work in preparing for an upcoming bond election. She and other district leaders had learned all they could about passing a bond by conducting research and talking with leaders in other districts who were successful. For 18 months she worked relentlessly toward the election. "Where was this book two years ago?" she asked. "Everything is here that I needed." 
Table 36

Evaluation of the Effectiveness of the Handbook

\begin{tabular}{|c|c|c|c|c|}
\hline \multicolumn{5}{|c|}{$\begin{array}{l}\text { School Bond Campaign Strategies } \\
\text { Effectiveness }\end{array}$} \\
\hline Handbook's Introductory Sections & $\begin{array}{c}\text { Least } \\
\text { Effective }\end{array}$ & $\begin{array}{c}\text { Not } \\
\text { Effective }\end{array}$ & Effective & $\begin{array}{c}\text { Most } \\
\text { Effective }\end{array}$ \\
\hline 1. Introduction & & 1 & 12 & 3 \\
\hline 2. Tale of Two Districts & & 3 & 7 & 6 \\
\hline 3. Review Communication Theory \& Practices & & & 8 & 8 \\
\hline \multicolumn{5}{|l|}{ Pre-Bond Campaign Strategies } \\
\hline $\begin{array}{l}\text { 4. Foundation: Teaching and Learning } \\
\text { Connection-Connect construction } \\
\text { improvements to teaching and learning }\end{array}$ & & 1 & 8 & 7 \\
\hline $\begin{array}{l}\text { 5. Evaluate School \& Community Relations- } \\
\text { Survey methods and feedback to assess } \\
\text { community perceptions }\end{array}$ & & & 10 & 6 \\
\hline $\begin{array}{l}\text { 6. Garner Support-Strategies to gain community } \\
\text { support }\end{array}$ & & & 9 & 7 \\
\hline $\begin{array}{l}\text { 7. Create the Communications Plan-Systematic, } \\
\text { formal plan for communications with internal } \\
\text { and external stakeholders }\end{array}$ & & & 9 & 7 \\
\hline $\begin{array}{l}\text { 8. Enlist Key Community Leaders-Identification } \\
\text { and commitment of internal and external } \\
\text { stakeholders }\end{array}$ & & 1 & 10 & 5 \\
\hline $\begin{array}{l}\text { 9. Develop \& Publish the Long-Range Facilities } \\
\text { Plan }\end{array}$ & & 1 & 9 & 6 \\
\hline 10. Identify Construction Projects \& Costs & & 1 & 9 & 6 \\
\hline $\begin{array}{l}\text { 11. Conduct a Survey-Knowing what the public is } \\
\text { willing to support }\end{array}$ & & 2 & 11 & 3 \\
\hline $\begin{array}{l}\text { 12. Prepare for the Bond Campaign-Brainstorming } \\
\text { and preparing for bond activities }\end{array}$ & & & 6 & 10 \\
\hline $\begin{array}{l}\text { 13. Select Consultants-e.g., architects, construction } \\
\text { management, engineers }\end{array}$ & & & 12 & 4 \\
\hline 14. Develop the Bond Calendar & & & 9 & 7 \\
\hline $\begin{array}{l}\text { 15. Create Campaign Literature \& Organize } \\
\text { Activities }\end{array}$ & & & 12 & 4 \\
\hline 16. Communicate with Media & & 2 & 7 & 7 \\
\hline $\begin{array}{l}\text { 17. Utilize Contemporary Marketing Strategies- } \\
\text { Facebook, Twitter, blogs, gamification, } \\
\text { YouTube videos }\end{array}$ & & 2 & 7 & 7 \\
\hline \multicolumn{5}{|l|}{ During-the-Bond Campaign Strategies } \\
\hline $\begin{array}{l}\text { 18. Count Down to Election Day-Scheduled of } \\
\text { events during a } 60 \text { or } 90 \text {-day period }\end{array}$ & & & 9 & 7 \\
\hline 19. Celebrate the Win-Key media releases & & & 9 & 7 \\
\hline
\end{tabular}


Table 36 (continued)

\begin{tabular}{|l|c|c|c|c|}
\hline \multicolumn{5}{|c|}{$\begin{array}{c}\text { School Bond Campaign Strategies } \\
\text { Effectiveness }\end{array}$} \\
\hline After-the-Bond Campaign Strategies & $\begin{array}{c}\text { Least } \\
\text { Effective }\end{array}$ & $\begin{array}{c}\text { Not } \\
\text { Effective }\end{array}$ & Effective & $\begin{array}{c}\text { Most } \\
\text { Effective }\end{array}$ \\
\hline $\begin{array}{l}\text { 20. Next Steps-Strategies to insure another win in } \\
\text { 5-10 years }\end{array}$ & & & 11 & 4 \\
\hline Supplemental Information & & & & \\
\hline 21. Epilogue & & 2 & 11 & 3 \\
\hline 22. Appendices & & & 8 & 7 \\
\hline 23. School Bond Campaign Links & & & 5 & 11 \\
\hline 24. References & & & 8 & 7 \\
\hline
\end{tabular}

Three out of 16 participants marked 2. Tale of Two Districts as not effective. Two out of 16 participants marked 11. Conduct a Survey; 16. Communicate with Media; 17. Utilize Contemporary Marketing Strategies; and 21. Epilogue as not effective. No strategies were considered least effective.

Results of the handbook's importance. After review of the handbook and their participation in the workshop, the same participants assessed the importance of the handbook Holding Successful Bond Campaigns: Not for Dummies. Importance was defined as meeting the district's needs at this time. Is this strategy important to the needs of your district? Participants assessed the handbook by rating the importance of the handbook's content in the Introductory Sections, Communication Section, Pre-, During-, Post-Campaign Strategies, and Supplemental Information on a 1 to 4 scale for Importance of the participants' district needs. Ratings are based on a 1-4 Likert-style scale with 1 being least important and 4 being most important. After reviewing the handbook and after participating in the workshop, participants rated the importance of the handbook to the needs of their district as shown in Table 37. 
Table 37

Evaluation of the Importance of the Handbook

\begin{tabular}{|c|c|c|c|c|}
\hline \multicolumn{5}{|c|}{$\begin{array}{l}\text { School Bond Campaign Strategies } \\
\text { Importance }\end{array}$} \\
\hline Handbook's Introductory Sections & $\begin{array}{c}\text { Least } \\
\text { Important }\end{array}$ & $\begin{array}{c}\text { Not } \\
\text { Important }\end{array}$ & Important & $\begin{array}{c}\text { Most } \\
\text { Important }\end{array}$ \\
\hline 1. Introduction & & 3 & 7 & 3 \\
\hline 2. Tale of Two Districts & & 3 & 8 & 3 \\
\hline 3. Review Communication Theory \& Practices & & & 8 & 6 \\
\hline \multicolumn{5}{|l|}{ Pre-Bond Campaign Strategies } \\
\hline $\begin{array}{l}\text { 4. Foundation: Teaching and Learning } \\
\text { Connection-Connect construction } \\
\text { improvements to teaching and learning }\end{array}$ & & & 7 & 7 \\
\hline $\begin{array}{l}\text { 5. Evaluate School \& Community Relations-- } \\
\text { Survey methods and feedback to assess } \\
\text { community perceptions }\end{array}$ & & & 9 & 5 \\
\hline $\begin{array}{l}\text { 6. Garner Support-Strategies to gain community } \\
\text { support }\end{array}$ & & & 8 & 6 \\
\hline $\begin{array}{l}\text { 7. Create the Communications Plan-Systematic, } \\
\text { formal plan for communications with internal } \\
\text { and external stakeholders }\end{array}$ & & & 6 & 8 \\
\hline $\begin{array}{l}\text { 8. Enlist Key Community Leaders-Identification } \\
\text { and commitment of internal and external } \\
\text { stakeholders }\end{array}$ & 1 & & 6 & 7 \\
\hline $\begin{array}{l}\text { 9. Develop \& Publish the Long-Range Facilities } \\
\text { Plan }\end{array}$ & 1 & & 6 & 7 \\
\hline 10. Identify Construction Projects \& Costs & 1 & & 7 & 6 \\
\hline $\begin{array}{l}\text { 11. Conduct a Survey-Knowing what the public is } \\
\text { willing to support }\end{array}$ & & 2 & 5 & 7 \\
\hline $\begin{array}{l}\text { 12. Prepare for the Bond Campaign-Brainstorming } \\
\text { and preparing for bond activities }\end{array}$ & & & 6 & 8 \\
\hline $\begin{array}{l}\text { 13. Select Consultants-e.g., architects, construction } \\
\text { management, engineers }\end{array}$ & 1 & & 8 & 5 \\
\hline 14. Develop the Bond Calendar & & 1 & 7 & 6 \\
\hline $\begin{array}{l}\text { 15. Create Campaign Literature \& Organize } \\
\text { Activities }\end{array}$ & & 1 & 7 & 6 \\
\hline 16. Communicate with Media & & 1 & 7 & 6 \\
\hline $\begin{array}{l}\text { 17. Utilize Contemporary Marketing Strategies- } \\
\text { Facebook, Twitter, blogs, gamification, } \\
\text { YouTube videos }\end{array}$ & & & 9 & 5 \\
\hline \multicolumn{5}{|l|}{ During-the-Bond Campaign Strategies } \\
\hline $\begin{array}{l}\text { 18. Count Down to Election Day-Scheduled of } \\
\text { events during a } 60 \text { or } 90 \text {-day period }\end{array}$ & & & 9 & 5 \\
\hline 19. Celebrate the Win-Key media releases & & 1 & 7 & 6 \\
\hline \multicolumn{5}{|l|}{ After-the-Bond Campaign Strategies } \\
\hline $\begin{array}{l}\text { 20. Next Steps-Strategies to insure another win in } \\
5-10 \text { years }\end{array}$ & & & 8 & 6 \\
\hline
\end{tabular}


Table 37 (continued)

\begin{tabular}{|l|c|c|c|c|}
\hline \multicolumn{5}{|c|}{$\begin{array}{c}\text { School Bond Campaign Strategies } \\
\text { Importance }\end{array}$} \\
\hline Supplemental Information & $\begin{array}{c}\text { Least } \\
\text { Important }\end{array}$ & $\begin{array}{c}\text { Not } \\
\text { Important }\end{array}$ & Important & $\begin{array}{c}\text { Most } \\
\text { Important }\end{array}$ \\
\hline 21. Epilogue & 1 & 1 & 8 & 4 \\
\hline 22. Appendices & & & 8 & 5 \\
\hline 23. School Bond Campaign Links & & & 6 & 8 \\
\hline 24. References & & 1 & 7 & 6 \\
\hline
\end{tabular}

The majority of the participants perceived the handbook to be Important or Most Important to their district's needs. One participant said: "Thanks for the good work on this, a very useful handbook that fills an important gap." Another said: “A small district doesn't have to hire a consultant if it has this manual."

Three out of the 16 participants marked 1. Introduction, and 2. Tale of Two Districts, as not important to the needs of their district. Two of the 16 participants marked 11. Conduct a Survey as not important. One participant, not necessarily the same participant, identified five of the handbook's strategies or items as least important to:

8. Enlist Key Community Leaders

9. Develop \& Publish the Long-Range Facilities Plan

10. Identify Construction Projects \& Costs

13. Select Consultants

21. Epilogue

Four of the listed items $(8,9,10$, and 13) are actual strategies that would aid a district in passing a bond election. For example, Fiore (2011) stated the importance of identifying key communicators from each external group. They will act as "opinion leaders who influence the directions and actions of the various community organizations" (pp. 120121). 
Develop and Publish the Long-Range Facilities Plan is of primary importance. Without a long-range plan, how can a district ask voters to support a bond? On what is the bond based? This professional plan, generally spearheaded by an architectural or engineering firm, provides the specific structural, engineering, life expectancy, remodeling specifications, and estimated costs of construction needed to present to the public. It also provides a direction for the school district on how to manage projects. At the very basic level, a facilities plan is a requirement to begin the first discussions of a bond election. From the facilities plan, the district, in collaboration with its internal and external constituents, will then determine priorities and the Construction Projects \& Costs.

Selecting Consultants is of utmost importance to a district that plans a bond election. A district can hire the consultants before or after the election. When I passed the Ontario bond, we waited until after the election to hire the architects, construction management company, and engineers. The drawback was that we were not prepared to begin construction until nine months after the election. The public wanted to see results quickly: at the very least, breaking ground on projects. That cannot be the case if a district waits until after the election to hire.

The Epilogue is similar to the Introduction and "The Tale of Two Districts." It does not directly describe the campaign strategies. However, the Epilogue in the handbook is discouraging because it deals with not being successful at the polls. It does answer the question, "What steps should be taken after the district loses its bond 
election?" Not all participants want to deal with the disappointment of a failed bond when they are seeking the strategies to win an election.

Summative evaluation of the results of the handbook's format and style. This is the third section of a four-section survey, the handbook's format and style. Participants were instructed to rate their level of agreement to the survey statements about the Format and Style of the handbook as shown in Table 34. Format and style are defined as the way the contents are presented: structure, method, and form. Structure has to do with the order of the contents. The order of the contents must be logical, and users must be able to quickly find the section they need. Method has to do with readability and whether the text is readable. Are the contents presented in a way so that the user can easily read and understand the information? Form has to do with the presentation of the contents. The contents and pictures must be attractive and the text should be presented in a way that involves the reader.

Participants were asked to rate their level of agreement to a series of statements about the handbook's format and style. Ratings were based on a 1-4 Likert-style scale with 1 being strongly disagree and 4 being in strongly agree with the statement. After reviewing the handbook and after participating in the workshop, participants rated their level of agreement to the survey statements about the format and style of the handbook.

A majority of the participants strongly agreed with all but five of the statements about the format and style of the handbook (see Table 38). Two statements garnered disagreement: 4. The "Tale of Two Districts" adds humor, with five participants rating 
disagreement and 23. Reflection pages help the reader to process the material, with four participants rating disagreement.

Table 38

\section{Evaluation of Format and Style of the Handbook}

\begin{tabular}{|c|c|c|c|c|}
\hline Format \& Style of the Handbook & $\begin{array}{l}\text { Strongly } \\
\text { Disagree }\end{array}$ & Disagree & Agree & $\begin{array}{l}\text { Strongly } \\
\text { Agree }\end{array}$ \\
\hline 1. The title of the handbook captures my interest. & & & 6 & 9 \\
\hline 2. The title reflects the contents of the handbook. & & & 6 & 9 \\
\hline 3. The introduction compels me to read further. & & 1 & 6 & 8 \\
\hline 4. The "Tale of Two Districts" adds humor. & & 5 & 5 & 5 \\
\hline $\begin{array}{l}\text { 5. The "Tale of Two Districts" introduces } \\
\text { important concepts. }\end{array}$ & & 2 & 7 & 6 \\
\hline 6. Information is in the right order. & & & 8 & 7 \\
\hline 7. Information is easy to find. & & & 6 & 9 \\
\hline 8. The text is easy read. & & & 6 & 9 \\
\hline 9. Illustrations/visuals make sense. & & & 7 & 8 \\
\hline 10. Illustrations/visuals add interest. & & 2 & 5 & 8 \\
\hline $\begin{array}{l}\text { 11. Titles and subtitles help the reader understand } \\
\text { the text. }\end{array}$ & & & 7 & 8 \\
\hline 12. Quotes support the content. & & & 5 & 10 \\
\hline $\begin{array}{l}\text { 13. The table of contents is arranged in the right } \\
\text { order. }\end{array}$ & & & 5 & 10 \\
\hline 14. The table of contents is easy to use. & & & 5 & 10 \\
\hline $\begin{array}{l}\text { 15. The language of the handbook is simple } \\
\text { enough for all users. }\end{array}$ & & & 4 & 10 \\
\hline $\begin{array}{l}\text { 16. The language of the handbook is advanced } \\
\text { enough to keep readers' interested. }\end{array}$ & & & 5 & 10 \\
\hline $\begin{array}{l}\text { 17. The vocabulary aligns with the abilities of the } \\
\text { reader. }\end{array}$ & & & 5 & 10 \\
\hline 18. Sentences are short and clear. & & & 7 & 8 \\
\hline $\begin{array}{l}\text { 19. The writing style is similar to everyday } \\
\text { reading in newspapers, magazines, or books. }\end{array}$ & & 1 & 7 & 7 \\
\hline 20. Layout is designed well. & & & 6 & 9 \\
\hline 21. Layout is visually pleasing. & & & 7 & 8 \\
\hline $\begin{array}{l}\text { 22. Adequate space is available for the reader to } \\
\text { plan or take notes. }\end{array}$ & & & 4 & 11 \\
\hline $\begin{array}{l}\text { 23. Reflection pages help the reader to process the } \\
\text { material. }\end{array}$ & & 4 & 3 & 8 \\
\hline $\begin{array}{l}\text { 24. The handbook's contents are understood } \\
\text { without a workshop. }\end{array}$ & & 1 & 8 & 6 \\
\hline
\end{tabular}

"The Tale of Two Districts" is set up as a satire, strongly dependent on hyperbole

to teach a lesson. The first tale describes a superintendent who does everything wrong in 
his attempt to pass a bond election. The second tale describes an ideal or model superintendent who passes a bond. Humor based on satire is not slapstick humor but a dark humor that drives home a real lesson. Some participants may not have understood this definition of humor. The survey statement then should be reworded. Some participants found the first tale more tragic than humorous.

The disagreement that four participants perceived with the second statement, 23. Reflection pages help the reader process the material, may be reflective of participants not having more time to work in groups to write responses to the questions. Reflection pages help the reader to process the material, take notes, and then plan strategies specific to each individual district. An interesting note is that I added additional pages for reflection and notes as a result of the Preliminary field test formative evaluation. Participants asked for more space to reflect and write.

An important statement for me is 24 . The handbook's contents are understood without a workshop. It answers the research question, "Can the handbook stand alone as a viable source?" Only one participate disagreed out of 16 who took the survey, which is a significantly high approval rating. This supports the overall efficacy of the handbook.

Additionally, it is also a critical finding if I plan to publish the handbook, which is a consideration in chapter 5 . This means, for me as the author of the handbook, that the contents are self-explanatory and that it does not require the support of a workshop to provide supplemental information.

Summative evaluation of the results of the workshop. This is the fourth section of a four-section survey, evaluation of the workshop. Participants were instructed to rate 
their level of agreement to the survey statements about the workshop as shown in Table 39. Statements were categorized under workshop content, design, facilitator, results, and presentation. A separate section asked participants how they would improve this workshop. Improvement to the handbook and workshop are discussed in the formative evaluation section in chapter 5 .

Participants were asked to rate their level of agreement to a series of statements in each section. Ratings were based on a 1-4 Likert-style scale with 1 being Strongly Disagree and 4 being Strongly Agree with each statement. After participating in the workshop, participants rated their level of agreement to the survey statements about the workshop.

The majority of participants either agreed or strongly agreed with each statement totaling 14 to 16 participants in agreement with all statements except one statement. Four participants disagreed with statement 17 . I would attend another workshop on this topic. The statement is somewhat ambiguous in that the workshop either did not meet expectations or that the workshop fulfilled expectations. 
Table 39

Evaluation of the Workshop

\begin{tabular}{|c|c|c|c|c|}
\hline \multicolumn{5}{|l|}{ Workshop Evaluation } \\
\hline Workshop Content & $\begin{array}{l}\text { Strongly } \\
\text { Disagree }\end{array}$ & Disagree & Agree & $\begin{array}{c}\text { Strongly } \\
\text { Agree }\end{array}$ \\
\hline $\begin{array}{l}\text { 1. I was well informed about the objectives of } \\
\text { this workshop. }\end{array}$ & & 2 & 6 & 7 \\
\hline 2. This workshop lived up to my expectations. & & 1 & 6 & 8 \\
\hline 3. The content is relevant to my job. & & & 5 & 10 \\
\hline \multicolumn{5}{|l|}{ Workshop Design } \\
\hline 4. The workshop objectives were clear to me. & & 2 & 4 & 9 \\
\hline $\begin{array}{l}\text { 5. The workshop activities stimulated my } \\
\text { learning. }\end{array}$ & & 1 & 6 & 8 \\
\hline $\begin{array}{l}\text { 6. The activities in this workshop gave me } \\
\text { sufficient practice and feedback. }\end{array}$ & & 1 & 9 & 4 \\
\hline $\begin{array}{l}\text { 7. The difficulty level of this workshop was } \\
\text { appropriate. }\end{array}$ & & 2 & 6 & 7 \\
\hline 8. The pace of this workshop was appropriate. & & 2 & 8 & 5 \\
\hline \multicolumn{5}{|l|}{ Workshop Facilitator } \\
\hline 9. The facilitator was well prepared. & & & 5 & 10 \\
\hline 10. The facilitator was helpful. & & & 3 & 12 \\
\hline 11. The facilitator was knowledgeable. & & & 2 & 13 \\
\hline \multicolumn{5}{|l|}{ Workshop Results } \\
\hline $\begin{array}{l}\text { 12. I accomplished the objectives of this } \\
\text { workshop. }\end{array}$ & & & 10 & 5 \\
\hline $\begin{array}{l}\text { 13. I will be able to use what I learned in this } \\
\text { workshop. }\end{array}$ & & & 3 & 12 \\
\hline \multicolumn{5}{|l|}{ Content Presentation } \\
\hline $\begin{array}{l}\text { 14. The workshop was a good way for me to } \\
\text { learn this content. }\end{array}$ & & 2 & 7 & 6 \\
\hline $\begin{array}{l}\text { 15. The content is best learned through the } \\
\text { workshop. }\end{array}$ & & 1 & 7 & 6 \\
\hline 16. I would like to learn more about this topic. & & 1 & 9 & 5 \\
\hline $\begin{array}{l}\text { 17. I would attend another workshop on this } \\
\text { topic. }\end{array}$ & & 4 & 6 & 5 \\
\hline
\end{tabular}

Of note are two participants who disagreed with 1 . I was well informed about the

objectives of this workshop and who disagreed with 4. The workshop objectives were

clear to me. The negative rating for these two statements could be attributed to two to

four different participants. I listed the objectives in the syllabus. All participants received

a copy of the syllabus when they registered. At the beginning of the workshop, I 
reviewed the objectives during the PowerPoint presentation. While two to four participants disagreed with being informed of the objectives and the clarity of the objectives, $100 \%$ of the participants either agreed or strongly agreed with 12 . I accomplished the objectives of this workshop. Can participants accomplish the objectives if participants do not know what the objectives are or if objectives are not clear?

Participants agreed or strongly agreed with all statements under Workshop Facilitator and Workshop Results (see Table 39). However, excluding the ones already discussed, there were one to two of the 16 participants who disagreed with eight statements:

2. This workshop lived up to my expectations.

5. The workshop activities stimulated my learning.

6. The activities in this workshop gave me sufficient practice and feedback.

7. The difficulty level of this workshop was appropriate.

8. The pace of this workshop was appropriate.

14. The workshop was a good way for me to learn this content.

15. The content is best learned through the workshop.

16. I would like to learn more about this topic.

The majority of participants either agreed or strongly agreed with the eight statements. In the five statements in the two sections Workshop Facilitator and Workshop Results, all 16 of the participants agreed or strongly agreed with all statements. In all but one of the five, the majority of participants' strongly agreed with the statements. Number 13, I will be able to use what I learned in this workshop, is important for me to know. That means that not only were all participants knowledgeable about campaign strategies, but they were also equipped to apply them.

Overall, the evaluation of the workshop was a positive experience for the participants and for me. Participants perceived the workshop to be a viable and useful 
training that would help prepare them to lead a bond election, and I appreciated my work being validated.

\section{Chapter Summary}

Holding Successful Bond Campaigns: Not for Dummies is a handbook developed for district leaders to conduct successful bond elections. The purpose of this study was to determine the efficacy of the handbook. The research study was theoretically grounded in PBL as defined by Bridges and Hallinger (1995) and Borg and Gall's (1989) R\&D. Chapter 4 followed Borg and Gall's Steps 1-7 of the R\&D process. The process included a series of steps that initiated input from key participants in order to improve the product or handbook.

In Step 1, I researched and collected information, and drafted the handbook. In Step 2, the handbook first was tested using "Small-scale testing." Small-scale testing consisted of interviewing four district leaders who recently passed a bond election. After district leaders reviewed the handbook, I interviewed them and used the feedback to further develop the handbook, which was Step 3.

In Step 4, I conducted the Preliminary field test. In the Preliminary field test, I invited district leaders to participate in a half-day mini workshop. The handbook was used extensively, and participants were surveyed before and after the workshop in a selfassessment of learning and on the usefulness, effectiveness, and importance of both the workshop and the handbook. Observation and survey data were used for product revision or Step 5 of the R\&D cycle. These data were used to improve the product to prepare for the final step of my research, Step 6, Main field testing. 
In Step 6, the Main field test, a full-day workshop was offered. As in Step 4, I surveyed participants before and after the workshop in a self-assessment of their learning and on the usefulness, effectiveness, and importance of both the workshop and the handbook and used the data for the final edit of the handbook, which was Step 7 of the $\mathrm{R} \& \mathrm{D}$ cycle.

Chapter 4 analyzed the steps in the R\&D cycle used to develop, field test, and revise the handbook Holding Successful Bond Campaigns: Not for Dummies. The chapter is divided into four major sections. The first section of chapter 4 reviewed the research questions and goals considered in conducting the research and the general design of the project. The second section described my experience through Step 6 of the R\&D process, including the development and implementation or field testing of the PBL project. The third section provided a summative evaluation of the results of the field testing. The fourth section focused on the formative assessment of the evaluation results.

Discussion of Step 7, Final product revision; field testing issues, concerns, and challenges of the study; speculations about future research, development, and use of the product; and recommendations for leadership are discussed in chapter 5 . 


\section{CHAPTER V}

\section{CONCLUSIONS, SPECULATIONS, AND RECOMMENDATIONS FOR LEADERSHIP}

Seventy percent of public schools in the United States are in need of major repairs and remodeling (Picus, n.d.). But in Oregon only about $60 \%$ of districts pass their construction bond elections (OSBA, 2013a). Handbooks and literature on passing bond elections are severely limited. I developed the handbook Holding Successful School Bond Campaigns: Not for Dummies to fill an educational need. Superintendents and other school district leaders need access to strategies that ensure passage of bond elections.

Sixteen superintendents and other district leaders, who were planning a construction bond election, took part in the Step 6, Main field test. The Main field test involved "implementation of the new product or handbook and a collection of data concerning its application" (Bridges \& Hallinger, 1995, p. 122). Product revision was then based on the analysis of data collected during the Main field test. I assessed the handbook using both summative and formative evaluation methods. According to Bridges and Hallinger (1995), summative assessment data evaluates the efficacy of the handbook, and formative assessment data points to ways in which I can improve the handbook.

In Step 6, I included participants in a pretest and posttest that served as a selfassessment of their knowledge and understanding of communications theory and bond campaign strategies. The pretest and posttest evaluated participants' assessment of their 
level of familiarity and comfort with communication theory and practices and campaign strategies and which strategies they perceived as needing the most help. The selfassessments took place before and after the workshop that used the handbook Holding Successful School Bond Campaigns: Not for Dummies as its exclusive resource. After completion of the workshop, participants were administered a final survey to evaluate the handbook's usefulness, effectiveness, and importance and its format and style. The last section of the survey included questions about participants' perception of the workshop. The evaluation provided summative feedback on the handbook's efficacy and formative feedback on improvements.

Chapter 5 describes the conclusions of the study on the handbook, Holding Successful School Bond Campaigns: Not for Dummies. This chapter determines the efficacy of the handbook and Step 7 revisions. I describe the revisions of handbook and improvements to the workshop, the overall conclusions and assessment of the experience, speculations about future research, development, and use of the product, Steps 8-10, and recommendations for leadership.

\section{Revisions of the Handbook and Workshop}

Borg and Gall's Step 7, Operational product revision, is based on the results of the Main field test. The handbook was assessed using four primary research questions to determine its efficacy and to guide improvements:

1. What is the usefulness of the handbook to district leaders embarking on a school bond election?

2. How effective is the handbook to district leaders embarking on a school bond election?

3. How important is the handbook to district leaders embarking on a school bond election? 
4. What is the perceived impression of the handbook's format and style?

The idea of the handbook was borne out of a severe need, almost a desperate need, of school district leaders' inability to pass construction bond elections. Since 1996, I have observed superintendents' frustration of not having the right tools, knowledge, or skills to pass a bond. Each time an election fails, it weighs heavily on superintendents' self-perception as described in Superintendent Young's experience in "The Tale of Two Districts." The superintendent in the first tale perceived that the school community no longer supported his efforts, and his leadership was no longer effective. Seeking employment elsewhere was the next logical step. Unfortunately, this scenario is often too close to the reality of superintendent turnover.

OSBA workshops on passing bond elections do not provide the entire picture or the steps needed to conduct a bond campaign. While the OSBA Bonds and Ballots workshop offers several sessions with presenters from public relations firms, construction management companies, architectural firms, and the like, there is no session that ties all of these together so that novice or even seasoned superintendents and district leaders know where to begin and progress through steps to ensure a successful a bond election. Besides incomplete information in workshops, the literature on passing a bond election is likewise limited. That is why I wrote the handbook Holding Successful School Bond: Not for Dummies and why the response of workshop participants was so favorable.

While the survey results clearly support the efficacy of the handbook, participants in the study also provided feedback to improve the handbook. To understand the progression of improvements to the handbook, a description of the revisions made during 
Steps 3, 5, and 7-Develop preliminary form of the product, Main product revision, and Operational product revision-is necessary. First, however, I describe the development of the first draft of the handbook.

\section{Launching of the Handbook}

The initial draft of the handbook was a much shorter version than the finished document. It started out with just more than 70 pages that included "The Tale of Two Districts" and 16 strategies with narratives. Each of the 16 strategies was first introduced with a cover sheet that listed the actions necessary to fully apply the strategy. The questions following the narrative served to guide district leaders in a self-reflective exercise. The objective was for superintendents or other district leaders to review and assess their current practices and then develop a plan to transform or alter their practices. Besides functioning as a handbook, it would also serve as a workbook.

In the initial draft of the handbook, I also included an addendum of items or examples that I planned to use to illustrate the strategies. If a reader needed additional information while reviewing the strategies, the reader would be directed to the back of the handbook for examples.

The design of the handbook was my own creation. I wanted a repetitive design to brand the book, so I played around with shapes. The intended outcome of using the strategies in the book was about passing a bond election to build or remodel schools. My first inclination was to structure a design with bricks like building blocks or steps but soon realized the image was overused, so I scrapped that idea. Then I experimented with basic architectural shapes of squares, rectangles, and triangles. I liked that idea and 
created a repetitive image of those shapes overlapping each other. The reason to overlap was also to show how dependent the strategies in the book were on each other. All strategies had to work together or fit just right in order to pass a bond election.

I also wanted muted, abstract pictures, or images in each section to connect with the theme of the book or with the subject of that particular section. Many of the photos and images are ones that my husband shot or ones that I found on in Microsoft Office. I used Photoshop extensively to artistically change the pictures so they became representations or symbols instead of realistic pictures of buildings or people.

Color choice was also deliberate. I chose colors that would match a typical color scheme of current new construction. I chose grays, golds, and tans for the cover with bluish-gray for color contrast. The colors throughout the handbook reflect a more neutral palette with no flashy tones that might distract more conservative readers.

The title of the handbook took much consideration although my first full draft of the handbook contained the current title. Depending on the branding design, the title would imitate the design. My first title, Steps to Success or Steps to a Successful Bond Election, would be characterized by bricks arranged as steps on the cover. But it seemed boring and did not reflect the creativity that I envisioned. My next thought was simply Holding Successful School Bond Campaigns. That too seemed dull and common.

But inspiration hit me. As I was reviewing literature for this dissertation, I discovered a book I used for an administrative leadership class I taught, Communicating Effectively for Dummies (Brounstein, 2001). Multiple books have been published with the designation of for dummies in their title. I did not want a title that would be associated 
with those bright yellow and black dummy books. I wanted something more original. Besides, there was nothing easy about passing a bond campaign, so I conceived of the current title Holding Successful School Bond Campaigns: Not for Dummies. Then I captured the word NOT in a box to link the title to the branding image. It added a touch of humor to attract the reader's attention to the handbook.

With a rough draft of my product completed, my next step was Small-scale testing.

\section{Step 3: Develop Preliminary Form of the Product}

The Step 2, Small-scale testing interviews with key district leaders provided rich guidance to improve and further develop the handbook. Thomas, superintendent of a 13,000 student school district, pointed out several improvement areas. First, he questioned a statement printed in the section Create Campaign Literature. I erroneously stated that board members were held to the same elections law standards as employees of the school district. He pointed out the ORS 260.432 statute that states: "An elected official may give political presentations and speeches, so long as no public employee work time is utilized" (Brown, 2012b, p. 6). However, as long as board members are not using district staff time or resources, they can advocate for passage of measures they vote to put on the ballot (OSBA, 2009). "An elected official may engage in political activity during work time. Elected officials are not considered public employees for the purposes of ORS 260.432" (Brown, 2012b, p. 8). I made immediate changes to the handbook to reflect this information and included the statute as reference in several sections of the handbook. 
Thomas also provided beneficial information in three other areas: Develop and Publish the Long Range Plan, Conduct a Survey, and District Owners Team. For facilities planning, he cited a statute that guides long-range planning for large school districts, defined as districts with an enrollment of more than 2,500, ORS 195-110. A city or county with a large school district must include the school district's long-range plan, described as 10 or more years, in the city or county's comprehensive plan. The plan must be prepared by the district in consultation with the affected city or county. This was new and valuable information to me, and I added that statute to the section in the handbook about long-range planning.

In the section Conduct a Survey, which describes surveying the public and polling, Thomas provided two observations that offered useful information: If surveys are paid for with district funds, then the results are public. Public entities, including campaign opposition groups, can request copies of the information. If a non-profit group such as the campaign committee or other advocacy group pays for the surveys or polling, then the data are owned by that group. Oregon Public Records Law, ORS 192.410 to 192.505, substantiates Thomas' advice and does not apply to private entities such as nonprofit corporations (Kroger, 2011). I added this information to the handbook.

Thomas noticed that the handbook mentioned the District Owners Team pages before District Owners Team was defined and suggested that that group be described earlier, which I did. Although Thomas' interview was short, he provided crucial information, strengthening the efficacy and integrity of the handbook. 
Robert's advice centered on facilities planning, communication, and election laws. As a communications director for a large school district, he experienced both a failed bond and a victorious one. He shared what he considered the most important part of passing a bond: a full facilities plan, prioritization of the plan, and choosing only the top projects for a bond. He cautioned that being greedy and attempting to do all projects at once just might alienate the voters. Communication of the facilities plan, priorities, and project costs was essential to pass the bond, and the communication must be brief, accurate, and simple to understand.

Robert did caution that any elections law violations, while only a slap on the wrist from the state, is magnified tenfold by public perception. He instructed: "Don't go there. Have all publications reviewed by Kate Brown's office.” Secretary of State Kate Brown is Oregon's chief elections officer who interprets and applies state election laws. Robert's ideas either enhanced or added new information to the corresponding sections of the handbook, and communication emerged as a key component of passing his district's bond. The elections law ORS was likewise cited in several sections of the handbook to call attention to the magnitude of not following the elections law.

Kathy, superintendent of a 5,500 student school district, liked the idea of the handbook so much that she saw very little to improve. She was ecstatic that a handbook was developed to help superintendents. Her only suggestion was to change the order of some of the sections. Since the sections do not have to be in any particular order, I did not make any changes. She did confirm the need for a communication plan for most sections of the handbook. 
Joyce, the district's business and operations manager, emphasized the importance of the section on Next Steps. Celebration was a fundamental component in her district's communication plan after a successful bond election. Her district had developed a fourphased approach to its facilities plan and needed the voters to support another bond election in five years. Phasing in the facilities plan, rather than asking voters for all projects at once, is an effective strategy in passing a bond (Holt, 2002). A lot of "pomp and circumstance," as she described it, around ground breaking and open houses were scheduled. District leaders knew that sustained support from the district's internal and external constituents would be crucial to its passing a bond again in 5 years. A strategic communications plan was essential to make this happen.

I quickly became aware that a common theme from the interviews meant that I needed a great deal more information on communication in the handbook. A simple, onepage summary would not suffice. As a result, I added a comprehensive section on communication to introduce the handbook: Review of Communication Theory and Practices. This 40-page section presents organizational theory, school community relations, and marketing strategies. It may serve as review for most school district superintendents and other district leaders, but it provides essential information to school board members, citizens, and others working toward passing a bond election. "Communication is the key to why referendums [school bond elections] pass or fail" (Fritz, 2012). 


\section{Step 5: Main Product Revisions}

With an improved product after the Small-scale testing, the handbook was ready for the next step, Step 4, Preliminary field testing. Three superintendents, a principal, and a communication director participated in the workshop to test the handbook. This section describes revisions to the handbook and to the workshop after Step 4.

Main product revisions: The handbook. Results of the survey on the usefulness, effectiveness, and importance of the handbook's introductory sections, prebond, during the bond, after the bond campaign strategies, and supplementary information pointed to a few key issues that required revision in the handbook. I rewrote the Epilogue, changed the title of "Artifacts" to "Appendices" and added additional information to the Appendices.

The Epilogue focused on steps to take when a bond election fails. It did not communicate a pleasant message. No one wants to fail especially when everyone has worked so hard. I rewrote it so the next steps are more obvious.

Originally, the handbook was going to include a variety of artifacts in the back of the handbook, but I soon realized obtaining permission from so many sources would take an excessive amount of time and create an even lengthier handbook. In the Preliminary field test, I included a limited number of artifacts that were narrow in focus. Most involved some facet of Oregon elections and ethics laws. After reviewing the survey results in which at least one participant rated Artifacts in each research question as not useful, not effective, and not important, I decided to provide links to specific information 
and websites instead and add a reference section. I also added a section with definitions of key vocabulary and an expanded references section.

For some reason, the Introduction was also cited by at least one participant in each section of the survey as Not Useful, Not Effective, and Not Important. I rationalized that the introduction was not that useful, effective, or important specifically to school districts passing a bond, but it did serve the purpose of offering the reader a glimpse of what the handbook offered. Every book contains an introduction. The majority of participants did see the Introduction as useful, effective, and important. So I decided to preserve the Introduction without improvements and examine whether the Main field test would render similar results.

What is not represented in the data or in the comments is the discussion that took place during the preliminary field test workshop. Selling a bond to the public must focus on the district's vision and mission and on teaching and learning. The structure of the buildings, whether remodels or new construction, needs to reflect that vision and direction of the district. As a result of that discussion, I added another section and nine additional pages to the handbook, Foundation: Teaching and Learning Connection. This section was placed prominently in the handbook in the first section as the first strategy.

The new section focuses on the research that confirms a positive connection between new and remodeled school facilities and improved teaching and learning. In general, the findings indicate that students score 5 to 17 points higher on standardized tests than those students who attend substandard buildings (Young, 2003).The section describes working conditions and job satisfaction for teachers and the relationship 
between the age of building, acoustics, lighting, temperature, air quality, health, safety, school climate, school size, beauty and aesthetics, technology, and green design to student learning (Florence, 2014). It also addresses the positive connection between sports, activities, and student academic achievement (Hartmann, 2008; Lamborn, Brown, Mounts, \& Steinberg, 1992; O'Brien \& Rollefson, 1995; U.S. Department of Education, 1995). Academic materials and research data correlated to school facilities are important to share with voters to authenticate the importance of new construction and school remodeling.

The last section of the survey pointed to revisions of format and style of the handbook in its structure, method, and form. Structure is defined as the logical order of the contents. Method has to do with readability, and form is the attractiveness of the materials. Only one participant marked two statements as disagree: "Space is available to take notes" and "The handbook is understood without a workshop." An easy solution to the first statement was to add one to two pages of "notes" to each section, which I added for the Main field test.

Main product revisions: The workshop. The second statement was more for my awareness of whether the handbook could stand alone on its own accord. Is it a viable informational handbook that someone would purchase? Can it stand on its own merits? Or is it only valuable in a workshop when topics can be further explained or clarified. Because only one participant marked this statement, I was somewhat assured that the handbook could survive on its own merits. Some participants simply prefer a more handson approach to learning new information. 
The survey asked participants to identify their level of agreement to 17 questions in five categories: Workshop Content, Workshop Design, Workshop Facilitator, Workshop Results, and Content Presentation. Two participants marked Disagree with the statement, "The pace of this workshop was appropriate." I knew this might be a problem because this workshop was scheduled for only three hours and 30 minutes. However, the Main field test would be scheduled for seven hours.

Participants were also asked to mark statements they agreed with from a list of workshop improvement areas. One participant marked, "Provide more information before the workshop"; three marked, "Make the workshop more collaborative"; three marked "Slow down the pace of the workshop"; and two marked, "Increase time for the workshop." All these adjustments were made for the next workshop in which I conducted the Main field test.

After Step 5 revisions, I sent reminders to Main field test participants with the brochure, agenda, and syllabus two times. I would have preferred to also send the handbook or, at a minimum, three sections of the handbook: The Tale of Two Districts, Review of Communication Theory and Practice, and Foundation: Teaching and Learning Connection. However, future workshops could allow for advance information. In the Preliminary and Main field test environments, I needed this information to be studied during the workshops to maintain the integrity of the survey outcomes.

Likewise, the Main field test workshop was scheduled for seven hours instead of half that amount of time, and the pace of the workshop would be pared down for participants to work together to assess current practices and to plan activities. 


\section{Step 7: Operational Product Revisions}

By the time I conducted the Main field testing, the handbook had already been thoroughly examined, evaluated, and revised two times. The Step 6, Main field test provided me not only with feedback from the surveys on the handbook and workshop but also feedback from observational data I gathered during the workshop. Would participants react to the handbook as if it were a publishable quality? Or would I see skepticism and doubt? My greatest fear was that workshop participants would consider the handbook and workshop as ineffective and inadequate and not describe it as a valuable or viable contribution to the educational field.

This section will analyze the formative assessment data from the pretest and posttest of the communication self-assessment, evaluation of the usefulness, effectiveness, and importance of the handbook, the evaluation of the format and style of the handbook, and the evaluation of the workshop and describe the revisions of the handbook and workshop. Formative assessment results seek to make changes to the product, the handbook and the workshop. Bridges and Hallinger (1995) described formative assessment as data pointing to ways in which the student can improve the product.

Operational product revisions: The handbook. Sixteen district leaders participated in the Step 6, Main field test: seven superintendents, five school board members, and four district office administrators.

Pretest and posttest of the communications self-assessment. The results of the pretest and posttest indicated that growth was exhibited in every area as shown in Table 
40. However, only one example remained below 3.0 after participants' review of the handbook and participation in the workshop: Social Media. The pretest in both sections began low at 1.88 and 1.94 and showed a significant amount of growth to 2.88. But in the areas participants perceived needing the most help, the number of participants marking this example increased. Twelve of the 16 participants in the workshop needed the most the help in knowledge, understanding and application of Social Media, and they were only slightly comfortable using this communication practice.

Table 40

Formative Results: Social Media

\begin{tabular}{|c|c|c|}
\hline Social Media-Ex. Facebook, Twitter, blogs, message boards & Pretest & Posttest \\
\hline $\begin{array}{l}\text { 1. } \begin{array}{l}\text { Level of Familiarity of Communication Theory and } \\
\text { Practice }\end{array} \\
\text { 2. Level of Comfort of Communication Theory and Practice }\end{array}$ & 1.88 & 2.88 \\
\hline 3. Areas you perceive that you need the most help & $\begin{array}{c}11 \\
\text { Participants }\end{array}$ & $\begin{array}{c}12 \\
\text { Participants }\end{array}$ \\
\hline
\end{tabular}

The handbook addressed this need by providing links and reference materials in the Appendices for readers to gain additional skill, knowledge, and understanding of social media. But in future workshops, an agenda item would be added to demonstrate the ease to which these tools can be employed. Beyond this, there seemed to be a wide technology gap between younger technology natives and older technology immigrants. This gap was particularly evident at the beginning of the workshop when participants were asked to take a survey using SurveyMonkey. Likewise, participants would need to be willing to learn about social media, which may be outside their comfort zone. Survey 
results indicated that participants were not comfortable using these kinds of media, but social media are the contemporary approach to passing elections. "Blogs, social media, and hyperlocal news websites can be a powerful force in driving local opinion" (Jackson, 2014, p. 40). If learning to use social media were an agenda item for the workshop, would that discourage some district leaders from registering or would that encourage more to attend?

Formative Assessment of the usefulness, effectiveness, and importance of the

handbook. The majority of the participants perceived the handbook to be useful, effective, and important or most useful, most effective, and most important. Only one to three participants rated the handbook's strategies and sections as not useful, not effective, and not important.

In Table 41, I combined the responses from these three research questions. Usefulness is defined as practical information for district leaders initiating a bond; effectiveness is defined as being able to apply the information; and importance is defined as meeting district's needs at this time. Sections of the handbook that received the most negative responses in these four areas were 1. Introduction; 2. Tale of Two Districts; 11. Conduct a Survey; and 21. Epilogue. 1, 2, and 21 might be superfluous to the actual work that a district must do to prepare for a bond election but 11. Conduct a Survey is essential to that preparation. 
Table 41

Number of Participants Choosing Least or Not Useful, Effective, or Important

\begin{tabular}{|c|c|c|}
\hline \multicolumn{3}{|l|}{$\begin{array}{l}\text { School Bond Campaign Strategies } \\
\text { Usefulness (U), Effectiveness (E), Importance (I) }\end{array}$} \\
\hline Handbook's Introductory Sections & $\begin{array}{l}\text { Least } \\
\mathrm{U}, \mathrm{E}, \mathrm{I}\end{array}$ & $\begin{array}{l}\text { Not } \\
\text { U, E, I }\end{array}$ \\
\hline 1. Introduction & & $1,1,3$ \\
\hline 2. Tale of Two Districts & & $2,3,3$ \\
\hline 3. Review Communication Theory \& Practices & & \\
\hline \multicolumn{3}{|l|}{ Pre-Bond Campaign Strategies } \\
\hline $\begin{array}{l}\text { 4. Foundation: Teaching and Learning Connection-Connect } \\
\text { construction improvements to teaching and learning }\end{array}$ & & $1--$ \\
\hline $\begin{array}{l}\text { 5. Evaluate School \& Community Relations-Survey methods and } \\
\text { feedback to assess community perceptions }\end{array}$ & & \\
\hline 6. Garner Support-Strategies to gain community support & & $1--$ \\
\hline $\begin{array}{l}\text { 7. Create the Communications Plan-Systematic, formal plan for } \\
\text { communications with internal and external stakeholders }\end{array}$ & & \\
\hline $\begin{array}{l}\text { 8. Enlist Key Community Leaders-Identification and } \\
\text { commitment of internal and external stakeholders }\end{array}$ & --1 & $1,1-$ \\
\hline 9. Develop \& Publish the Long-Range Facilities Plan & --1 & $-1-$ \\
\hline 10. Identify Construction Projects \& Costs & --1 &,-- \\
\hline $\begin{array}{l}\text { 11. Conduct a Survey-Knowing what the public is willing to } \\
\text { support }\end{array}$ & & $3,2,2$ \\
\hline $\begin{array}{l}\text { 12. Prepare for the Bond Campaign-Brainstorming and preparing } \\
\text { for bond activities }\end{array}$ & & $1--$ \\
\hline $\begin{array}{l}\text { 13. Select Consultants-e.g., architects, construction management, } \\
\text { engineers }\end{array}$ & & $1--$ \\
\hline 14. Develop the Bond Calendar & & --1 \\
\hline 15. Create Campaign Literature \& Organize Activities & & --1 \\
\hline 16. Communicate with Media & & $-2,1$ \\
\hline $\begin{array}{l}\text { 17. Utilize Contemporary Marketing Strategies-Facebook, Twitter, } \\
\text { blogs, gamification, YouTube videos }\end{array}$ & & $-2-$ \\
\hline \multicolumn{3}{|l|}{ During-the-Bond Campaign Strategies } \\
\hline $\begin{array}{l}\text { 18. Count Down to Election Day-Scheduled of events during a } 60 \\
\text { or } 90 \text {-day period }\end{array}$ & & $1--$ \\
\hline 19. Celebrate the Win-Key media releases & & $2-1$ \\
\hline \multicolumn{3}{|l|}{ After-the-Bond Campaign Strategies } \\
\hline 20. Next Steps-Strategies to insure another win in 5-10 years & & $1--$ \\
\hline \multicolumn{3}{|l|}{ Supplemental Information } \\
\hline 21. Epilogue & --1 & $1,2,1$ \\
\hline 22. Appendices & & \\
\hline 23. School Bond Campaign Links & & \\
\hline 24. References & & $2-1$ \\
\hline
\end{tabular}


1. Introduction, 2. The Tale of Two Cities, 8. Enlist Key Community Leaders, 11. Conduct a Survey, and 21. Epilogue all received a Least or Not Useful, Effective, and Important in all three research questions. Two of these, the Introduction and Epilogue were already rewritten in Step 5, Main product revision. So this result is puzzling because these two areas of the handbook were again identified as least or not useful, effective, and important. My speculation, then, is that participants may be comparing these to the other items in the handbook as in a rank-ordering from highest to lowest. To these one or two participants, the strategies in the handbook are the most useful, most effective, and most important in passing a bond election. In comparison to other strategies or items listed, the Epilogue and Tale of Two Cities have the least potential to pass a bond.

Equally confusing is the one to two participants who identified 8. Enlist Key Community Leaders and 11. Conduct a Survey as strategies that are least or not useful, effective, and important in all three questions. Both of these strategies are essential in passing a bond election. Key community leaders are comprised of both internal and external constituents. These leaders represent the breadth of the school community including teachers, board members, students, parent groups, community groups, and young, old, retired, and active people (Porterfield \& Carnes, 2008). The citizen's advisory, advocacy, or action committee is comprised of these key players who communicate and advocate for the bond election. This group campaigns for the district (Bagin \& Gallagher, 2001). Election campaigns are not initiated without this group in place. Jackson (2014) pointed out by including a "broad-based representative sample of community members" in the decision-making process and actions of the district, they 
become the cheerleaders for the district and campaign. "The school board and superintendent can no longer win on their own" (Jackson, 2014). Finally, Holt et al. (2006) found that the establishment of a diverse community task force had a profound impact on the campaign.

Conducting a survey is common sense. Knowing how to conduct a survey is not (Holt, 2002). A district must know what the voters will support before election language shows up on the ballot. Will they support a new high school for $\$ 80$ million or will they support \$20 million for various projects? Will they support a phased-in project list with multiple bonds every five years rather than one for $\$ 200$ million? A survey of the community or voters allows the superintendent and school board to make better decisions. Those monetary bond decisions will make the difference between a successful bond and a defeated one. Conducting a survey is a useful, effective, and important strategy and should remain intact in the handbook.

Several written comments also provided areas of improvement to the handbook.

"Remove - - - Research [firm] from your manual. They are poor service providers."

"Personally, I could do with less reflection sections and a little more physical examples of products."

"Show me a quality press release; don't just tell me what should be in it."

"Would include more detailed information around each topic especially technical pieces like construction costs, strategic planning, etc."

"Please add some examples of various kinds of communications or plans to the handbook." 
Many of these suggestions are easy fixes, changes, or additions to the handbook. I added examples of press releases and other communications to the blank pages on the flip side of section pages.

An interesting topic is district leaders' perceptions of consultants and research firms. In this workshop a district leader was very vocal about not hiring a research firm that her district used. Since this workshop, without solicitation, I have heard from other district leaders that this same research firm is the best one to hire. Experiences of others may not always be the most reliable or credible. Each district must base decisions on its own research.

\section{Formative Assessment of the format and style of the handbook. Participants}

were instructed to rate their level of agreement to the survey statements about the format and style of the handbook. Format and style are defined as the way the contents are presented: structure, method, and form. Structure has to do with the order of the contents. The order of the contents must be logical, and users must be able to quickly find the section they need. Method has to do with readability and whether the text is readable. Form has to do with the presentation of the contents. The contents and pictures must be attractive, and the text should be presented in a way that involves the reader.

The majority of participants strongly agreed with all but five statements as shown in Table 42. Two statements garnered the most disagreement: 4. "The Tale of Two Districts" adds humor and 5. "The Tale of Two Districts" introduces important concepts. Seven participants, in all, disagreed with the statements. 
Table 42

Formative Results: Format and Style of the Handbook

\begin{tabular}{|c|c|c|c|c|}
\hline Format \& Style of the Handbook & $\begin{array}{l}\text { Strongly } \\
\text { Disagree }\end{array}$ & Disagree & Agree & $\begin{array}{l}\text { Strongly } \\
\text { Agree }\end{array}$ \\
\hline 3. The introduction compels me to read further. & & 1 & 6 & 8 \\
\hline 4. The "Tale of Two Districts" adds humor. & & 5 & 5 & 5 \\
\hline $\begin{array}{l}\text { 5. The "Tale of Two Districts" introduces important } \\
\text { concepts. }\end{array}$ & & 2 & 7 & 6 \\
\hline 10. Illustrations/visuals add interest. & & 2 & 5 & 8 \\
\hline $\begin{array}{l}\text { 19. The writing style is similar to everyday reading } \\
\text { in newspapers, magazines, or books. }\end{array}$ & & 1 & 7 & 7 \\
\hline $\begin{array}{l}\text { 23. Reflection pages help the reader to process the } \\
\text { material. }\end{array}$ & & 4 & 3 & 8 \\
\hline $\begin{array}{l}\text { 24. The handbook's contents are understood } \\
\text { without a workshop. }\end{array}$ & & 1 & 8 & 6 \\
\hline
\end{tabular}

"The Tale of Two Districts" is set up as a satire, strongly dependent on hyperbole to teach a lesson. The first tale describes a superintendent who does everything wrong to attempt to pass a bond election. The second tale describes an ideal or model superintendent who passes a bond. Humor based on satire is generally not slapstick humor to be taken lightly, but often is dark humor that drives home a real lesson.

My thought is that some participants did not understand that definition and disagreed based on their definition of humor. I interpreted it that way because of the second statement about "The Tale of Two Districts," 5. "The Tale of Two Districts" introduces important concepts. Only two participants disagreed with that statement. The survey statement then should be reworded. Perhaps, rather than humor, it should be expressed as thought-provoking. An introduction explaining the Tale of Two Districts would help to deliver the narrative's significance. Allowing participants adequate time to leisurely read the two tales would also benefit the reader. In the future, participants could 
receive a copy of the handbook in advance of the workshop and be better prepared. Verbal comments attested to most participants' interest in the Tale of Two Districts. Many said, "Wow" as a positive. Most participants clearly enjoyed the narrative. They read it thoroughly without skimming.

Another statement, 23. Reflection pages help the reader to process the material, collected four ratings of disagreement. This disagreement of the statement may be in response to not having enough time to work in groups than the actual time spent on writing the responses to the questions. Reflection pages help the reader to process the material, take notes, and then plan strategies specific to individual districts. However, one participant offered: "Some reflection is good, but I think reflection and notes in every section are a little too much." Reflection pages would be more valuable if the workshop had been advertised for district teams to begin their bond election planning. Additional notes pages were added after the formative evaluation of the Preliminary field test in which the participants asked for more places to take notes.

Two participants disagreed with a fourth statement, 10. Illustrations/visuals add interest. Their disagreement may be more about not having enough visuals than criticizing the type of visuals in the handbook. Comments seem to support this interpretation. One participant said: "Include graphics from the PowerPoint in the manual. Those graphics were great tools." Another said simply: "More graphics to communicate information visually." I added more graphics from the PowerPoint presentation to the handbook so participants can use them for planning in their district. These came from the communication section of the PowerPoint presentation. A verbal 
suggestion during the workshop asked about including a CD of the handbook for participants to be able to use the reflection sheets, graphics, and other images in their planning work rather than writing in the handbook. This is an easy addition to the handbook. The addition of the CD would enhance the handbook's usefulness and increase its value to users.

Operational product revisions: The workshop. The last section of the Main Field Test asked participants how they would improve the workshop as shown in Table 43. They could check all that would apply. "Make workshop activities more collaborative," "Shorten the time for the workshop," and "Increase the content covered in the workshop" received four checks each. One participant commented: "Breaking into groups to share experiences would have helped." Another said: "I would like to see teams develop a bond plan for their district through the workshop even if the workshop would be longer." This would be an excellent way to organize workshops in the future. Having teams of district leaders working on each district's bond calendars and plans would give members of each group a tangible plan from which to work when they returned to their district. The workshop then would be genuinely practical and productive.

A direct result of the preliminary field test showed that there was too much information in the time constraints of a half-day workshop. It would be most difficult to shorten the time of the workshop and increase content, as these seem to be conflicting requirements. 
Table 43

Formative Results: Workshop

\begin{tabular}{|c|c|}
\hline \multicolumn{2}{|l|}{$\begin{array}{l}\text { How would you improve this workshop? } \\
\text { Check all that apply. }\end{array}$} \\
\hline Provide more information before the workshop. & 3 \\
\hline Clarify the workshop objectives. & 1 \\
\hline Reduce the content covered in the workshop. & 0 \\
\hline Increase the content covered in the workshop. & 4 \\
\hline Update the content covered in the workshop. & 1 \\
\hline Improve the presentation format. & 2 \\
\hline Make workshop activities more collaborative. & 4 \\
\hline Make workshop activities less collaborative. & 0 \\
\hline Improve workshop organization. & 0 \\
\hline Slow down the pace of the workshop. & 2 \\
\hline Speed up the pace of the workshop. & 2 \\
\hline Increase time for the workshop. & 0 \\
\hline Shorten the time for the workshop. & 4 \\
\hline
\end{tabular}

"Provide more information before the workshop" received three checks. One comment stated: "We could have done some prep work before the meeting." Another comment with a positive and negative: "Linda did a great job but sitting that long was too much." In the future, I would provide the long narrative sections of the handbook before the workshop so participants would be better prepared. For example, reading "The Tale of Two Districts" is not beneficial if it must be skimmed and scanned in a hurry. A number of important topics occur in the two tales that help support the work in both the workshop and the handbook. There is so much reading in the handbook that it is no wonder that one participant said it was "too much to cover in a single day." 
Two of my favorite statements exemplify the diversity of opinion and diversity in skills in any workshop: Two participants checked, "Slow down the pace of the workshop." Two participants checked, "Speed up the pace of the workshop."

In a workshop that was advertised as a Main Field Test for a Portland State University dissertation, I found the last comment amusing: "Not such long surveys."

\section{Conclusion: Step 7, Operational Product Revision}

Overall, the formative data pointed toward a few minor improvement areas that would strengthen the handbook: improve the handbook's introduction, introduce "The Tale of Two Districts," add more planning graphics, insert more examples of strategies such as news releases and brochures, and provide more information about contemporary media and contemporary marketing strategies. This last area could be a half-day workshop in itself and another manual that would need to be updated every year as new technologies and media are invented, improved, and introduced. I provided supplementary links and added to the reference listings for readers to gain additional skill, knowledge, and understanding of social media.

\section{Conclusions and Assessment of the Experience}

Writing the handbook, Holding Successful School Bond Campaigns: Not for

Dummies, improving the handbook, and offering the workshop have been an incredible experience. The most rewarding compliments have been from the participants in the studies who were so excited that a product is now available to guide them in their work to pass a bond election. One superintendent asked: "Where was this handbook when I 
started the process?" Another superintendent said: "I could have used this when I tried my first bond. It failed!"

The R\&D process and PBL model helped to guide my research study and to strengthen and improve the handbook through seven specific steps. During those steps, I learned from various participants in the study what was important to them and to their districts and improved the handbook to reach those audiences. The greatest changes to the handbook were adding two major sections: (a) Review of Communication Theory and Practice and (b) Foundation: Teaching and Learning Connection. These two sections established the base from which all the work surrounding a construction bond election must be framed.

The degree of planning and preparation involved when conducting Small-scale, Preliminary, and Main field testing was staggering. Small-scale testing involved one-onone interviews with pre-planned questions on a form. For the study, I preferred to work with superintendents only but soon found I needed to include other district leaders. Superintendents tend to be busy and often empower district administrators to replace them at meetings.

My idea of working solely with superintendents was foiled early in the process when, without my knowledge, one superintendent scheduled his communication director to replace him in the interview. That became the key moment when I revised my focus of the study to include "other district leaders." For this study, I defined "other district leaders" as district office administrators and board members. This turned out to be a positive change because the focus broadened the range of participants and provided my 
study with rich information from various points of view. Being flexible can be advantageous.

In interviews that are recorded, I also found it essential to take notes as well. In one interview, I thought the digital recorder was activated but it was off for about 15 minutes. I had taken verbatim notes so my oversight did not interfere with the outcomes. In another interview, the interview was interrupted with a fire drill. I forgot to turn the recorder off. There were 10 minutes of a fire alarm recording. But when we returned, I hit the tiny "play" button; however, that turned it off. About 10 minutes later, I saw the light was not activated for recording and then fixed it. In both instances, taking notes along with the recording became a critical step and a fortuitous plan.

The Preliminary field testing also proved to have some surprises. One superintendent, the day before the field test, said he would not attend. I asked him to send another district administrator, which he did. The administrator arrived late and had to catch up on the pretest. Finding superintendents to give up half a day of their busy schedule to participate in the Preliminary field test was difficult, which was the reason I developed a shortened version of the workshop. Every minute counted.

For the Main field test I emailed 90 superintendents and invited them and other school district leaders to the workshop. Seventeen registered. Of the 17, eight were superintendents. On the day of the workshop, one superintendent was ill so seven participated. Advertised as a free workshop, that designation may have carried with it a stigma of not being valuable. Also, advertising brochures identified the workshop as a university study with participants responding to surveys. That too may have attributed to 
lower attendance. I sent reminder emails four times to superintendents. I hoped for 20 to 25 participants but conducted the workshop with 16 . This is good to know if a researcher would want to replicate the study. It is difficult to entice executive leaders to participate in a workshop and research study.

In both the Preliminary and Main field test, participants had difficulty using technology. Several participants either did not bring the technology required or they did not know how to manage simple operations such as accessing wireless or logging into SurveyMonkey. I observed these events in the Preliminary field test, so I prepared for these challenges to occur to a higher degree in the Main field test. I asked two people to attend to help workshop participants to access wireless and ensure that participants experienced few difficulties as they took the surveys. We also brought six extra iPads and used them all, including one of our laptops.

One caveat in administering online surveys is that, in both the Preliminary and Main field tests, at least one participant skipped questions or entire sections of the survey. Some participants had difficulty scrolling from one page to the next. Clearly, for some, this may have been their first experience using an iPad or laptop. That may be the reason behind one participant's comment: "Too many surveys."

During this past year, I attempted to offer either the Preliminary field test or Main field test at two OSBA conferences. My first attempt to hold the workshop and use the handbook was at the OSBA 2013 Summer Conference in Bend. I submitted the required paperwork early in the spring of 2013 well before deadlines. I not only sent the required synopsis of the workshop, but I also provided OSBA with a copy of the handbook for the 
executives to peruse. I know several OSBA executives and thought they would welcome my handbook and workshop.

OSBA had not offered the Bonds and Ballots workshop to school boards, superintendents, and other central office personnel since 2007. However, my offer was rejected. I resubmitted my application for the OSBA Fall Convention. It, too, was rejected. After the second rejection, OSBA began advertising for the Bonds and Ballets workshop for January 2014. Did OSBA consider my handbook and workshop competition? I received no feedback as to why my proposed workshop was rejected.

Fortunately, COSA was amenable to holding the Main field test and workshop in the COSA conference room in Salem. Offering the workshop in a central location in the state was important to me so districts wanting to attend were in close proximity. Districts came from as far away as 200 miles from the south and 100 miles from the coast.

The R\&D PBL model is the only way that I would have accomplished this research study. The PBL model gave me an opportunity to develop a needed product that, according to Bridges and Hallinger (1995), "will have instrumental value in [my] future work" (p. 116). Once I developed the product, Holding Successful School Bond Campaigns: Not for Dummies, and began to follow the R\&D process as described by Borg and Gall (1989), I was able to test the product in three settings to improve and revise it. Now the handbook is ready for use in my district as I work toward the demands of a construction bond election proposal to our voters; thus this "experience will have instrumental value in [my] future work" (Bridges \& Hallinger, 1995, p. 117). 


\section{Operational Field Testing and Final Product Revision}

\section{Step 8: Operational Field Testing}

The R\&D process for doctoral students of education ends after Step 7; however, it is noteworthy to speculate about future research in the subject of passing bond elections and next steps to determine if the handbook or "educational product is fully ready for use in school" (Borg \& Gall 1989, p 793).

Several opportunities are available at the state and national level for Operational field testing of the product Holding Successful School Bond Campaigns: Not for Dummies. At the state level there are two educational organizations that offer professional conferences throughout the year: OSBA and COSA. At the national level there are the AASA, National School Boards Association, and National School Public Relations Association. These national associations generally hold one major convention or conference each year.

State-level conferences. OSBA offers two main conferences, the OSBA Summer Conference and the Fall Convention. The summer conference, located in Bend, is generally set up for new board members, but many experienced board members attend the two-day conference because of the camaraderie that is fostered. When board members attend, so do their superintendents. The OSBA Fall Convention in Portland is the largest and longest with several hundred board members, district office personnel and superintendents in attendance during a 4-day schedule of workshops, meetings, and keynote sessions. 
Either of the conferences offers 1-hour and 2-hour sessions. The two-hour session would be the most suitable to provide a workshop using the handbook. However, the workshop would be structured differently from the Preliminary and Main field tests. First, to accommodate the shortened workshop length, participants would be required to read the handbook in advance. Participants would then attend the workshop. In the months following the workshop, participants would provide follow-up information via a survey about how they implemented the information in their districts. Step 8 in the $R \& D$ process is substantially different from the feedback needed earlier in the process. The idea is to prepare others to implement the product in a variety of natural setting (Bridges \& Hallinger, 1995).

COSA similarly offers conferences throughout the year. There are two conferences, however, that often have longer sessions available which would be suitable for the workshop: Oregon Association of School Executives Winter Conference at Salishan and the COSA Summer Conference at Seaside. As the pre-conference, half-day sessions are often available. This would provide a three- to four-hour venue that would allow some deeper discussions of implementing the campaign and election strategies in districts. In the months following the workshop, participants would provide follow-up information via a survey about how they implemented the information in their districts. Another way I would engage in the Operational field test is though offering my own workshop as I had accomplished in the Preliminary and Main field tests. I would offer the workshop to school district teams who are in the early stages of preparing for a bond. Then the districts could provide feedback on their implementation of the strategies 
before, during, and after their bond campaign. This would provide rich feedback and data about each strategy districts used.

National conferences. Just as there are opportunities to present workshops at the state-level professional organizations, these are also available at the national level. The national organization for OSBA is the National School Boards Association and the national organization for COSA superintendents (Oregon Association of School Executives) and district office administrators is the AASA. Requirements to present generally coincide with each organization's conference theme. My handbook and workshop unfortunately may not match the theme of the convention, but these are still viable options depending how I would frame the workshop.

The national association that would best fit my needs for the Operational field test is with National School Public Relations Association. Public relations is closely related to passage of a school bond election. A call to submit proposals for the 2014 National Seminar "Winning the Battle for Public Education" ended Friday, December 6, 2013. While this was not an opportune time for me to submit a proposal, I now understand the requirements to submit proposals. I shall submit a proposal the fall of 2014 for the national seminar in 2015 .

\section{Step 9: Final Product Revision}

Attaining feedback at either the state or national level would provide a wealth of information to improve both my workshop and the handbook. Bridges and Hallinger (1995) indicated, "These data then lead to a final revision of the product" (p. 122). 
At the national level, I can see that I would need to make some strategies in the handbook more general to accommodate the differing laws in states. For example, rather than identifying the Oregon statute for elections law or the Oregon statute for the state's ethics law, I would need to refer participants to access their state laws that govern these areas. However, early in the process, one interview participant said: "This is generic enough that it could go anywhere in the nation."

\section{Step 10: Dissemination, Implementation, and Institutionalization}

According to Bridges and Hallinger (1995), students implement Step 10 at their own discretion. This final step in the $\mathrm{R} \& \mathrm{D}$ process extends the use of the product by making others aware of the product. In the case of the handbook Holding Successful School Bond Campaigns: Not for Dummies, presentations of the handbook in workshops or at professional meetings, publication of articles about the handbook, or publishing the handbook would extend the use of the product.

All of these could be used to extend the use of the product. Only a few years away from retirement, I could become a consultant to districts embarking on a school bond election. I would offer my services to districts and use the handbook to educate district leaders and community members on useful, effective, and important strategies to employ to pass school bond elections. Rather than a half-day or full-day workshop, I could help districts plan for their entire campaign in a 2-day or longer training.

In addition to consulting and holding presentations at professional associations, I would also publish the handbook. I have already consulted Corwin Press, a company that publishes educational books, to determine the steps I would need to take. Corwin's goal 
is "to publish substantive and practical books that contribute to practitioners' knowledge while also being readable and useful" ("Publish with Corwin," 2013, para. 4). The ideal Corwin book includes the following:

1. It is based on theory, research, and/or practical experience.

2. It discusses the implications of that theory, research, or experience for universal practice.

3. It draws on real-world examples and practices to illustrate points.

4. It offers practical, hands-on advice to educators who want to be successful in their chosen careers.

5. Most often, it is authored or coauthored, rather than an edited book.

6. Our audiences need substantive works that are also 'user-friendly' and tailored to their busy schedules. ("Publish with Corwin," 2013, para. 4)

The handbook seems to fit the specifications in all six categories. The handbook is based on theory, research, and practical experience, and theory and research are linked to practice through the actual steps needed to see successful results in passing a bond election. The handbook draws on real-world examples to illustrate points and offer practical, hands-on advice for participants or readers to plan and implement actions. An original piece, the handbook is user friendly with several pages allotted for planning, in an easy-to-read format. A published handbook would certainly help to institutionalize it.

As one superintendent said:

It gives direction and a sequence. Most people would be panicking over "what the heck do I do now." It really gives people a logical direction. You have experience in passing one so it's not like you are writing it out of thin air-about how to grow a garden and never had your hands in the dirt.

\section{Recommendations for Leadership}

November 2013 proved to be a woeful election day for 12 school districts in Oregon. Only three districts passed their construction bond elections. Nine failed at the 
polls. While a hefty $\$ 74$ million was passed by voters, 12 districts asked voters to approve more than $\$ 565$ million, still significantly less than the construction needs of the districts (OSBA, 2013a). One of the three districts passed its bond by a mere three votes. Any district experiencing a failing election would have been overjoyed with a three-vote win. Instead, the depressing news lay like a pall over the campaigners who worked so diligently and tirelessly for the past 2 years, only to be devastated by such poor results at the polls. For one superintendent, making appearances in public after such a severe loss was difficult. His self-assessment was certainly not an accurate one: The community no longer supported him. Such losses are often career-altering events. In his case, his position will survive the failure.

The strategies outlined and described in the handbook would transform such failures into successes, similar to the description of Superintendent Young and Superintendent Masters in "The Tale of Two Districts." The handbook brings a wealth of information to school district leaders who do not have the time, knowledge, or understanding to possibly conduct all their own research in preparation for such a complicated task. That research has been completed for them in the handbook, as one district leader remarked: "It is practical and useable." Using the handbook as a tool to guide districts through the challenges of a bond campaign will make the process easier and produce better results-a winning bond election.

Three districts that lost their November elections were represented in the Main field test in September. However, most of their work with the community had already been completed at the time of the workshop. What they gleaned from the handbook and 
workshop could not be applied in such a short timeframe before the November election.

In a follow-up to the workshop, one district's superintendent said he was using the handbook immensely.

The handbook has been great. I have been using it as a tool with my school board on how to better communicate with our community. We are really using that communication section and the section about building community partners. I think that is what we were missing when we didn't pass our election.

This district was unsuccessful in gaining support for its local option levy. Now the district is planning more strategically and preparing for a May election. Although his district was not seeking a construction bond, many of the same strategies in the handbook apply to gaining public support for local option levies.

Another district's superintendent was complementary about the handbook and workshop but her district also saw its bond defeated:

Your workshop was awesome. I can't tell you enough how detailed and organized your handbook and workshop were. I was really impressed. I truly enjoyed it. However, our community just was not ready to support our bond. It is very disappointing.

The Epilogue to the handbook provides a number of key steps that should be initiated following a loss in preparation for another election. Conducting a SWOT analysis is one step. Districts should systematically evaluate their strategies and identify the strengths, weakness, opportunities, and threats of their campaign.

One district administrator simply said, "You were right on about a split board. We did not pass the bond. You said that people would find any excuse not to vote in favor of a bond, and our community used that as their excuse." Holt (2002) maintained that the "failure of the board to reach a consensus appears to doom the results of the election" (p. 23). If the board is not $100 \%$ behind the bond, attempting a bond election is pointless. 
"Slow and steady wins the race." Aesop's moral applies to districts in their plans for a win at the polls. A successful bond campaign begins one to two years in advance of the election, and a hurried approach generally ends in a loss. The handbook provides the steps necessary to strategically plan for that slow and sure win.

The handbook is step one of several future research studies that can assist school districts in passing a bond election. A next step might be to test the strategies themselves to determine which are the most valuable and have the most impact on an election. Another might produce a qualitative study in which two or more districts are studied, one district that passed a bond and one that failed. What strategies did the districts use that were different? What strategies did they use that were the similar?

Still another study could center on presenting ways to gain support through social media and contemporary marketing strategies. A technology gap is expanding between young voters who depend on social media to learn new information and district office leaders who still use traditional methods. This could be an interesting study on communication patterns between campaigners and various groups of voters. Which communication strategies effectively communicate to each group of voters?

The importance of passing a bond election cannot be underestimated. It means the difference between the satisfaction of remodeling and building new schools for today's learners and the disappointment of managing unsafe, unhealthy, old schools built for yesterday's pupils. 


\section{Chapter Summary}

Chapter 5 described the conclusions of the study on the handbook, Holding Successful School Bond Campaigns: Not for Dummies. A formative assessment of steps $1-6$ of the R\&D process was briefly reviewed. The main changes to the handbook in these steps resulted in two major additions: (a) Review of Communication Theory and Practice and (b) Foundation: Teaching and Learning Connection.

This chapter also briefly reviewed the field testing results and determined the efficacy of the handbook and workshop. Overall results were positive. Few revisions to the handbook and workshop were required.

In Step 7, participants perceived the handbook to be useful, effective, and important in nearly all categories. Changes to the handbook included improving the handbook's introduction, introducing the Tale of Two Districts, adding more planning graphics, inserting more examples of strategies such as brochures and press releases, and providing more information and links about contemporary media and contemporary marketing strategies.

Step 8, Operational field testing, and, Step 9, Final product revision determine whether a product is ready for full use in a school setting. Step 10 is Dissemination, Implementation, and Institutionalization. These last three steps of Borg and Gall's (1989) Steps in the R\&D Cycle are not required of students in a doctoral program. These are steps that a student may wish to complete after Step 7. The ultimate goal for me would be to publish the handbook with a publishing company like Corwin Press. 
Future studies in this topic might be to test the handbook's strategies themselves to determine which are the most valuable and have the most impact on an election. Other studies might be qualitative or quantitative studies in which two or more districts are studied that passed and failed bond their elections. Still other studies could delve deeply into the districts' use of social media and contemporary marketing strategies to gain voter support.

The importance of passing a bond election cannot be underestimated. It means the difference between the satisfaction of remodeling and building new schools for today's learners and the disappointment of managing unsafe, unhealthy, old schools built for yesterday's. Using the handbook Holding Successful School Bond Campaigns: Not for Dummies provides the steps necessary for district leaders to hold a successful school construction bond campaign (see Appendix K). 


\section{REFERENCES}

Abramson, P. (2012, February). 2012 annual school construction report: $17^{\text {th }}$ annual report; It's still billions of dollars. School Planning and Management. Retrieved from http://www.peterli.com/spm/pdfs/SchoolConstructionReport2012.pdf

Anderson, G. L., Herr, K., \& Nihlen, A. S. (1994). Studying your own school: An educator's guide to qualitative practitioner research. Thousand Oaks, CA: Corwin.

Asmussen, K. J., \& Creswell, J. W. (1995). Campus response to a student gunman. Journal of High Education, 66(5), 575-591.

American Association of School Administrators. (2010). The American school superintendent: 2010 decennial study. Upper Saddle River, NJ: Pearson.

Bagin, D., \& Gallagher, D. R. (2001). The school and community relations $\left(7^{\text {th }}\right.$ ed.). Boston, MA: Allyn \& Bacon.

Bagin, D., Gallagher, D. R., \& Moore, E. H. (2008). The school and community relations $\left(9^{\text {th }}\right.$ ed.). Boston, MA: Allyn $\&$ Bacon.

Bogdan, R. C., \& Biklen, S. K. (1998). Qualitative research for education: An introduction to theory and methods ( $3^{\text {rd }}$ ed.). Boston, MA: Allyn \& Bacon.

Borg, W., \& Gall, M. (1989). Educational research and development. In Educational Research: An Introduction (5 ${ }^{\text {th }}$ ed.; pp. 782-863). White Plains, New York, NY: Longman.

Bowers, A. J., \& Lee, J. (2013, May). Carried or defeated? Examining the factors associated with passing school district bond elections in Texas, 1997-2009. Educational Administration Quarterly, 49(5), 732-767. doi:10.1177/0013161X13486278

Bowers, A. J., Metzger, S., \& Militello, M. (2010). Knowing what matters: An expanded study of school bond elections in Michigan, 1998-2006. Journal of Education Finance, 35(4), 374-396. doi:10.1353/jef.0.0024

Bowman, D. (n.d.). The five best ways to build-and lose-trust in the workplace. Los Angeles, CA: TTG Consultants. Retrieved from www.ttgconsultants.com/articles/ trustworkforce.html 
Brandon, E. (2012). States with the best older voter turnout. U.S. News and World Report. Retrieved from http://money.usnews.com/money/retirement/ slideshows/states-with-the-best-older-voter-turnout/9

Bridges, E., \& Hallinger, P. (1995). Implementing project-based learning in leadership development. Eugene, OR: ERIC Clearinghouse on Educational Management.

Brounstein, M. (2001). Communicating effectively for dummies: A reference for the rest of us! Hoboken, NJ: Wiley.

Brown, K. (2012a). State of Oregon: 2012 election law summary. Retrieved from www.oregonvotes.org

Brown, K. (2012b). State of Oregon: Restrictions on political campaigning by public employees, ORS 260.432. Retrieved from http://oregonvotes.org/doc/ publications/restrictions.pdf

Bullock, C. (2007). The relationship between school building conditions and student achievement at the middle school level in the commonwealth of Virginia. Unpublished doctoral dissertation. Calvin C. Virginia Polytechnic Institute and State University. Blackburg, Virginia.

Bushaw, W. J., \& Lopez, S. J. (2012). The 44th annual Phi Delta Kappa/Gallup Poll of the public's attitudes toward the public schools public: Education in the United States; A nation divided. Kappan, 9(1), 9-18.

Campbell, G., \& Magmer, J. (2007). Election success: Proven strategies for public finance campaigns. Rockville, MD: National School Public Relations Association.

Carroll, S. R., \& Carroll, D. (2000). EdMarketing: How smart schools get and keep community support. Bloomington, IN: National Education Service.

Carr, N. (2010, December 15). Demographic shifts require changes in school communication: School leaders must broaden their thinking to engage new groups of parents and stakeholders. eSchool News. Retrieved from http://www. eschoolnews.com/2010/12/15/demographic-shifts-require-changes-in-schoolcommunication

Collins, J. (2001). Good to great: Why some companies make the leap...and others don't. New York, NY: HarperCollins. 
Costello, K. (2012, July 30). 10 reasons why I think Lake Oswego placed in Family Circle's " 10 best towns for families" list. Retrieved from http://lovelakeoswego. com/2012/07/30/10-reasons-why-i-think-lake-oswego-placed-in-family-circles10-best-towns-for-families-list

Council of Great City Schools. (2010). Urban school superintendents: Characteristics, tenure, and salary. Urban Indicator. Retrieved from http://www.cgcs.org/cms/lib/ DC00001581/Centricity/Domain/4/Supt_Survey2010.pdf

Covey, S. R. (1989). The 7 habits of highly effective people: Powerful lessons in personal change. New York, NY: Free Press.

Creswell, J. W. (1998). Qualitative inquiry and research design: Choosing among five approaches. Thousand Oaks, CA: Sage.

Creswell, J. W. (2002). Educational Research: Planning conducting, and evaluating quantitative and qualitative research. Upper Saddle River, NJ: Pearson, Merrill, Prentice Hall.

Creswell, J. W. (2005). Educational Research: Planning conducting, and evaluating quantitative and qualitative research. Upper Saddle River, NJ: Pearson, Merrill, Prentice Hall.

Creswell, J. W. (2009). Research design: Qualitative, quantitative, and mixed methods approaches. Thousand Oaks, CA: Sage.

Creswell, J. W. (2013). Qualitative inquiry and research design: Choosing from among five approaches $\left(3^{\text {rd }}\right.$ ed.). Thousand Oaks, CA: Sage.

Crow, G., \& Wiles, R. (2008). Managing anonymity and confidentiality in social research: The case of visual data in community research (Working Paper Series). Retrieved from www.ncrm.ac.uk

Crowson, R. L. (1998). School-community relations, under reform ( $2^{\text {nd }}$ ed). Berkeley, CA: McCutchan.

Darling-Hammond, L., LaPointe, M., Meyerson, D., Orr. M. T., \& Cohen, C. (2007). Preparing school leaders for changing world: Lessons from exemplary leadership development programs. Stanford, CA: Stanford University, Stanford Educational Leadership Institute.

DeBruyn T., \& DeBruyn, R. L. (1987). School promotion, publicity, and public relations: Nothing but benefits. Manhattan, KA: The Master Teacher. 
Department of Defense Education Activity. (2007, September 17). Hierarchy of effective communication. Communication PRinciples for Principals, (2). Retrieved from http://www.dodea.edu/newsroom/publications/loader.cfm?csModule=security/get file \&pageid $=93036$

El Nasser, H., \& Overberg P. (2011, June 24). Census: Census reveals plummeting U.S. birthrates. USA Today. Retrieved from http://www.usatoday.com/news/nation/ census/2011-06-03-fewer-children-census-suburbs_n.htm

Erickson, P. W. (2011). Passing the bond: Elements, strategies, issues, and messages that can assist education institutions in their next elections. Retrieved from http://asumag.com/Maintenance/business/bond-issue-advice-201107

Fairbank, R. (2006, October). How to win a bond referendum. American School Board Journal, 193(10), 42-44.

Filardo, M., Cheng, S., Allen, M., Bar, M., \& Ulsoy, J. (2010, November). State capital spending on PK-12 school facilities. $21^{\text {st }}$ Century School Fund: Improving Urban Public School Facilities. U.S. Department of Education: National Clearinghouse for Educational Facilities.

Fiore, D. J. (2011). School-community relations ( $3^{\text {rd }}$ ed.). Larchmonth, NY: Eye on Education.

Florence, L. (2014). Holding successful school bond campaigns: Not for dummies. Unpublished manuscript.

Folmer, H. R., Moynihan, M. N., \& Schothorst, P. M. (n.d.). Testing and evaluating manuals. Amsterdam, Netherlands: Royal Tropical Institute. Retrieved from http://www.nrsp.org.uk/pdfs/resources/CPG/17_Testing\%20\&\%20evaluating\%20 manuals.pdf

Forner, M., Bierlein-Palmer, L., \& Reeves, P. (2012). Leadership practices of effective rural superintendents: Connections to Waters and Marzano's leadership correlates. Journal of Research in Rural Education, 27(8), 1-13.

Fraser, M., \& Dutta, S. (2008, November 19). Barack Obama and the Facebook election. US News. Retrieved from http://www.usnews.com/opinion/articles/2008/11/19/ barack-obama-and-the-facebook-election

Frey, W. H. (2011, August 31). The new metro minority map: Regional shifts in Hispanics, Asians, and Blacks from Census 2010 (No. 37). Brookings Institute Series: State of Metropolitan America. Retrieved from http://www.brookings.edu/ research/papers/2011/08/31-census-race-frey 
Fritz, B. (2012). Communication key to why referendums pass, fail. Madison, WI: EdUtopia Wisconsin. Retrieved from http://sites.journalism.wisc.edu/edutopia/ educational-costs/referendum

Gagne, J. (2012, August 23). Why public school leaders must embrace social media now. Retrieved from http://www.forbes.com/sites/dorieclark/2012/08/23/why-publicschool-leaders-must-embrace-social-media-now

Golafshani, N. (2003). Understanding reliability and validity in qualitative research. The Qualitative Report, 8(4), 597-607. Retrieved from http://www.nova.edu/ssss/ QR/QR8-4/golafshani.pdf

Gradstein, M., \& Kaganovich, M. 2004. Aging population and education finance. Journal of Public Economics, 88(12), 2469-2485.

Grandoni, D. (2012, October 14). Facebook has 1 billion users, Mark Zuckerberg announces in a status update. The Huffington Post. Retrieved from http://www.huffingtonpost.com/2012/10/04/facebook-1-billionusers_n_1938675.html

Gunther, V., McGowan, J., \& Donegan, K. (2011). Strategic communications for school leaders. New York, NY: Rowman \& Littlefield.

Hannah-Jones, N. (2011, May 25). Fewer Oregon homes include children, new census data show. The Oregonian. Retrieved from http://www.oregonlive.com/pacificnorthwest-news/index.ssf/2011/05/fewer_oregon_homes_include_children_ new_census_data_show.html

Hanson, C. (Director). (2012, August 25). The nightly news. [Television broadcast]. Portland, OR: KPTV-KPDX Broadcasting Corporation.

Hanson, E. M. (2003). Education administration and organizational behavior ( $\left.5^{\text {th }} \mathrm{ed}\right)$. Boston, MA: Allyn \& Bacon.

Harfoush, R. (2009). Yes, we did! An inside look at how social media built the Obama brand. Berkeley, CA: New Riders.

Hartmann, D. (2008). High school sports participation and educational attainment: Recognizing, assessing, and utilizing the relationship. Madison, WI: University of Minnesota. Retrieved from http://thesocietypages.org/files/2013/03/ HighSchoolSportsParticipation1.pdf

Holt, C. R. (2002). School bond success: A strategy for building America's schools. Lanham, MD: Scarecrow Education. 
Holt, C. R., Wendt, M. A., \& Smith, R. M. (2006, Winter). School bond success: An exploratory case study. The Rural Educator, 27(2), 11-17.

Hoy, W. K., \& Miskel, C. G. (2001). Educational administration: Theory, research, and practice $\left(6^{\text {th }}\right.$ ed.). Boston, MA: McGraw Hill.

Hoyle, J. R., English, F. W., \& Steffy, B. E. (1994). Skills for successful school leaders: Why are some administrators more successful than others? ( $2^{\text {nd }}$ ed.). Arlington, VA: American Association of School Administrators.

Hughes, L. W., \& Hooper, D. W. (2000). Public relations for school leaders. Boston, MA: Allyn \& Bacon.

Jackson, N. M. (January, 2014). How to win your next bond issue: District leaders must win trust and prove funds are critical. District Administrator, 50(1), 39-42.

Johnson, P. A., \& Ingle, W. K. (2008, November). Why levy efforts pass or fail: Lessons from Ohio school superintendents. A paper presented at the annual meeting of the University Council for Educational Administration, Orlando, Florida.

Kirby, E. H., \& Kawashima-Ginsberg, K. (2009, August 17). CIRCLE fact sheet: The youth vote in 2008. Retrieved from http://www.whatkidscando.org/youth_on_the_ trail_2012/pdf/CIRCLE\%20youith\%20vote\%202008.pdf

Kotler, P. (2000). Marketing management: The millennium edition. Upper Saddle River, NJ: Prentice Hall.

Kowalski, T. J., Petersen, G. J., \& Fusarelli, L. D. (2007). Effective communications for school administrators: A necessity in an information age. Toronto, Canada: Rowman \& Littleton Education.

Kroger, J. R. (2011). Attorney general's public records and meetings manual. Salem, OR: Oregon Department of Justice. Retrieved from http://www.doj.state.or.us/ pdf/public_records_and_meetings_manual.pdf

Lake Oswego School District Foundation. (2011). Annual report. Retrieved from http://www.losfoundation.org/wp-content/uploads/2014/02/2012-2013-LOSFAnnual-Report.pdf

Lamborn, S. D., Brown, B. B., Mounts, N. S., \& Steinberg, L. (1992). Putting School in perspective: The influence of family, peers, extracurricular participation, and parttime work on academic engagement. In F. M. Newman (Ed.), Student engagement and achievement in American secondary schools (pp. 153-181). New York, NY: Teachers College Press. (ERIC Document Reproduction Service No. ED371047) 
Leithwood, K., Jantzi, D., \& Steinbach, R. (2000). Changing leadership for changing times. Philadelphia, PA: Open University Press.

Lofgren, K. (2013, May 19). Qualitative analysis of interview data: A basic step-by-step guide. Retrieved from http://www.youtube.com/watch?v=DRL4PF2u9XA

Long, C. (2011, November 16). A national crisis: NEA spotlights urgent need for school modernization. NEA Today. Retrieved from http://neatoday.org/2011/11/16/anational-crisis-nea-spotlights-urgent-need-for-school-modernization

MacManus, S. A. (1995). Taxing and spending politics: A generational perspective. The Journal of Politics, 57(3), 607-629.

McKim-Bell, L. (2012, September 17). Why I support schools [Letter to the Editor]. Oregonian, p. 9A.

Meador, D. (2013). Tips to successfully pass a school bond issue. Retrieved from http://teaching.about.com/od/ParentalInvolvement/a/Tips-To-Successfully-PassA-School-Bond-Issue.htm

Michel, G. J. (1997). Building schools: The new school and community relations. Lancaster, PA: Technomic.

Mills, G. E. (2003). Action research: A guide for the teacher researcher $\left(2^{\text {nd }}\right.$ ed). Upper Saddle River, NJ: Merrill/Prentice-Hall.

O'Brien, E., \& Rollefson, M. (1995). Extracurricular participation and student engagement. National Center for Education Statistics. Retrieved from http://nces.ed.gov/pubs95/web/95741.asp

Oregon Department of Education. (2013). Student ethnicity: Student ethnicity, 20122013. Retrieved from http://www.ode.state.or.us/sfda/reports/r0067Select2.asp

Oregon Revised Statutes, 244.047, (2013). Retrieved from http://www.oregonlaws.org/ors/244.047

Oregon Revised Statutes, 246-260, (2011). Retrieved from http://www.oregonvotes.gov/doc/publications/elec_law.pdf

Oregon Revised Statutes, 6(240-260), (2013). Retrieved from https://www.oregonlegislature.gov/bills_laws/Pages/ORS.aspx

Oregon Revised Statutes, 6(244), (2013). Retrieved from https://www.oregonlegislature.gov/bills_laws/Pages/ORS.aspx 
Oregon School Boards Association. (2009, January). Update: Bond and local option levy, 2008 election. Salem, OR: Author.

Oregon School Boards Association. (2012, November). Resources: Bond and local option levy results. Retrieved from http://www.osba.org/Resources/Article/ Budget_and_Finance/Election-Recent_Bond-ocal_Option_Election_Results.aspx

Oregon School Boards Association. (2013a, May). Resources: Bond and local option levy results. Retrieved from http://www.osba.org/Resources/Article/ Budget_and_Finance/Election-Recent_Bond-ocal_Option_Election_Results.aspx

Oregon School Boards Association. (2013b, February 6). Resources: Finance campaigns regional workshop-Salem. Retrieved from http://www.osba.org/Calendar/Events/Finance_Campaigns_Regional_Workshops \%20-\%20SAL\%202013.aspx

Oregon University System. (2012). From goal to reality, 40-40-20: A report on strategies to meet Oregon's 40-40-20 education goals. Based on the 2011 leadership symposium sponsored by the Oregon University System. Retrieved from http://www.oregon.gov/gov/oeib/docs/nnousreport.pdf

Palmer, S. (2012, April 19). Eugene schools repair bill skyrockets: The board learns that an estimated \$244 million is needed for improvements. The Register-Guard, p. B1.

Picus, L. O. (n.d.). Maintenance and modernization of school facilities. Retrieved from http://education.stateuniversity.com/pages/2394/School-Facilities.html

Porterfield, K., \& Carnes, M. (2008). Why school communication matters: Strategies from PR professionals. New York, NY: Rowman \& Littlefield Education.

Porterfield, K., \& Carnes, M. (2012). Why social media matters. Bloomington, IN: American Association of School Administrators.

Portland Public Schools. (n.d.). School modernization. Retrieved September 30, 2012, from http://www.pps.k12.or.us/departments/schoolmodernization/index.htm

Portland Public Schools. (2013). PPS student home languages 2011-12. Retrieved from http://www.pps.k12.or.us/about-us/6499.htm

Portland Public Schools. (2014). PPS bond: Educational facilities long-range plan. Retrieved from http://www.pps.k12.or.us/departments/ schoolmodernization/1031.htm 
Proximity Resources. (2012a). Resources to create and apply insight: David Douglas School District 40, OR (4103940)-DP1 general demographic characteristics. Retrieved from http://proximityone.com/acs/dpor/dp1_4103940.htm

Proximity Resources. (2012b). Resources to create and apply insight: Gervais School District 1, OR (4100015)-DP3 economic characteristics. Retrieved from http://proximityone.com/acs/dpor/dp3_4100015.htm

Proximity Resources. (2012c). Resources to create and apply insight: Ontario School District 8, OR (4109270)-DP1 general demographic characteristics. Retrieved from http://proximityone.com/acs/dpor/dp1_4109270.htm

Publish with Corwin. (2013). Thousand Oaks, CA: Corwin. Retrieved from http://www.corwin.com/about/publish.html

Rebuild America's Schools. (2011, October 10). Schools in need. Retrieved from http://www.rebuildamericasschools.org

Rosenberg, S. (Director). (1967). Cool hand Luke [Film]. Los Angeles, CA: Warner Bros.

Salem-Keizer Coalition for Equality. (2012-2013). Parent and family workshop overview: Educate and inspire curriculum. Retrieved from http://www.skcequality.org/documents/2012-2013educateinspireworkshops.pdf

Smith, J. (2008, Dec 16). Facebook now growing by over 600,000 users a day. Retrieved from http://www.insidefacebook.com/2008/12/16/facebook-now-growing-byover-600000-users-a-day-and-new-engagement-stats

Stover, D. (2012, October). Building a bond. American School Board Journal. 199(10), 12-15.

Study finds elderly tend to oppose school bonds. (1991, February 17). Los Angeles Times. Retrieved from http://articles.latimes.com/1991-02-17/local/me-1894_1_schoolbond-issues

Tanden, N., \& Johnson, A. (2013). Millennials are key to making America stronger. Retrieved from http://www.huffingtonpost.com/neera-tanden/millennials-are-keyto-ma_b_3677506.html

Tedin, K. L., Matland, R. E., \&. Weiher, G. R. (2001). Age, race, self-interest, and financing public schools through referenda. The Journal of Politic, 63(1), 270294. Retrieved from http://orion.luc.edu/ rmatlan/pdf/2001AgeRaceSelfInterest.pdf 
Theobald, N. A., \& Meier, K. J. (2002, April). The politics of school finance: Passing school bonds. National Meeting of the Midwest Political Science Association, Palmer House Hotel, Chicago, IL. Retrieved from http://teep.tamu.edu/pubs/ bonds.pdf

Thompson, J. (2009, August). Improving voter participation: Oregon challenges and opportunities. Retrieved from www.commoncause.org/oregon

United States Census Bureau. (2010). 2010 population finder; 2010 demographic profile:

Oregon. Retrieved from http://www.census.gov/popfinder/?s=41

United States Department of Education. (1995). National education longitudinal study: Second follow-up. Retrieved from http://nces.ed.gov/surveys/els2002

United States Department of Education. (2010). School district demographics system: Census 2010. Geography: Gervais School District 1. Retrieved from http://nces.ed.gov/surveys/sdds/2010/master.aspx?GeoID=97000US4100015\&Ta bleID=P2\&intSecCat=0)

United States Election Assistance Commission. (2010). EAC releases data from 2010 election. Retrieved from http://www.eac.gov/eac_releases_data_from_ 2010_election

Vance, A. (2012, October 4). Facebook: The making of 1 billion users. Bloomberg Businessweek. Retrieved from http://www.businessweek.com/articles/2012-1004/facebook-the-making-of-1-billion-users

Wortham, J. (2012, October 7). Campaigns use social media to lure younger voters. New York Times. Retrieved from http://www.nytimes.com/2012/10/08/technology/ campaigns-use-social-media-to-lure-younger-voters.html

Young, E. (2003). Do K-12 School facilities affect education outcomes? A staff information report. Nashville, TN: The Tennessee Advisory Commission on Intergovernmental Relations. Retrieved from http://www.state.tn.us/tacir/ PDF_FILES/Education/SchFac.pdf 
APPENDIX A

PARTICIPANTS' CONSENT FORM 
Dear Workshop Participant,

Welcome to Holding Successful Bond Campaigns: NOT for Dummies.

Linda Florence, superintendent of Reynolds School District, is completing a project-based dissertation through Portland State University. This workshop and participant use of the handbook will help to satisfy requirements of her dissertation project. The handbook used is in its final stage of revision. During the workshop, she will request participants take a communications pre and post self-assessment tied to strategies in the handbook and the workshop and to complete a survey of their perceptions of the handbook and workshop. The results of the surveys about the handbook and workshop will be used in her research study.

This study is based on the research from survey respondents to improve a product Holding Successful Bond Campaigns: NOT for Dummies: the handbook and the workshop.

While participants will be asked district demographic data, individuals and their districts will not be identified in the study. No original names/districts are needed in the written report after the workshop. Participant information will be entirely confidential.

Participants are also asked to keep workshop discussions and identities of participants confidential.

Please sign this informed consent as part of the requirements of research at PSU.

Please review and sign below.

I agree to participate in the problem-based study School District Bond Campaigns: Strategies That Ensure Successful Outcomes. I understand that I will participate in pre and post self-assessments and a survey of the handbook and workshop. The research from these assessments and surveys will be entirely confidential.

I may be asked to complete a survey several weeks after the workshop to determine how I have used the handbook and workshop information.

Many thanks for your participation!

PRINT NAME

SIGNATURE DATE

\section{EMAIL}


APPENDIX B

INTERVIEW PROTOCOL 
Interview Protocol

Name___ Date

Position

District

Description

District Demographics

Enrollment

$\%$ Poverty

$\%$ Diversity

Number of Languages

\section{Primary Questions}

1. How useful and effective is the handbook to district leaders embarking on a school bond election?

2. How useful and effective is the workshop to district leaders embarking on a school bond election?

\section{Secondary Questions}

14. What effective strategies do districts employ to gain public support in school district construction bond elections?

15. What strategies are missing in the handbook? 
16. What strategies should be deleted for the handbook?

17. What are the current processes districts use to conduct a campaign?

18. Which strategies in the handbook are new to school districts? Which are commonly used?

19. How will the strategies in the handbook help districts plan a more focused and organized campaign?

20. Which pre-campaign strategies are most important to districts? (During the campaign; post campaign strategies?)

21. What strategies are considered innovative?

22. What strategies are considered common knowledge?

23. What campaign strategies are most effective for the particular needs each school district?

24. What communication strategies are most important to districts seeking a bond?

25. How does the handbook compare to other materials or information used by school districts to prepare for a bond election?

26. What improvements would district leaders make to the handbook?

Thank you for participating in this interview! 
APPENDIX C

SYLLABUS 


\title{
Holding Successful \\ School Bond
}

Campaigns: for Dummies

\section{Strategies That Ensure Successful Outcomes}

\author{
Workshop Plan
}

Date: $\quad$ September 27, 2013

Time: $\quad$ 8:30 a.m. to $3: 30$ p.m.

Location: COSA Conference Room

Facilitator: Linda Florence

Resource

Florence, L. L. (2013). Holding Successful School Bond Campaigns: NOT for

Dummies.

\section{Workshop Description}

This one-day workshop will lead participants through a handbook of proven strategies that successful districts use to gain support of voters in school construction bond elections. The workshop and handbook center on pre-bond campaign activities, during the campaign activities, and post-bond campaign activities. 


\section{Workshop and Handbook Goals and Objectives}

The goal of this workshop is to prepare district leaders for the multiple challenges of a school construction bond election. Today's school leaders are faced with a multitude of daily decisions and challenges. They do not have time to research requirements of a bond election. Yet a construction bond election is necessary for the maintenance of school buildings, upgrading and remodeling of buildings, and for new construction. The workshop and handbook will help district leaders become more knowledgeable in the bond election process and they will understand and be able to apply what is needed to pass a bond.

Participants will...

1. Assess current knowledge and skills

2. Understand and apply new vocabulary of school bond elections

3. Know and apply pre-, during- and post-bond activities

4. Understand the value of surveys to learn school-community perceptions

5. Construct a calendar of events

6. Plan a communications strategy

7. Evaluate the usefulness of the handbook as a tool for passing a bond

\section{PROGRAM}

\section{PRE-ASSIGNMENT}

1. Participants will take a self-assessment to determine their understanding of a construction bond election.

\section{PLANNED WORKSHOP ACTIVITIES}

- Introductions

- Workshop Overview

- Rationale for Workshop

- Defining Steps in School Bond Election Process

- Communications Template

- Timeline Template

- Collaborative Group Discussions

- SWOT Analysis

\section{PRE-BOND ACTIVITIES}

- Evaluate School \& Community Relations

- Garner Support

- Create the Communications Plan

- Enlist Key Community Leaders

- Develop \& Publish the Long-Range Facilities Plan

- Identify Construction Projects \& Costs 
- Conduct a Survey

- Prepare for the Bond Campaign

- Select Consultants

- Develop the Bond Calendar

- Create Campaign Literature \& Organize Activities

- Communicate with Media

- Utilize Contemporary Marketing Strategies

\section{DURING-BOND ACTIVITIES}

- Count Down to Election Day: 90-day, 60-day, 30-day plan

- Celebrate the Win

\section{POST-BOND ACTIVITIES}

- Next Steps: Example of RFPs, Construction management, architects, citizen oversight, district oversight team

- Epilogue

Words of Wisdom: "Follow through and follow up!" If the district plans to be successful in future bond levies, the superintendent and board need to act as prudent guardians of taxpayers' dollars. Open, honest communication must continue throughout the building process with updated information on the website, in the papers, in newsletters, several tours, ribbon cuttings, celebrations, and "Thank You's."

\section{POST WORKSHOP}

- Evaluation of Workshop and Handbook on SurveyMonkey 
APPENDIX D

WORKSHOP POWERPOINT PRESENTATION 


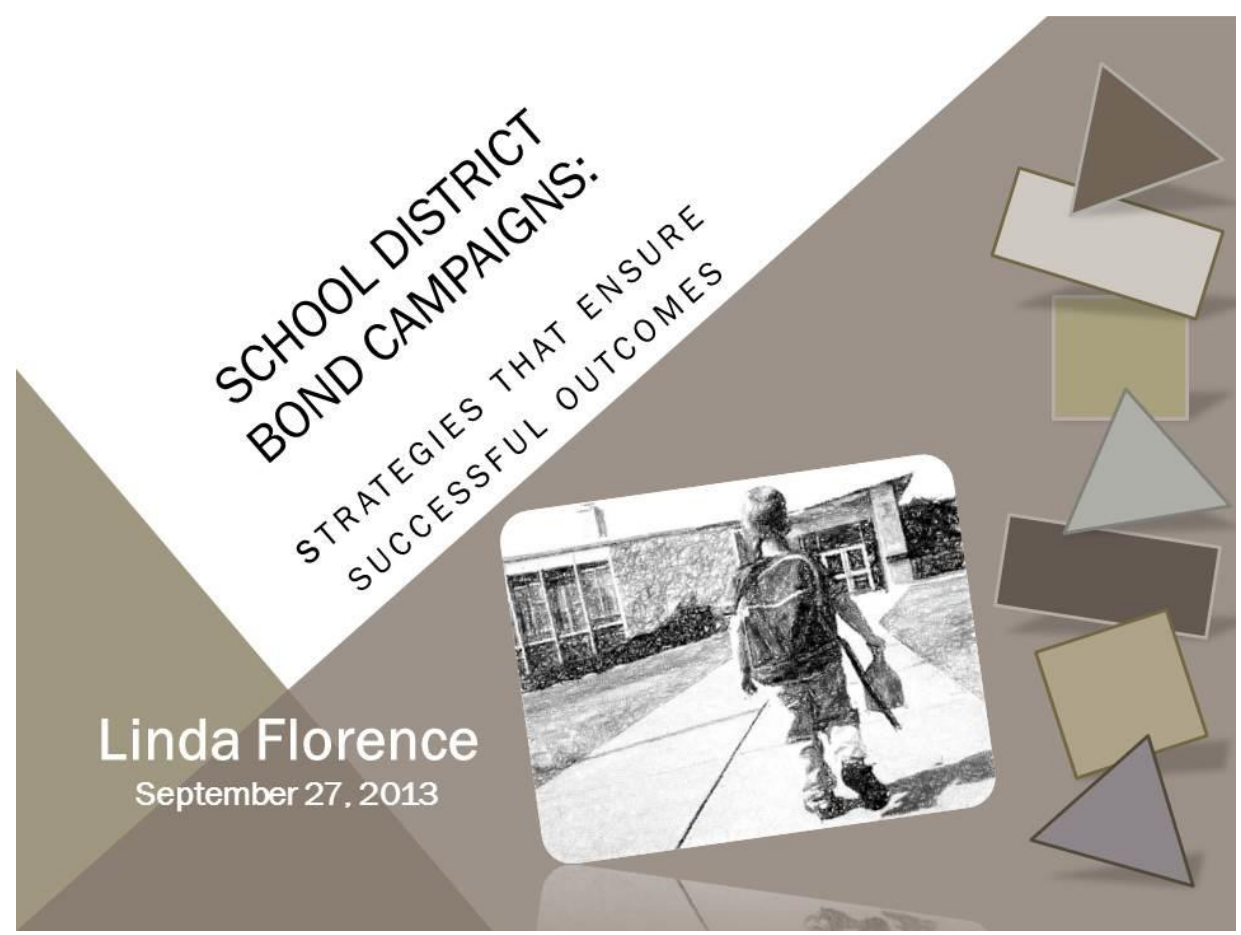

HOUSEKEEPING

\section{PORTLAND STATE UNIVERSITY STUDY}

The study is both anonymous and confidential and participants' identities will be kept private. The information collected cannot be traced back to individual participants because participants will be identified by numbers or pseudonyms and not by names or districts. No original names/districts are needed in the written report after the workshop.

You are asked to sign an informed consent form as part of the requirements of research at PSU.

Please review and sign the consent form. 


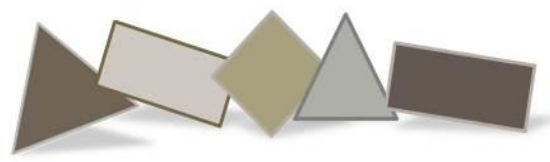

AGENDA

1. Welcome and Introductions

2. Communication Pre-Assessment

3. Today's Objectives/Agenda

4. Introduction to the Handbook

5. Tale of Two Districts

6. Sharing Stories

7. Communication, Communication, Communication

8. Foundation: Teaching and Learning Connection
September 27, 2013

9. Pre-Bond Campaign Activities

10.Pre-Bond Activities, Con't

11. During the Campaign Activities

12. Post Campaign Activities

13. Summation

14. Post Bond Assessment

15.SurveyMonkey Handbook \& Workshop Assessment

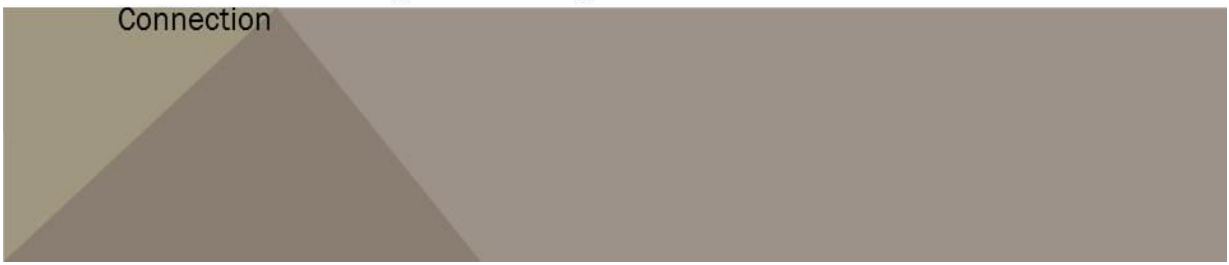

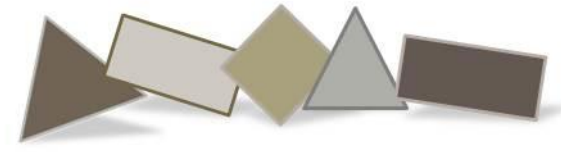

OBJECTIVES

1. Assess current knowledge and skills

2. Understand and apply new vocabulary of school bond elections

3. Know and apply pre-, duringand post-bond activities
4. Understand the value of surveys to learn school-community perceptions

5. Construct a calendar of events

6. Plan a communications strategy

7. Evaluate the usefulness, effectiveness, and importance of the handbook as a tool for passing a bond 


\section{PRE-WORKSHOP ASSESSMENT: SURVEYMONKEY}

\section{SECTION 1: Communication:}

- Level of Familiarity of Communication Theory and Practices

- Level of Comfort with Communication Theory and Practices

- Areas participants perceive they need the most help

\section{PRE-WORKSHOP ASSESSMENT:} SURVEYMONKEY

\section{SECTION 2: School Bond Campaign Strategies}

- Level of Familiarity of School Bond Campaign Strategies

- Level of Comfort with School Bond Campaign Strategies

- Areas participants perceive they need the most help 


\title{
ACCESSING SURVEYMONKEY
}

\author{
Pre-Test Self Assessment
}

https://www.surveymonkey.com/s/92713pretest

Thank you!

APPLAUSE

\section{BACKGROUND}

- My Personal Journey

o High school principal

o Superintendent of small school district

o Superintendent of medium-sized school district

- Reynolds School District Superintendent

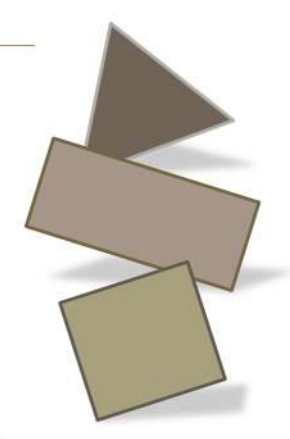




\section{THE PROBLEM}

- Introduction

o Seventy percent of the nation's schools need remodeling (Picus, n.d.)

- Sixty percent are successful in passing a bond (OSBA, 2012)

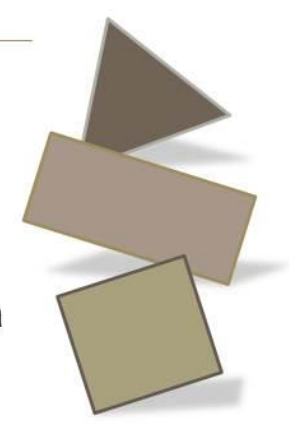

\section{THE PROBLEM}

- Need for capital improvements and new construction

- Aging, dilapidated schools

- Safety, repair of deteriorated buildings, updated learning environments

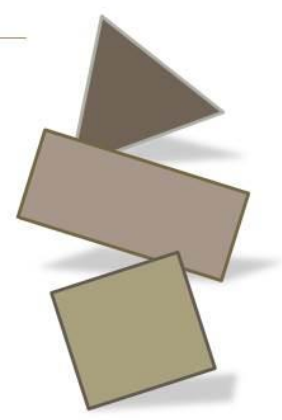




\section{THE PROBLEM}

Children are learning under third world conditions...toilets not replaced since the 1950s, asbestos, poor temperature control, peeling paint, old furnaces, dirty windows and brown water, cracked floors, 30 adults using two telephones, poor ventilation, outdated electronics... Right now our schools are crumbling. 99 (PPS parent)
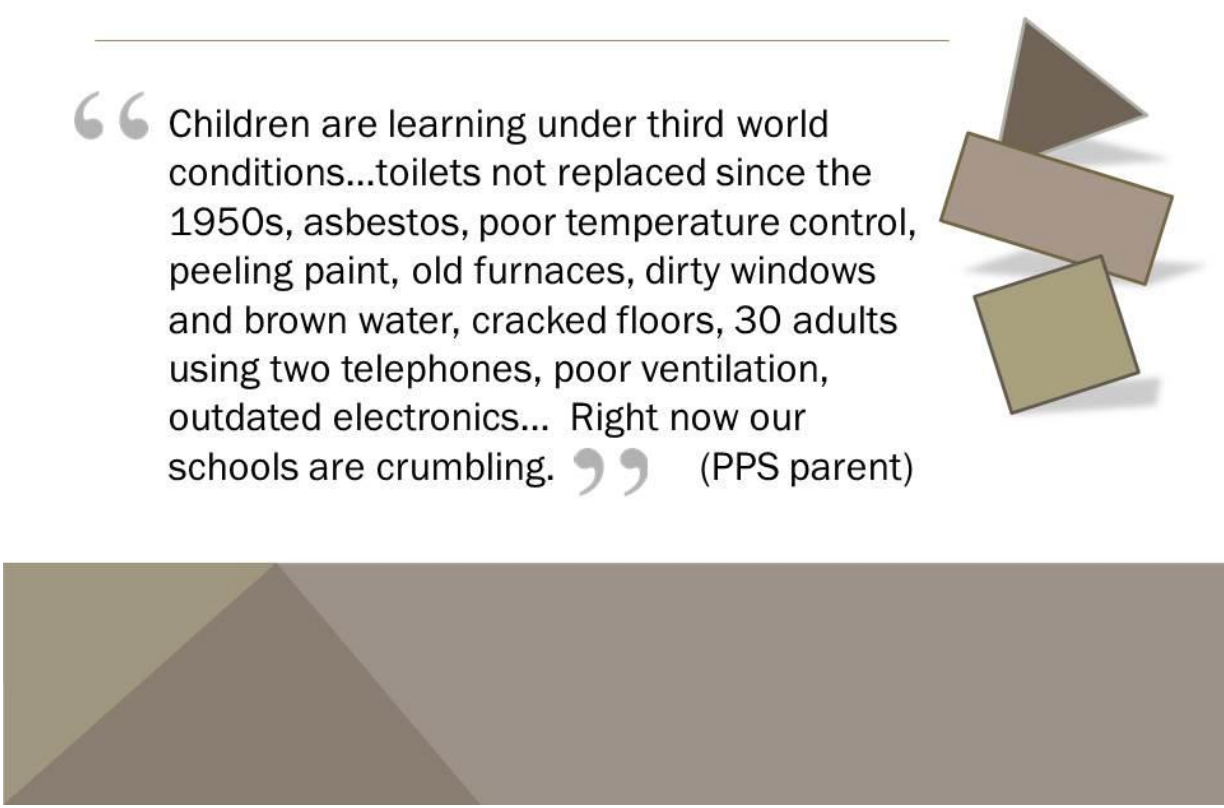

TALE OF TWO DISTRICTS

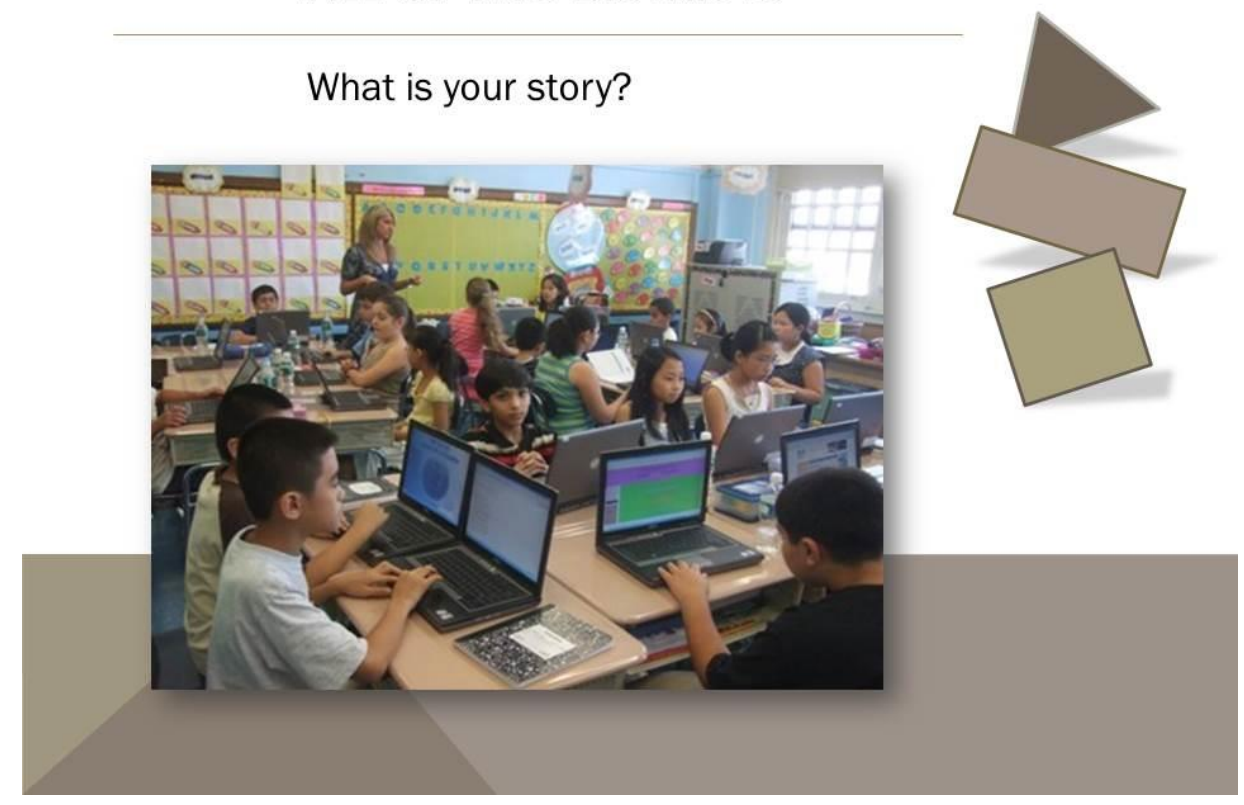




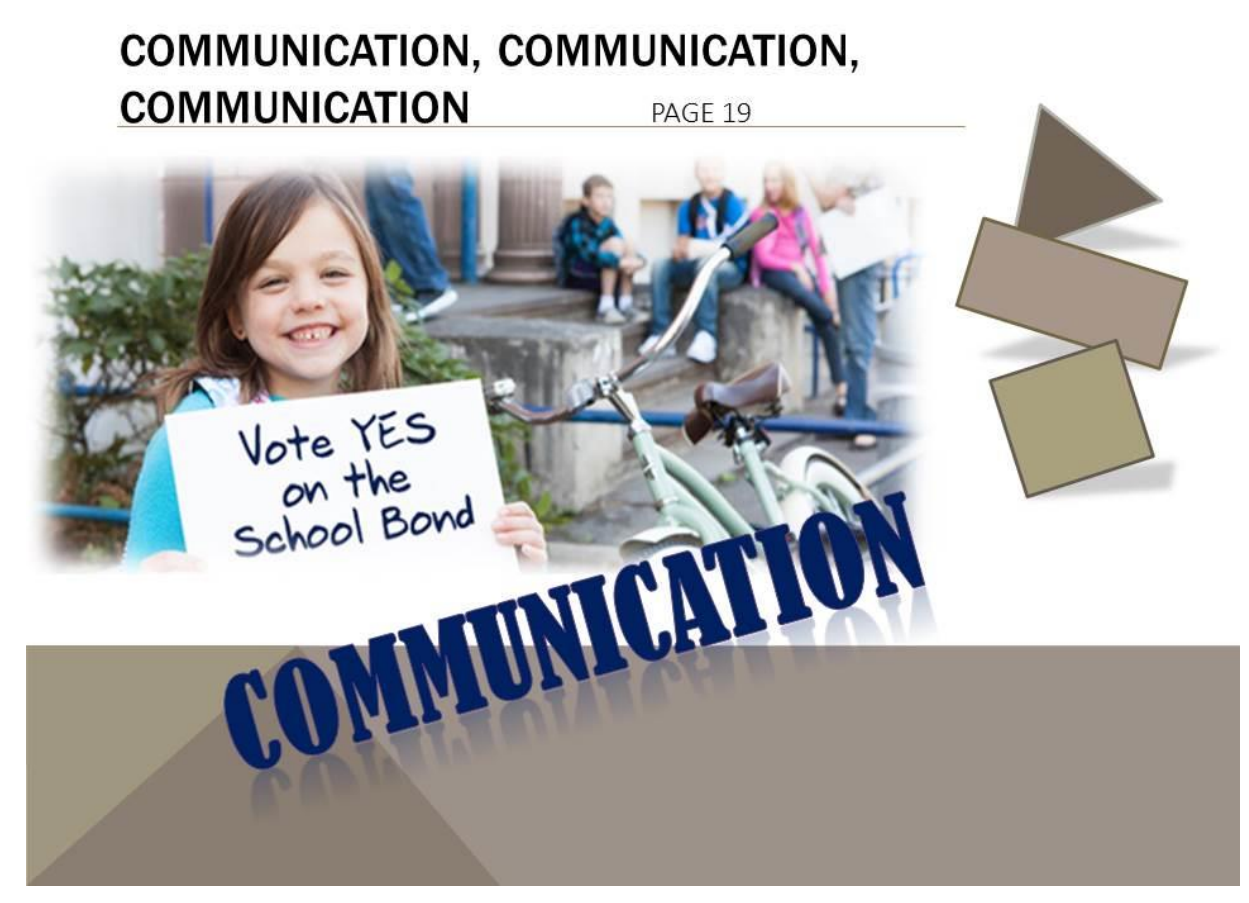

\section{COMMUNICATION THEORY AND PRACTICE}

- Introduction

- Lack of literature/research on passing bonds

- Few workshops on passing bonds

- Not sufficiently addressed in administrators' licensure programs

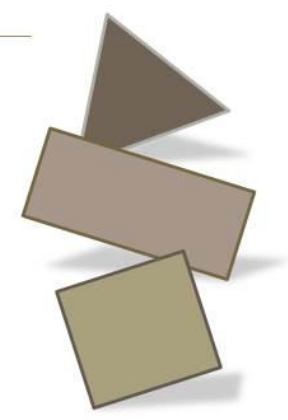

- Importance of effective communication 


\section{COMMUNICATION THEORY \& PRACTICE}

- Communication, page 19

- Organizational communication, page 23

- School \& community relations, page 30

- Marketing strategies, page 37

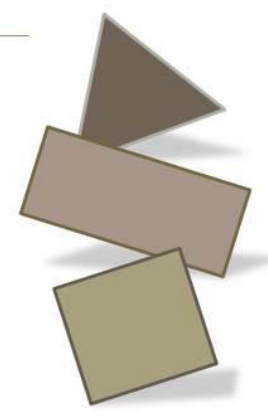

COMMUNICATION THEORY \& PRACTICE

- Organizational Communication

o Formal and Informal, page 23

\begin{tabular}{|l|l|l|}
\hline & FORMAL & INFORMAL \\
\hline DESCRIPTION & $\begin{array}{l}\text { Planned, } \\
\text { intentional, } \\
\text { controlled }\end{array}$ & $\begin{array}{l}\text { Unplanned, } \\
\text { unintentional, not } \\
\text { controlled, brief }\end{array}$ \\
\hline
\end{tabular}

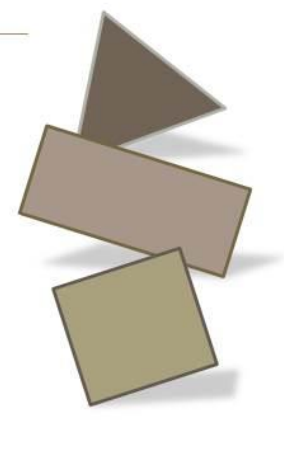




\section{COMMUNICATION THEORY \& PRACTICE}

- Organizational Communication

ONE-WAY COMMUNICATION, page 24

(Sender) SCHOOL

(Receiver) HOME
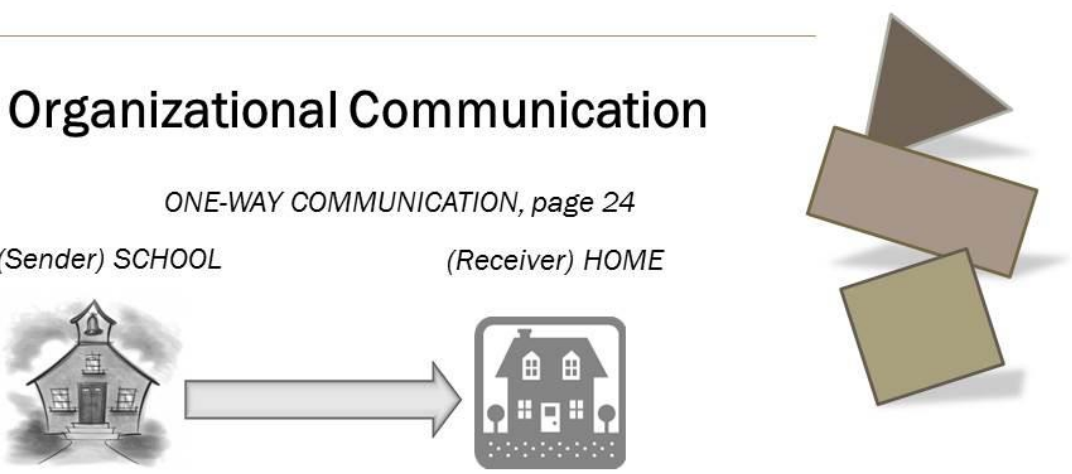

COMMUNICATION THEORY \& PRACTICE

- Organizational Communication

TWO-WAY COMMUNICATION, page 25

$\mathrm{SCHOOL}$

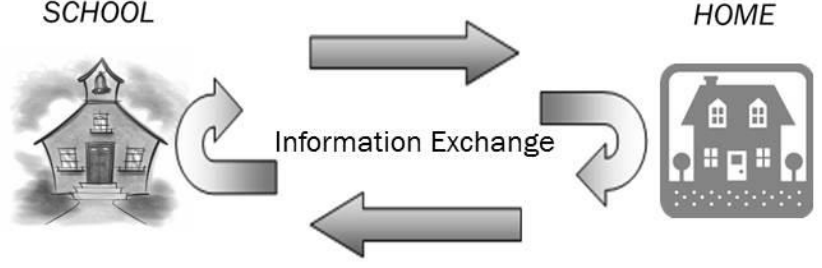

Information Exchange

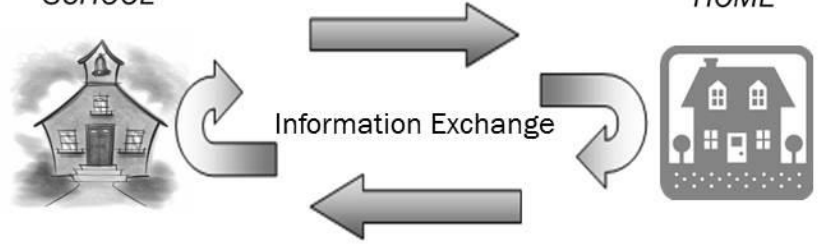

HOME

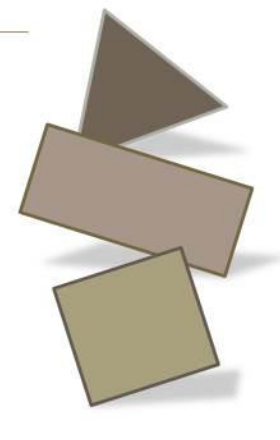




\section{COMMUNICATION THEORY \& PRACTICE}

- Organizational communication

- Internal \& external publics, page 26
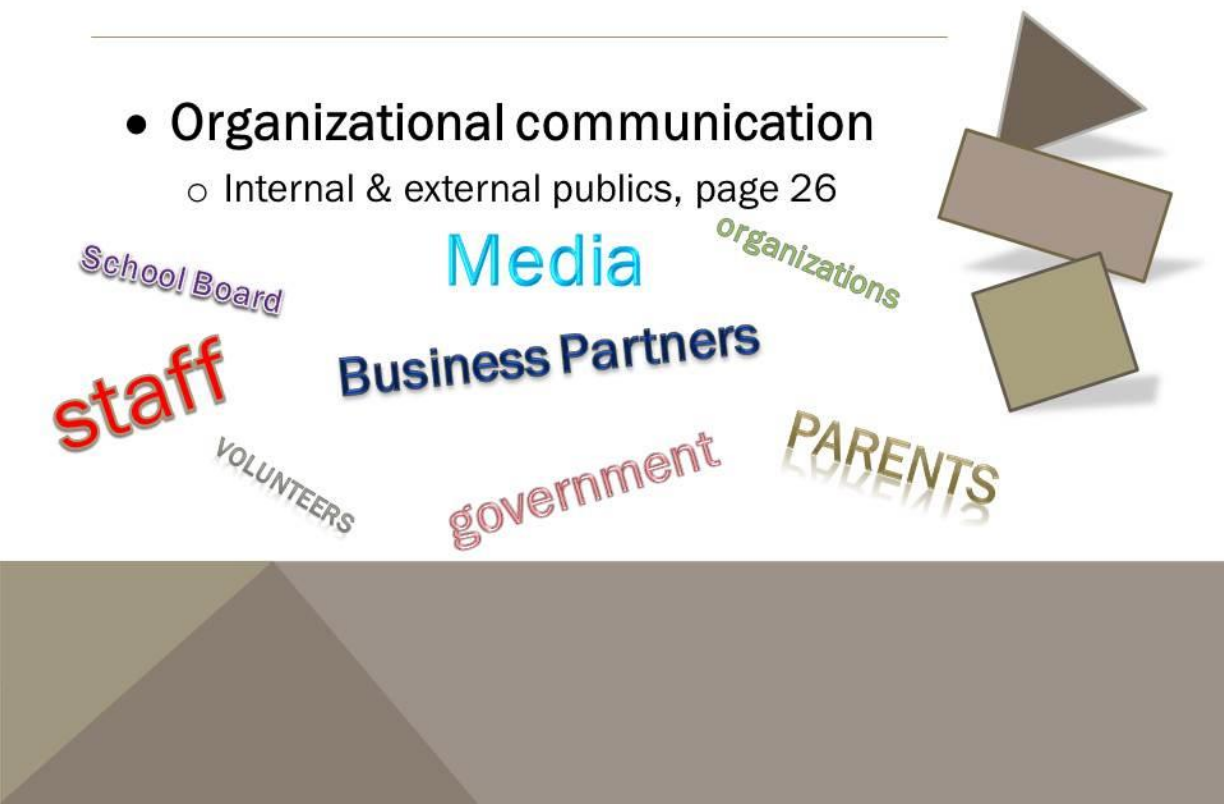

COMMUNICATION THEORY \& PRACTICE

- Organizational communication

- Communication as a leadership skill, page 29

Building public support for school is not something an effective school

administrator does on the side. It should

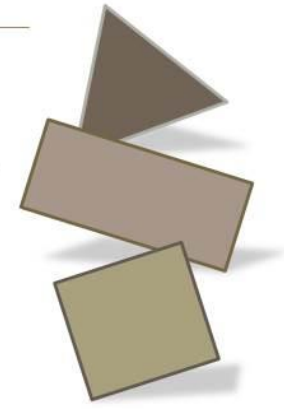
in fact be the first act of survival. 99

(Hoyle, English, \& Steffy, 1994) 


\section{COMMUNICATION THEORY \& PRACTICE}

6 ...leaders must be judged on their commitment to communicate, their skill in doing so, and the extent to which they can bring stakeholders together through communication. 9) (Gunther, 2012)

Bagin, Gallagher, \& Moore (2008) refer to the

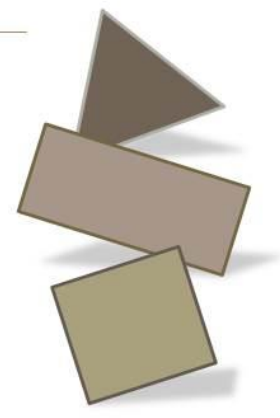
superintendent's role as an "educational diplomat." Skills go beyond writing, speaking, and listening well.

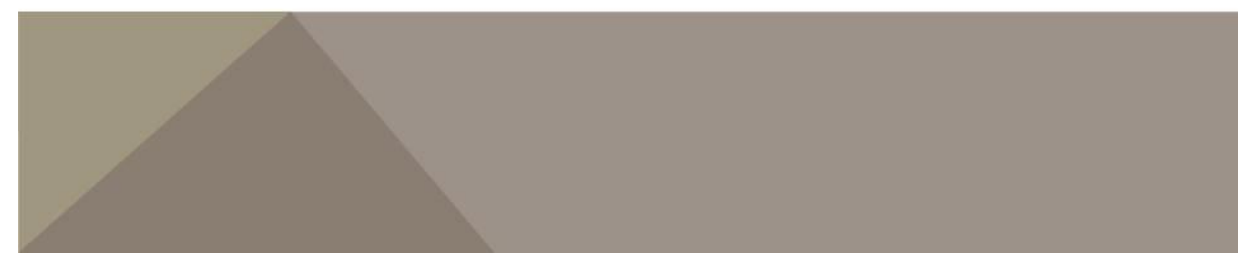

\section{COMMUNICATION THEORY \& PRACTICE}

- School \& community relations

- Perceptions of schools, page 31

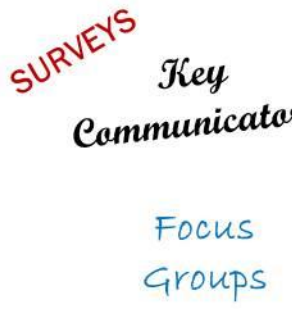

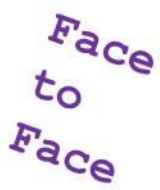

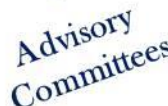

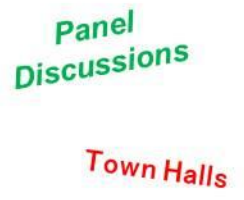

FORUMS

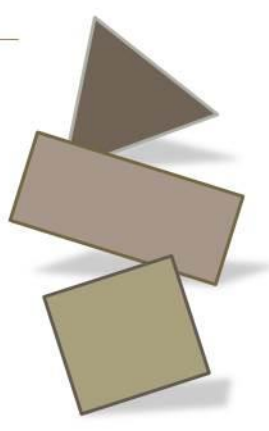

Cormenting 
COMMUNICATION THEORY \& PRACTICE

Continuum for Communication Media and Richness, page 32

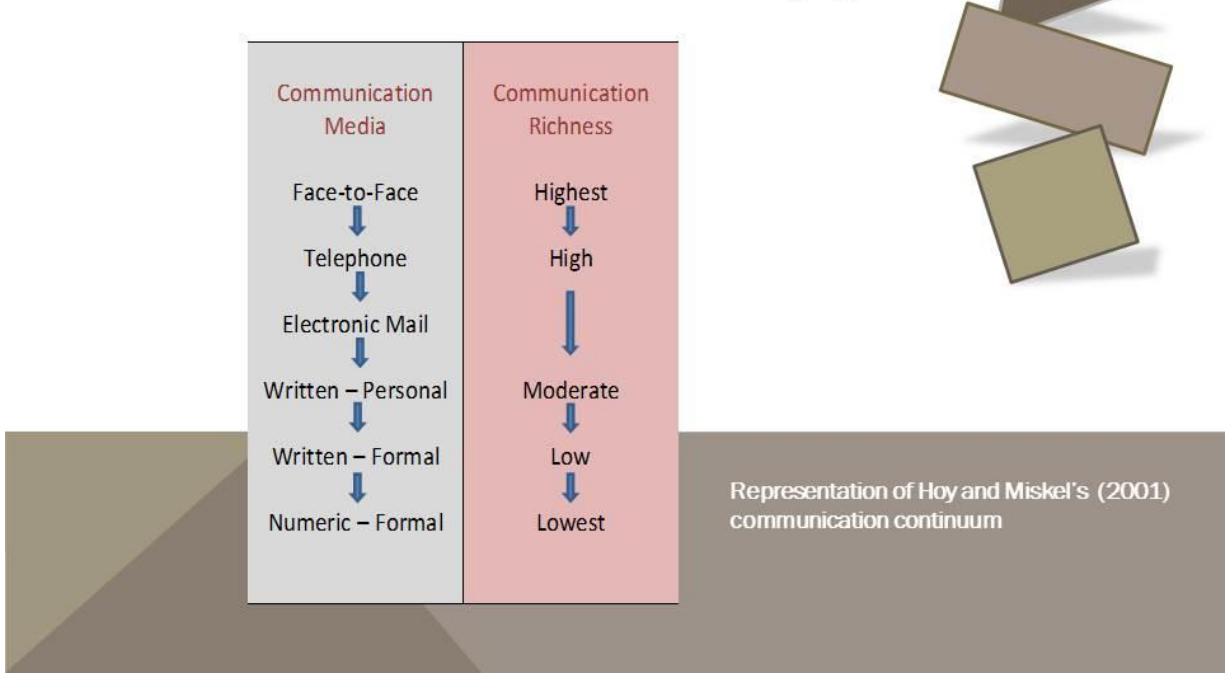

COMMUNICATION THEORY \& PRACTICE

- School \& community relations

- Strategies for internal \& external communications, page 33

66 Trying to pass a finance referendum without a formal plan in place is like hiring a carpenter to frame a house without first constructing the foundation. 9 (Campbell \& Magmire, 2007)

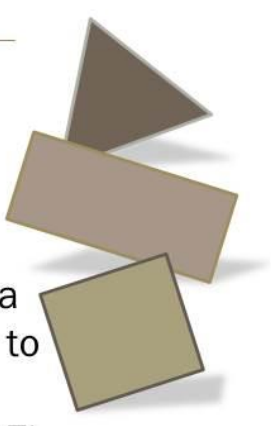




\section{COMMUNICATION THEORY \& PRACTICE}

1. Focus energy on overall climate of the school and district (Fiore, 2011)

2. Identify internal and external stakeholders/develop communication strategies (Hoyle, et al., 1994)

3. Eliminate educational jargon (Bagin, et al., 2008)

4. Offer advisory committees for employee groups; offer new staff orientation (Bagin and Gallagher 2001)

\section{COMMUNICATION THEORY \& PRACTICE}

Two-way communication with your employees is fundamental to the smooth operation of your organization. Employees help make change happen... Staff members must feel engaged in the mission of the school... Your job as leader is to make them feel part of the team. 9 (Porterfield \& Carnes 2012)

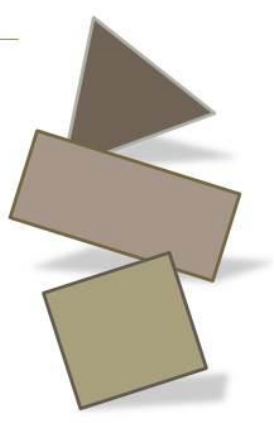




\section{COMMUNICATION THEORY \& PRACTICE}

Massed produced one-way communication strategies are least effective.

Most effective:

1. Face to face \& one to one

2. Small group discussions or meetings

3. Speaking before a large group

4. Telephone conversation

5. Handwritten or typed personal notes or letters

6. Personal form letter

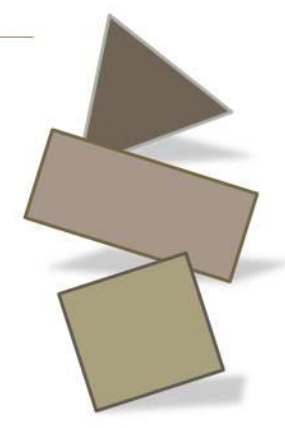

(National School Public Relations, 2007)

\section{COMMUNICATION THEORY \& PRACTICE}

- School \& community relations

o Media relations, page 35

66 Wounded and Bloody 99 or

Naively Optimistic 9

(Kowalski et al., 2007)

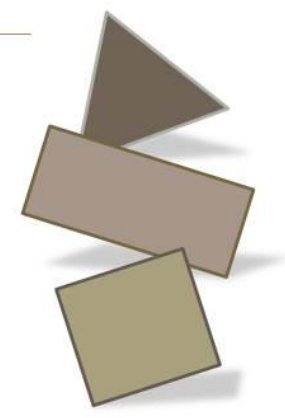



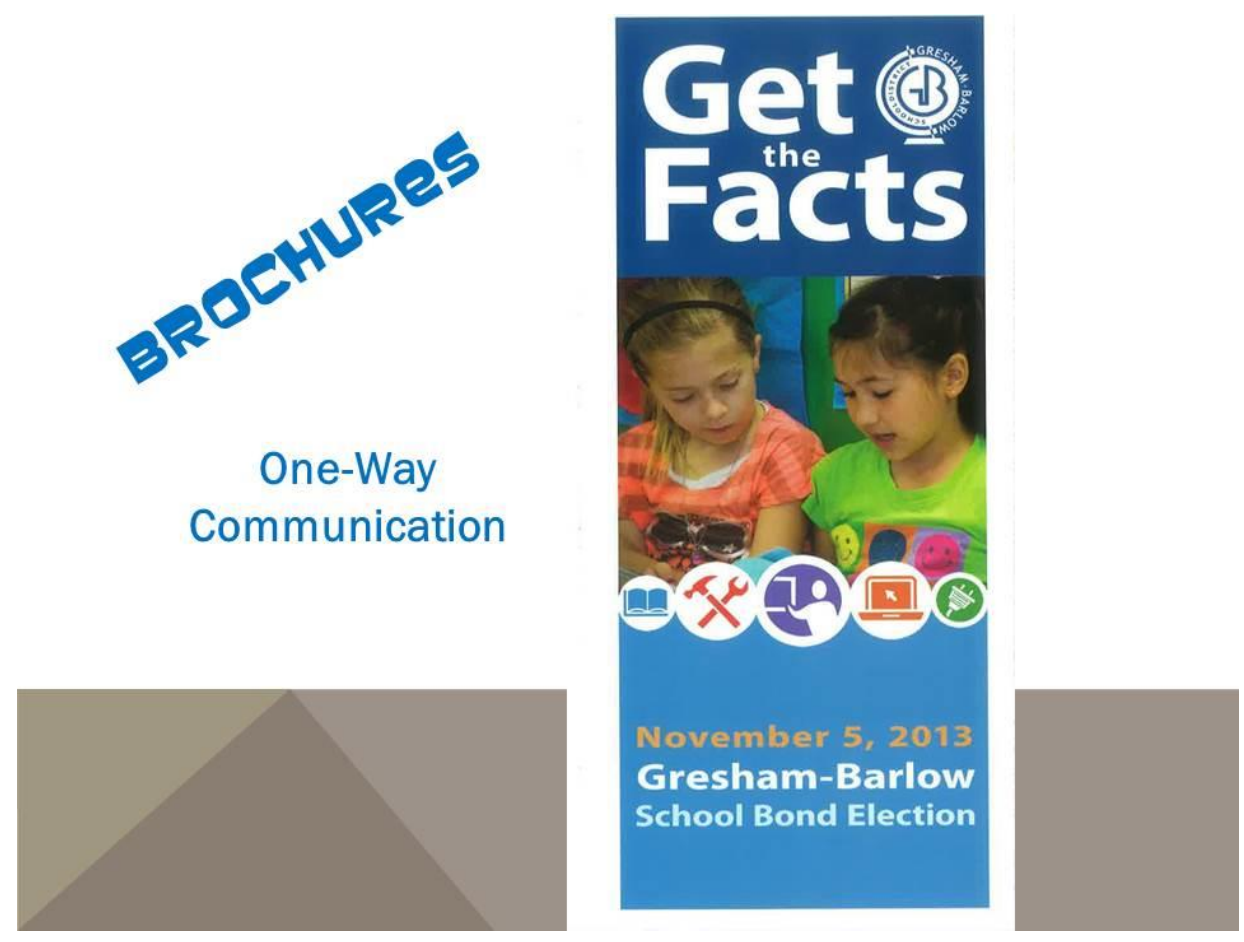

\section{COMMUNICATION THEORY \& PRACTICE}

- Marketing techniques, tools, and publications, page 39

- Direct mail

- Free media

- Letters to the editor

- Material drops to homes

- Paid advertising: Print and broadcast media

- Public speaking

- Telephone banks

- Meet and greet (Carroll \& Carroll, 2000; (Campbell \& Magmer, 2007; Porterfield \& Carnes, 2012) 


\section{COMMUNICATION THEORY \& PRACTICE}

- Types of contemporary media beneficial to bond campaigns: Blogs, gamification, ideation programs, podcasts, really simple syndication, social networks, Twitter town hall, wikies, video

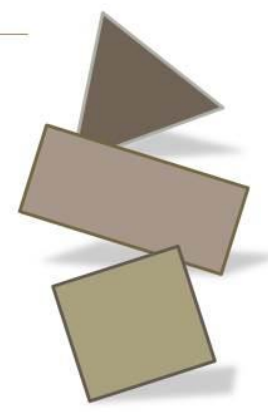

(Gagne, 2012; Smith, 2008)

\section{REVIEW OF THE RESEARCH LITERATURE}

- Marketing strategies

o Social media, page 41

I'm convinced that if schools want to improve their image with taxpayers, they must begin to use social media. 9 (Gagne, 2012)

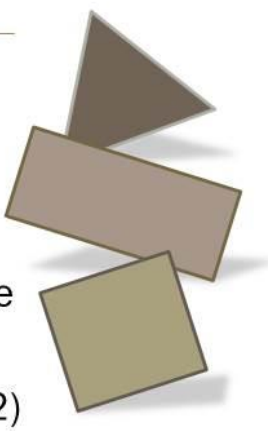




\section{REVIEW OF THE RESEARCH LITERATURE}

- Marketing strategies

o Social media, page 41

66 You can't market a poor product. No amount of marketing will help. Sooner or later, everyone recognizes lipstick on a pig. ?9

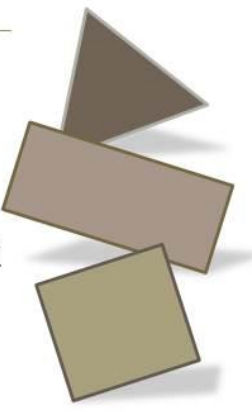

Porterfield and Carnes (2008)

\section{FOUNDATION:}

\section{TEACHING AND LEARNING CONNECTION}

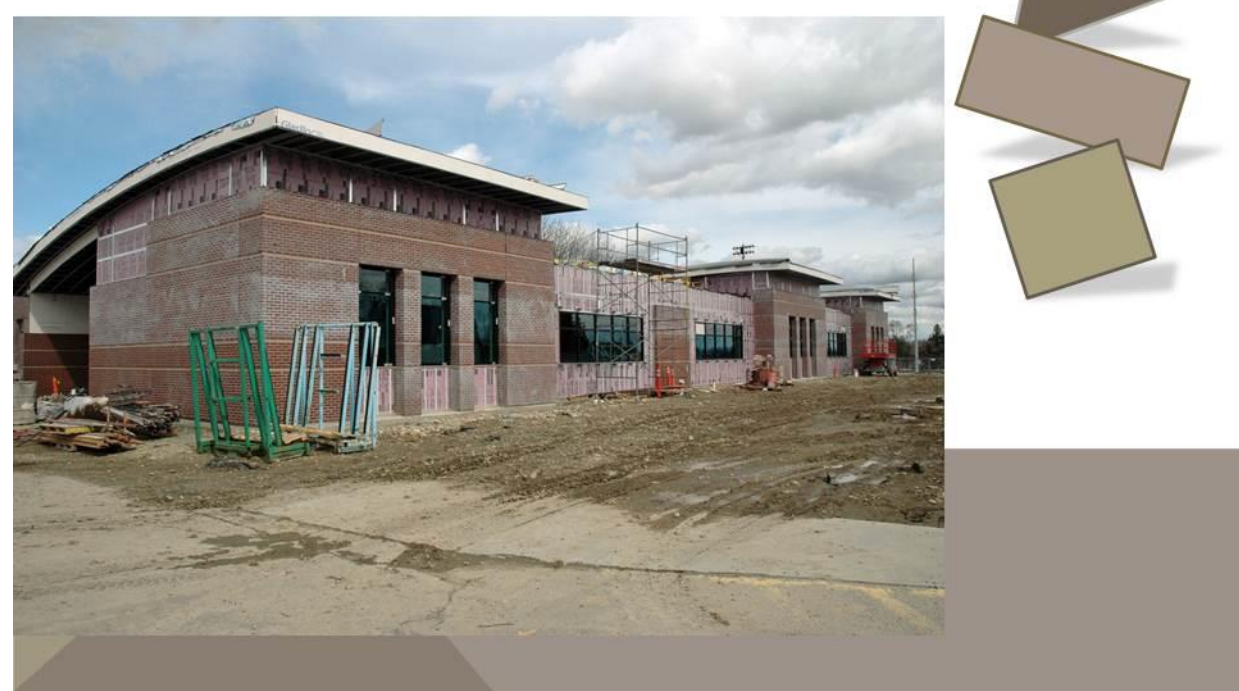


FOUNDATION:

TEACHING AND LEARNING CONNECTION

Rationale for Construction

Bonds, page 47

Schools designed to facilitate the best possible education for all students in $21^{\text {st }}$ century learning ...

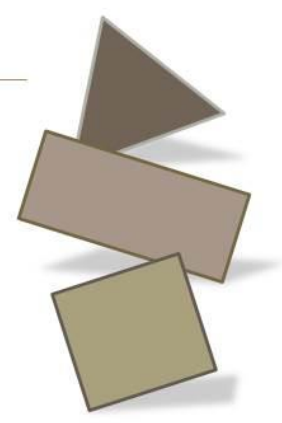

FOUNDATION:

TEACHING AND LEARNING CONNECTION

Teaching and Working

Conditions and Job

Satisfaction, page 50.

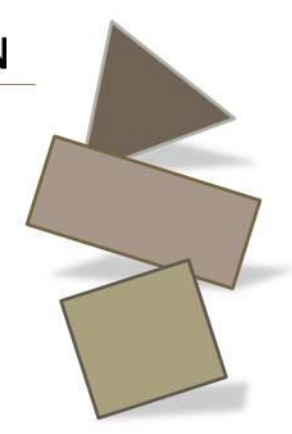


FOUNDATION:

TEACHING AND LEARNING CONNECTION

Research: Connections between the condition of schools and student learning, page 51

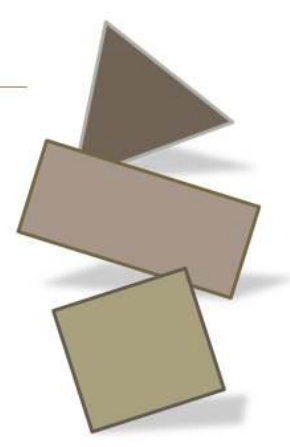

FOUNDATION:

TEACHING AND LEARNING CONNECTION

- Age of Building

- Acoustics

- Lighting

- Temperature

- Air Quality, pages 50-55

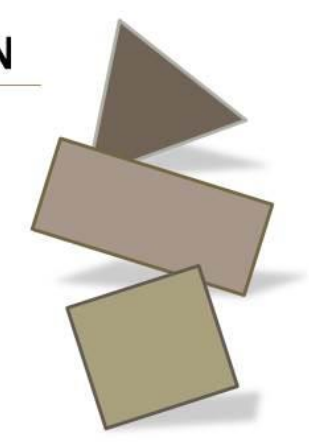




\section{FOUNDATION:}

\section{TEACHING AND LEARNING CONNECTION}

- Health, Safety, \& Climate

- School Size

- Beauty \& Aesthetics

- The Community School

- Technology

- Green Design, pages 50-55

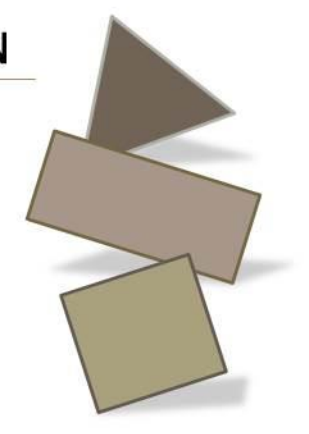

\section{FOUNDATION:}

\section{TEACHING AND LEARNING CONNECTION}

Connections between the Condition of Schools and Student Learning

- How do we educate the public about $21^{\text {st }}$ century teaching and learning and gain voters' support?

- What should $21^{\text {st }}$ century classrooms/schools look like?

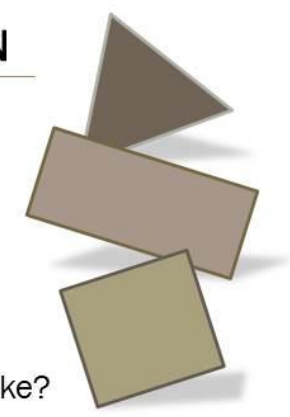


FOUNDATION:

TEACHING AND LEARNING CONNECTION

Sports, Activities, \& Student Academic Achievement

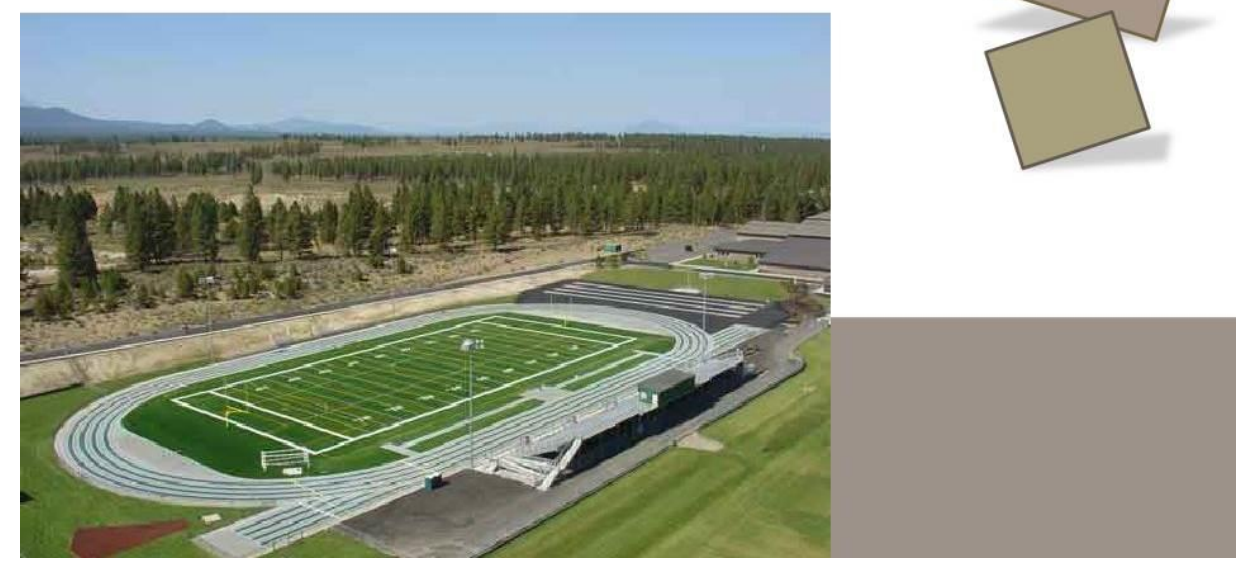

BREAK

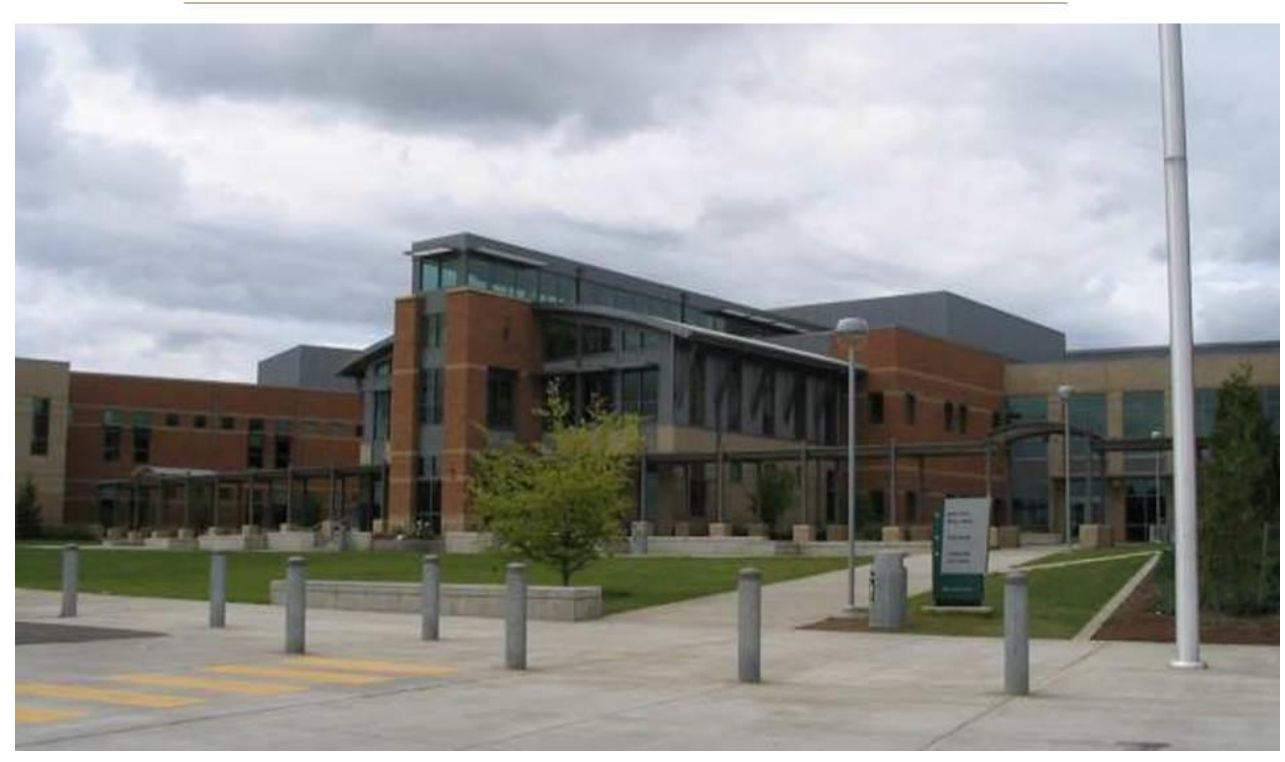



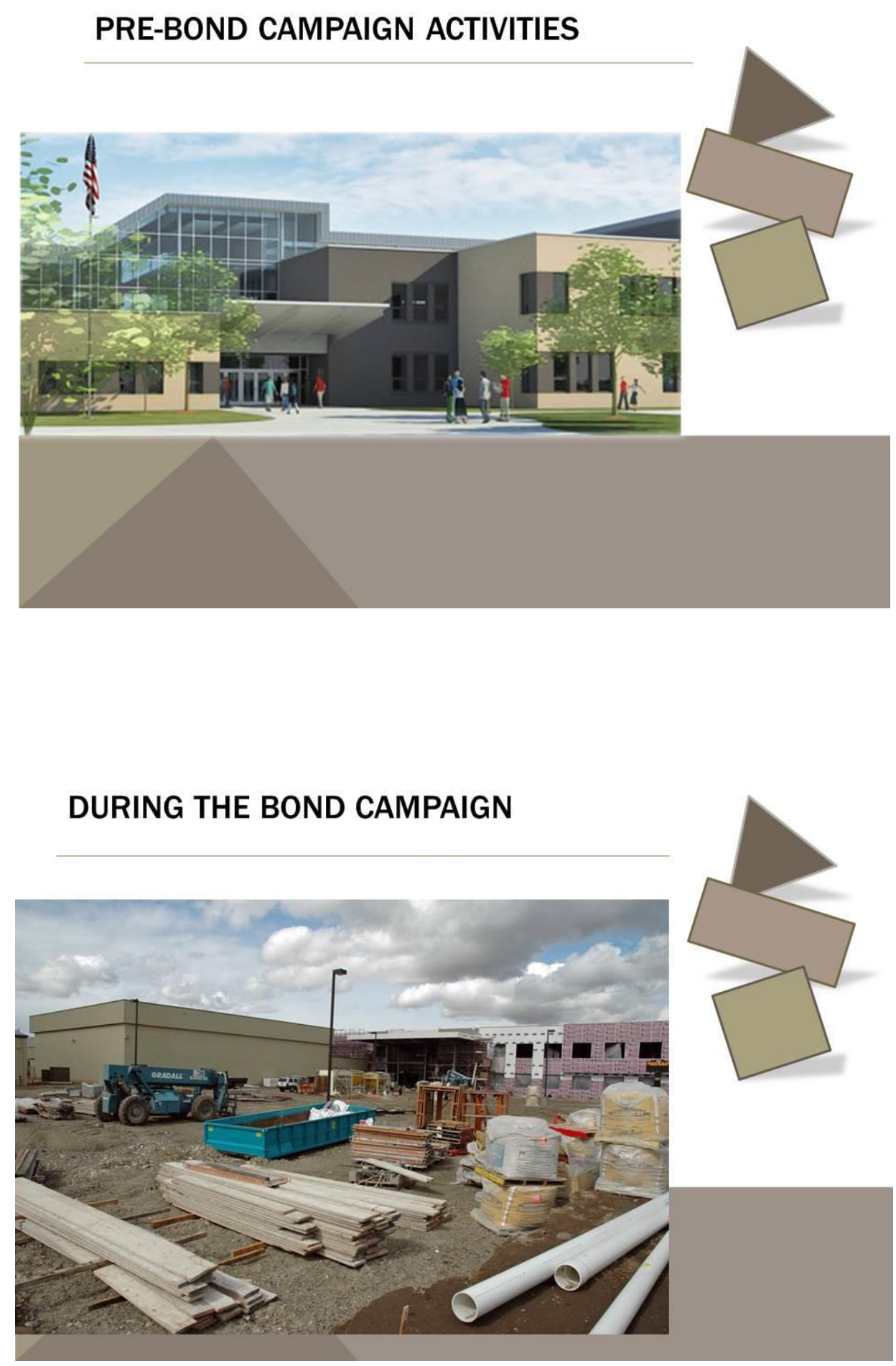


\section{DURING THE BOND CAMPAIGN}

- Count Down to Election Day

- Celebrate the Win
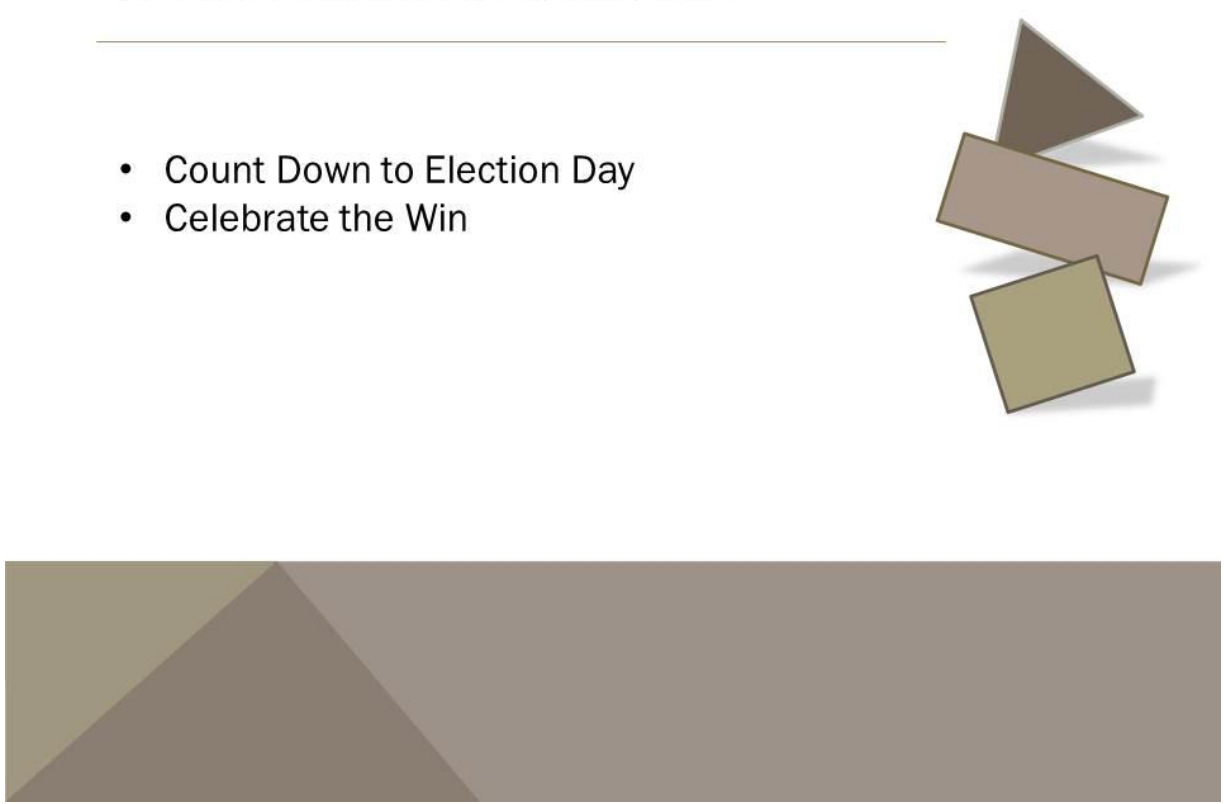

AFTER THE BOND CAMPAIGN

- Next steps

- Epilogue:SWOT analysis
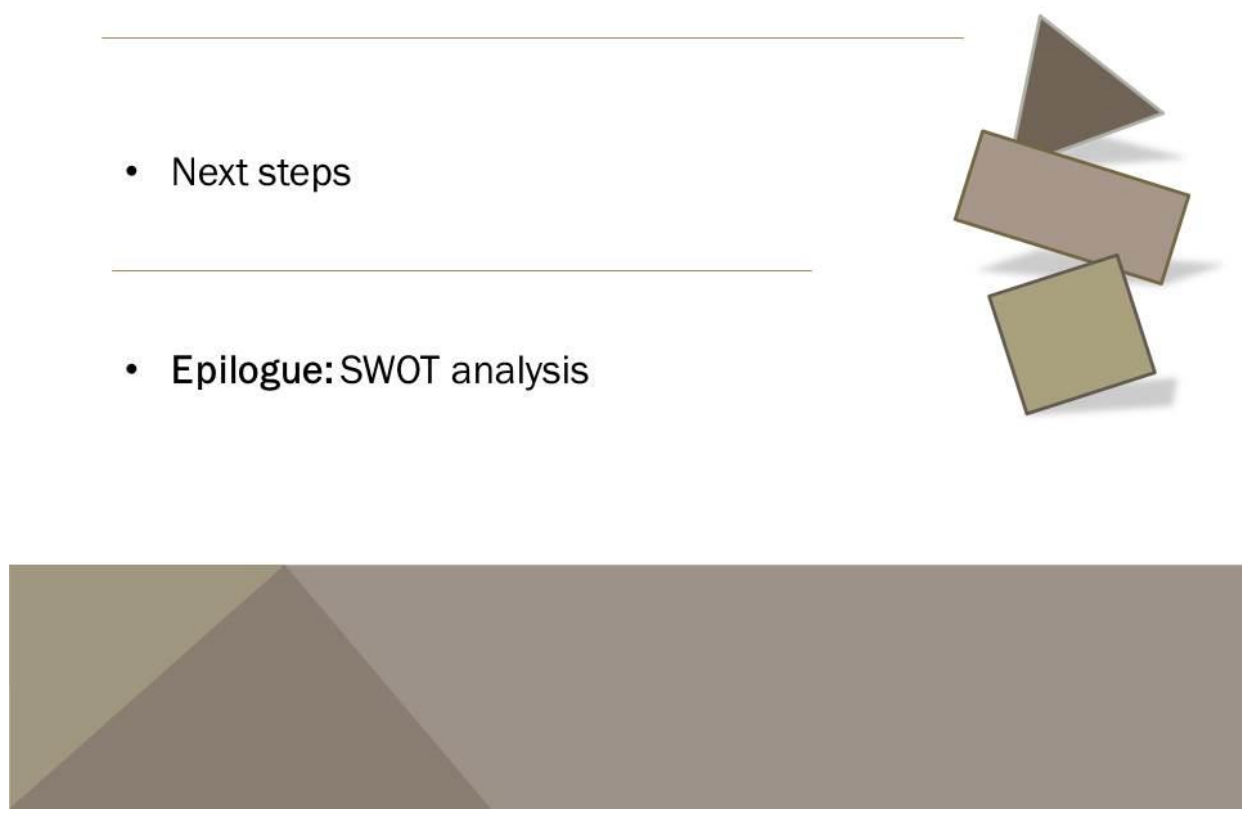

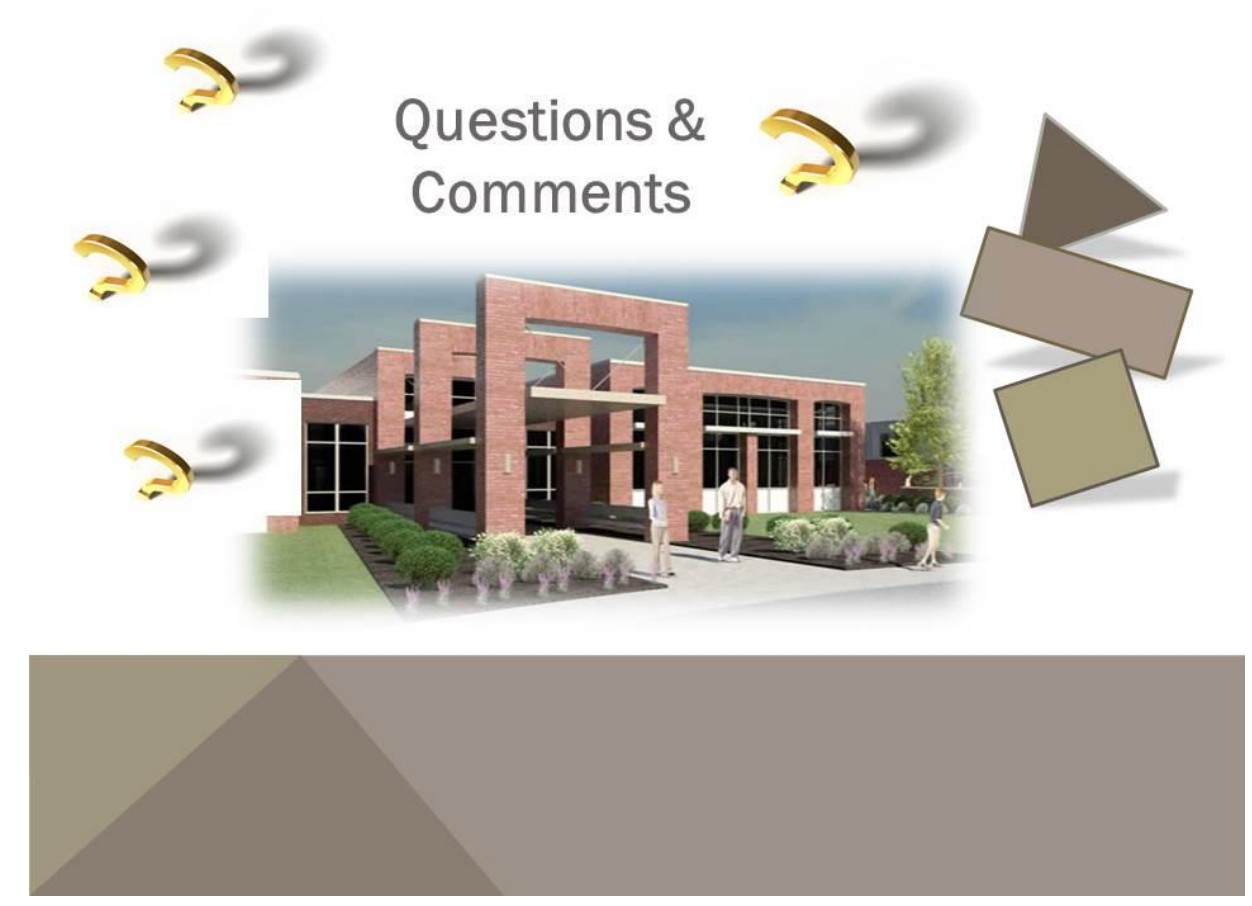

- Communication Post Assessment https://www.surveymonkey.com/s/92713posttest

- Handbook and WorkshopSurvey

https://www.surveymonkey.com/s/92713workshop

\section{Thank you!}

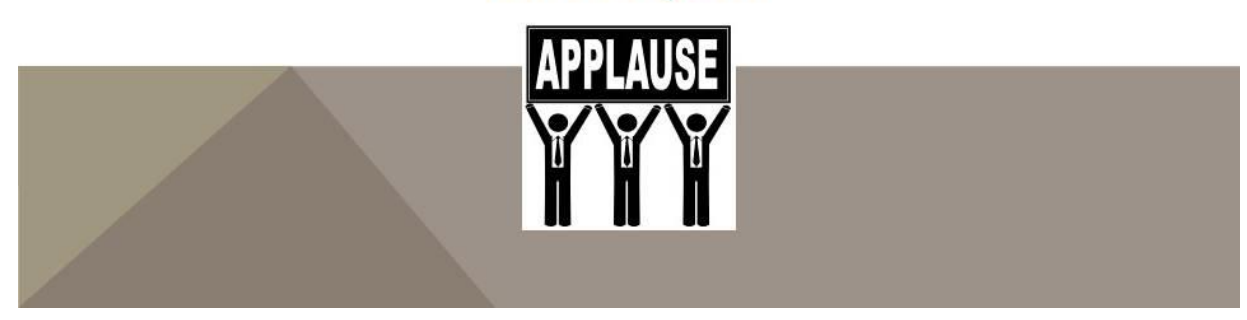


APPENDIX E

WORKSHOP BROCHURE 


\section{School District Construction}

\section{Bond Campaigns:}

\section{Strategies That Ensure}

\section{Successful Outcomes}

This one-day workshop will lead participants through a handbook of proven strategies that successful districts use to gain support of the public in school bond elections.

The workshop and handbook, which are free to those who participate, lead participants through pre-bond campaign, during the campaign, and post-bond campaign activities.

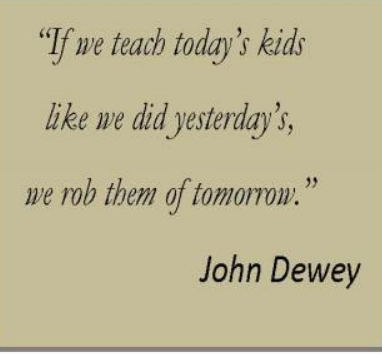

FRIDAY, SEPTEMBER 27, 2013

8:30 AM - 3:30 PM

COSA, Salem, Oregon

Who should attend this workshop?

School Districts

Superintendents

Communication Directors

Directors of

Operations/Finance

Board Members

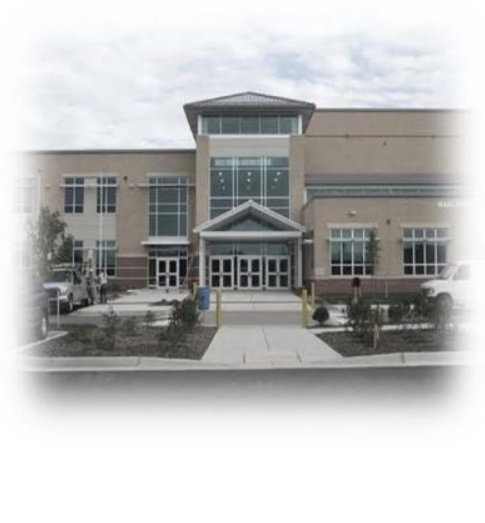

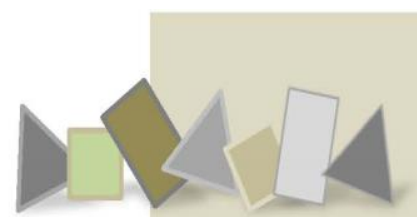

Holding Successful

School Bond

Campaigns:

ot for Dummies
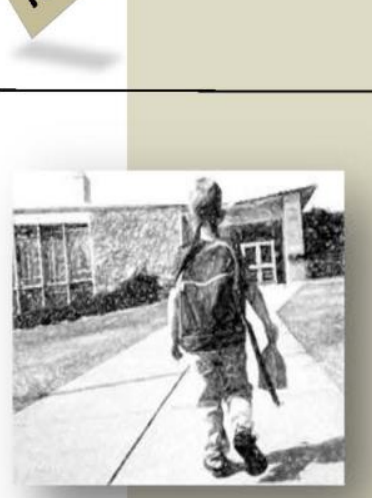

When:

September 27, 2013 8:30 AM-3:30 PM

Where: COSA, Salem, Oregon $70713^{\text {th }}$ St. SE, STE. 100

$\$ 15$ Registration Fee: For Breakfast \& Lunch

Contact:

lflorence@rsd7.net 
What is the answer for school districts that are in dire need of upgrading outdated, crumbling schools? I wish I could say that any school district can win a bond campaign in four easy steps. That, however, is not the case. It does take work - not the work of the superintendent or a principal or a board member. It takes the collective work of the entire school district

\section{Holding Successful} School Bond Campaigns: community.

Whether a $\$ 4$ million or $\$ 400$ million bond, certain strategies play a key role in the success of a bond campaign. When districts employ these strategies, the outcome is more likely to be a festive celebration of winning at the polls instead of a pity party wallowing in a defeated campaign.

All students deserve new and improved buildings in which to learn. But as long as new construction, remodeling, and upgrades require a vote of the taxpayers, there will be defeated measures. Only about 60 percent of school bond measures passed in the last five years in Oregon. Those percentages are less nationally. Why? Only 18 to 30 percent of the taxpayers have children in school, depending on the location of the school district, and they are the ones who typically vote in favor of bond measures. That is not an encouraging statistic for districts in urgent need of improvements.

deteriorate. Children need safe, warm, and dry schools in which to learn and new equipment and technologies to advance to higher levels.

This handbook is the result of studying several failed bond measures and several successful ones and compiling the strategies that make a campaign successful.

Contact Linda Florence at Iflorence@rsd7.net to begin registration. Text: 503-508-6827

This workshop and handbook will assist districts in making more informed decisions about their bond campaign and provide the strategic steps to ensure they win at the polls.

\section{ABOUT THE PRESENTER}

Linda Florence, superintendent of Reynolds School District, is completing a project-based dissertation through Portland State University. This workshop and use of the handbook will help to satisfy requirements of her dissertation project. The handbook used is in its final stage of revision. She will be requesting participants in the workshop to complete a survey of their perceptions of the workshop and handbook. The results of the survey about the handbook and workshop will be used in her research but participants will not be identified.

Linda passed a bond election in Ontario School District in May 2010, the first to pass in the district in 30 years and during one of the worst recessions in U.S. history. 


\section{APPENDIX F}

WORKSHOP NAME PLATES 


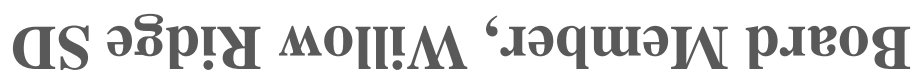
NOSXVT MAYUNV
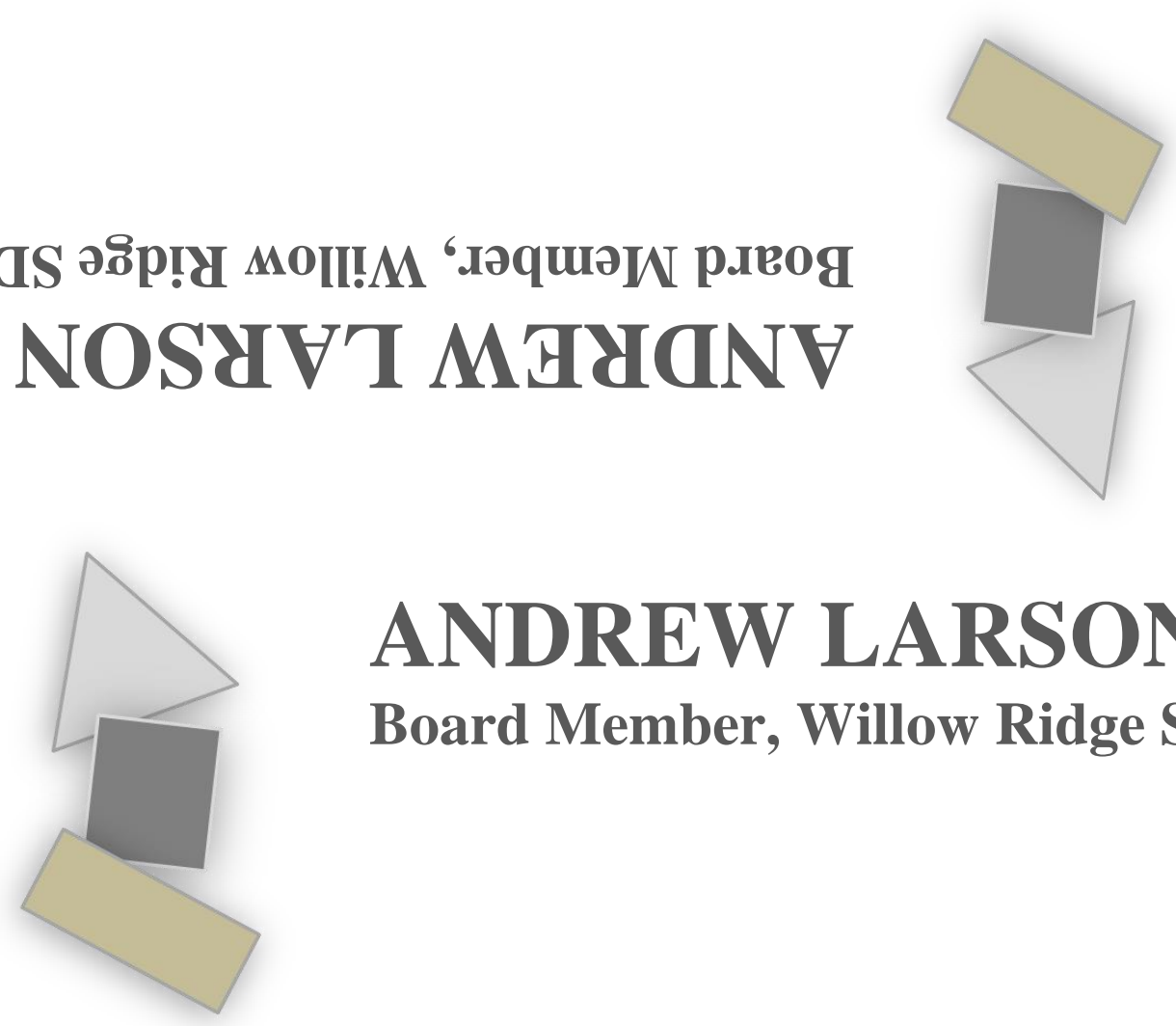

\section{ANDREW LARSON} Board Member, Willow Ridge SD

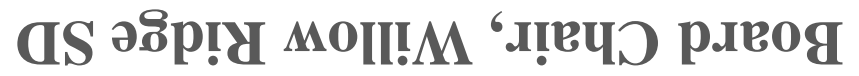
NOLYOW K.IEW
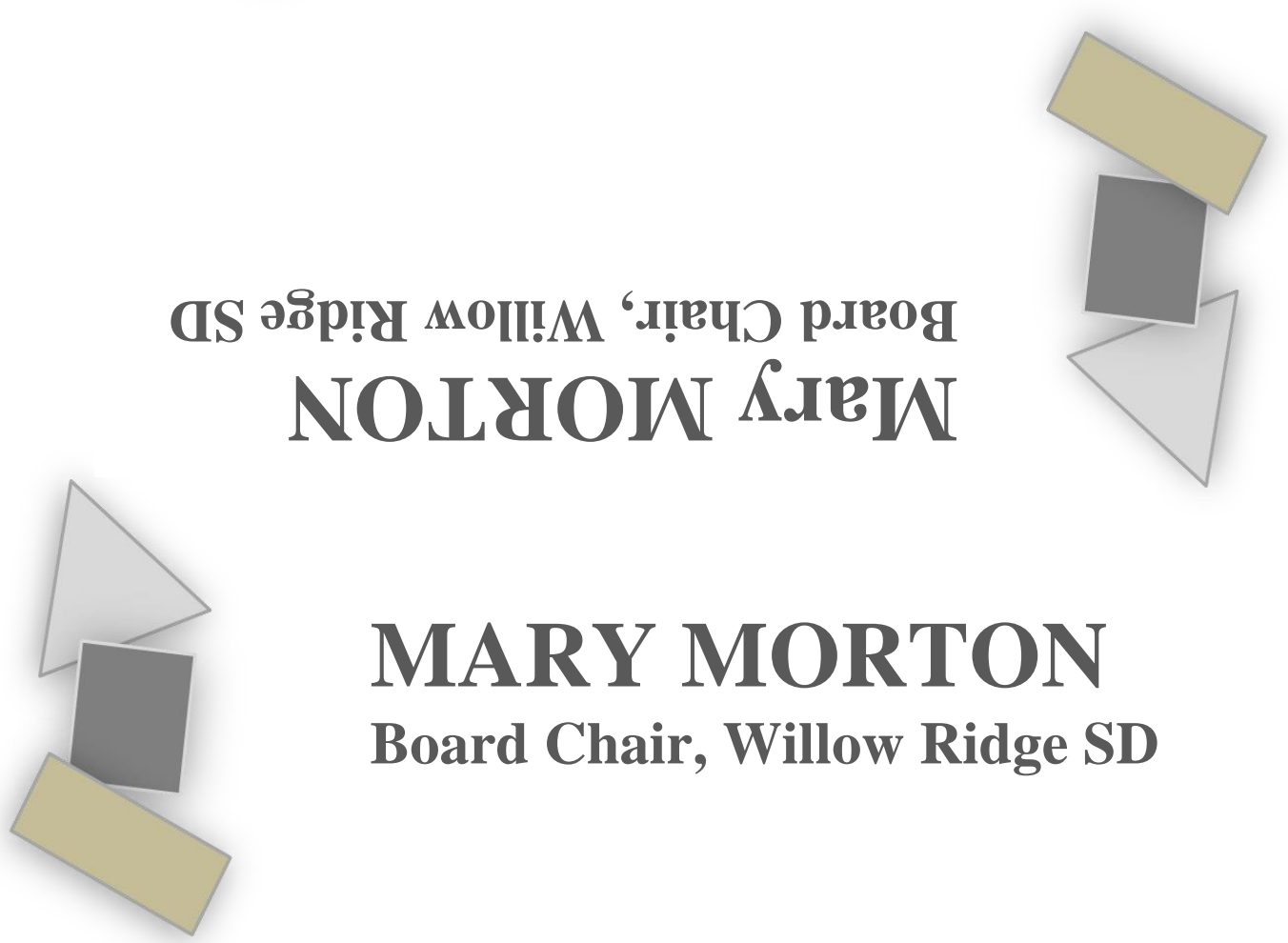

MARY MORTON Board Chair, Willow Ridge SD 
APPENDIX G

WORKSHOP NAME BADGES 


\section{BOB KEIZER}
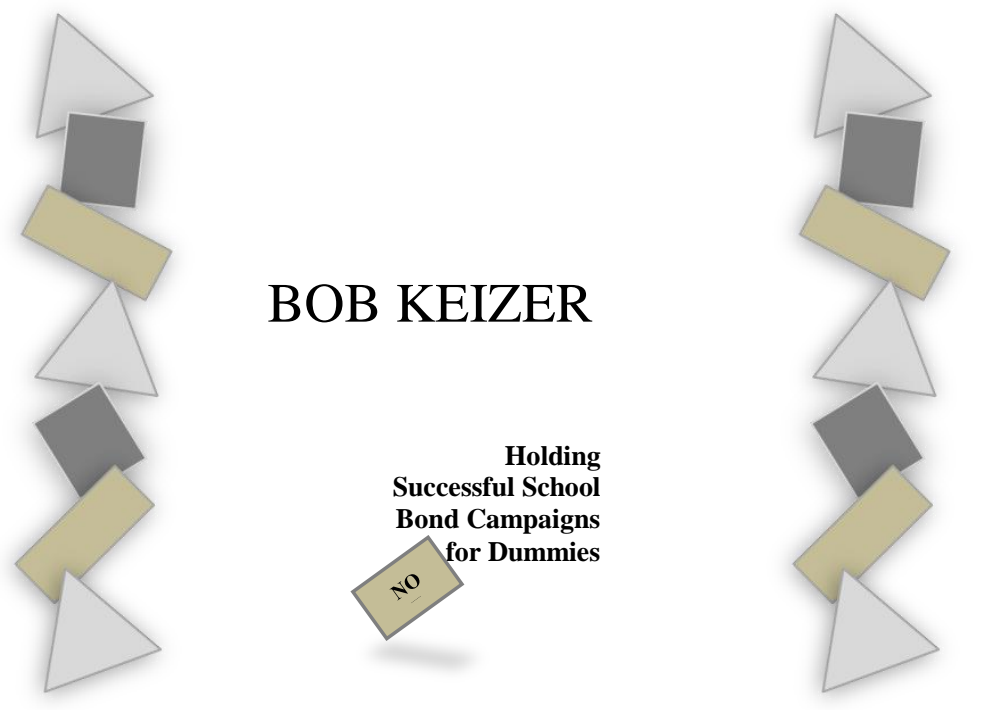

\section{LORI MURRAY}

Successful School

Bond Campaigns

for Dummies 
APPENDIX H

WORKSHOP AGENDA 


\section{Holding Successful School Bond Campaigns: 5. for Dummies}

\section{September 27, 2013 \\ 8:30am-3:30pm \\ AGENDA}

1. Welcome and Introductions

2. Communication Pre-Assessment

3. Today's Objectives/Agenda

4. Introduction to the Handbook

5. Tale of Two Districts

6. Sharing Stories

7. Communication, Communication, Communication

8. Foundation: Teaching \& Learning Connection (BREAK)

9. Pre-Bond Campaign Activities

- Evaluate School \& Community Relations

- Garner Support

- Create the Communications Plan

- Enlist Key Community Leaders (LUNCH)

10. Pre-Bond Campaign Activities, Continued

- Develop \& Publish the Long-Range Facilities Plan

- Identify Construction Projects \& Costs

- Conduct a Survey

- Prepare for the Bond Campaign

- Select Consultants

- Develop the Bond Calendar

- Create Campaign Literature \& Organize Activities

- Communicate with Media

- Utilize Contemporary Marketing Strategies (BREAK)

11. During-the-Campaign Activities

- Count Down to Election Day

- Celebrate the Win

12. Post-Campaign Activities

- Next Steps

- Epilogue

13. Summation, Next steps, \& Closing

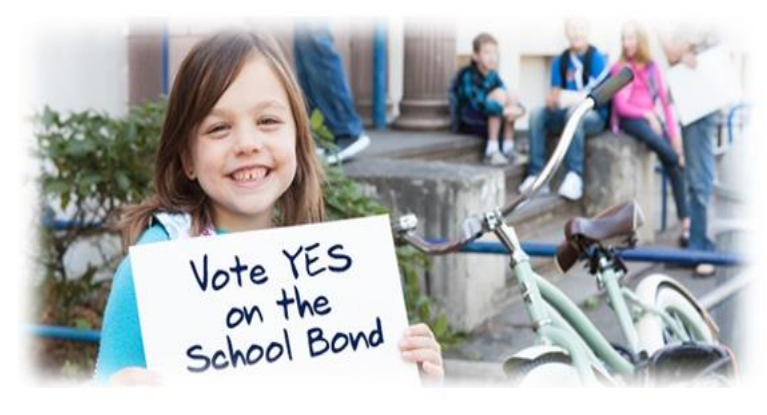

14. Communication Post-Assessment

15. SurveyMonkey Handbook \& Workshop

Example of "campaign" literature 
APPENDIX I

WORKSHOP NOTEPADS 


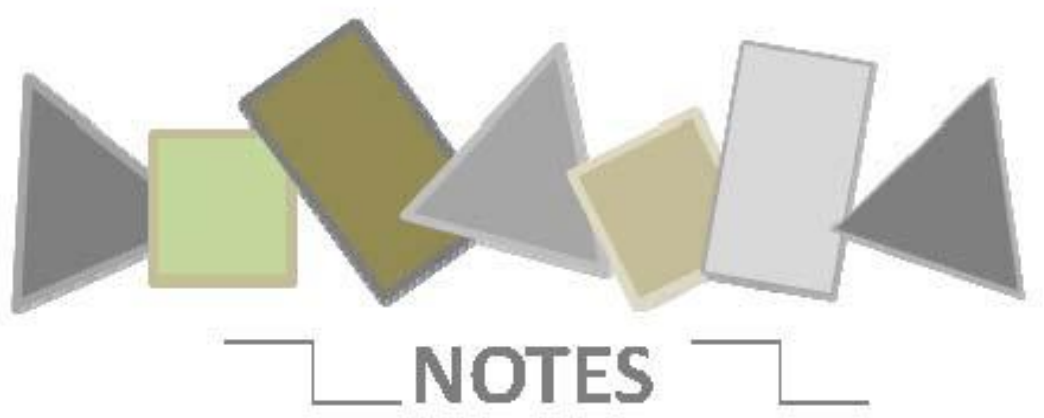

Holding Successful School Band Campaigns:

of for Dummies $\because \div$

BY: LINDA FLORENCE 
APPENDIX J

PARTICIPANTS' THANK-YOU NOTES 

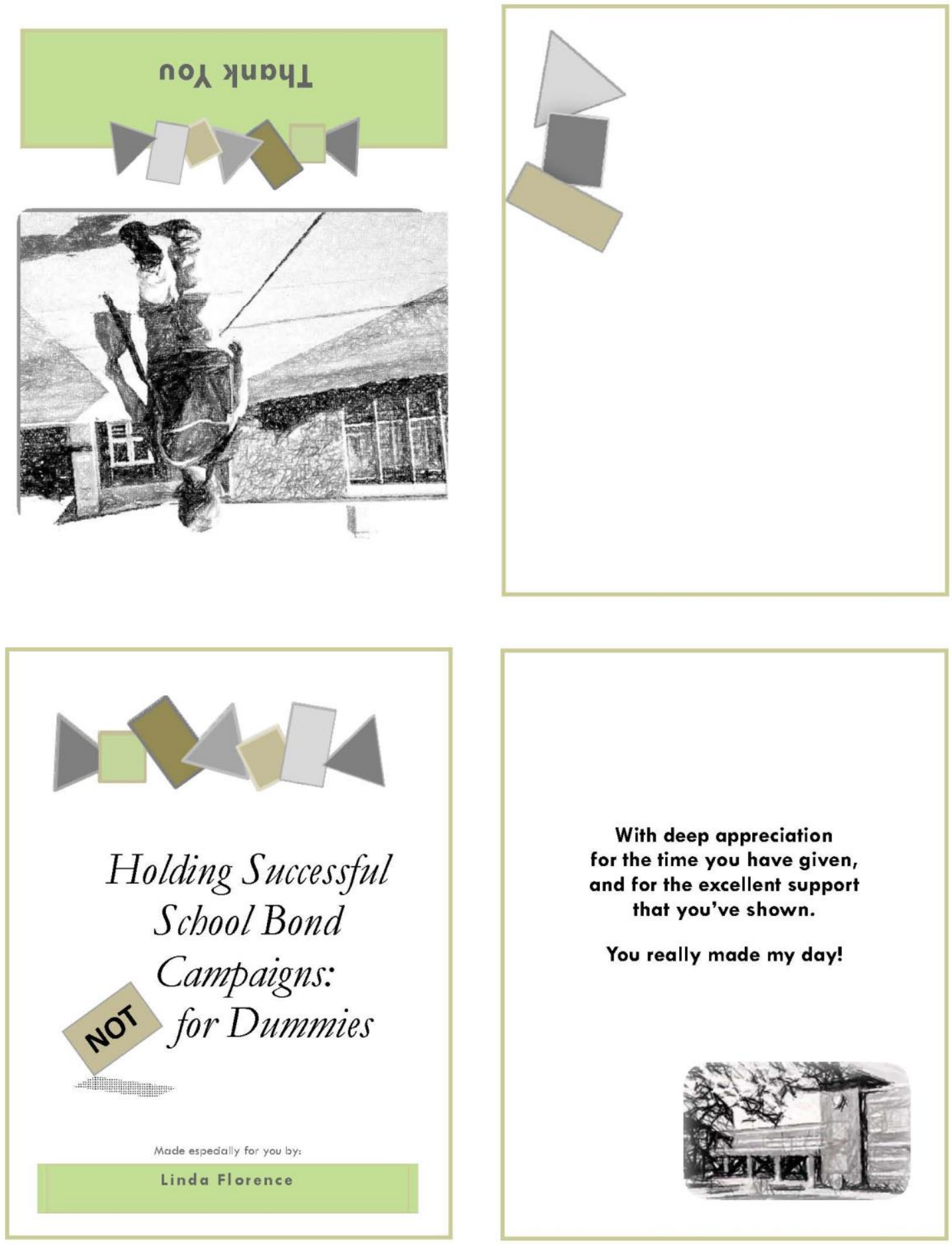

With deep appreciation for the time you have given, and for the excellent support that you've shown.

You really made my day!

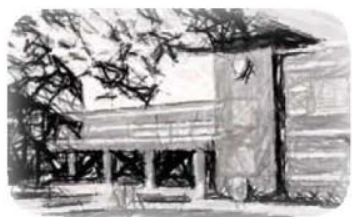




\section{APPENDIX K \\ HOLDING SUCCESSFUL SCHOOL BOND CAMPAIGNS:}

NOT FOR DUMMIES 


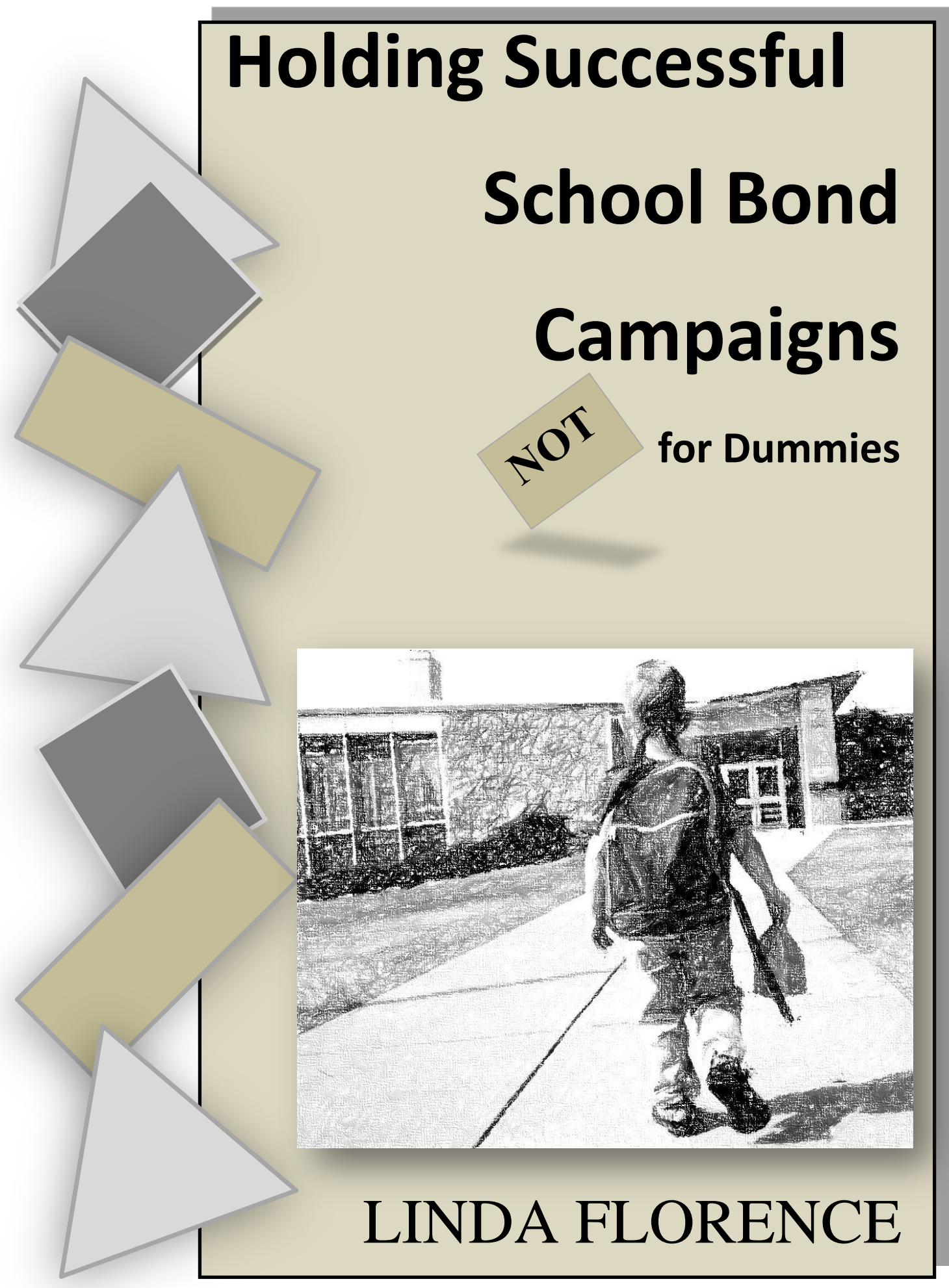




\section{Holding Successful School Bond Campaigns:}

\section{for Dummies}

Even districts with a history of passing bond levies have not been successful in recent years. Yet school buildings continue to deteriorate. Children need safe, warm, and dry schools in which to learn and new equipment and technologies to advance to higher levels.

This handbook is the result of studying several failed bond measures and several successful ones and compiling the strategies that make a campaign successful. With this handbook, sprinkled with hope and pixiedust, a successful bond election can be in your future.

If we teach today's kids like we did yesterday's, we rob them of tomorrow.

\section{John Dewey}

School Bond Campaigns

December 2013

By: Linda Florence

Portland State University 


\section{Holding Successful School Bond Campaigns:}

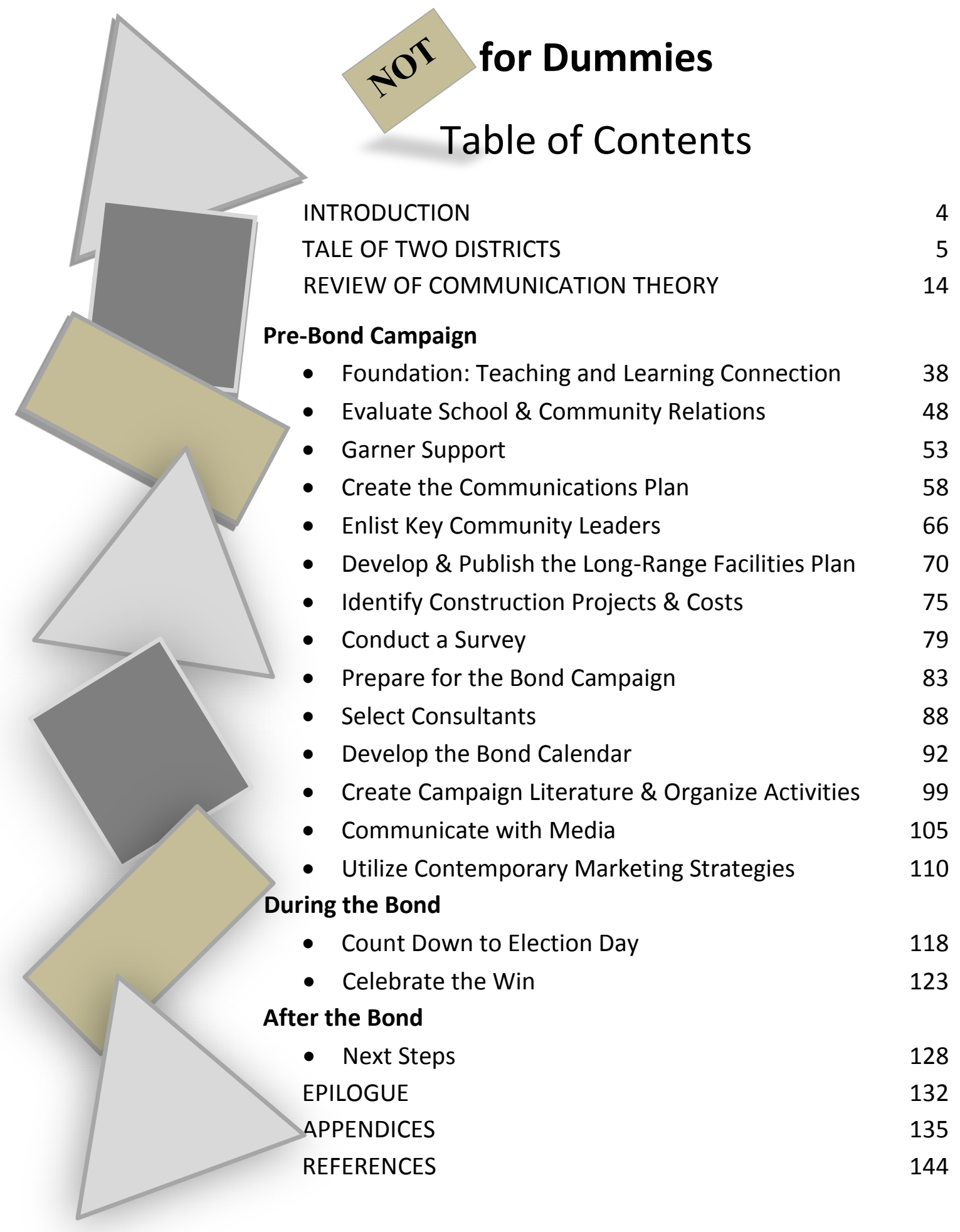




\title{
Holding Successful School Bond Campaigns:
}

\author{
or for Dummies \\ Introduction
}

Safe, Warm, and Dry! Remodel, Refurbish, Renew! New Construction!

What is the answer for school districts that are in dire need of upgrading outdated, crumbling schools? I wish I could say that any school district can win a bond campaign in four easy steps. That, however, is not the case. It does take work - not the work of the superintendent or a principal or a board member. It takes the collective work of the entire school district community.

Whether a $\$ 4$ million or $\$ 450$ million bond, certain strategies play a key role in the success of a bond campaign. When districts employ these strategies, the outcome is more likely to be a festive celebration of winning at the polls instead of a pity party wallowing in a defeated campaign.

All students deserve new and improved buildings in which to learn. But as long as new construction, remodeling, and upgrades require a vote of the taxpayers, there will be defeated measures. Only about 60 percent of school bond measures passed in the last five years in Oregon. Those percentages are less nationally. Why? Only 18 to 30 percent of the taxpayers have children in school, depending on the school district, and parents are the ones who typically vote in favor of bond measures. That is not an encouraging statistic for districts in urgent need of improvements.

This handbook will assist districts in making more informed decisions about their bond campaign and provide the strategic steps to ensure they win at the polls. 


\section{Complexities of Passing School Construction Bonds:}

\section{The Tale of Two Districts}

Passing a construction bond measure is as difficult or as easy as sailing a yacht. Sailing requires a strong captain, a committed crew, appropriate preparation and supplies, good sailing weather, and a charted course. Removing one requirement will interfere with the outcomes. Just as unpredictable as sailing can be, so it is in running a construction bond campaign. Some districts seemingly sail the open seas with skill, and the voters reject the bond. Did the angry weather churn the waters, causing the rough ride? Other districts may float in the shallows protected from danger and pass a bond with little effort.

Why do some districts pass bond levies while others do not? Holding a bond campaign is demanding and complicated work with an unpredictable ending. A district, however, can incorporate certain steps and activities to increase the likelihood of a favorable outcome or clear sailing. That is the purpose of this handbook.

The following scenarios of Novato School District \#1 and Talent School District \#2, while fictional and embellished, describe the actual complexities associated with holding a construction bond campaign. Leaders of a campaign must be able to provide the voters with specific information about the district's capital needs. They need to have experience in conducting a bond campaign. They must assess the district's reputation and know how to communicate with the district's constituents. And they must understand the demographic makeup of the district and its current socioeconomic conditions in relation to the campaign.

Superintendent Young, inexperienced but confident, does not have the skills or knowledge to plot his course for a successful bond campaign and generates one poor decision after another. His destination is inevitable. Conversely, because of her rich experiences of both failed and successful bond elections, Superintendent Masters has developed the skills and knowledge. While the sailing may not always be through calm seas, her destination is in sight.

\section{Novato School District \#1}

A rural school district with a highly diverse student enrollment, Novato School District \#1 suffered repeated rejections from the voters on construction bond levies. Superintendent Young was entirely baffled with the most recent failure last night. He felt voters had been well informed about the school buildings' dire need of repair. In his estimation, construction of a new elementary school, while more expensive, was a more efficient use of taxpayer money than remodeling the old elementary school; however, he personally reduced the amount of the bond when voters rejected a costlier one that included a new elementary school. He hoped voters would see his flexibility as a positive change and support the second bond. But that was not the outcome.

The election results from the night before proved otherwise. The superintendent believed that if the district could just pass a bond that included deferred maintenance - safe, warm, and dry - with much lower costs, then buildings could be sustained for a few more years. In the past year, four bond elections were held and all substantially defeated. The campaign work took so much time and effort. He felt like such a failure. What happened? He sat in his executive chair, elbows planted on his desk, his hands cupping his face, and gazed out the 
window. Across the street was the old elementary building. In its place could have been a new elementary school or perhaps a remodeled building. But after this fourth attempt, he was ready to throw in the towel. What led to the series of defeated efforts?

Two years previously, Superintendent Young began contemplating a bond election to upgrade the five schools in the district. He had just been hired as superintendent. To his credit, he came up through the ranks of District \#1, having first served the district as a classroom teacher and then as an elementary principal. He knew the district well. He was excited about his new position and all the challenges that came with it. Now that he was at the top, he wanted to make an impression on the school board and community. Schools were in need of remodeling. What better way to demonstrate leadership than to pass a bond levy!

The district, however, did not have money to hire an engineering company or firm to evaluate the condition of the school facilities, but a new architectural firm, Xavier, Inc., had contacted him about free services. If he hired Xavier as the architect for the bond projects, then the firm would conduct the district facilities audit and facilities plan including estimated costs, provide support during the bond campaign, and proceed as the architects for the bond projects once the voters approved the bond. Xavier would be paid for services already provided after the successful bond election. If the bond did not pass, the architects would still help with future bond campaigns.

Superintendent Young sold the idea to the board, and he immediately began working with Xavier. A facilities plan was first on the agenda. Superintendent Young developed a facilities planning committee, comprised of district personnel: one principal from each level, teachers from each level, the district business manager, district curriculum director, district office classified employees, and two school board members. While it first appeared as if there were no parents or community members involved, Superintendent Young rationalized the decision by characterizing the board members as representatives of the business community and the teachers and classified employees as parents of children in the district. Xavier, Inc., led the facilities planning process during that first year and developed the plan that included deferred maintenance, capital projects, and a new elementary school.

A new subdivision directly across the street from the high school was slated for 75 stand-alone homes when completed. He knew that the infrastructure for streets, sewer, and water would begin in the fall of his second year, just in time for the public to understand that the houses equaled additional students in the district, another reason to build a new school. The superintendent thought that land adjacent to the subdivision would be in the best location for a new elementary school and the bond could pay for the land needed. Xavier, Inc., architects began drawing up a rough sketch of plans for a new elementary school in that location in anticipation of the bond campaign.

Superintendent Young spoke with his board about the most opportune time to hold a bond election. Would an election be more favorable in November or May? More voters would vote in November and fewer in May. Which time of year would generate more "yes" voters? A decision was made to hold the election in November. If the bond did not pass, another election could be held in March and/or May. Even though the time of year was mid-August, it still allowed 10 weeks to campaign. The board supported the superintendent and passed a resolution to hold a \$22 million bond election in November which, when approved, would fund all of the work identified in the facilities plan including construction of a new elementary school. 
Now the work would begin. First, the campaign needed a budget for advertising. To accomplish this task, he asked administrators, teachers, staff, the board, and friends in the community to contribute. Unfortunately, several employees were not receptive to personal contributions, but thought they would need to donate or be spurned by the superintendent. He pulled the former facilities planning committee members together and asked them to become the campaign committee and he encouraged them to involve their friends. He developed various committees. Committees in charge of fundraising, marketing and advertising, and voter registration were needed for the campaign. He asked everyone to volunteer for a committee and to appoint one member of each committee to lead it. He felt good about the campaign preparation.

In addition to serving two towns with a high degree of poverty, the district also served affluent families who were large landowners in the agricultural business. The school district was comprised of about 45 percent Latino families and an overall district poverty rate of 60 percent as measured by the National School Lunch Program (NSLP). Twenty percent of the students were second language learners whose parents were not U.S. citizens and, therefore, could not vote. To save campaign dollars, Superintendent Young determined that this group did not require campaign literature.

A vocal group of district parents refused to send their children to the high school, once their children graduated from the K-8 country school. After their children's eighth grade year, parents filled out paperwork for inter-district transfers to send their children to a neighboring district where they believed the high school offered better courses for their children. Superintendent Young did not want to cater to this group either. He was convinced that the affluent families in his district held the key to passing the bond, so his energies were spent building relationships with them to convince them to vote for the bond. He did not want to spend his valuable time informing people about the needs of the district when they either could not vote or would not vote in favor of the bond.

During the bond campaign, he recognized that an increasing number of constituents spoke out against the bond. The cost was too much. It would create an undue burden on the taxpayer. Large landowners calculated their taxes and thought they could not manage the additional expense. But Superintendent Young did not let the naysayers deter him; he continued advocating for the new school and the remodeling of the other schools. Grumblings also gushed from school administrators' conversations. They were overwhelmed with too many evening meetings and too many "volunteer" activities. Several administrators also reflected on the multiple elections violations such as conducting campaign business during district work time.

Superintendent Young should not have been surprised with the outcome of the November election. Sixty-two percent voted against the bond. The superintendent immediately regrouped, hired a survey company, and studied the results of the community member's perceptions of the district and the amount the taxpayers would be willing to spend. The results were not stellar. The survey outcomes concluded that there was little support for the bond at any cost. So the superintendent took a different approach, and the board approved a second bond election in May, which omitted the new elementary school, and lowered the cost to \$15.5 million. It, too, failed by a slightly higher margin. Regrouping a third time, he raised the amount to $\$ 19.5$ in a September election. He had heard from someone that voters often support a higher bond, but that too failed at an even higher level of 71 percent. 
Now, Superintendent Young was desperate. Something needed to be done. It felt as if the entire community was against him. What should he do? With optimism refreshed and additional determination, he thought of the adage: "If at first you don't succeed, try, try again." In one last-ditch effort, he took a $\$ 4.5$ million bond to the voters in November. His idea was to complete deferred maintenance projects only: roofs, heating systems, lights, and electrical. Certainly, the taxpayers would support this one. But the resounding "no" from 82 percent of the voters last night told him his vision for the district did not match the community's vision. A new elementary school was not an option. Remodeling the old elementary school was not an option. Completing any safe, warm, and dry projects were not options.

"Was there anything that I would have done differently?" he pondered. "Probably not." Leaning back in his chair, turning and then staring at his computer, he decided it was time to search for superintendent openings in other districts. His work was finished in this district.

\section{Talent School District \#2}

"The perfect storm!" Newly hired Superintendent Masters heard this comment for the second time during the meeting of the Facilities Task Force. She jokingly interjected that she hoped she did not sink during this perfect storm. Young Dr. Samuels, a local physician and graduate of the Talent School District \#2 high school, made the comment during his introductory remarks and now again as he talked about next steps. The new superintendent brought a new direction to the district, one of transparency, trust, respect, and collaboration.

She had already met with several groups of people including the civic clubs like Lions, Elks, Rotary, and Kiwanis. Her speaking engagement at the Chamber lunch in July was attended by over 100 interested business professionals. There was standing room only. The audience's ovations during and after her speech about student achievement, school facilities, communications, and celebrations told her that her openness and honesty about district goals were valued and refreshing. Superintendent Masters knew she had to make connections with district constituents well before a bond levy could be brought to their attention. A bond was the direction of the board and one of the reasons she was hired. Her previous experience in passing bond levies and her strong communication skills were qualities the members of the board sought in their superintendent search. She immediately became an active member of Chamber, the Chamber board, and Kiwanis Club. Her schedule included regular meetings with the publisher of the local newspaper, the mayor, the president of the college, CEOs of the hospitals and several other leaders in the community. Communication with all these groups and civic leaders would be a key factor in passing a bond.

Communication with city leadership was not her only challenge. During the previous decade, the community and district demographics had been rapidly changing. Because yearround work was plentiful in this agricultural area, Latino families, who used to be migrant farm workers, made the small city their permanent residence. This school year's demographics placed Latino students over 60 percent of student body. The federally-funded free and reduced lunch counts had risen to over 70 percent districtwide. The entire county also held the distinction of having the highest poverty rate in the state. In addition, only 23 percent of the registered voters had children in schools. A communication plan would have to be developed to ensure that each group received accurate information about the school district whether in meetings or by mail. 
Print materials would need to not only address each group's needs but also be translated in their home language. Passing a bond would be a challenge on several fronts.

The Facilities Task Force was a large group of committed community and business leaders, parents, board members, and a few employees of the district totaling about 50 people. Dr. Samuels was unanimously selected as the chairman of the Task Force. Both he and his wife were passionate about the school district passing a bond. His business depended on the growth of the small city. Well cared for schools indicated community support and would attract more businesses and industry to the area. The Task Force had initiated the facilities planning process and compiled a comprehensive document of all district facilities, culminating into a 20-year master plan, completed two years before the new superintendent was hired. Previous attempts at a bond levy had been unsuccessful. In fact, the district had not passed a bond for 30 years. In a bond attempt the previous year, voters cited district leadership as one of the reasons for voting against the bond in a post-bond survey. One of the leaders of that group was now a board member and an active member of the Facilities Task Force. The district had a tarnished record, and that record had to be rectified before voters would have enough faith in the district to support a bond.

The district and Task Force developed a four-phase master plan. Phase 1 was the district's responsibility to demonstrate a good faith effort in maintaining and improving upon existing facilities. That was accomplished during the prior two years with finishing touches in July to the high school athletic fields and gymnasiums. Phases 2-4 would be the voters' responsibility by passing bonds with proceeds earmarked for new schools, demolition of 1917 and 1920s buildings, and improvements upon and renovations to other school buildings.

Superintendent Masters was impressed and secretly ecstatic with the grass-roots effort. The most difficult part of passing a bond levy, she knew, was in identifying a well-respected community member to take the lead. She did not want anyone to think that she wanted to build schools based on a conceited effort instead of a concerted effort. Passing a bond was not about her but about what was best for the community and the children of District \#2. Her job was to make sure others took the lead and received the credit for the work that they did. She would place her efforts behind the scenes. The discussion topic changed to wondering when the Task Force would become the Bond Campaign Committee. Superintendent Masters thoughtfully approached the topic. The longer the Task Force could delay the actual bond campaign, she stated, the better. Elections laws would activate as soon as the District \#2 board passed a resolution to approve a bond campaign. She suggested building a calendar of events leading to the board's passage of the bond resolution. In the meantime, she would develop her own communications' calendar to begin communicating specific information to the public and to the press. It was important that the community build its faith in and support of the school district first. Only then would bond passage be possible. The next Task Force meetings were scheduled. Superintendent Masters would explore ethics, campaign, and elections laws so the Task Force would become thoroughly educated. The campaign must be entirely free of any ethics or elections violations or public complaints. A clean campaign - to honor the ideals of the community - was imperative.

Young Dr. Samuels was a go-getter. He wanted to start the campaign immediately. In each Task Force meeting he wanted to begin fundraising or ordering campaign flyers and posters. The superintendent held multiple conversations with him explaining how easy it is for campaign managers to get burned out. The strategy would be to work on the plans now that 
would be implemented later. If the board passed a resolution in February to hold a May bond, that would then be the appropriate time period to unleash all the campaign strategies. In the meantime, the Facilities Task Force would lay plans for a bond campaign but be discreet about the district plans to hold a bond election. The superintendent still wanted to collaborate with both internal and external constituents about the district's vision, mission, and goals to gain their support, trust, and respect.

In November and December, Dr. Samuels and several volunteers began to collect contributions for the bond campaign. While the Task Force knew the district had made deep cuts to its budget recently because of the economic recession, they also knew that the community was becoming more supportive of the school district. The community perceptions from a comprehensive survey provided those data. Large landowners vocally supported the new superintendent, who managed to gain their confidence. It also helped that each school board member was fully dedicated to passing the bond and often communicated such convictions with friends, neighbors, and church parishioners. The superintendent had been attending retirees' coffees and business professionals' luncheons, Chamber events, and club meetings. She held community forums to provide information about the district, the budget and financial picture, and her vision for the children of the district to all parents and community leaders at each of the elementary schools, middle schools, and high school. She met with the staff from each school multiple times to provide transparent two-way conversations that all the teachers and staff craved.

At the January board meeting, the board listened to a presentation from Dr. Samuels asking the board to approve a bond election of $\$ 45$ million, exactly the amount that had not passed in the previous bond election.

Two weeks before the board meeting, in an intense discussion with Dr. Samuels, the superintendent held her ground in support of not changing the $\$ 45$ million bond. Dr. Samuels was considering raising the amount, maybe by just $\$ 5$ million, "for a little padding" to the construction budget.

The superintendent countered: "The amount of the bond must remain unchanged. Public support depends on trust. If the amount is changed without a significant reason, why would voters support it?" Voters would certainly use any modification as an excuse to reject the bond.

"Voters are fickle," she continued. "They are looking for any excuse to save money."

After the discussion with Superintendent Masters, Dr. Samuels agreed: No changes to the $\$ 45$ million.

The board approved the May bond election at the February board meeting. That night after the February board meeting campaign signs popped up across the city, posted in several private yards, public lots, and in business windows. Campaign literature was distributed according to law; letters to the editor were strategically planned; the newspaper published an editorial in support of the bond; and the city council passed a resolution in support of the school bond. The Facilities Task Force was now the Campaign Committee.

Early in February Superintendent Masters received a call from the state education department. One of the district's schools was identified in the bottom five percent in achievement in the state. While this was truly negative news and a black eye on the school district, the designation also brought with it several million dollars to turn the school around. Again, not missing a beat, the superintendent turned a negative into the positive and 
immediately planned how to share this information with the media, staff, parents, community and voters. Being transparent was one of her qualities and one of the reasons the community supported her.

Superintendent Masters continued her circuit of disseminating clear information to the public. Spanish-speaking Campaign Committee members visited the churches where Latino parishioners attended and provided them with accurate information about the bond. Over 60 percent of the children in the district were of Latino heritage. They were recognized as an important part of the community, and targeted parent meetings with Spanish-speakers leading the meetings were also scheduled to keep parents fully informed. Other members of the Campaign Committee had frequent and ongoing discussions with friends, neighbors, and relatives. Voters were promised a Citizens' Oversight Committee to monitor bond expenditures once the bond was passed and construction begun. That requirement would be embedded into the election language on the ballot.

The third Tuesday of the third week in May arrived and the Campaign Committee met at a local Mexican restaurant. No one was very hungry, yet chips, salsa, nachos and other snacks littered the tables in the private banquet room. What would be the next steps if the bond did not pass? Everyone waited for the polls to close and ballots to be officially counted. Eight o'clock came and went; 9:30 brought no word. At 10:07 p.m. an announcement was made. The bond was passing by a wide margin. Instead of cheers, a collective sigh of relief and air of disbelief filled the room. The strategic campaign paid off. Then the excitement and noise rose. "Now, the work will really begin," Superintendent Masters reflected. "Selling the bonds, selecting participants for the citizens' oversight committee, and hiring the construction management company, architects, and engineers," she thought, as she began her mental list. But most important on the list was thanking the community for their overwhelming support.

The newspaper, the next day, proudly featured a headline: "Over 65 percent of voters say 'Yes' to District \#2."

\section{Reflection}

1. What personal qualities or skills do you bring to a bond campaign? 
2. At what point is your district in the process of seeking a bond?

3. Rate yourself from 1 to 4 in confidence of holding a bond and being successful. Why?

$$
1=\text { No experience } 2 \text { = Basic } 3 \text { = Proficient } 4=\text { Advanced }
$$

4. Do you identify with Novato School District \#1 or Talent School District \#2? Explain. 
NOTES 


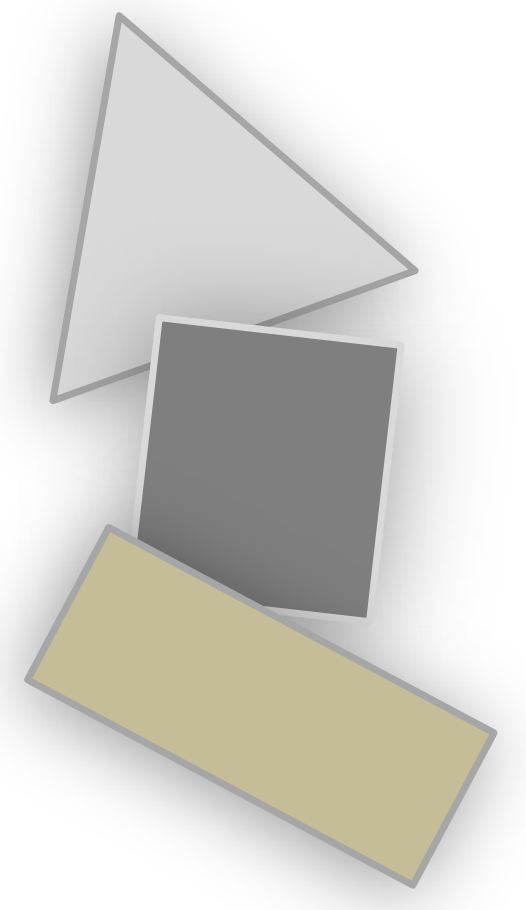

\section{Review of}

\section{Communication}

Theory

\& Practice

$\checkmark$ Organizational Theory

$\checkmark$ School Community Relations

$\checkmark$ Marketing Strategies

65 communication is the key to why

referendums [school bond elections] pass or fait.

(Fritz, 2012) 


\section{Communication Self Assessment}

Level of Familiarity of Communications Theory and Practices

$$
\begin{aligned}
& \text { 1- Not at all familiar } \\
& \text { 2-Slightly familiar } \\
& \text { 3-Somewhat familiar } \\
& \text { 4-Moderately familiar } \\
& \text { 5-Extremely familiar }
\end{aligned}
$$

Rate how familiar you are with the following examples of communications theory and practices.

\begin{tabular}{|l|l|}
\hline \multicolumn{1}{|c|}{ Communication Self Assessment } & \\
\hline 26. Formal Communication & 12345 \\
\hline 27. Informal Communication & 12345 \\
\hline 28. One-Way Communication & 12345 \\
\hline 29. Two-Way Communication & 12345 \\
\hline 30. Strategic Communications Planning & 12345 \\
\hline 31. Communication with Internal Publics & 12345 \\
\hline 32. Communication with External Publics & 12345 \\
\hline 33. School Community Relations & 12345 \\
\hline 34. Communications Strategies & 12345 \\
\hline 35. Media Relations & 12345 \\
\hline 36. Marketing Strategies & 12345 \\
\hline 37. Marketing Techniques, Tools, and Publications & 12345 \\
\hline 38. Social Media & 12345 \\
\hline Communication as a Leadership Skill by & 12345 \\
\hline \multicolumn{1}{|c|}{ 39. being a good listener } & \\
\hline
\end{tabular}




\begin{tabular}{|l|l|}
\hline 40. being a good writer & 12345 \\
\hline 41. being a prepared speaker & 12345 \\
\hline 42. building relationships with board members & 12345 \\
\hline 43. building relationships with teachers and staff & 12345 \\
\hline $\begin{array}{l}\text { 44. building relationships with taxpayers } \\
\text { communication channels }\end{array}$ & 12345 \\
\hline $\begin{array}{l}\text { 46. establishing, maintaining, and nurturing open } \\
\text { school and community relations }\end{array}$ & 12345 \\
\hline $\begin{array}{l}\text { 48. always keeping the school board, staff, and general public } \\
\text { informed of school matters }\end{array}$ & 12345 \\
\hline $\begin{array}{l}\text { 49. ensuring the school and community relationship is assessed } \\
\text { and evaluated regularly }\end{array}$ & 12345 \\
\hline $\begin{array}{l}\text { 50. making sure that influential groups and community leaders } \\
\text { are provided with factual information }\end{array}$ & 12345 \\
\hline
\end{tabular}

(Florence, 2013)

Which communication areas were identified with a lower rating of 1 or 2 ?

Which communication areas were identified with a higher rating of 4 or 5 ?

After review of the communications section, did you change any of your ratings? Why? 


\section{Organizational Communication}

\section{Effective communication is the key to a successfut campaign.}

Stephanie Curtis, Redmond School District's communications director said, after Redmond passed its 2008 bond levy for $\$ 110$ million (OSBA, 2009).

Why is communication important? First and foremost, communication develops trust. Covey (1989) introduced the concept as an emotional bank account "that describes the amount of trust that is built up in a relationship" (p. 188). Just as any bank account, people can make deposits and withdrawals. However, instead of dealing with units of monetary value, people deal with emotional units and these are, according to Covey, units of trust. If a positive reserve is kept in relationships by making regular deposits, there is greater tolerance for mistakes; and open communication is the result. However, when withdrawals are made and the balance becomes low or maybe "overdrawn," then bitterness, mistrust, and discord develop. If a relationship is to be salvaged, a conscious effort to make regular deposits must be employed. So it is with communication.

Ongoing communication, when planned appropriately, will develop that high level of trust so that if a withdrawal is made, it will hardly be noticed. Covey says that people would know you, understand, and not worry about the withdrawal. This is the level of trust that must be established with a school district's internal and external stakeholders well before a construction bond is advanced with the public.

\section{Formal and Informal Communication}

Formal communication is a deliberate interaction and flow of information from one person to another or one organization to another. Conversely, informal communication is not controlled, structured, or systematic as noted in Table 1 below. Informal communication may be unplanned, but it is time that must be planned for.

How would a school district leader know, for example, that a group of citizens was not supportive of a bond or some parents were dissatisfied with the district? It is often through informal structures such as during the wait time before a meeting or event. Informal communication builds relationships. Porterfield and Carnes (2008) provide this example: 
...we know of a superintendent in a small school district who shakes the hand of each staff member at the beginning of the year and again at the end of the year. And rather than asking staff members to come to him, he goes to them. Walking the hallways, moving in and out of classrooms, pressing flesh, he makes a point of calling staff members by name. And if he doesn't know a name, he asks.

(p. 183)

The superintendent in the Porterfield and Carnes' example knew that by being courteous, on staff turf, and available, he was creating a positive culture and making deposits to his bank account.

Table 1

Formal and Informal Communication

\begin{tabular}{|l|l|l|}
\hline Descriptors & \multicolumn{1}{|c|}{ Formal } & \multicolumn{1}{|c|}{ Informal } \\
\hline Structures & Planned, Intentional, Controlled & $\begin{array}{l}\text { Unplanned, Unintentional, Not } \\
\text { Controlled, Brief }\end{array}$ \\
\hline Types & $\begin{array}{l}\text { Organizational Chart, } \\
\text { Communication Plan, Mailing } \\
\text { Lists }\end{array}$ & $\begin{array}{l}\text { Random, List of Community } \\
\text { Leaders, Parents, Students, } \\
\text { School and District Employees }\end{array}$ \\
\hline Situations & $\begin{array}{l}\text { Speeches, Documents, } \\
\text { Newsletters, Meetings }\end{array}$ & $\begin{array}{l}\text { Conversations, Brief Meetings/ } \\
\text { Encounters, Emails, Notes }\end{array}$ \\
\hline $\begin{array}{l}\text { School Collaboratives, } \\
\text { Partnerships, PTA/PTO, Key } \\
\text { Communicators, Teacher/Staff } \\
\text { Associations, Leadership Teams, } \\
\text { Government Agencies, Civic } \\
\text { Clubs/Organizations, Special } \\
\text { Events, Forums }\end{array}$ & $\begin{array}{l}\text { Grocery Store, School/District } \\
\text { Offices, Church, Civic } \\
\text { Clubs/Organizations, Schools, } \\
\text { Before/After Meetings/Events, } \\
\text { Social/Neighborhood/Family } \\
\text { Gatherings, Athletics/Activities }\end{array}$ \\
\hline
\end{tabular}

\section{One-Way and Two-Way Communication}

Any communications plan should include both one-way and two-way communication. One-way communication can be defined as information out to a receiver, which tends to be the most prevalent type in schools and districts. One-way communication is linear, unilateral, but limited because it occurs in a straight line from sender to receiver and serves to inform, persuade, or dictate as noted in Figure 1. 


\section{One-Way Communication}

SCHOOL

(Sender)

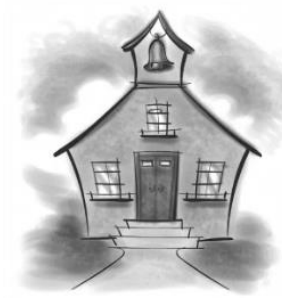

HOME

(Receiver)

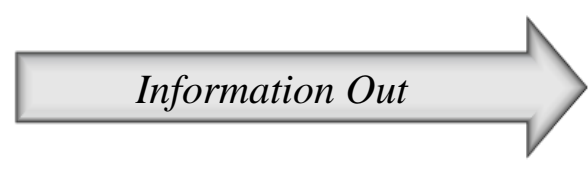

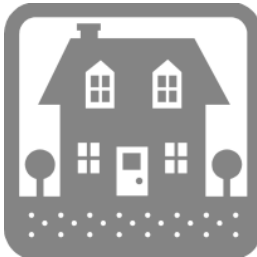

Figure 1. One-Way Communication.

Two-way communication is different from one-way because it includes feedback from the receiver back to the sender (see Figure 2). Two-way communication is negotiated, meaning that both the sender and receiver listen to each other and gather information they need before responding. They are also willing to make changes to work together as in a dialogue. Hoy and Miskel (2001) approach the definition of two-way communication as "a reciprocal, interactive process directed toward discovery and new understandings through speaking and listening" ( $p$. 262). Fiore (2011) cautions about only communicating during bond elections. Strong two-way communication should be a consistent practice. "...[T] he twenty-first century demands that school leaders communicate regularly and purposefully with all stakeholder groups. This communication...must be two-way with the school leader listening as much or more than he or she speaks" (p. 222).

\section{Two-Way Communication}

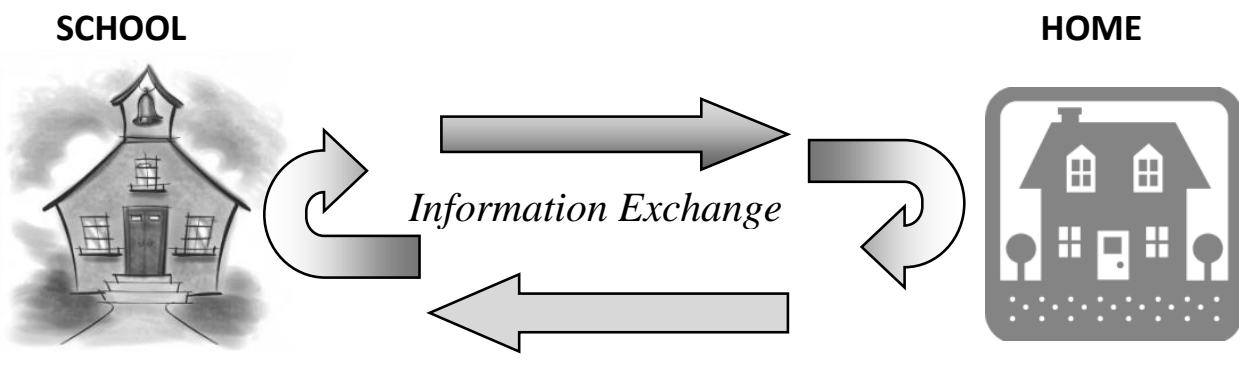

Figure 2. Two-Way Communication.

\section{Communication with Internal and External Publics}

A communication plan that strategically targets the key internal and external stakeholders and provides open, honest, accurate, timely, and two-way communication is a district setting itself up for continued public support (Gunther, McGowan, \& Donegan, 2011). 
Bagin et al. (2008) provide three reasons for a strong internal communication program: "(1) A good external communication program cannot survive without it; (2) constructive ideas will be suggested by employees because someone is listening and informing them; and (3) human needs, such as recognition and sense of belonging, will be met, thus making employees more productive" (p. 90).

A district has a variety of internal stakeholders as demonstrated in Figure 3. Each of the internal stakeholders listed could also have subgroups creating even more groups. This is why communication must be thoughtfully planned.

Why is internal communications important to a bond campaign? Employees are visible members of the community (Fiore, 2011). Because they live in the community and vote in the school district as well, they take on an important role as messenger of what is happening in the district, schools, and departments. The information they receive daily is communicated to their friends, neighbors, and family daily. If they do not receive accurate information, they will share inaccurate information. If they do not feel positive about the district, they will most assuredly communicate their negative views. Hughes and Hooper (2000) share that "If internal stakeholders are valued and engaged, they will assist in promoting positive and effective communications" (p. 87). 


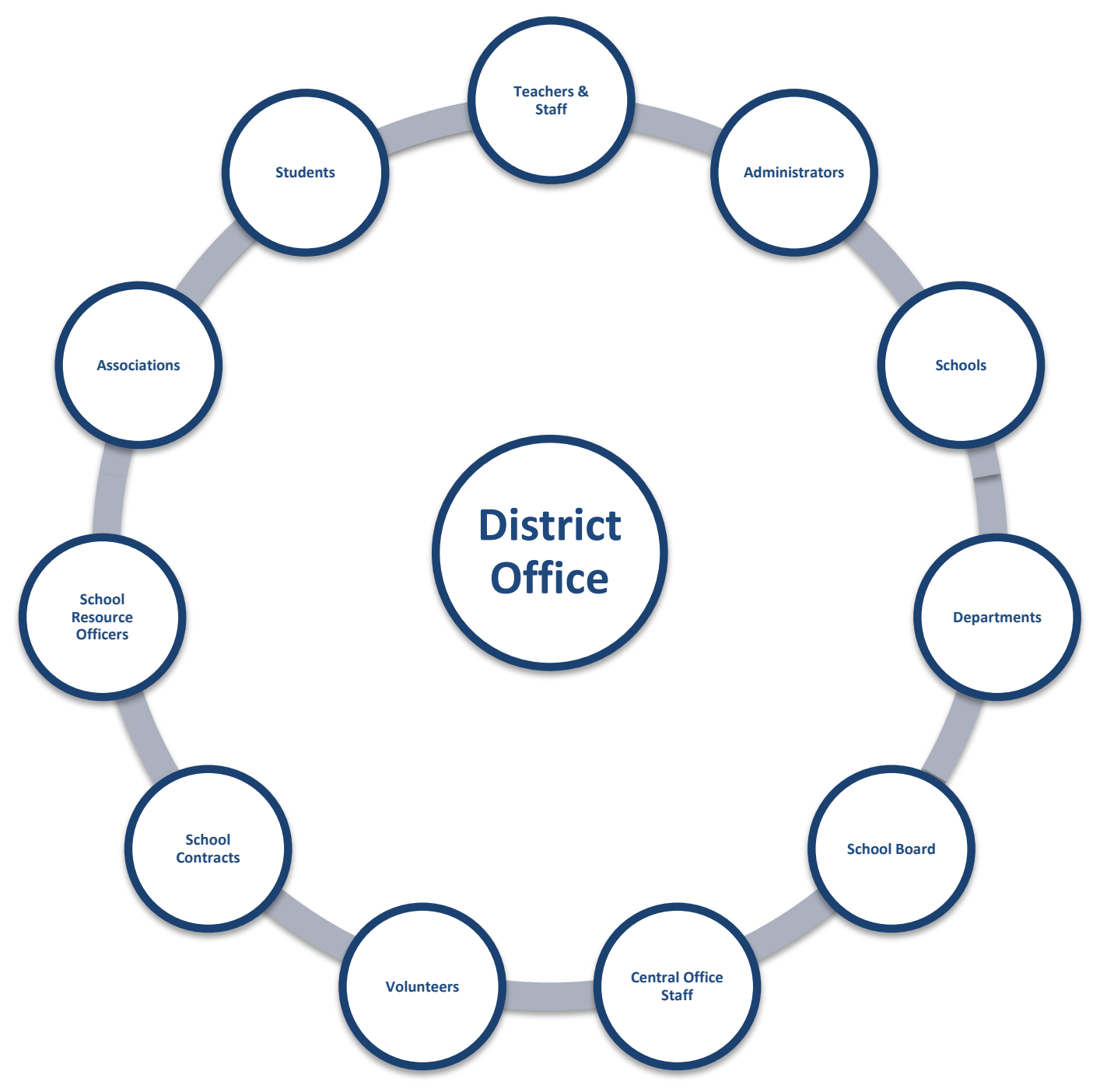

Figure 3. District communication with internal stakeholders.

With a plan targeting internal communications solidly in place, the next step is to plan for external communications (see Figure 4). While a district has some control over its internal stakeholders, the external stakeholders are continually changing. Specifically about school community demographic changes, Carr (2010) addresses possible communication issues:

Unprecedented demographic shifts in the U.S. are creating a communications gap between teachers, principals, and the students and families they serve, forcing educators to rethink their school communication strategies. Minorities will become the majority of children under 18 by 2023, according to the U.S. Census Bureau. Educators and school communicators, on the other hand, are predominately non-Hispanic white females. 
The gap is also socioeconomic in nature, because children of color are often poor as well, while teachers and other school officials are solidly middle to upper-middle class.... In terms of education, the gap widens even further, with educators holding more advanced degrees than most other American workers have-including their students' parents.

All these trends will require profound changes in parent engagement and school communication, as well as classroom instruction. Tried-and-true school communication methods, such as fliers, memos, teacher notes, eMail messages, and newsletterstypically written in college-level English - aren't going to reach parents who struggle to read or who might not be literate in their own native language.

In districts with high demographic shifts, communicating with the external publics takes additional time and financial resources. There are no quick and easy guides to work with such diverse populations, and the literature reviewed often reflects a 1950s model of communication. Bagin et al. (2008) do, however, provide a list of suggestions in communicating with diverse school communities. Mainly, the authors advise listing all the ethnic groups in the district; learning who each group's key communicators are; creating an advisory committee within each group, if possible; training teachers in working with diverse families; printing publications in the language spoken; providing transportation to conferences and other school activities for parents; teaching students to respect all languages; learning the most effective strategies to communicate with the parent groups; believing that all students can succeed; and using resources of public and government agencies and organizations who serve minority groups.

Both internal and external communications are important to successfully build community support and trust in a school district. A comprehensive communication plan provides open, honest, accurate, and timely information structured for both one-way and two-way communication with the many and varied internal and the external stakeholders. Employees groups are the voice of the district in the community. These internal stakeholders must feel supported by having the most accurate information available to share with the public. External stakeholder groups must be evaluated so that each group is provided with the communication that best fits its particular needs. Successful external communication results in stakeholders who have a sense pride and ownership for the district and its schools. According to Gunther et al. (2011), "Those who feel that sense of ownership volunteer, attend school events, nod affirmatively when you describe your new initiatives, vote for your budgets and tax increases, and give you the benefit of the doubt when there's bad news" (p. 115). These responses would be the ultimate endorsement for a successful communications plan. 


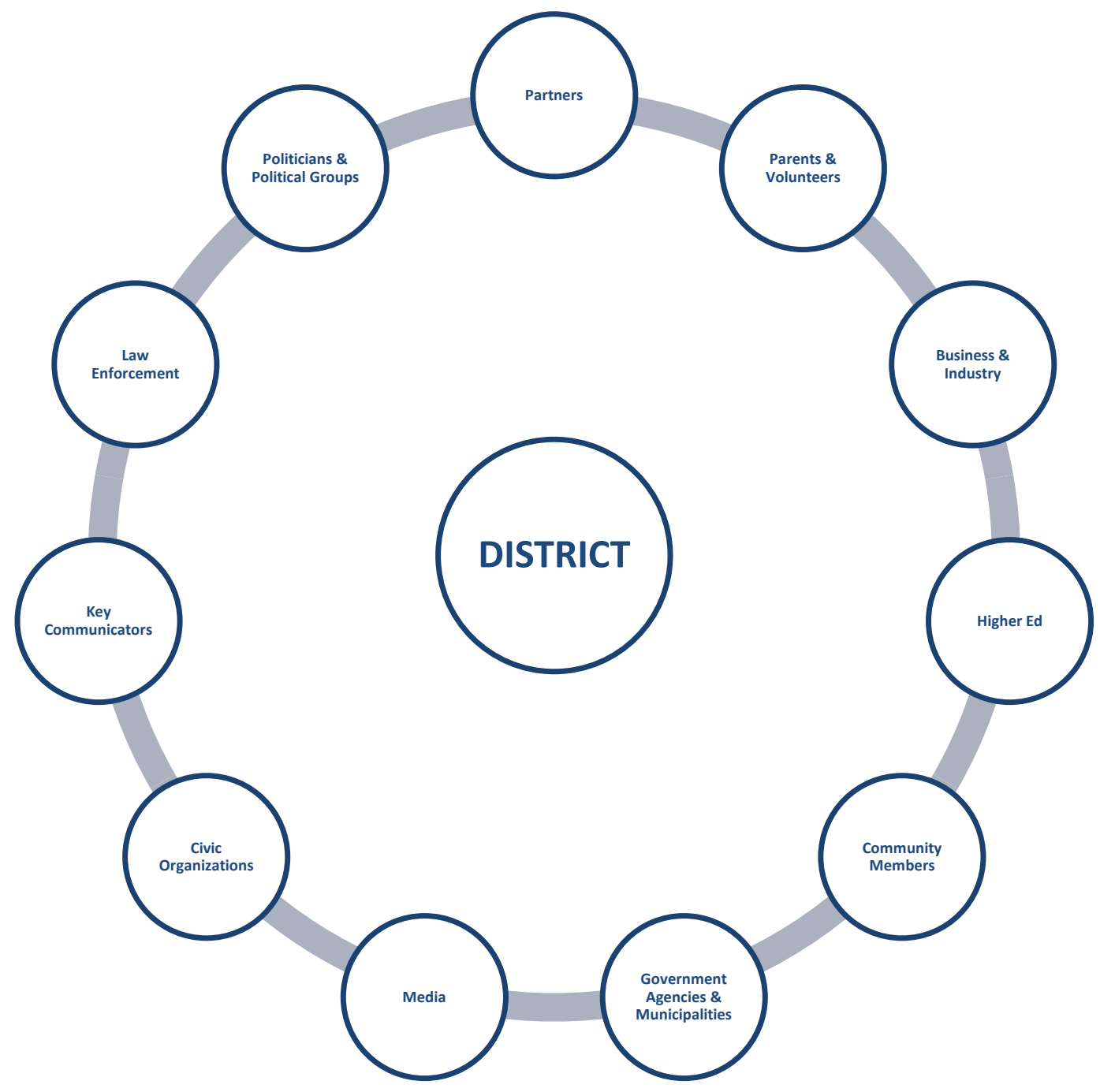

Figure 4. District communication with external stakeholders.

\section{Communication as a Leadership Skill}

"Building public support for school is not something an effective school administrator does on the side. It should, in fact, be the first act of survival" (Hoyle, English, \& Steffy, 1994, p. 49).

Guenther et al. (2011) say that "leaders must be judged on their commitment to communicate, their skill in doing so, and the extent to which they can bring their stakeholders together through communication" (pp. 115-116). Bagin et al. (2008) add further comment onto these skills by describing the superintendent's role as an "educational diplomat" (p. 58). Top leadership skills for communicating have gone beyond simply writing, speaking, and listening 
well. While these skills remain necessary to any school leadership position, leading a school system requires much more. In smaller school districts, the superintendent may assume additional responsibilities for curriculum, personnel, and public relations. In larger school districts the superintendent may supervise and direct others to do this work but have further responsibilities in building relationships with the external community. The skills needed to conduct school business are multiple. If a school bond is well planned, excellent communication skills are vital to the election's success.

Bagin et al. (2008) reports that superintendents may be excellent instructional leaders or financial wizards but fail to communicate well with the board, staff, or taxpayers. Fiore (2011) states administrators must be role models who model honesty, integrity, care, and understanding; be flexible and adaptable; develop listening skills; and practice humility. They must possess effective human relations skills. In other words, they must have the skills known to improve employee satisfaction and enhance community perceptions of the schools.

Superintendents are responsible for keeping internal and external groups informed by establishing, maintaining, and nurturing open communication channels both internally and externally; developing and championing policies created to enhance school and community relations; always keeping the school board, staff and general public informed of school matters; ensuring the school and community relationship is assessed and evaluated regularly and the outcomes are reported to the school board; and by making sure that influential groups and community leaders are provided with factual information that will cause them to act on behalf of the school children and their education (Fiore, 2011).

Superintendents must be highly skilled in writing, speaking, and listening. These communication skills are necessary for the top job as well as the skills to plan, assess and evaluate the pulse of the community and to work with a variety of stakeholders. Skilled communicators understand that there is not one "public" and the superintendent must be savvy in knowing how to communicate with each of the different external groups as well as with the various internal groups (Hoyle et al., 1994). The message or the type of communication cannot be the same. Holding a meeting about a possible school bond needs to be entirely different when planned for the city chamber, the boosters club, a teachers' meeting, or for the Latino parent night. 


\section{School Community Relations}

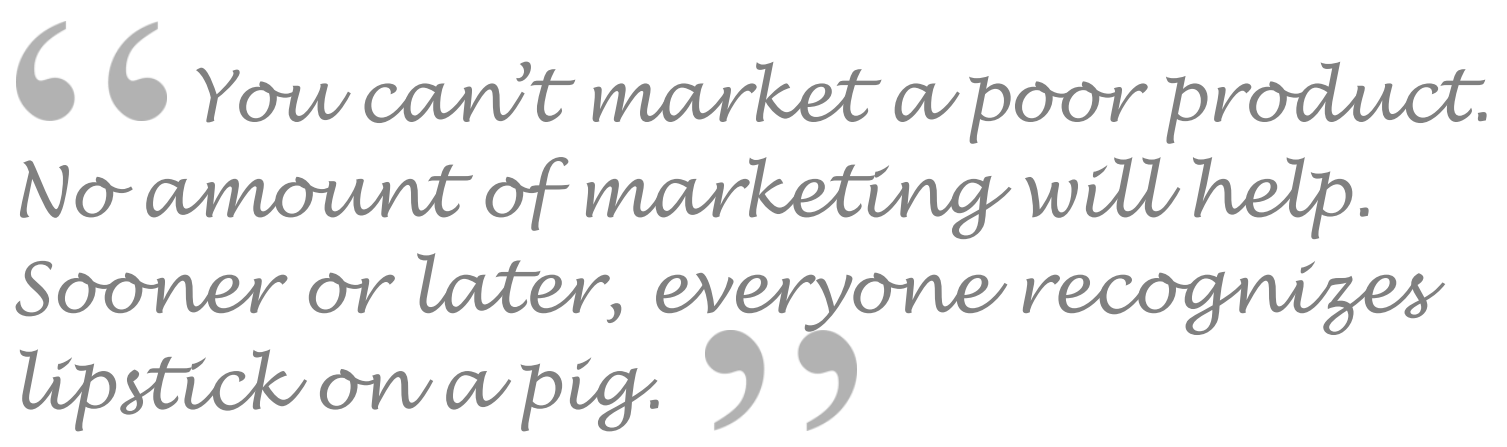

Porterfield and Carnes (2008)

The most important work in winning elections occurs long before a measure is placed on the ballot (Campbell \& Magmer, 2007). One to two years in advance of a bond election, districts must learn how the community perceives their schools. Are parents satisfied with their children's education? Do community leaders support the schools? Are newspaper articles favorable? Are teachers and staff highly motivated? Is morale high? If the answer to these questions is affirmative, chances are the district has an active school and community relations program. School and community relations can be defined as formal or informal interactions between an educational institution and the surrounding community while public relations can be defined as the professional maintenance of a favorable public image by an organization.

Winning at the polls will mean evaluating and analyzing the current perceptions and conditions of the district and then, if needed, making strategic changes to transform those perceptions. The first step in determining community support is to evaluate public perceptions of the district as a whole. Next is the development of develop public relations strategies for effective internal and external communication as well as ideas for improving media relations.

\section{Perceptions of the Schools}

Both internal and external stakeholder perceptions of the schools should be assessed and evaluated. Hughes and Hooper (2000) suggest determining the general impressions of the districts from parents, community, and staff through surveys developed for each key public relations audience. Bagin et al. (2008) relate how indispensable a survey is when the public is asked for its opinion. For example, a survey can determine how the public might react to purposed district changes, learn how citizens judge the quality of the schools, ascertain how staff will react to a proposed curriculum, or discover how willing the public would be to support a proposed bond. An added bonus, according to Bagin, is how opinion research actually stimulates individuals who are contacted to form opinions: 
Individuals who have not thought seriously about the schools and the school programs for some years are forced to do some thinking about them when their opinions are being sought in a research study. Moreover, they feel important for being asked their opinions." (p. 27)

Community perceptions gleaned from surveys are valuable. Survey results determine perceptions of various groups including parents, senior citizens, business people, community members, and district employees (Campbell \& Magmer, 2007). Fiore (2011) concurs that the effectiveness of a school organization cannot be determined through feelings and observations. Formal opinion surveys, questionnaires, rating scales, and telephone surveys provide effective feedback on community perceptions. SurveyMonkey, Fluid Survey, Zoomerang, and InstantSurvey are all free and simple-to-use online surveys.

While online surveys have reduced costs or no cost and a quick turnaround associated with them, Hughes and Hooper (2000) also suggest other more in-depth methods to understand the community's attitudes and beliefs about the district. Focus groups, public meetings, town halls, panel discussions, and advisory committees provide a face-to-face venue. Hoyle, English, and Steffy (1994) concur: "Face-to face communications are still the most effective of all 'other means.'”

Figure 5 represents Hoy and Miskel's (2001), representation of the communication continuum, depicting face-to-face rating highest in richness because it provides immediate feedback through verbal and visual cues (p. 55). Bagin et al. (2008) add to the context of face-to-face communication with key communicators and conferences while Carroll and Carroll (2000) emphasize a more comprehensive key communicator program that disaggregates participants into internal and external stakeholders. Instead of one key communicators group, the district may develop three or four.

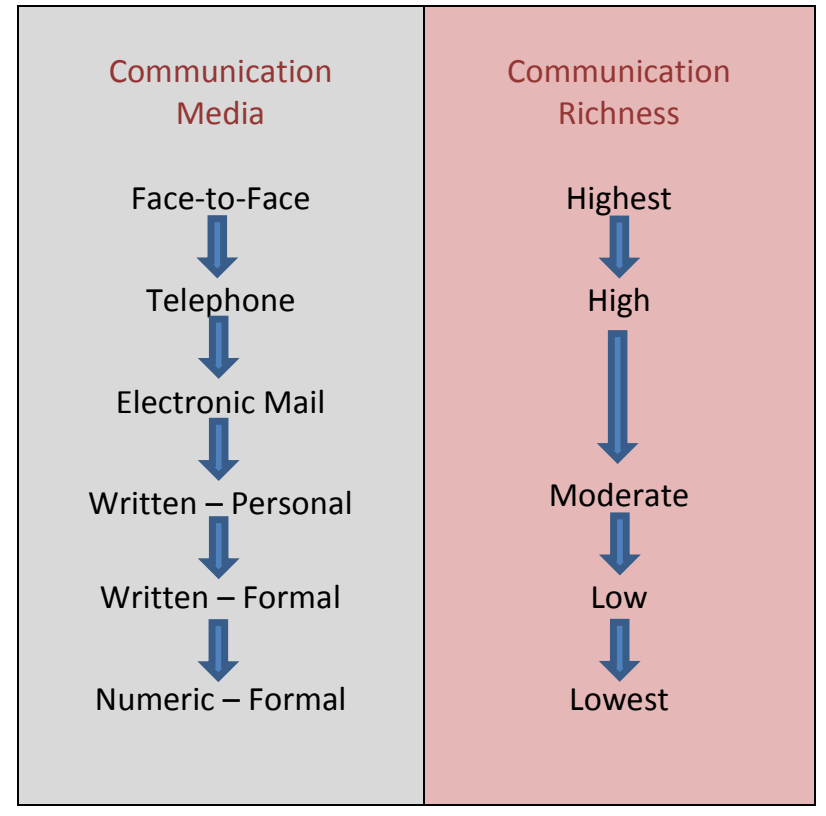

Figure 5. Continuum for communication media and richness 
Face-to-face communication provides the most beneficial venue in providing information to the community and receiving the feedback in district decision-making. More time and planning is involved but the results are much richer in trust developed and relationships garnered.

\section{Strategies for Internal and External Communication}

Campbell and Magmer (2007) provide insight in enhancing community relations:

Community support is built with an effective researched-based, strategically planned, year-round communication program that engages people from all segments of a community. Trying to pass a finance referendum without a formal plan in place is like hiring a carpenter to frame a house without first constructing the foundation. (p. 13)

The first step in developing a communication program is identifying who the internal and external stakeholders are. Hoyle et al. (1994) report that part of the planning effort is not just in identifying the specific public to be targeted but in identifying the specific communication method and determining how to get that message to hit home. "The more focused a message is, the more effective it can be. Conversely, the more universal a message is, the less impact it will have on any one recipient" (p. 57). Bagin et al. (2008) says to keep it simple, "This means to eliminate educational gobbledygook and long polysyllabic sentences (p. 308)."

Bagin et al. (2008) and Bagin and Gallagher (2001) suggest a key strategy for enhancing internal relations is offering both a general advisory committee and special advisory committees. $\mathrm{A}$ general advisory committee, as the name implies, would be comprised of membership from all constituencies in the school system. It would be designed to hear from the internal community but also to receive information from the school district. Special advisory committees would be formed representing the different employee groups in the district such as a licensed committee and classified committee. Members on the committees would then serve to communicate information back to their buildings or departments and, likewise, communicate to the superintendent about concerns or questions from the buildings and departments.

New staff, new teacher, and new administrator orientation programs help transition new employees into the culture of the school district. Bagin et al. (2008) and Bagin and Gallagher (2001) share that employees new to a school can become "bitter and resentful" if they are not properly familiarized with the school or do not know what is expected of them.

Taking time to employ two-way communication strategies helps to build strong relationships with internal stakeholders. Porterfield and Carnes (2008) provide a rationale:

Two-way communication with your employees is fundamental to the smooth operation of your organization. Employees help make change happen. They can be a powerful marketing arm. They can provide good customer service to parents and community members. But before they offer their help, your staff members must feel engaged in the mission of the school and the school division. Your job as leader is to make them feel part of the team. (p. 81) 
When the district plans to hold a bond election, the internal constituents will be ready to support the district in its efforts even if it just to speak positively about what is happening in the district.

Where are the external stakeholders? Porterfield and Carnes (2012) say they have developed into an online community. School districts communicating with their external constituents may need to update their communications plans and use blogs, Twitter, message boards, and Facebook. Most districts and schools now have a Facebook page and many often use Twitter. But some school board policies remain antiquated and leaders fear using social networks to convey district news and information. Yet using these strategies will make connections to parents and younger stakeholders. Gunther et al. (2011) offer these strategies:

Based on your experience and knowledge of your community, you already have a sense of what information your parents need. But do you know how many prefer getting newsletters in the mail rather than online? What percentage of your parents or larger community expects to hear from you on the Web, via email, or via Twitter? (p. 43)

To communicate well with the different school stakeholder groups, the district must continually assess its publics and determine its choice of communication as stakeholders get older or younger and speak different languages. These changes seem to take place on a yearly basis in most districts. Gunther et al. adds, "To communicate well your district must respond appropriately" (p. 43). More traditional forms of communication strategies must still be utilized for parents who do not have technology. However, no one should make any assumptions about who has Internet access. Many families in poverty make Internet a priority whether on computer or smart phone. The point of using Twitter or a paper newsletter is dependent on the intended audience, the identified outcome to be achieved, and the best medium in which to make that happen.

\section{Media Relations}

According to Kowalski et al. (2007), school administrators have historically approached media relations as either "wounded and bloody" or "naively optimistic" (p. 187). In many cases reporters are often thought to be the enemy. District administrators often fear the press because they have not been trained to work with the print or broadcast media. The adage, "Never argue with a man who buys ink by the barrel" (attributed to former Indiana Congressman Charles Bruce Brownson in 1964), evokes fear. Additional embellishments add "paper by the ton." Unfortunately, these symbolic scare tactics do not build positive relationships, and that is the first step to resolve the mystery of media relations.

Porterfield and Carnes (2008) call working with the media an investment. As with any school community group, the district leaders would take the first step to build positive relationships through face-to-face meetings. Hughes and Hooper (2000) and Porterfield and Carnes advocate for information meetings to discuss working together. Reporters are often on deadline. Deadlines mean reporters need a fast turnaround; so when they contact the district communications director, school administrator, or superintendent, those calls should be 
returned promptly. Informal meetings will help establish the protocol of how the reporter will work with the district and vice versa.

Kowalski et al. (2007) offer a few tips on working with media and building positive relationships with them:

- Understand the reporter's job, roles and timelines;

- Realize that the media is a business with the goal of attracting viewers and readers;

- Acknowledge that the school and media relationship is more of a marathon than a sprint;

- Being proactive rather than reactive when it comes to media coverage; and

- Being willing to take the bad news with the good. (p. 191)

Fiore (2011) and Hughes and Hooper (2000) add to this list that "nothing is ever off the record." The best way to work with the media is always to be prepared - to be proactive.

Caution should be taken when speaking to a reporter in not sharing more than the question asks. When a story is written or aired, will the statement hold up and still be accurate even if it is taken out of context? A final caveat from Hughes and Hooper: "No comment" is never without an implication. Fiore urges to use phrases such as the following: "This is a privacy issue"; "You know that I cannot release that information because of confidentiality or state law"; or "What I can say is..." (p. 137). The "no comment" response should never be an option. Simply explaining that personnel issues, for example, are confidential and protected by law is preferred over "no comment."

The school district's reputation relies on strong media relations. The school public is always interested in news about the district because schools are responsible for two prized possessions: their children and their tax dollars (Hughes \& Hooper, 2000). The district leaders must be prepared to share the news of the district. In working with the media, a strong working relationship must be developed as a proactive step. Reporters find it difficult to write something malicious about someone whom they like and respect. 


\section{School Community Relations}

\section{If you don't manage your reputation, someone else will.}

Porterfield and Carnes (2008)

Educators are often fearful of using marketing strategies to tell the school or district story because it sounds too commercial and cheapens the genuine mission of educating students. Yet districts must tell their story.

Marketing assists in telling the story and managing the school district reputation. Bagin et al. (2008) defines marketing as "the process of discovering, defining and delivering what people need and want. Marketing also has to do with helping people see things that they haven't seen before" (p. 323). With charter schools, online schools, private schools, parochial schools, and the option to transfer to other districts, families have multiple choices for their children's education. While this is good news for families with children, it presents a challenge to public education. Public education is no longer the Mercedes in an empty parking garage. Instead, it is now one of many choices in a car lot filled with similar-priced vehicles. Even so, education leaders have avoided thinking of schools in a competitive sense because they have essentially refused to acknowledge any connection between business and education (Kotler, 2000). Educators do not want to be viewed as used car dealers. Nevertheless, in today's competitive education market, using marketing strategies has become a necessity to enhance a school district's public image.

Image matters. Only one poorly handled crisis could permanently damage the reputation of a school or district. Carroll and Caroll (2000) recount that marketing experts believe image to be more important than reality because "image - the sum of perceptions, aptitudes, beliefs, ideas, and feelings held about an object - makes people act in certain ways and shapes attitudes toward a product, service, business, corporation, organization, or public school system" (p. 69). Closing a deal with the public in a bond election takes a thorough understanding of which marketing strategies will influence a "yes" vote.

\section{Marketing Techniques, Tools, and Publications}

As Porterfield and Carnes (2008) cleverly described, putting lipstick on a pig will not cover up the underlying problem. Underneath the lipstick is still the pig. No matter how leaders try to frame their districts, if a district is not progressing toward its strategic education goals, no amount of 
marketing will enhance the district's image. The district must show progress toward its goals and then share the improvements and outcomes with its stakeholders.

Carroll and Carroll (2002) offer several marketing strategies to communicate effectively with a district's stakeholders:

10. Seize all opportunities that communicate quality to the customer.

11. Use word-of-mouth marketing to spread good news about your school system.

12. Use repetition to make your message memorable.

13. Develop a solid relationship with the media.

14. Name an EdMarketing coordinator.

15. Issue press releases and PSAs [public service announcements].

16. Start building an arsenal in writing and in pictures.

17. Develop your marketing communication with senior citizens in mind.

18. Develop and maintain a website. (p. 129)

These nine strategies can be developed into a marketing plan of action for the district. Holt (2002) also offers marketing techniques appropriate to employ for routine communications or communications during a bond campaign. First, the district or campaign committee should provide information to voters with honest facts about the issues. Second, they should identify their varied audiences and provide the information which best suits the needs of each group. For example, Holt offers special communication for senior citizens who may be out of touch with schools and need additional information about the schools that parents would not need because of their familiarity with their neighborhood schools. In other words, the district and campaign committee would target each audience with materials specific to each group's identified needs. Third, the information medium chosen would also match the audience. Holt describes a 1994 study prepared for the American Association of School Administrators:

The Mellman-Lazarus-Lake polling firm determined that most people believe they get a majority of their information about the schools from newspapers, friends, and children. The interesting result is that those surveyed placed one-on-one sources much higher than all media in terms of the quality of information they provide. (p. 117)

Participants in the study rated principals highest in the "very good" category at 37 percent and superintendents lowest in the "very good" category at 29 percent. When both "good" and "very good" were added together, parents came out in the lead as the best medium for information at 80 percent. Newspapers were rated lower in "good" and "very good" at 63 percent. What the 
data indicates is one-to-one communication is the favored medium to receive information; and the farther up the organizational chart an individual is, the less trusted he or she becomes.

General marketing tools, implemented months in advance of a bond campaign and others during the bond campaign, include a variety of communication tools as described in Table 2 . While several are considered one-way communication, which tends to be the least effective form of communication, one-way communication becomes more effective the more often it is repeated (Carroll \& Carroll, 2000; Campbell \& Magmer, 2007). The campaign committee members can advertise and market using any of the marketing tools listed in Table 2. 
Table 2

Marketing Tools

\begin{tabular}{|c|c|c|}
\hline Tools & Definition & Characteristics \\
\hline Direct Mail & $\begin{array}{l}\text { Flyers, brochures, } \\
\text { information sheets }\end{array}$ & $\begin{array}{l}\text { - One-way communication } \\
\text { - Impersonal } \\
\text { - Persuasive (Holt, 2002) } \\
\text { - Informs “no" voters (Campbell \& Magmer, } \\
\text { 2007) } \\
\text { - Effectiveness greatly increases through } \\
\quad \text { repeated contact (Carroll \& Carroll, 2000) }\end{array}$ \\
\hline Free Media & $\begin{array}{l}\text { Video } \\
\text { presentations, } \\
\text { Facebook. Twitter, } \\
\text { Blogs, public } \\
\text { announcements, } \\
\text { press conferences }\end{array}$ & $\begin{array}{l}\text { - One-way, two-way, and repeated } \\
\text { communication } \\
\text { - Detailed information } \\
\text { - Can reach large numbers and various } \\
\text { audiences } \\
\text { - Online requires continual updates and } \\
\text { - } \text { monitoring (Porterfield \& Carnes, 2012) } \\
\text { - Lowncial impact }\end{array}$ \\
\hline $\begin{array}{l}\text { Letters to } \\
\text { the Editor }\end{array}$ & $\begin{array}{l}\text { Letters written to } \\
\text { editors of print } \\
\text { media to express } \\
\text { support of the } \\
\text { school district or } \\
\text { bond election }\end{array}$ & $\begin{array}{l}\text { - One-way, external communication } \\
\text { - Can be persuasive } \\
\text { - Effectiveness greatly increases through } \\
\text { repeated contacts from several writers } \\
\text { (Carroll \& Carroll, 2000) }\end{array}$ \\
\hline $\begin{array}{l}\text { Material } \\
\text { Drops }\end{array}$ & $\begin{array}{l}\text { Distribution to } \\
\text { homes by teams of } \\
\text { volunteers }\end{array}$ & $\begin{array}{l}\text { - One-way communication } \\
\text { - Impersonal contact with voters } \\
\text { - Detailed communication } \\
\text { - Can target supporters } \\
\text { - Fewer voters targeted than other tools }\end{array}$ \\
\hline $\begin{array}{l}\text { Paid } \\
\text { Advertising }\end{array}$ & $\begin{array}{l}\text { Billboards, yard } \\
\text { signs, bumper } \\
\text { stickers }\end{array}$ & 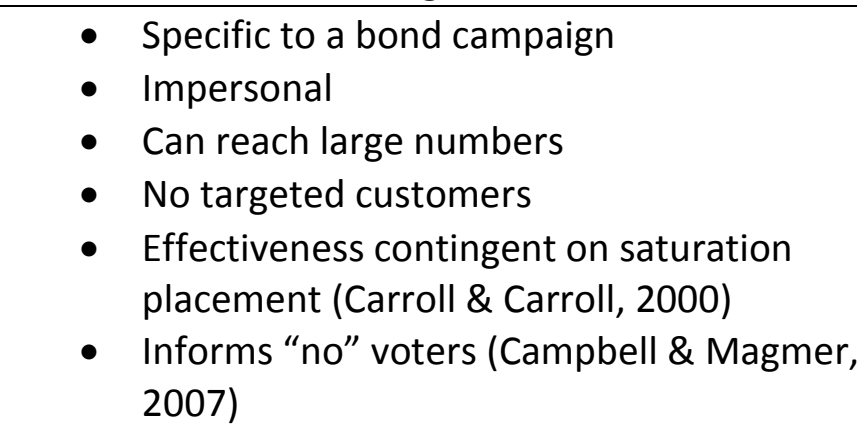 \\
\hline
\end{tabular}




\begin{tabular}{|c|c|c|}
\hline $\begin{array}{l}\text { Print and } \\
\text { Broadcast } \\
\text { Media }\end{array}$ & $\begin{array}{l}\text { Paid political } \\
\text { announcements on } \\
\text { radio, } T V \text {, } \\
\text { newspapers }\end{array}$ & $\begin{array}{l}\text { - } \text { One-way communication } \\
\text { - Impersonal } \\
\text { - High cost } \\
\text { - } \text { Effectiveness greatly increases through } \\
\text { repeated contacts (Carroll \& Carroll, 2000) } \\
\text { - Can be persuasive and dramatic (Carroll \& } \\
\text { Carroll, 2000) }\end{array}$ \\
\hline $\begin{array}{l}\text { Public } \\
\text { Speaking }\end{array}$ & $\begin{array}{l}\text { Formal } \\
\text { presentations to } \\
\text { civic clubs, parent } \\
\text { groups, forums }\end{array}$ & $\begin{array}{l}\text { - Special events (Superintendent and board } \\
\text { should not consistently take the lead } \\
\text { during a bond campaign) (Holt, 2002) } \\
\text { - Speakers must be thoroughly familiar with } \\
\text { all aspects of the bond (Bagin et al., 2008) }\end{array}$ \\
\hline $\begin{array}{l}\text { Telephone } \\
\text { Banks }\end{array}$ & $\begin{array}{l}\text { Personal phone } \\
\text { calls to targeted } \\
\text { "yes" voters }\end{array}$ & $\begin{array}{l}\text { - } \quad \text { Specific to a bond campaign } \\
\text { - } \text { Man be very persuasive (Campbell \& } \\
\text { - } \text { High degree of control over message } \\
\text { - General information } \\
\text { - } \quad \text { Reaches fewer voters than advertising }\end{array}$ \\
\hline $\begin{array}{l}\text { Meet and } \\
\text { Greet }\end{array}$ & $\begin{array}{l}\text { Face-to-face } \\
\text { contact with voters } \\
\text { by walking to } \\
\text { homes in targeted } \\
\text { neighborhoods }\end{array}$ & $\begin{array}{l}\text { - } \quad \text { Specific to a bond campaign } \\
\text { - Highly personal, one-to-one contact } \\
\text { - } \quad \text { Detailed information } \\
\text { - Can be very persuasive (Carroll \& Carroll, } \\
\text { 2000) }\end{array}$ \\
\hline
\end{tabular}

Direct mail, free media, letters to the editor, material drops, paid advertising, and print and broadcast media are all one-way communications. Free media, Facebook, blogs, or Twitter, may contain both one-way and two-way communication. Public speaking telephone banks and meet and greet are two-way communication, which are more persuasive marketing tools (Campbell \& Magmer, 2007). While all these can be effective marketing tools, the district would have to determine which are most cost effective, which target the intended audiences, and which provide the most appropriate information to that audience.

Schools and districts often do not do a good job of self-promotion. Whether knowledge, time, or cost factors are inhibiting the utilization of marketing tools, publicizing the district's successes is essential. Marketing techniques, tools, and publications all help to create a positive image to internal and external school district stakeholders. Carroll and Carrol (2002) list several advantages for districts that monitor their image and work toward improving it:

5. They are more likely to be more effective in securing community support for school projects and instituting changes sought by teachers, administrators, and boards of directors. 
6. "Them-us" attitudes are minimized.

7. They experience increased parental support and involvement.

8. They have greater staff morale because the staff feels it is part of a winning team. (p. 78)

Marketing the district's accomplishments in tandem with a strategic improvement plan will ensure the public does not see "lipstick on a pig," but instead a district achieving its goals and stated actions. 


\section{Social Media}

The 2008 Presidential election was a social media success. Obama won nearly 70 percent of the vote among Americans under age 25 - the highest percentage since U.S. exit polling began in 1976, according to US News (Fraser \& Dutta, 2008). In 2008 about 140 million members were actively using Facebook each month (Smith, 2008). In 2012, Businessweek reported Facebook hitting one billion active monthly users in September (Vance, 2012), while the median age of a Facebook user has actually fallen from age 26 in 2008 to 22 in fall of 2012 (Grandoni, 2012). Still, this social medium can help win elections, whether presidential or district bond elections and can swiftly and effectively provide information about the district to its many stakeholders. Many school districts have developed a Facebook page to post events and to keep in touch with constituents and other institutions, but many districts still fear social media and continue to adhere to antiquated school board policies that forbid usage of these special communication tools. Many district school boards worry about the liability of students and staff using social media. The occasional news story that garners national attention about online improprieties between students and teachers has many rural board members apprehensive.

But times have changed. Porterfield and Carnes (2012) explain that educators must do more than educate students. They must build relationships with the students' families and the taxpayers in the communities they serve:

School leaders have the responsibility to reach out to the larger community - to listen to their stakeholders and include them in new ways, to provide information more quickly than ever before, and, ultimately, to build stakeholder trust. To do this, leaders must develop new communication skills that utilize new technologies. (pp. 1-2)

Using social media such as Facebook, Twitter, blogs, and message boards, can serve that purpose. Gagne (2012), CEO of Allerton Hill Consulting, a communications firm that works with school districts, concurs:

I'm convinced that if schools want to improve their image with taxpayers, they must begin to use social media. The benefits are just too great, and as more of the taxpaying community ties into social media through mobile devices, "traditional" public schools have to become non-traditional, and join the conversation.

Just like email and websites, which eventually became the norm in every school district, school leaders will ultimately need to embrace social media. Gagne describes school districts thriving if they use social media to engage their community and to aggressively enhance and protect their reputation. The ones who do not will "find themselves playing defense with an unengaged public and a healthy number of skeptics who may question the value of public education in their community."

Marketing the school district has several advantages but two rise to the top: First, marketing enhances the district's image by providing the public with specific information about the district. Second, it specifically develops a communication tool to target an intended audience. Bagin et al. (2008) defines marketing as "the process of discovering, defining, and delivering what people 
need and want" (p. 323). Districts are finding themselves in survival mode. Students daily transfer out of the K-12 public school system to online charter schools, alternative schools, or private schools. The K-12 system, apparently, is not "delivering what people want." This dissatisfaction is then spread throughout the greater school communities. In a competitive marketplace, it is critical that districts investigate what the public wants, develop the programs that fit the needs of the students and community, and then inform the public of those changes through meaningful two-way, face-to-face communication. Using marketing strategies has become a necessity in order to enhance a school district's image.

Likewise, when a bond election draws near, the district's image shapes the public's attitudes toward the public school system. Closing a deal with the public in a bond election takes a thorough understanding of which marketing strategies will influence a "yes" vote.

\section{Conclusion}

\section{Everything that our organization does - and sometimes what we don't do-sends a message.}

(Gunther, McGowan, Donegan, 2011).

The importance of an effective communications program cannot be underestimated: It can enhance a school district's image and reputation and be the impetus to passing a bond campaign. While Bagin et al. (2008) describe the vulnerability of school districts in their communication to the public on finance issues, it can also apply to any topic of school communications: "If a school district does not maintain ongoing and clear communications with its parents and taxpayers on finance and budget issues, confusion and distrust can develop" ( $p$. 297). Erickson (2011) warns that whether answers to public questions are positive or negative, people should see that district leaders are transparent. Communication ultimately builds trust and confidence in the school district. 
NOTES 


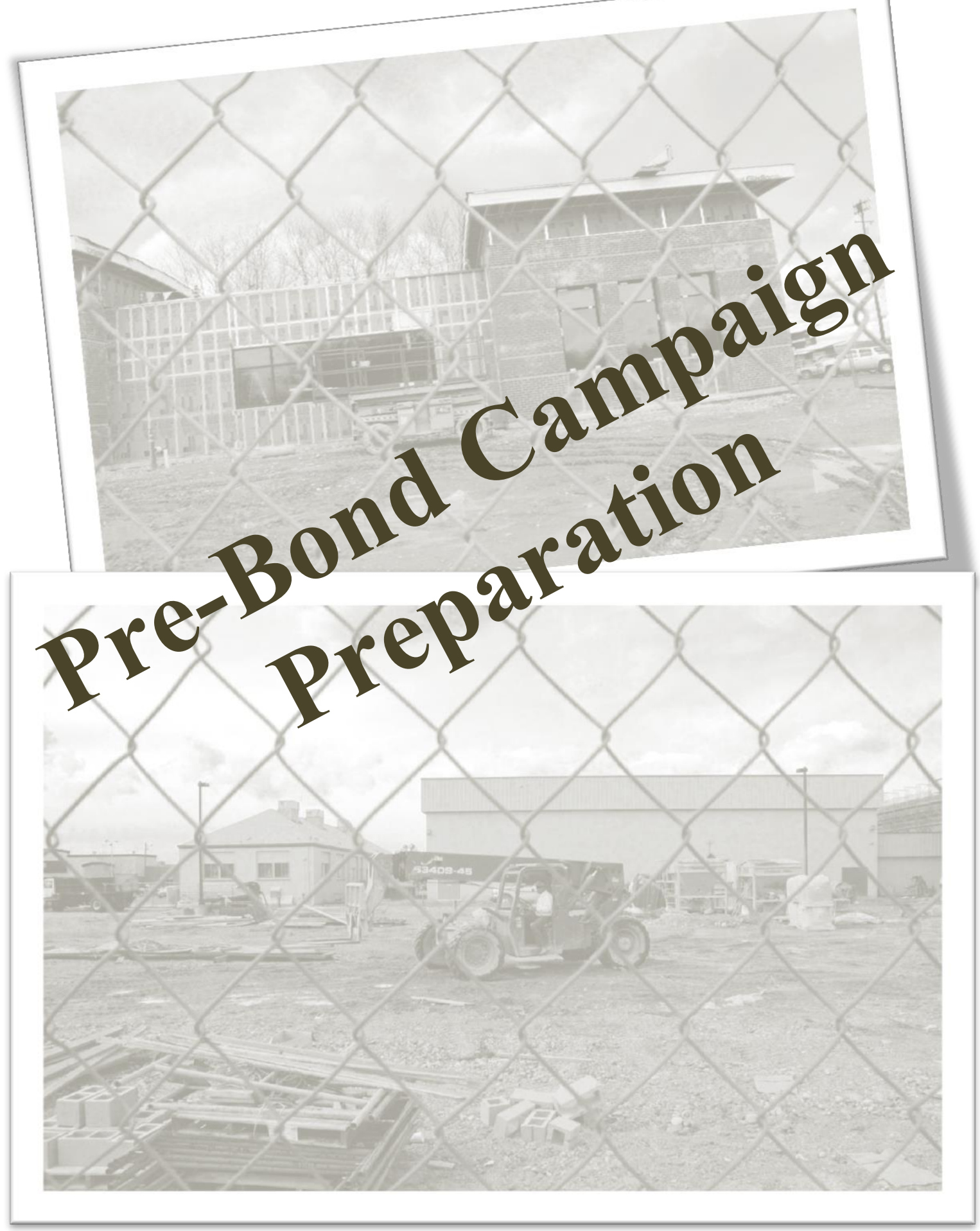




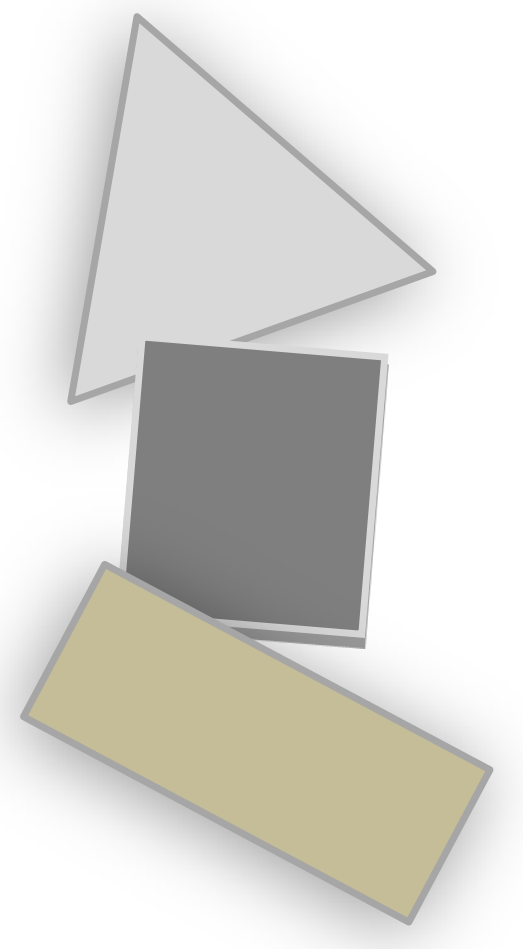

\section{Foundation:} Teaching \& Learning Connection

$\checkmark$ Conduct strategic planning

$\checkmark$ Create a vision for school facilities linked to $21^{\text {st }}$ century teaching \& learning

$\checkmark$ Include all key stakeholders

$\checkmark$ Connect facility improvement to student success

66 The schoothouse should be a temple, consecrated in prayer to the physical, intellectual and moral culture of every child. 


\section{Foundation: Teaching and Learning Connection}

Research points to a positive connection between new and/or upgraded school facilities and improved teaching and learning. In response, districts need to develop a clear vision for their facilities planning and policies in order to curb dropout rates, accommodate growing enrollments, increase student achievement, and provide educational environments responsive to the changing nature of learning, communities, and necessary workforce skills.

According to a Tennessee study of school facilities, there is growing evidence of a correlation between the adequacy of a school facility and student behavior and performance (Young, 2003). Several of the studies cited in the Tennessee study show a statistically significant positive relationship between the condition of a school or classroom and student achievement. In general, the findings point to students who attend school in newer, better facilities score 5 to 17 points higher on standardized tests than those who attend substandard buildings.

Copa (2008) introduced four school construction priorities for facility planners on best practices in teaching and learning: Engagement, Personalization, Connectivity, and Authenticity. He focuses on how these priorities can be addressed in school design.

- Engagement requires spaces that are more lively, open, and visually interesting. These spaces would accentuate areas for project-based learning activities and collaboration.

- Personalization provides more learner-centered environments with study space, storage space, and options of varied learning and working environments. The focus is on each and every child and takes into account the different needs of each learner.

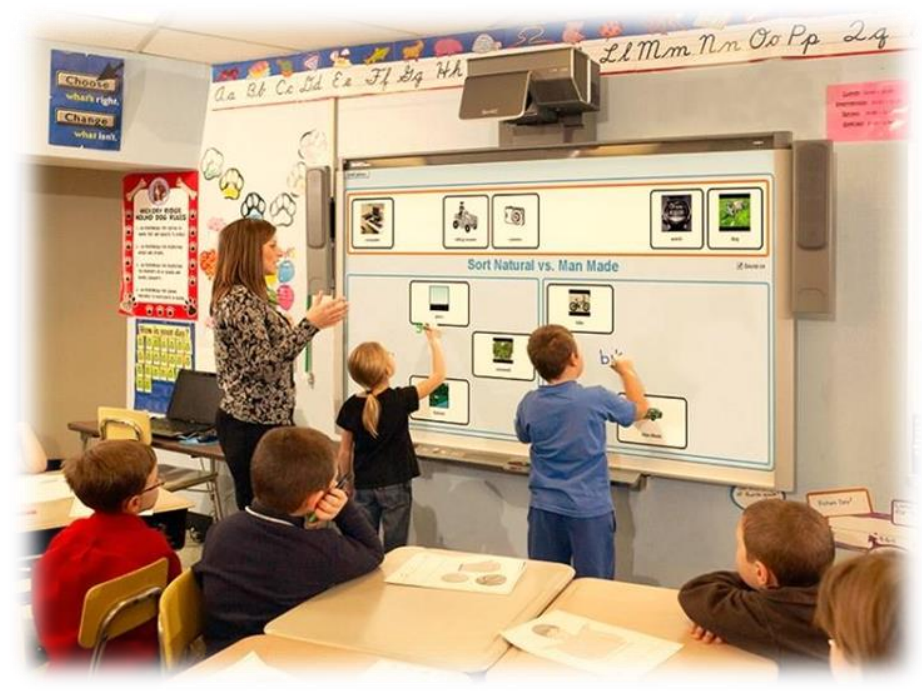


- Connectivity relates to the ability of students to collaborate effectively with each other, with other students in different schools, and with the community. A priority is for students to learn the importance of teamwork, networks, and communities and to understand how they fit into larger local and global contexts.

- Authenticity provides opportunities for students to learn in real life experiences and contexts, not through the typical instructions, exercises, and worksheets. Copa advocates for more joint-use facilities throughout the community, where students are literally learning in different locations. These spaces can resemble workplaces, promoting collaborative work and interdisciplinary exchange.

School facilities should be designed to facilitate what we know today about providing the best possible education for all students in the 21 st century. In reality, the majority of 86,000 public school buildings currently in use were designed to sustain a model of education characterized by large-group, teacher-centered instruction taking place in isolated classrooms. Current knowledge and research about learning calls for new models according to the U.S Department of Education (2000):

- Increased student involvement in their learning

- Engaged learners who are active participants in thinking, working, and solving problems

- Involved learners using strategies such as cooperative, project-based and interdisciplinary learning, all requiring students to move about, work in various sized groups and be active

- Increased emphasis on learning styles

- Increased emphasis on the special needs of each student

Educational facilities should be designed to support these and other examples of current research and best practices in the learning sciences.

What is the school, district, and community philosophy on optimal environments for student learning? What are the needs of teaching and learning in the future?

\section{TEACHING: WORKING CONDITIONS \& JOB SATISFACTION}

A study of working conditions in urban schools concluded that "physical conditions have direct positive and negative effects on teacher morale, sense of personal safety, feelings of effectiveness in the classroom, and on the general learning environment." Building renovations in one district led teachers to feel "a renewed sense of hope, of commitment, a belief that the

district cared about what went on that building." In dilapidated buildings in another district, the atmosphere was punctuated more by despair and frustration, with teachers reporting that leaking roofs, burned out lights, and broken toilets were the typical backdrop for teaching and learning (Corcoran, Walker, \& White, 1988). 
Similarly, Poplin and Weeres (1992) reported that, based on an intensive study of teachers, administrators, and students in four schools, "the depressed physical environment of many schools...is believed to reflect society's lack of priority for these children and their education."

Another study also found that "where the problems with working conditions are serious enough to impinge on the work of teachers, they result in higher teacher absenteeism, reduced levels of effort, lower effectiveness in the classroom, low morale, and reduced job satisfaction. Where working conditions are good, they result in enthusiasm, high morale, cooperation, and acceptance of responsibility" (Corcoran et al., 1988).

\section{RESEARCH: CONNECTIONS BETWEEN THE CONDITION OF SCHOOLS AND STUDENT LEARNING}

\section{Age of Building}

The findings show that the age of the school results in a significant negative effect upon the student (Bullock, 2007). Students performed better in newer or recently renovated buildings than they did in older buildings. Building age, windows in the instructional area, and overall building condition were positively related to student achievement.

\section{$\underline{\text { Acoustics }}$}

Research demonstrates that classroom acoustics must be considered in order to maximize student achievement and learning. The interplay of sound, hearing, and learning is a complex phenomenon and affected by many factors (Anderson, 2001). Students in noisy environments are more likely to quit tasks than students in quiet ones. Studies agree in one general conclusion: Poor acoustics in the learning environment is detrimental to student performance (Green, Pastemak, \& Shore, 1982; Evans, Hygge, \& Bullinger, 1995; Bradley, 1986).

\section{Lighting}

To summarize, the Heschong Mahone (2003) study found that any characteristic having to do with direct sunlight or glare had a negative effect upon student learning.

\section{$\underline{\text { Temperature }}$}

While previous studies focused primarily on the effects of avoiding temperatures of $80^{\circ} \mathrm{F}$ or higher, the influence of more moderately elevated temperatures on student performance was investigated more recently via field studies conducted in classrooms (Wargocki \& Wyon, 2007). Performance tasks representing eight aspects of schoolwork, from reading to mathematics, were embedded into the normal school work. The speed and accuracy of task performance was assessed. The average speed of eight simulated schoolwork tasks decreased by approximately 1.1 percent per each $1^{\circ} \mathrm{F}$ as temperatures increased from $68^{\circ} \mathrm{F}$ to $77^{\circ} \mathrm{F}$.

Beaverton students from Westview High School conducted a study on temperature affecting student performance that supports the Wargochi \& Wyon study (Perez, J., Montano, J., \& Perez, 
J., 2006). While results from initial testing in Phase 1 of the project were not conclusive, the researchers' more stringent tests during Phase 2 revealed that temperature clearly impacts the attention span of students. According to the research findings, the average test scores for students in different classes were similar in the same category. In the cold classroom, the average temperature was $61^{\circ} \mathrm{F}$; average test results were 78 and 74 percent. In the classroom that was too warm (the average temperature was $81^{\circ} \mathrm{F}$.), average scores were 72 and 73 percent. And in the neutral or control classrooms, students' average scores were 87, 92, and 93 percent with the average temperature set at $72^{\circ} \mathrm{F}$.

\section{Air Quality}

Research indicates that the quality of air inside public school facilities may significantly affect students' ability to concentrate. The evidence suggests that youth, especially those under 10 years of age, are "more vulnerable than adults to the types of contaminants (asbestos, radon, and formaldehyde) found in some school facilities" (Andrews \& Neuroth, 1988).

There is growing evidence that contaminated indoor air can produce verbal, perceptual, motor and behavioral disabilities in children. It can also cause hearing impairments, irritability and developmental delays (Healthy Schools Network, 2012).

\section{Health, Safety, and School Climate}

According to Frieberg (1998), "Much like the air we breathe, school climate is ignored until it becomes foul."

The Center for Innovative School Facilities reports school facilities have a measurable impact on student achievement. From K-12, the environment in which students learn affects their performance and, ultimately, their future. The quality and quantity of light that students receive impact their health, behavior, and achievement. Airborne pollution and thermal discomfort have well documented negative effects on attendance and concentration. Finally, a quiet learning environment benefits both students and teacher by positively impacting the retention of information.

Children's health is uniquely affected by the environment. Children are not adults and are especially vulnerable to environmental risks because

- Their bodies are still developing

- They proportionately eat, drink and breathe more per pound of weight than adults

- They are exposed to more environmental threats

- They are less able to identify or protect themselves from exposures to environmental hazards (HSN, 2012)

\section{$\underline{\text { School Size }}$}

Currently, most researchers agree that a small elementary school should be three hundred to four hundred, while a small high school should be four to eight hundred (Williams, 1990). The 
Bill and Melinda Gates Foundation and other philanthropic groups typically set the high school limit at four hundred in the schools they support (Overbay, 2003).

\section{Beauty and Aesthetics}

Some experts describe characteristics of aesthetically pleasing buildings and grounds, joint-use facilities, the inclusion of state-of-the-art technology to aid instruction, and harnessing green technologies to reduce the carbon footprint and ongoing operating costs of future facilities (Ciardullo, 2001).

The quality of the physical environment affects how a building is perceived and even how it is used (Ciardullo 2001). Heschong Mahone (2003) study demonstrated that students in classrooms with views of mountains or open spaces outperformed their counterparts with less attractive views. Any aspect involving exposure to natural beauty was also identified as a significant factor in student achievement. Researchers looking for real-world impacts discovered that views of nature potentially improve people's health and well-being (Ulrich, Simons, Losito, Fiorito, Miles, \& Zelson, 1991).

Investigations show:

- That pupils with plenty of daylight in the class room learn up to 21 percent more than pupils with less daylight.

- That noise has a negative impact on the behavior of the pupils

- That a fuzzy physical environment with a lot of strong colors results in jumpy children

- That senses are activated by diversity

- That bullying is worse in sad asphalted school yards than in well-ordered, challenging and varying outdoor areas.

- That there is a connection between feelings and learning. A good atmosphere in the room creates better learning. (Kjærvang, 2006)

\section{The Community School}

The Oregon governor's vision of 40-40-20 requires that by 202540 percent of the students will graduate from a four-year university, 40 percent will graduate from a two-year college or technical school, and 20 percent will graduate from high school. That means 100 percent of children will graduate from high school in 2025.

It is obvious that 12 or 14 years of learning will not be sufficient to equip people for the rest of their lives. We cannot afford to think of high school graduation as a finish line, and this means that one of the most important end products of schools need to be a people who have learned how to continue to learn. School facilities should support learning for people of all ages by creating access to flexible and comprehensive programs to meet all their learning needs. They should also provide space for everything from early childhood learning to adult education and training (U.S. Department of Education, 2000). 
Restoring schools to the center of community life can be accomplished in many ways, including joint-use, placing human resources on site, and integrating the facility into the cultural history of the locale in which it is built. Schools designed with these goals in mind are then referred to as community learning centers, neighborhood-centered schools, and full-service schools depending upon the journal or resource cited.

A caveat: School and community leaders must address potential issues of safety and security, upkeep, operational costs, and coordination when schools facilities become shared spaces (American Architectural Design, 2005).

\section{Technology}

It may take years for studies to scientifically measure the effects of technology on student achievement. As students and staff members become more digitally aware, design teams will need to address their needs.

However, Apple (2002) has listed several research findings in technology's impact on student learning:

- Students, especially those with few advantages in life, learn basic skills-reading, writing, and arithmetic - better and faster if they have a chance to practice those skills using technology.

- Technology engages students, and as a result they spend more time on basic learning tasks than students who use a more traditional approach.

- Technology offers educators a way to individualize curriculum and customize it to the needs of individual students so all children can achieve their potential.

- Students who have the opportunity to use technology to acquire and organize information show a higher level of comprehension and a greater likelihood of using what they learn later in their lives.

- By giving students access to a broader range of resources and technologies, students can use a variety of communication media to express their ideas more clearly and powerfully.

- Technology can decrease absenteeism, lower dropout rates, and motivate more students to continue on to college.

- Students who regularly use technology take more pride in their work, have greater confidence in their abilities, and develop higher levels of self-esteem.

While technology has a positive impact on student learning, one study identified 123 barriers to technology implementation found from reviews of past studies (Hew \& Brush, 2007). The number one barrier is resources. Even in cases where technology is abundant, there is no guarantee that teachers have easy access to the resources. Access to technology is more than merely the availability of technology in a school; it involves providing the proper amount and right types of technology in locations where teachers and students can use them (Fabry \& Higgs, 1997). 


\section{Green Design}

A LEED building would by definition have excellent indoor air quality, would efficiently monitor and maintain thermal comfort, and would utilize natural light to offset or eliminate costs associated with florescent lighting (U.S. Green Building Council, 2007). Additionally, the various levels of certification help design teams make structured choices about which elements to include or exclude. Using LEED guidelines to guide the facility specifications will more than likely reduce conflict among team members and lead to a more harmonious design and construction process.

\section{CONCLUSIONS: CONNECTIONS BETWEEN THE CONDITION OF SCHOOLS AND STUDENT LEARNING}

School design is crucial in order to accommodate the changing needs of students, staff and teachers. School spaces should provide the best opportunities for student learning. With new technologies and innovative teaching methods, classroom spaces must become much more than rows of desk-filled rooms. New classroom designs should feature flexible learning spaces that have the ability to take student learning to the next level.

Facilities planning teams should develop building priorities with these optimal learning environments. Once generated, the priorities should be cross-checked according to the current research. While the research on appropriate learning environments is abundant, the research is often unheeded by the design teams for varying reasons. How do we educate the public about $21^{\text {st }}$ century teaching and learning? What should $21^{\text {st }}$ century classrooms look like? How will they operate?

\section{A FEW WORDS ABOUT ... SPORTS, ACTIVITIES, AND STUDENT ACADEMIC ACHIEVEMENT}

Students who participate in sports or activities are three times more likely to perform in the top quartile on a composite math and reading assessment compared with nonparticipants (US Department of Education, 1995).

Almost every public high school offers extracurricular activities such as music, clubs, and sports. These activities offer opportunities for students to learn the values of teamwork, responsibility, physical strength and endurance, competition, diversity, and a sense of culture and community. Extracurricular activities provide a channel for reinforcing the lessons learned in the classroom, which offer students the opportunity to apply academic skills in a real-world context, and are thus considered part of a well-rounded education (O'Brien \& Rollefson, 1995).

Research suggests that participation in extracurricular activities may increase students' sense of engagement or attachment to their school, and thus decrease the likelihood of school failure and dropping out (Lamborn, Brown, Mounts, \& Steinberg, 1992). If, indeed, participation in extracurricular activities can lead to success in school, then the availability of these activities to students of all backgrounds becomes an important equity issue and an issue that should be 
addressed in school facilities planning and construction (U.S. Department of Education, 1995). In a University of Minnesota study the outcome continues. Hartmann (2008) stated: "This research has time and again demonstrated a strong and positive correlation between high school sports participation and academic achievement" (p. 3). Maintaining strong sports and activities programs by investing in those facilities that support the programs have an impact on student learning and student achievement. 


\section{Reflection}

1. What are the district policies?

2. Who would you include in the design of the district's teaching and learning connection to school facilities?

3. What areas would you research?

4. Decide the type of report.

5. Suppose there is a disconnection between the outcomes of the research and what the community will support in a construction bond election. How will you address this? 


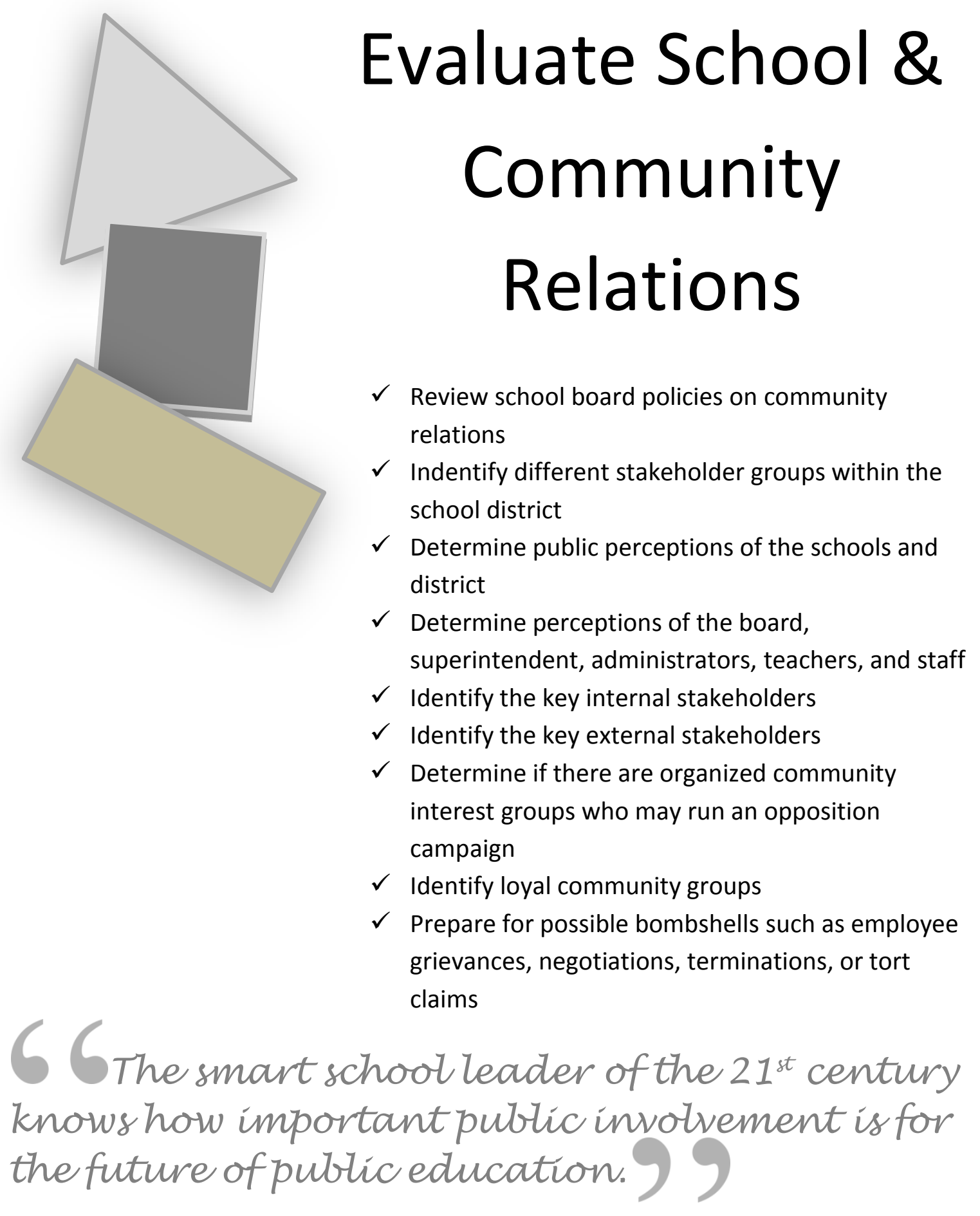

(Fiore, 2011) 


\section{Evaluate School \& Community Relations}

Sometimes districts such as Novato School District \#1 just don't want to know.

However, district leaders should assess the community's perceptions of the district one to two years before a bond levy is planned. If the district has been receiving negative press or schools are low performing or both, these are potential roadblocks in a bond campaign.

So districts must investigate and ascertain the community's perceptions of the schools.

What was the outcome of the last bond measure? If the vote was not positive, an assessment of the current climate between the schools and community is certainly in order. But even if a district had been successful 5 to 10 years previously, assessing the climate is still a worthy effort. How the community views its schools is paramount to passage of a bond.

How does a district evaluate the effectiveness of school and community relations?

School districts can conduct their own opinion surveys, or they can hire an outside agency to conduct the survey. One school district conducted a mass survey to include the entire school district and city. The survey was intended to assess what projects the community would support in a bond measure, but the planning team received much more. The members of the planning team found that the community was dissatisfied with the direction of the district and the district leadership and would not support a bond measure unless the school board took action. When the board took action and hired a new superintendent, the community passed the bond measure. School communities simply desire results.

Once the survey results are tabulated, the planning team must candidly evaluate the results. If the community is moderately supportive, then attempting a bond campaign is acceptable. Otherwise, the district will need to conduct a strong public relations campaign before the bond.

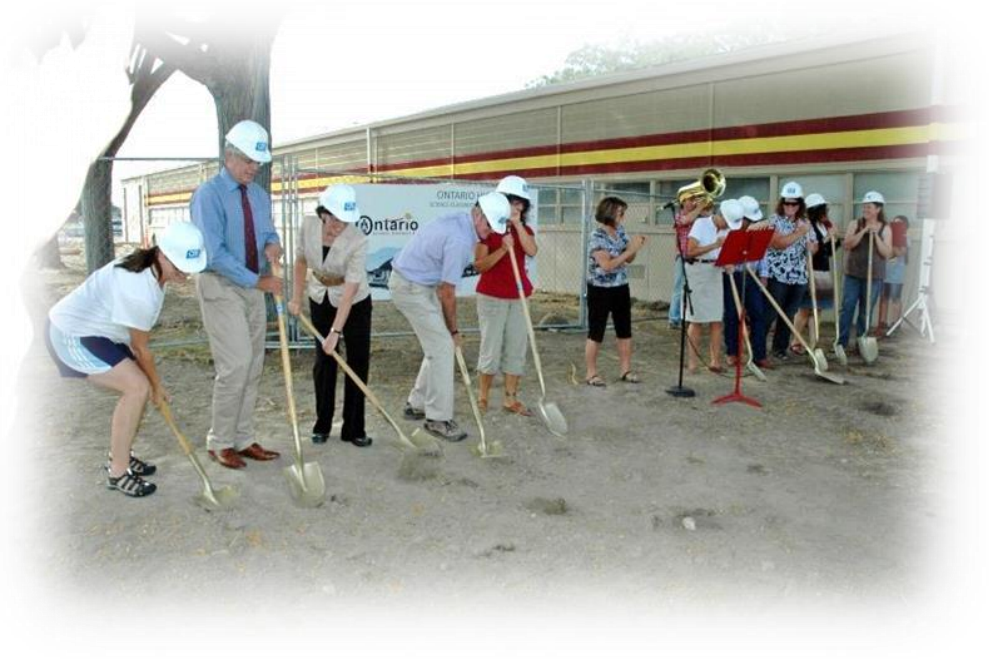




\section{Reflection}

1. What are the district policies?

2. Who are the different groups that make up the school district?

3. What are the public perceptions of the schools and district?

4. What are the perceptions of the board, superintendent, administrators, teachers, and staff? 
5. Who are the key internal players?

6. Who are the key external players?

7. Are there any organized community groups opposed to the district?

8. Are there community groups supportive of the school district?

9. Are there any suspected "surprises" in the future for the district? 


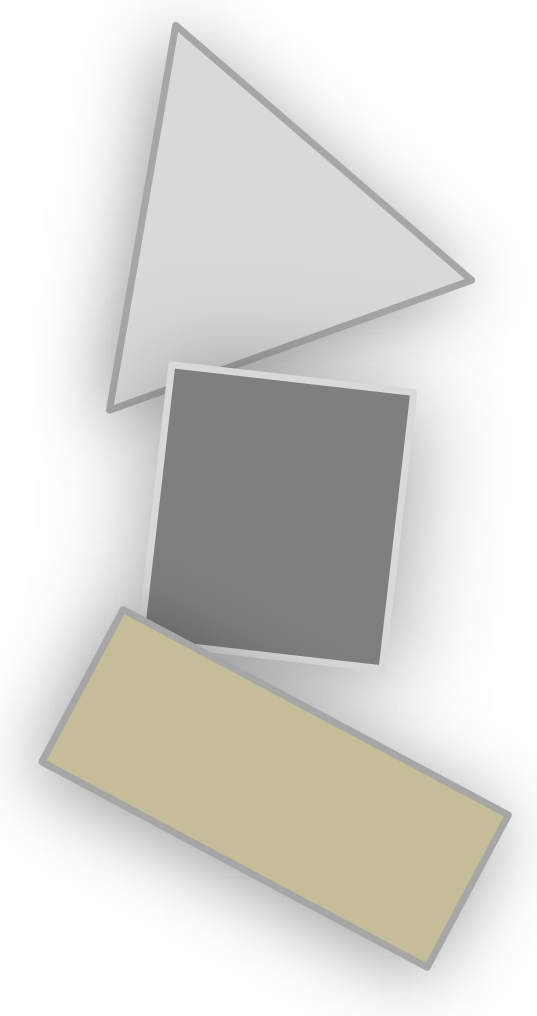

\section{Garner District}

\section{Support}

$\checkmark$ Name the leaders of the community

$\checkmark$ Analyze the schools' academic achievement

$\checkmark$ Analyze athletic teams/school activities successes

$\checkmark$ Determine the quality of the district's ability to connect with parents and embrace cultural and ethnic diversity

$\checkmark$ List the school and community partners

$\checkmark$ Identify school climate issues

$\checkmark$ Describe the relationship between the district and licensed and classified associations

$\checkmark$ Assess the school board's agreement to the planning, process, and direction of the bond

$\checkmark$ Identify the key communicators

$\checkmark$ Choose community members early as future campaign leaders and campaign contributors

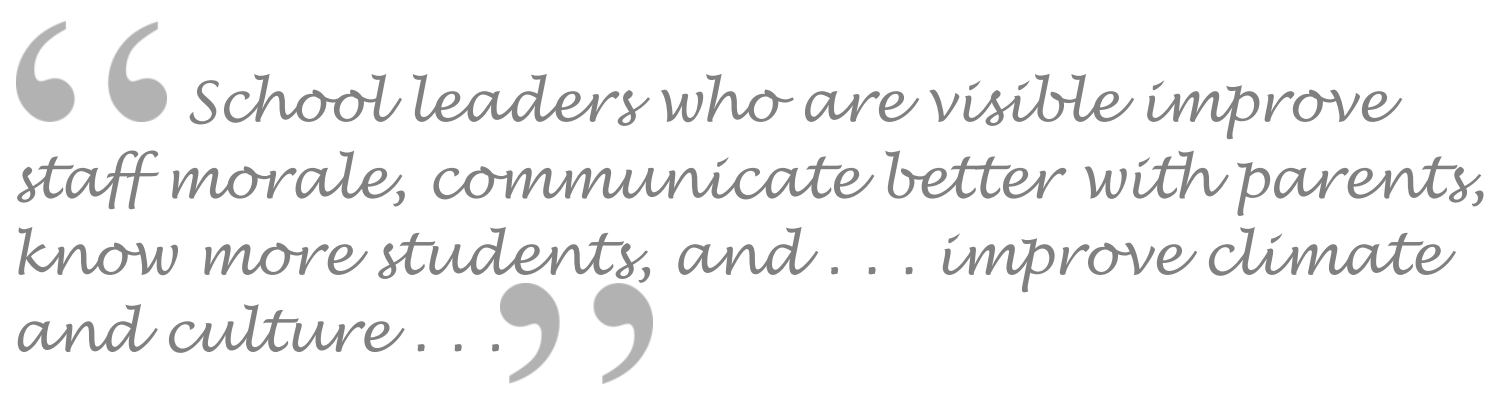

(Fiore, 2011) 


\section{Garner District Support}

When is the best time to garner district support?

Right now! Time is of the essence. Gaining supportive constituents should start years in advance of a bond levy. It should be a common endeavor district leaders practice each day of the year.

Support for a school bond levy originates within the district. District leaders should assess the climate within the school district to ensure that it is collaborative, friendly, respectful, and supportive. Determining the climate can be accomplished in a number of ways such as through feedback from staff surveys, focus groups, school staff meetings or a combination of these. Employee groups supply the bulk of district information to those outside the district - their friends, family, neighbors, and acquaintances - and the information can be factual and positive or biased and destructive. What would a $3^{\text {rd }}$ grade teacher, for example, share with a parent about the district or her school in the grocery store checkout line?

The district's external constituents are recipients of news from employees, newspapers, blogs, $\mathrm{TV}$, radio, schools, and district. Vital to a bond is news that accurately reflects the true work of the district and its schools. Administrators, communications personnel, the school board, and the superintendent should all embrace purposeful efforts to build partnerships by joining and participating in clubs, chambers, and community meetings. Speaking engagements, focus groups, key communicators, and district-led community meetings will garner the supportive culture needed to further the mission and vision of the district.

Like Talent School District \# 2, communication about the school district must be transparent. A district must take ownership of the information whether that information is pleasant or unpleasant. District leaders who attempt to manipulate data or not divulge all information are only fooling themselves. The public is more likely to support a district that is honest about its flaws and has a plan of action to correct those flaws than a district that tries to mask its failings through deceptive practices.

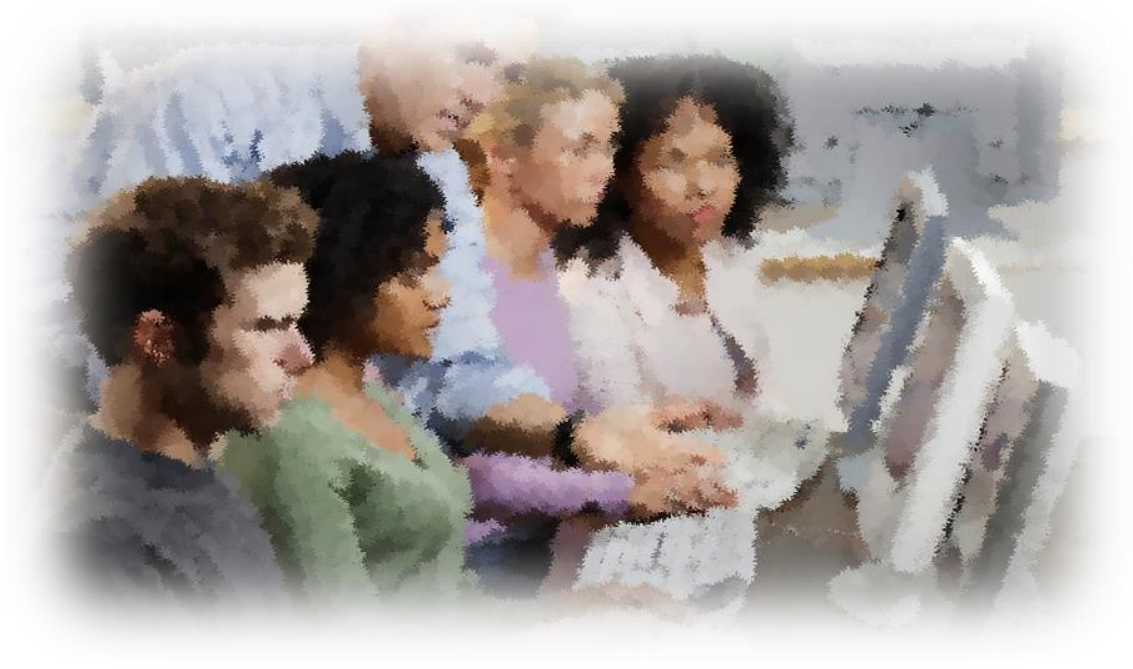




\section{Reflection}

1. Who are the leaders of the community?

2. How successful are the schools academically?

3. Are athletic teams successful?

4. How do schools reach out to parents and embrace cultural and ethnic diversity?

5. Who are the school and community partners? 
6. Are there school climate issues?

7. What is the relationship between the district and licensed and classified associations?

8. Is the school board in $100 \%$ agreement of the planning, process, and direction?

9. Who are the key communicators?

10. Can interested community members be identified early in the process as future campaign leaders and campaign contributors? 


\section{$\square \quad$ NOTES}

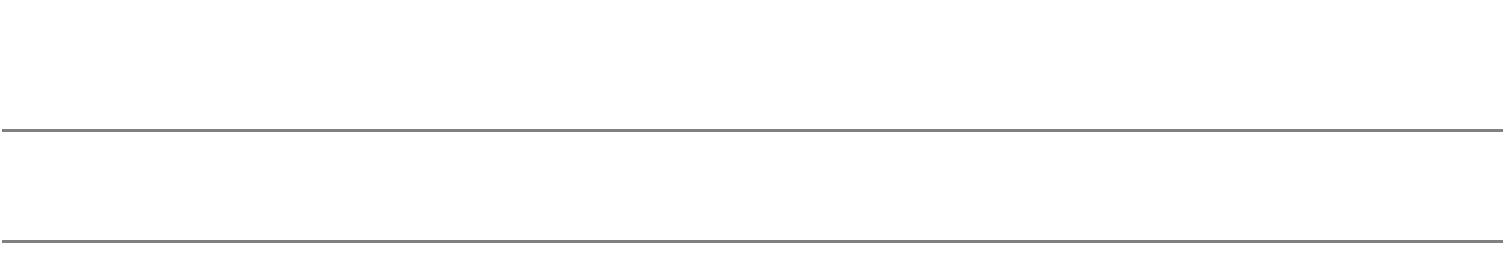




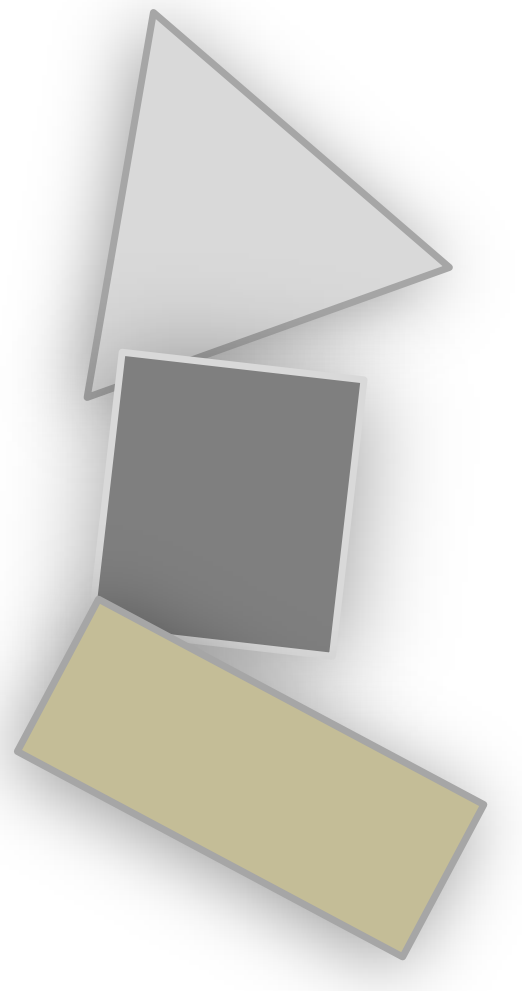

\section{Create the}

\section{Communications Plan}

$\checkmark$ Review school board policies on communications

$\checkmark$ Review elections laws

$\checkmark$ Identify internal and external constituents

$\checkmark$ Determine the appropriate medium in which to communicate with each group

$\checkmark$ Describe the one-to-one communications plan

$\checkmark$ Identify lead person for print media

$\checkmark$ Identify lead person for social media

66

Gaining community acceptance of an idea - whether it is a budget, school plan, curriculum change, or construction bond requires an organized plan of action.

(Bagin et al., 2008) 


\section{Create the Communications Plan}

Every school district should develop an updated communications plan and not wait to communicate with the public when in need of remodeling and upgrading schools. That might be too late.

An effective communications plan equates to improved school-community relations and a supportive public. Novato School District did not enlist communications strategies with all its constituents, and Superintendent Young's communication plan was significantly deficient. He did not find it necessary to communicate with his Spanish-speaking parents; he refused to communicate with parents who sent their children to a neighboring district; and he only communicated with the more affluent families. Unfortunately, being selective does not win supporters or votes. Other language speakers may know voters or are voters themselves. A superintendent should not make such costly assumptions.

An effective communications plan must serve all district constituents, both internally and externally. It should be an all-encompassing, comprehensive plan that identifies all forms of communications for each school or school level, department, and office and is firmly established before the inception of a bond levy. It should include two-way and one-way communication and all forms of media including social media. The communications plan should mirror the manner that business is conducted in the school district - well planned and well thought out.

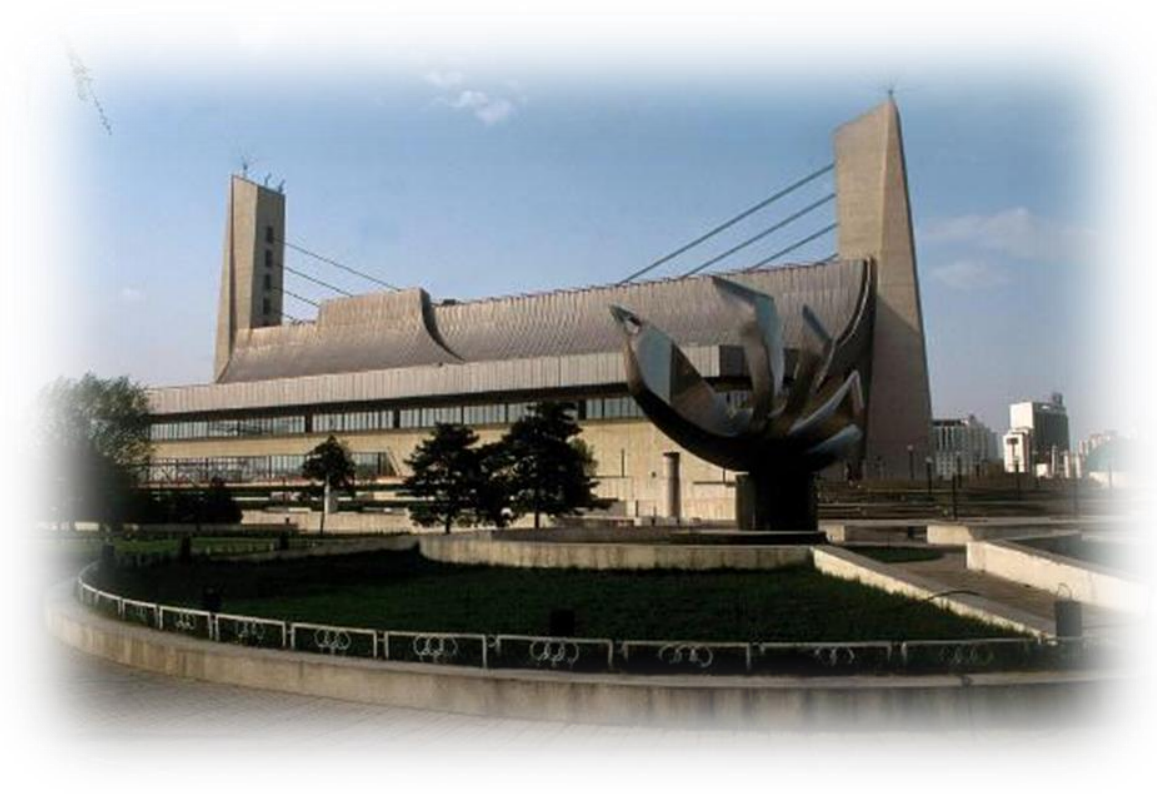




\section{Strategic Communications Plan Outline}

Mission: The reason for the plan.

Example: To communicate in an ongoing dialogue with the district communities in order to pass a bond levy

Goals: General guidelines of what must be accomplished.

Example: Enhance and improve community relations.

Objectives: The actions necessary to achieve the goals.

Example:

Objective 1: Compile a list internal and external stakeholders

Objective 2: Create, administer, and evaluate survey of perceptions of school district

Objective 3: Target each stakeholder group with the appropriate communication venue, tactic, and/or tool

Action Plan: The actions necessary to achieve the goals; the timeline to accomplish the actions; the outcomes anticipated; the evaluation of outcomes; person or department responsible; budget/costs associated with the action.

The actions would include the following types of communication:

- Communication with Internal/External Stakeholders

- One-way Communication

- Two-way Communication 
Communication with Internal Stakeholders

Identify Internal Stakeholders

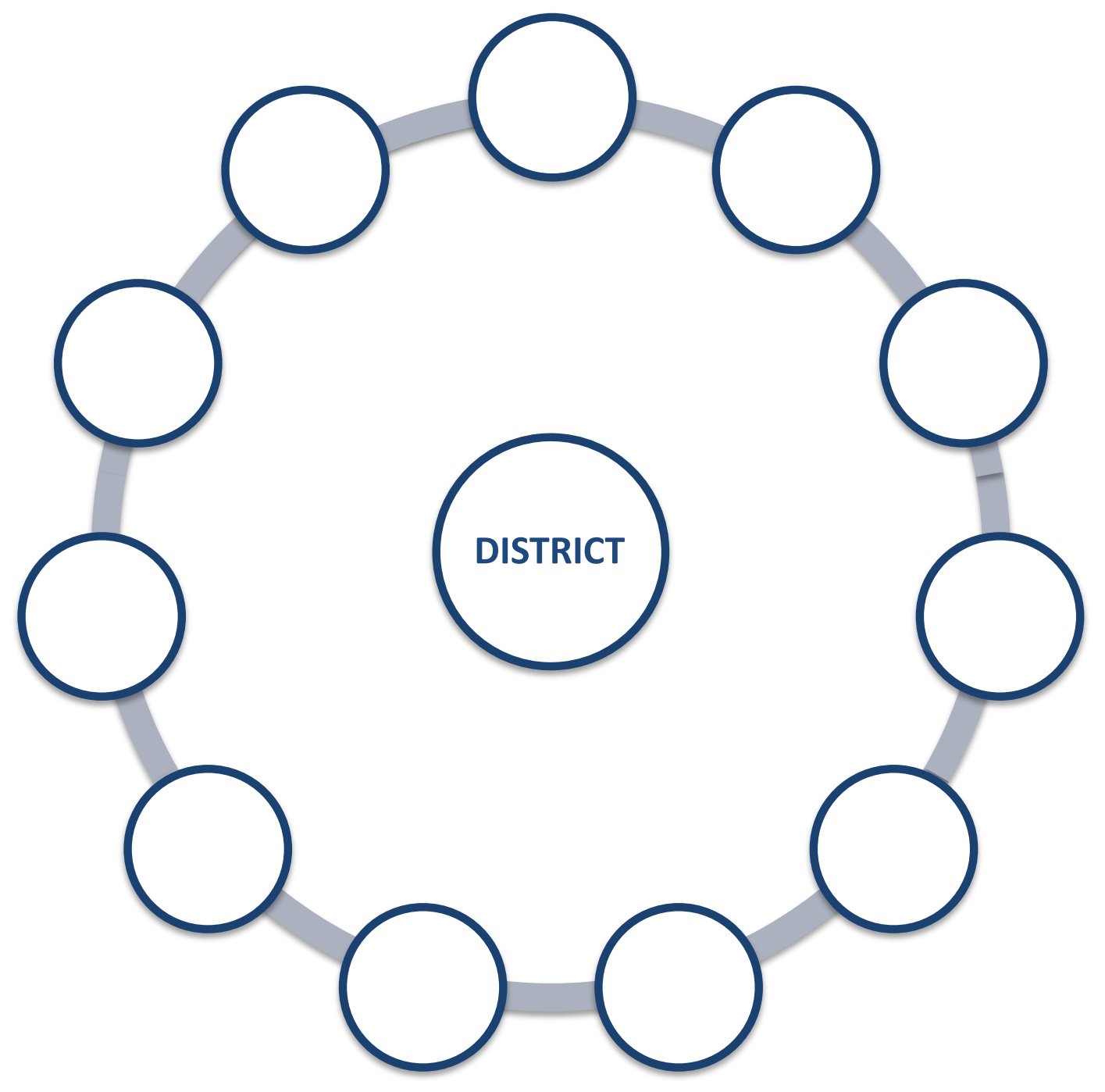




\section{Communication with Internal Stakeholders}

Identify External Stakeholders

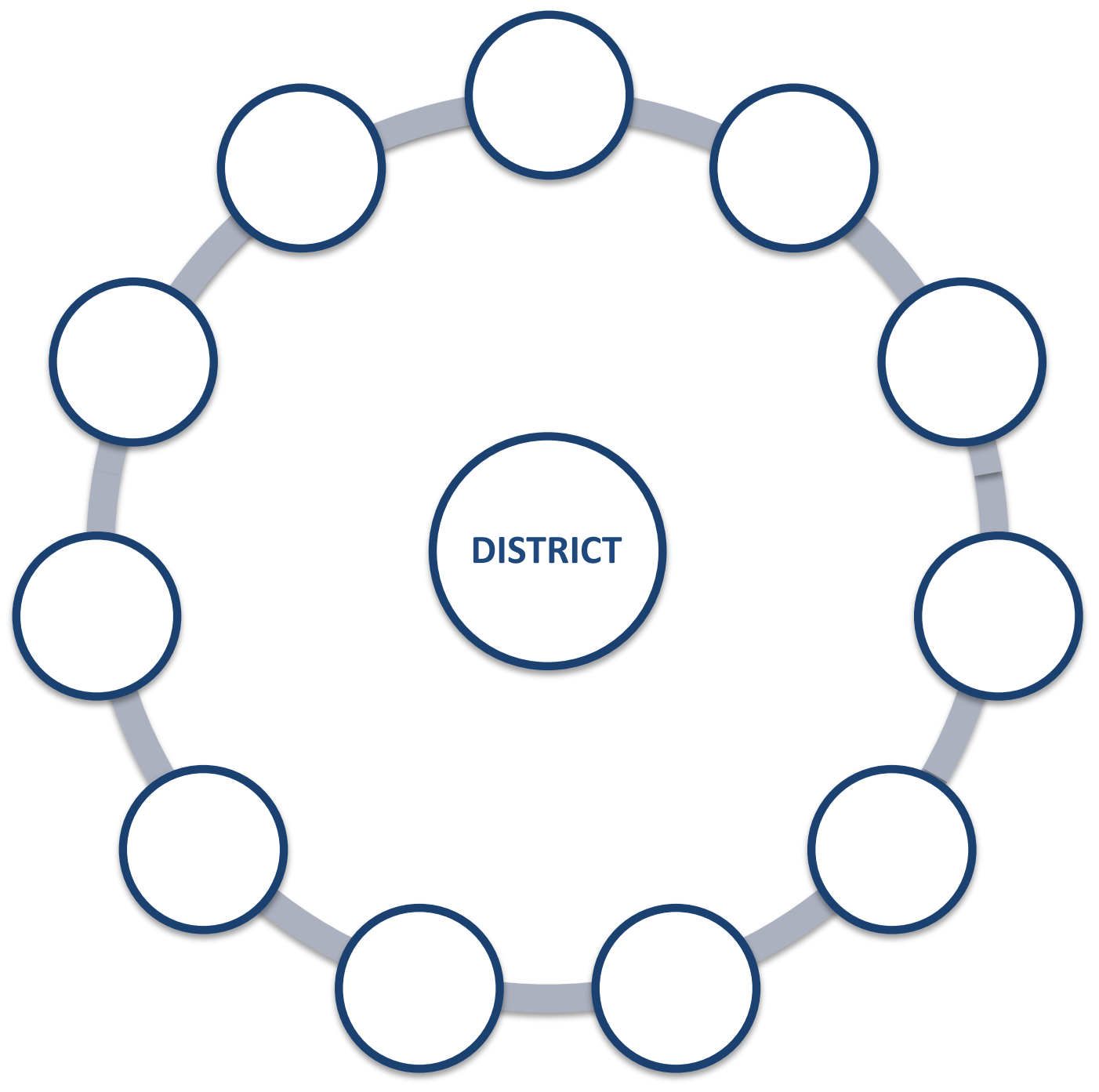




\section{Communications Action Plan Template}

Mission Example: To communicate in an ongoing dialogue with the district communities in order to pass a bond levy

Goal 1 Example: Targeting the various parent groups ...

\begin{tabular}{|l|l|l|l|l|l|}
\hline \multicolumn{5}{|c|}{ Communications Action Plan Example } \\
\hline $\begin{array}{l}\text { Activities/ } \\
\text { Objectives }\end{array}$ & $\begin{array}{c}\text { Expected } \\
\text { Outcomes }\end{array}$ & Evaluation/Artifacts & Timeline & $\begin{array}{c}\text { Person/Group } \\
\text { Responsible }\end{array}$ & Resources \\
\hline Activity 1 & & & & & \\
\hline Activity 2 & & & & & \\
\hline Activity 3 & & & & & \\
\hline Activity 4 & & & & & \\
\hline Activity 5 & & & & & \\
\hline
\end{tabular}

Goal 2 Example: Targeting internal stakeholder groups ...

\begin{tabular}{|l|l|l|l|l|l|}
\hline \multicolumn{7}{|c|}{ Communications Action Plan Example } \\
\hline $\begin{array}{l}\text { Activities/ } \\
\text { Objectives }\end{array}$ & $\begin{array}{c}\text { Expected } \\
\text { Outcomes }\end{array}$ & Evaluation/Artifacts & Timeline & $\begin{array}{c}\text { Person/Group } \\
\text { Responsible }\end{array}$ & Resources \\
\hline Activity 1 & & & & & \\
\hline Activity 2 & & & & & \\
\hline Activity 3 & & & & & \\
\hline Activity 4 & & & & & \\
\hline Activity 5 & & & & & \\
\hline
\end{tabular}




\section{Reflection}

1. What are the board policies that include communication?

2. Who are the internal and external constituents?

3. What is the best medium in which to communicate with each group?

4. What is the one-to-one communication plan?

5. Who is responsible for print media?

6. How will social media be utilized? 


\section{$\square \quad$ NOTES}

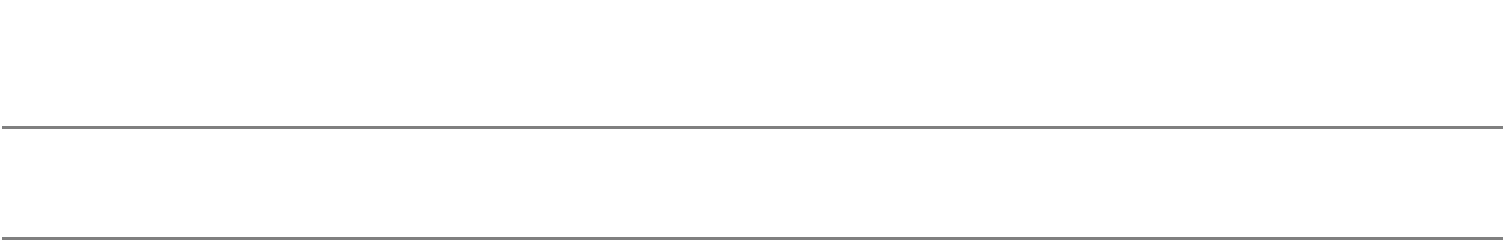




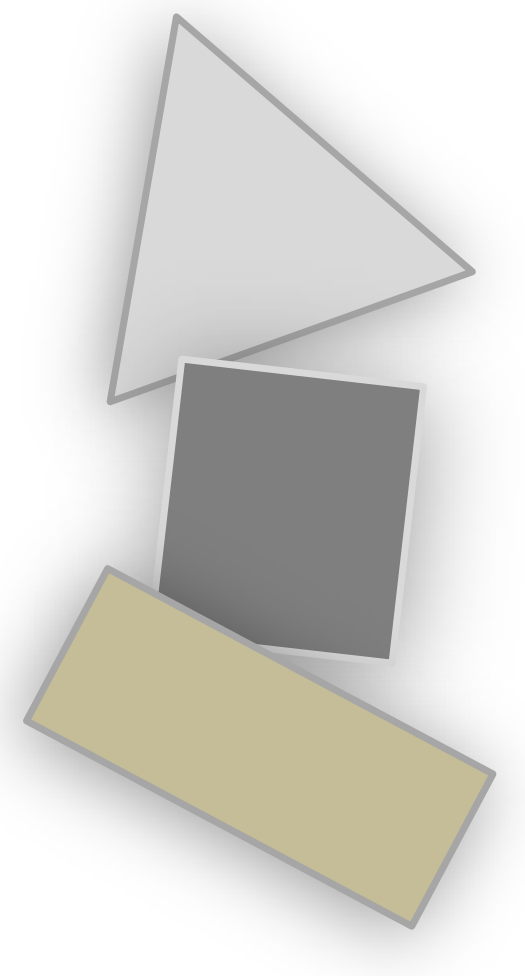

\section{Enlist Key \\ Community \\ Leaders}

$\checkmark$ Identify the respected community leaders, parents, and business professionals who will take the lead

$\checkmark$ Ensure the school board is in complete agreement

$\checkmark$ Inform the local media and obtain their endorsements

$\checkmark \quad$ Identify any organized groups that might run a counter campaign

$\checkmark$ Identify interested community members be identified early as future campaign leaders and campaign contributors

If these groups send mixed messages to the public about the architectural design or the need for the bond issue, most voters will develop a concern about the advisability of the project. Voters apply the adage, "When in doubt, vote no.'

(Holt, 2002) 


\section{Enlist Key Community Leaders}

Enlisting leaders of the community may be the most difficult but also the most valuable strategy in operating a successful bond campaign. The superintendent and school board should brainstorm the names of those influential and passionate community leaders, business professionals, and parents who might later lead the campaign or volunteer to work on the campaign.

Campaign leaders who are not employed by the district or elected officials of the district are most influential in serving in this capacity. They have legitimate trustworthiness in the eyes of the public because they come from outside the school organization. Equally important are enthusiastic teachers and staff who devote their time and energy to the campaign. Their expertise would engage both internal district employees and external constituents in the communication process.

Talent School District recruited a young medical doctor, an alumnus of the high school, to serve as the Campaign Committee chairman. He was passionate and enthusiastic about serving as the leader of the committee even after he had served on the Facilities Planning Committee. His story and reason for his involvement was so his children could graduate from safe, warm, and dry school facilities. Several community business leaders likewise served on the Facilities Planning Committee. They were older and their children had graduated several years before. But they believed it was their duty to give back. They too served on the Campaign Committee.

While the superintendent, administrators, and teachers may be avid supporters of a bond levy, they are limited by what they can say and do once the board votes to approve a bond election; political advocacy of public employees is restricted by ORS 260.432. Employees can serve on committees and be strong advocates before the board officially approves a bond election but once the board approves the bond election, then active campaigning lies in the hands of those trusted community leaders. District personnel can henceforth only deliver factual information during contracted hours and not actively campaign for "yes" votes, according to their position and title. Specific information is published in the manual on Restrictions on Political Campaigning by Public Employees ORS260.432 on the www.oregonvotes.gov website.

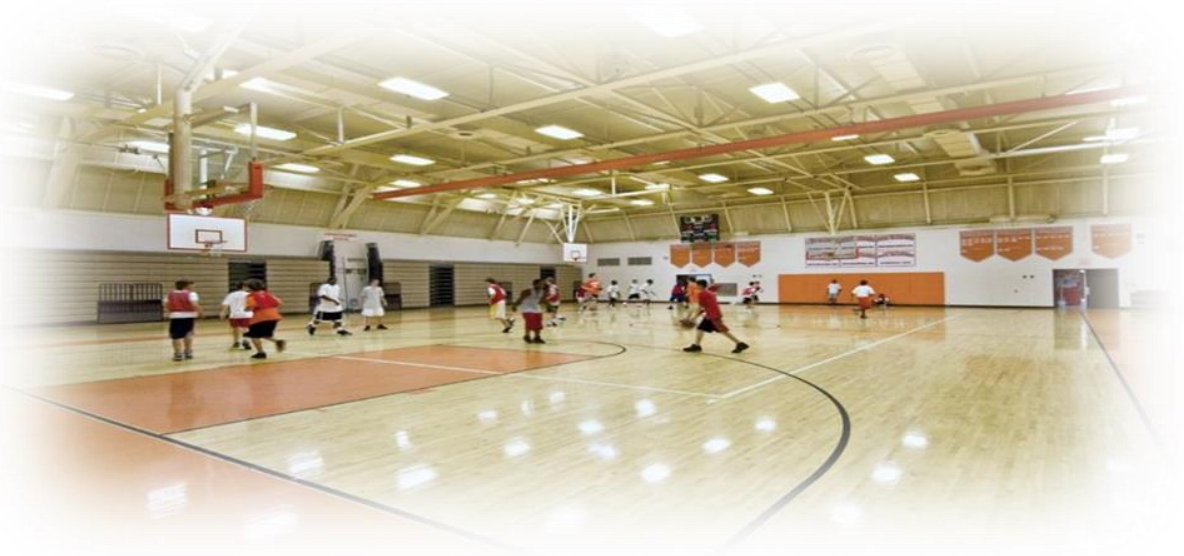




\section{Reflection}

1. Who are the respected community leaders, parents, and business professionals who will take the lead?

2. Is the school board in $100 \%$ agreement?

3. Are the local media informed and supportive?

4. What groups might oppose the bond?

5. Can the interested community members be identified early as future campaign leaders and campaign contributors? 


\section{—NOTES}




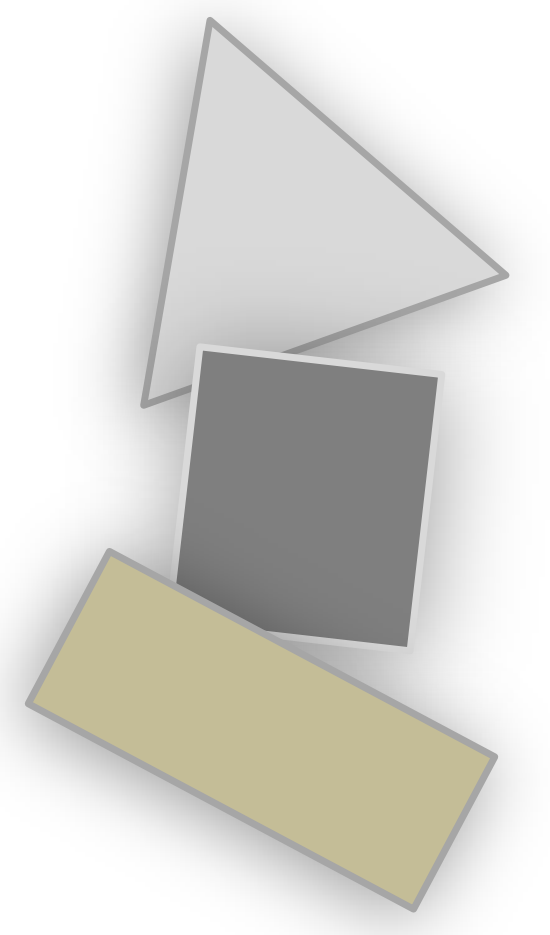

\section{Develop \& Publish}

the Long-Range Facilities Plan

$\checkmark$ Review district facilities policies

$\checkmark$ Decide whether to hire an outside agency to lead the planning

$\checkmark$ Identify members of the planning team

$\checkmark$ Communicate the plan to the public

$\checkmark$ Once facilities plan is completed, decide venue for communication

6 GThe key to deating with any problem
or project is effective planning.)

(Holt, 2002) 


\section{Develop \& Publish the Long-Range Facilities Plan}

Many medium-sized or larger districts usually hire an architectural or facilities planning firm to conduct formal facilities planning. Smaller school districts may not have the resources to hire a firm and often conduct a grass-roots effort. Some firms may conduct the planning and defer payment for services until after the bond levy passes. If the bond does not pass, the work performed is gratis.

While Oregon does not dictate the composition of the planning committee, the following members are highly encouraged to participate: parents; teachers; building administrators; facilities directors; central office staff; local board members; local governmental building, code enforcement, or planning officials; civic leaders; and the school superintendent. When the board and superintendent deliberate on the structure of the committee, they should consider participants who would represent various constituencies within the school district and who would likewise act as communication liaisons with the various community groups. This committee and associated meetings may be regulated by school board policy and rules governing open meetings laws.

Facilities planning and the final facilities plan may be long, tedious work and should be accomplished one to two years in advance of the bond election. The facilities planning process itself may take six months to a year in assessing the needs of the district schools, departments, and buildings and in publishing the plan and sharing it with the community. The district would be prudent to consider using the facilities planning committee to convey a unified message to the public about the current condition of the school properties and the need for new and/or improved district buildings and facilities.

Note: While the Facilities Planning Committee and the Campaign Committee are two different groups, they often share common leaders. Involvement of these valuable citizen volunteers must be nurtured so they do not become exhausted or feel underappreciated. They are one of the most significant factors in passing a bond. ORS 195.110 includes long-range planning requirements of districts with 2500 students and over.

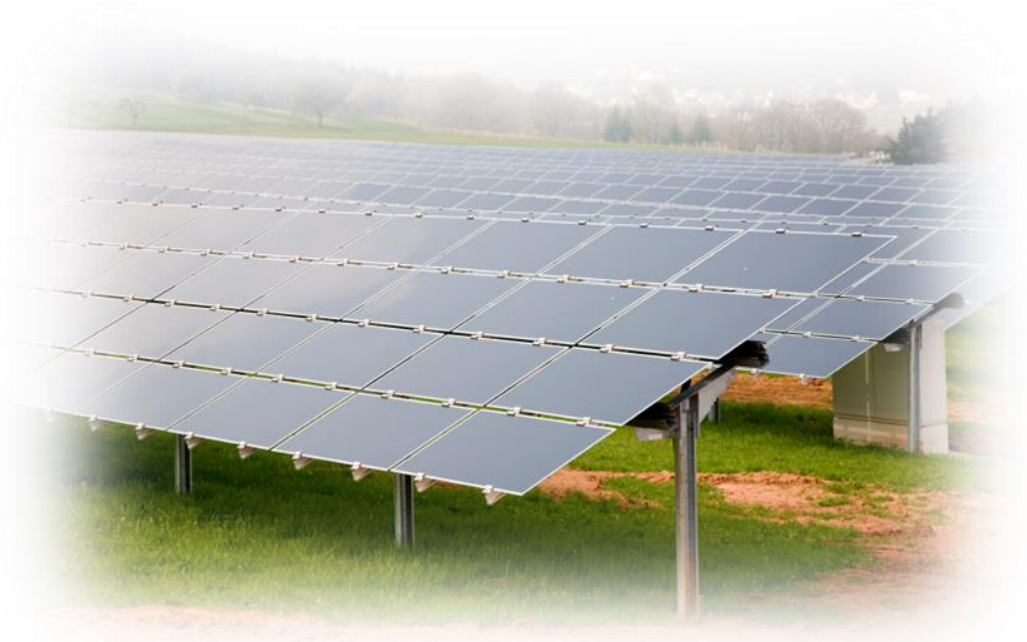




\section{Reflection}

1. What are the district policies?

2. Who should participate on the planning team?

3. Should a district hire an outside agency to lead the planning?

4. How should the planning be communicated to the public?

5. Once completed, who should be informed? 


\section{MASTER PLANNING}

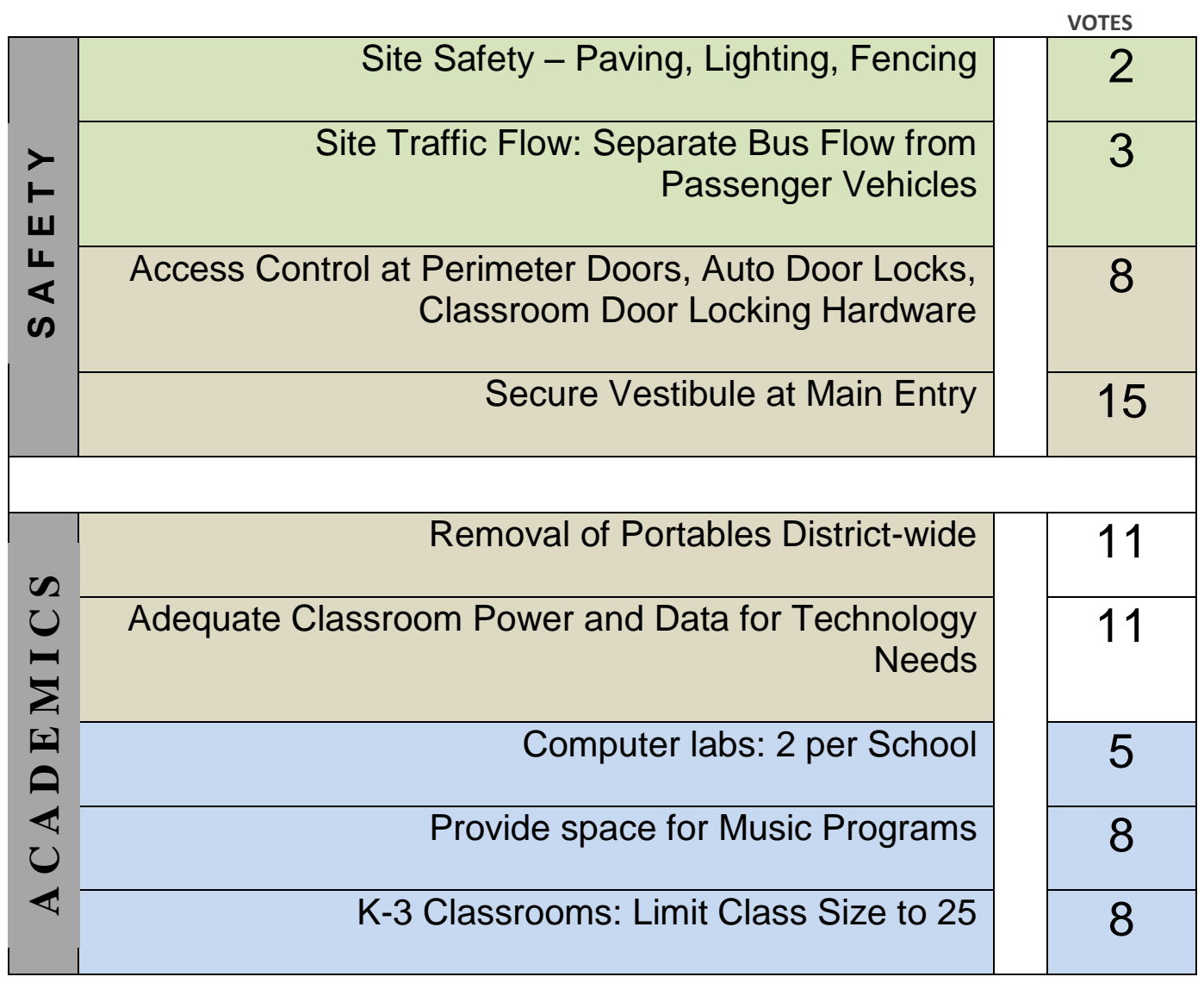

Color Key

Site Initiative

Building Initiative

Program Initiate

Functional Classification 


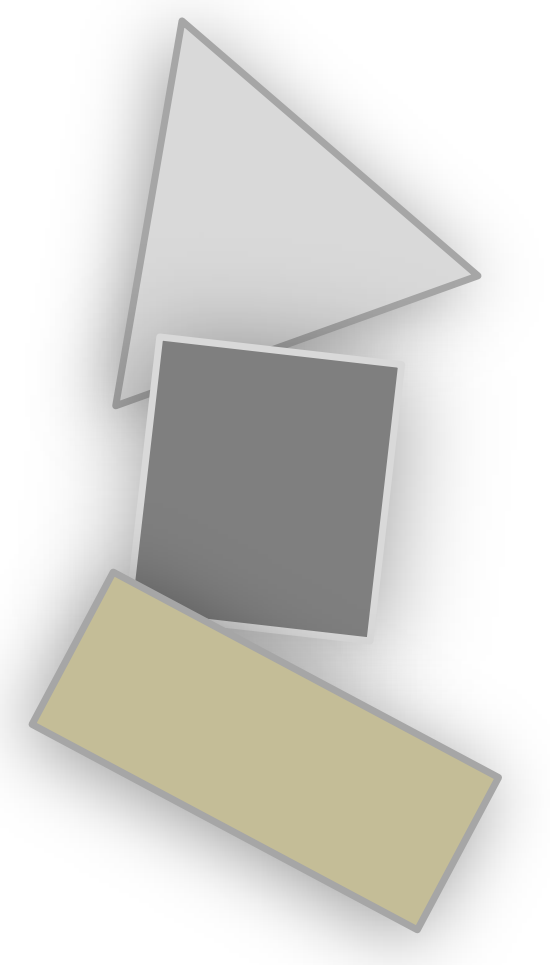

\section{Identify}

\section{Construction}

\section{Projects and Costs}

$\checkmark$ Decide whether to include phases for long-term needs in the Facilities Plan

$\checkmark$ Research impact a long-range plan would have on voters and taxpayers

$\checkmark$ Identify short-term facilities requirements and costs

$\checkmark$ Research deferred maintenance issues and costs

$\checkmark$ Plan how bond projects are identified

$\checkmark$ Estimate costs of projects and phases

$\checkmark$ Ask for consultants' recommendations

$\checkmark$ Identify final decision makers, final decisions, and costs

$\checkmark$ Identify board policies that affect decisions

The school superintendent should be gathering as much information as possible about community attitudes toward the need for the specific projects - be it building a new structure or renovating an existing structure.

(Holt, 2002) 


\section{Identify Construction Projects and Costs}

Novato School District \# 1 wanted to complete all deferred maintenance projects on each elementary school, remodel the middle school, and a build a new elementary school. The superintendent chose to take a comprehensive \$2 million bond to the small Novato community. It was soundly defeated. Community support appears to drop drastically when the levy exceeds $\$ 2.00$ per $\$ 1,000$ valuation (Holt, 2002).

Talent School District \#2 chose a different route. During its facilities planning process, the board and superintendent saw over $\$ 150$ million worth of projects to bring schools up to a warm, safe, and dry level. Instead of taking a bond with an excessive price tag to the voters, the facilities plan broke up the projects into four phases over a 20-year period. Phase 1 projects were completed through district resources and savings. For phases 2 through 4 , the district and the Facilities Task Force expected voters to support. Phase 2 had a price tag of $\$ 45$ million, significantly less than the total cost. A smaller chunk would be easier for Talent's voters to accept. And it was. Talent passed its bond.

Lesson learned? The board and superintendent should not be greedy. That greed often backfires. The total cost of the bond is a key issue with both taxpayers and voters. A district must know what the voters will support.

Specific costs of projects may or may not be identified before the bond goes to the voters. Construction costs vary from one year to the next so any costs associated with projects must be considered soft estimates. One school district published a facilities plan with several phases just before the market crash in 2008. The district then passed a bond during the economic crisis, and district leaders found they had much more buying power. Additional bond money allowed them to add several projects from future phases. They could legally make these adjustments because the ballot language was general enough to incorporate additional projects.

Simple calculations on costs are based on a per square foot rate for either new construction or remodeling and an additional $18-20 \%$ for soft costs such as architectural and engineering fees, construction management fees, contingencies, and equipment. A facilities consultant would relieve the district of calculating estimates that may not incorporate all costs.

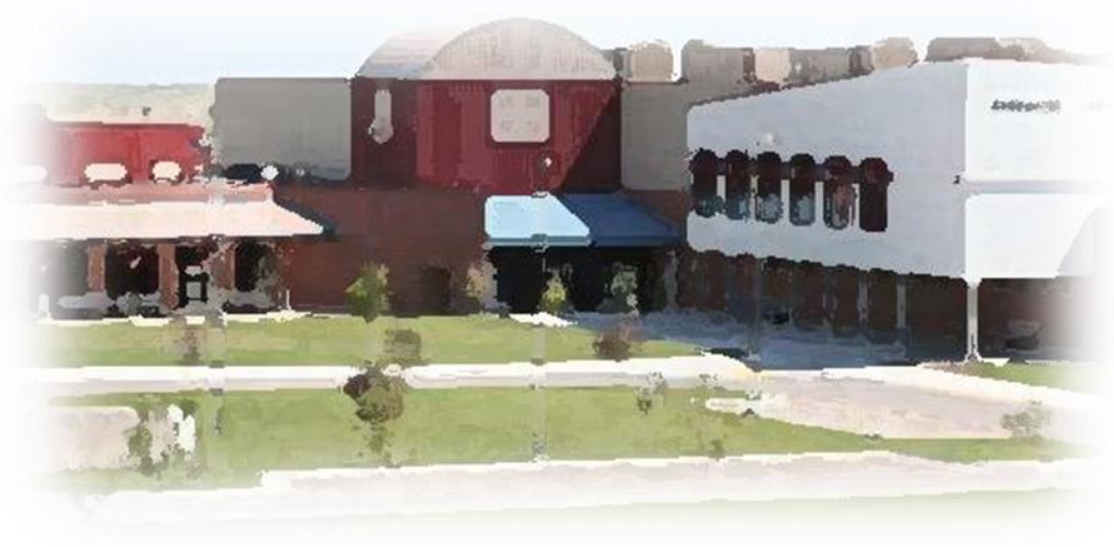




\section{Reflection}

1. Does the Facilities Plan include phases for long-term needs?

2. If so, what impact will that have on voters?

3. What are the short-term requirements?

4. Are there deferred maintenance issues?

5. Is there more than one scenario on what projects are identified?

6. What are the consultants' recommendations?

7. Who makes the final decisions?

8. What board policies affect these decisions? 


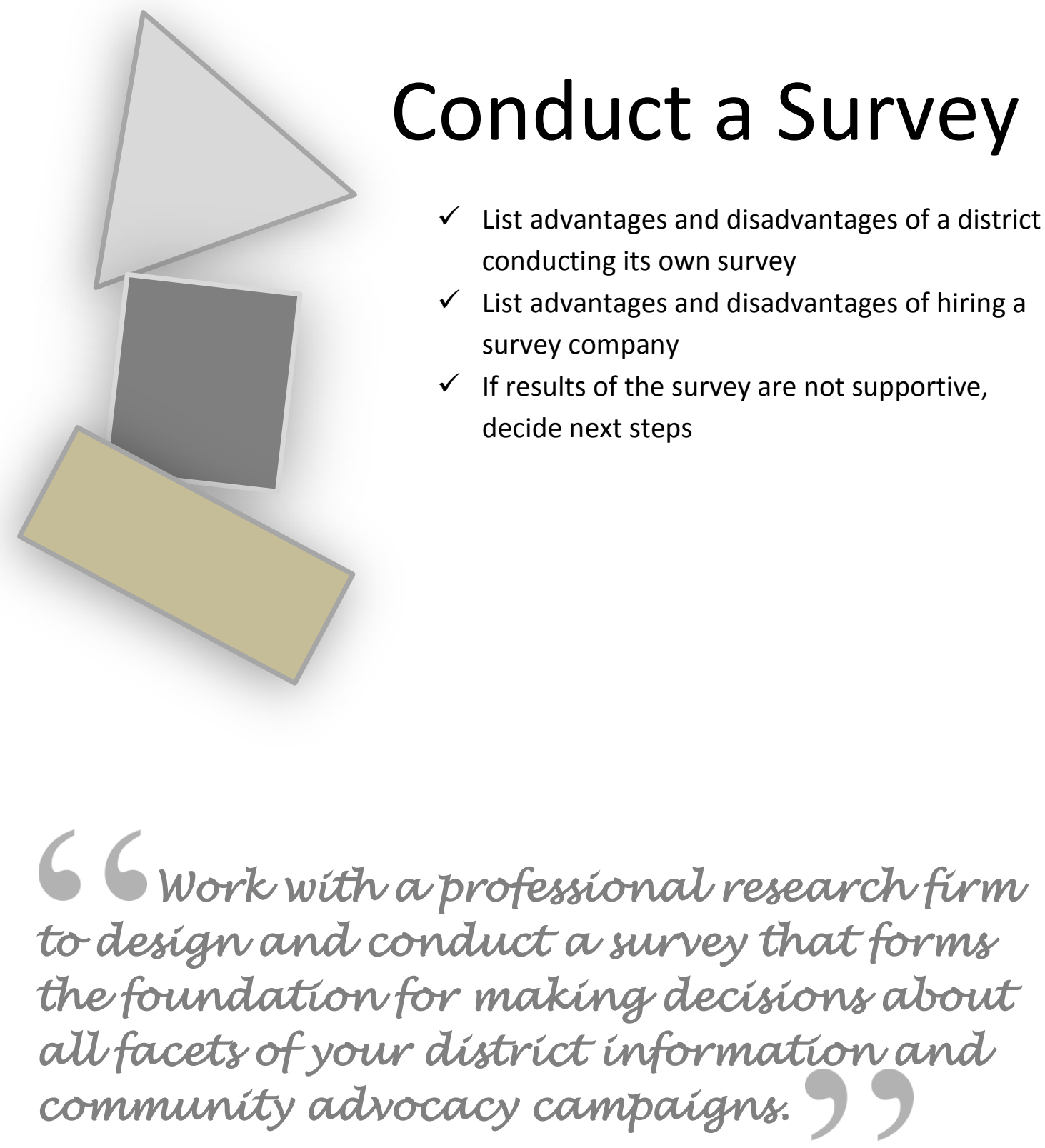

(Campbell \& Magmire, 2007) 


\section{Conduct a Survey}

The Nelson Report; Grove Insight; Consumer Opinion Services; Davis, Hibbitts, and Midghall Research; and Definitive Insight are some local firms in Oregon and Washington that have conducted surveys of public opinion for Oregon school districts. Districts often conduct a survey a year in advance of the bond campaign to gain an understanding of what voters are likely to support. Results of the polls or surveys help districts in their planning and decision-making. For example, districts often consider feedback on specific projects as well as the dollar amount voters would support. Districts often poll during the campaign to determine if other communication needs to take place.

Polling takes many different formats such as telephone and online surveys, focus groups, large group studies, one-on-one interviews, public outreach, and, in some cases, the development and utilization of online panels. While these various services are important, they do not come free of charge. Depending on the number of participants and the type of feedback employed, these services can range from $\$ 10,000$ to $\$ 50,000$. If the bond is successful, bond proceeds can reimburse the district for these costs if the ballot includes that language. Surveys during the campaign are generally picked up through campaign contributions, entirely separate from the district.

Medium and small school districts sometimes manage their own opinion polls. While this is less costly, the results are also less reliable. Sometimes overzealous volunteers may not accurately keep count. Or comments on surveys undermine the main purpose of the survey. One example is when a district survey committee, comprised of community members and school board members, read a few malicious comments about an employee. These comments spurred pressure on the board and superintendent to terminate that employee even though the comments were erroneous.

Note on surveys and polls: If surveys and polls are funded with district funds, the data can be requested by the public - possibly those who would politically oppose the bond. If an outside research agency or firm pays for the survey, that agency controls the data.

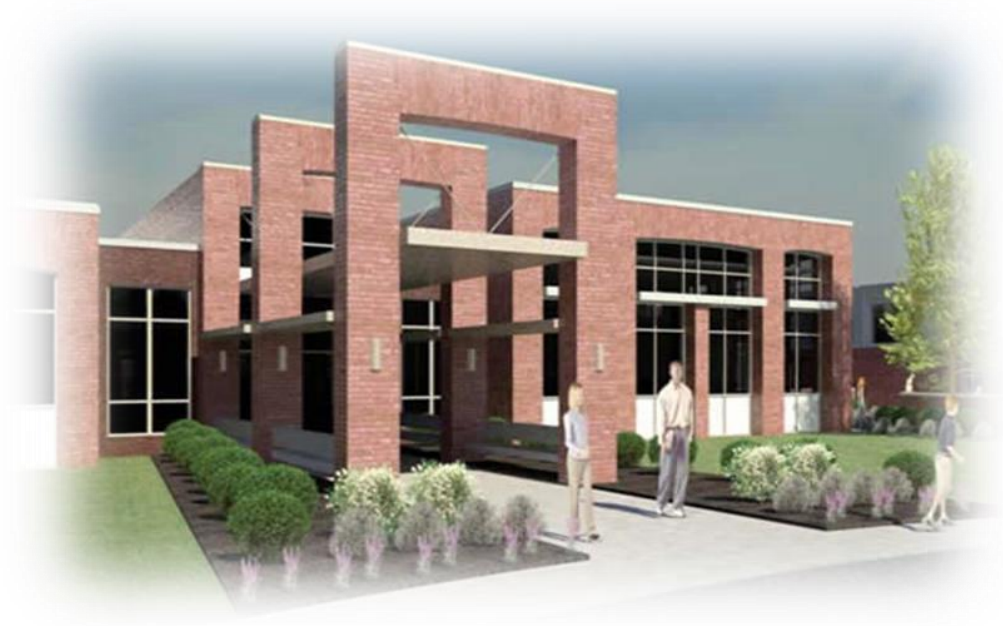




\section{Reflection}

1. What are the advantages and disadvantages of a district conducting its own survey?

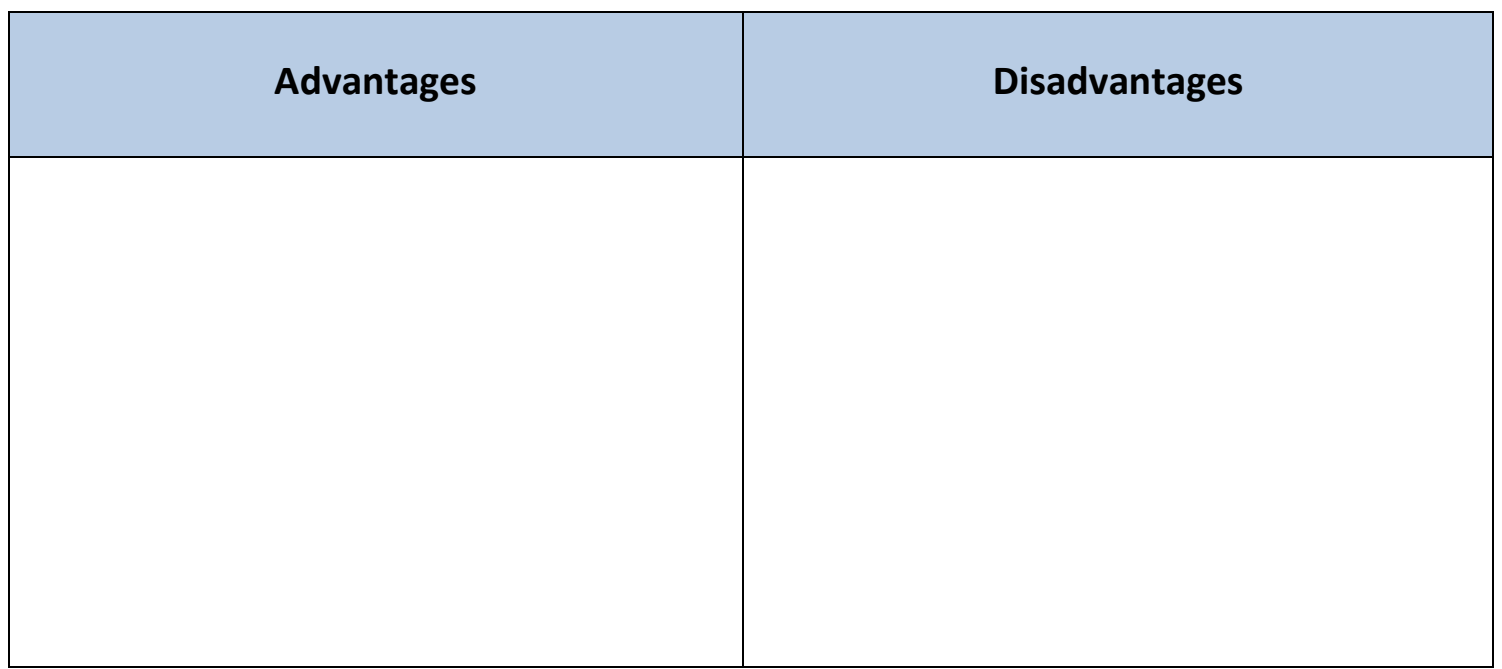

2. What are the advantages and disadvantages of hiring a survey company?

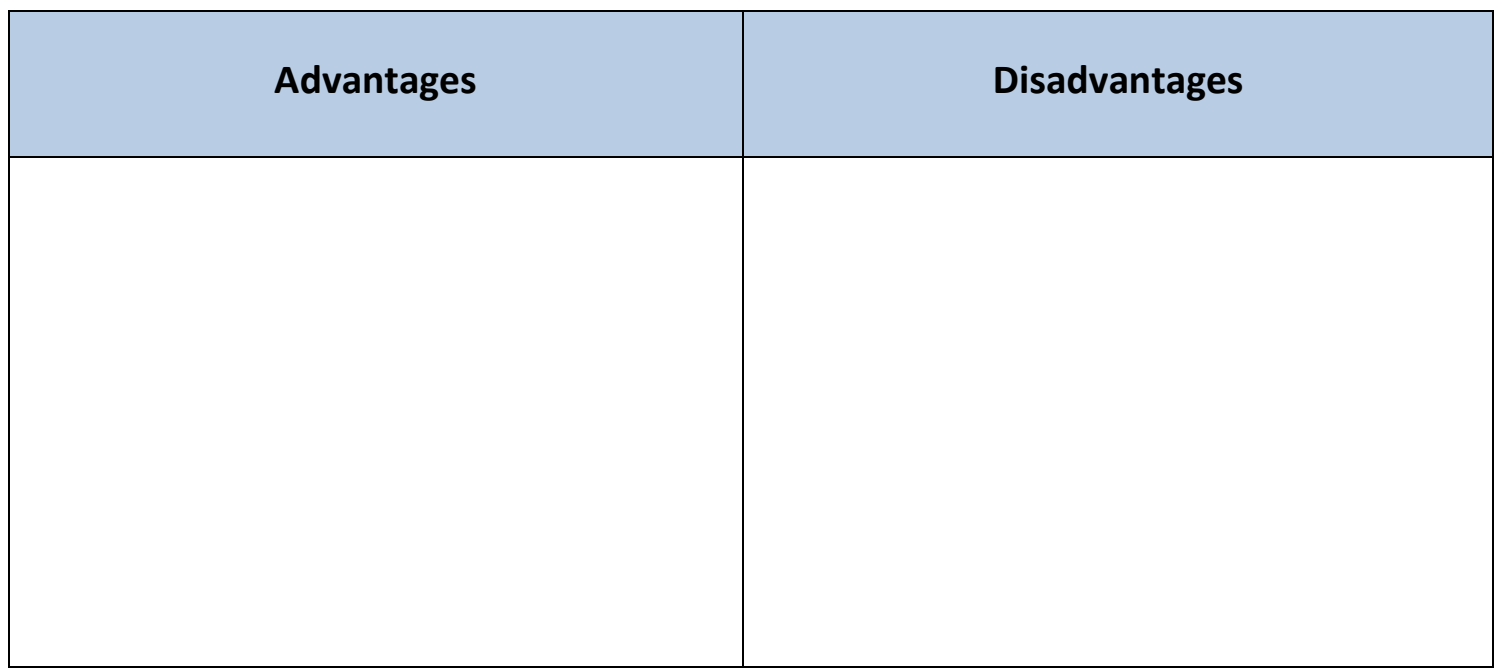

3. Suppose the results of the survey are not supportive? 
NOTES 


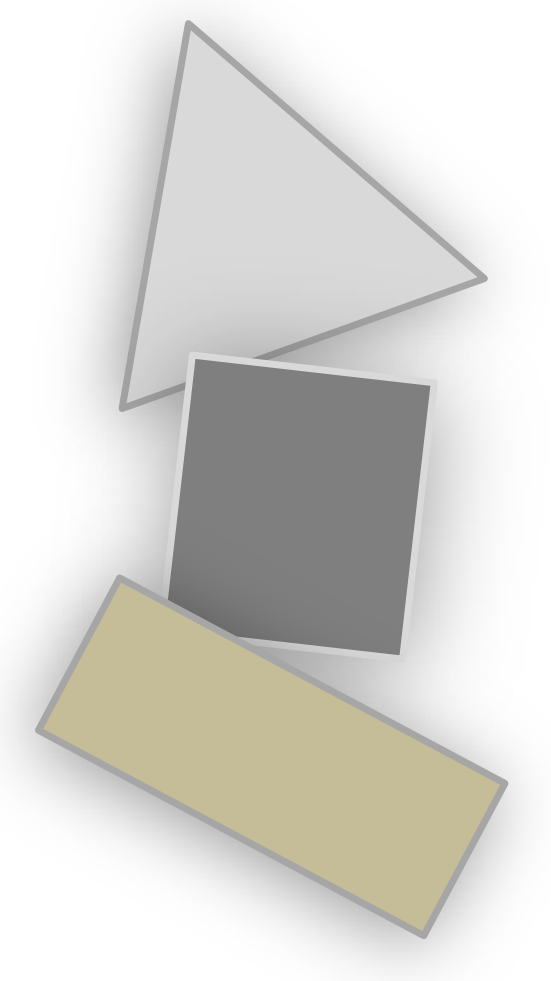

\section{Prepare for the}

\section{Bond Campaign}

$\checkmark$ Deliberate with Campaign Committee leader(s)

$\checkmark$ Identify appropriate date for school board approval of the bond election

$\checkmark$ Invite community members to serve on the campaign committee

$\checkmark$ Review laws to ensure compliance with Campaign Finance Laws

$\checkmark$ Review laws to comply with Oregon election laws

$\checkmark$ Review Oregon ethics laws

$\checkmark$ List responsibilities and functions of campaign committee members

$\checkmark$ Identify subcommittees needed in a campaign

$\checkmark$ Research restrictions in fundraising and campaign contributions

$\checkmark$ Choose length of the campaign

$\checkmark$ Develop election language

$\checkmark$ Hire marketing consultants or not

$\checkmark$ Think ahead about hiring architects

$\checkmark$ Think ahead about hiring a construction management company

$\checkmark \quad$ Think ahead about bond sales

$\checkmark$ Consult with bond counsel about drafting the ballot message

\section{An effective campaign is one that embodies the concept of year round, two-way} communication. (Bagin et al., 2001) 


\section{Prepare for the Bond Campaign}

Know the law. District leaders should review school board polices and state law and share with all district employees. In Oregon, ORS Chapter 260 "Campaign Finance Regulation; Election Offenses" is essential to review. In September 2012 Oregon Secretary of State Kate Brown added another important document, Restrictions on Political Campaigning by Public Employees ORS 260.432. This document includes updated and more detailed information on offenses that were confusing to administrators and boards in the past.

Recruit the best. Campaign Committee chairmen or women are critical to the success of the bond campaign and need to be reputable and highly regarded in the community. Responsibilities and duties of the chair(s) and each subcommittee should be developed well in advance so volunteers know what they are accepting. Depending on the size of the district, the superintendent and board will determine whether hiring a marketing firm or communications consultant is worth the cost.

Develop a campaign slogan/theme. The slogan or theme should represent what the bond election is all about. It should be focused on students and imply the benefit to the community and voters. A slogan will help voters to remember the issue through positive feelings (Bagin \& Gallagher, 2001).

Develop the ballot message. The superintendent or designee should not wait to the last minute to work with bond counsel on the ballot language. Having the message developed in advance can help with verbiage printed on pamphlets and flyers. It will also ease the pressure on the superintendent who is greatly restricted on what he or she can say about the bond.

Determine the length of the campaign. People, especially volunteers, burn out fast. Some campaigns have been shorter than 90 days and some longer, but 90 days is generally the conventional number. A timeline can be developed to determine completion dates and number and types of activities planned up to the day of the election. As a caveat, the longer the campaign, the more likely that an organized opposition group will form.

Seek the major election dates. Bond counsel or the county elections officials have all the important dates and the necessary documents for holding the election. The superintendent or designee should inquire early in the process for this information.

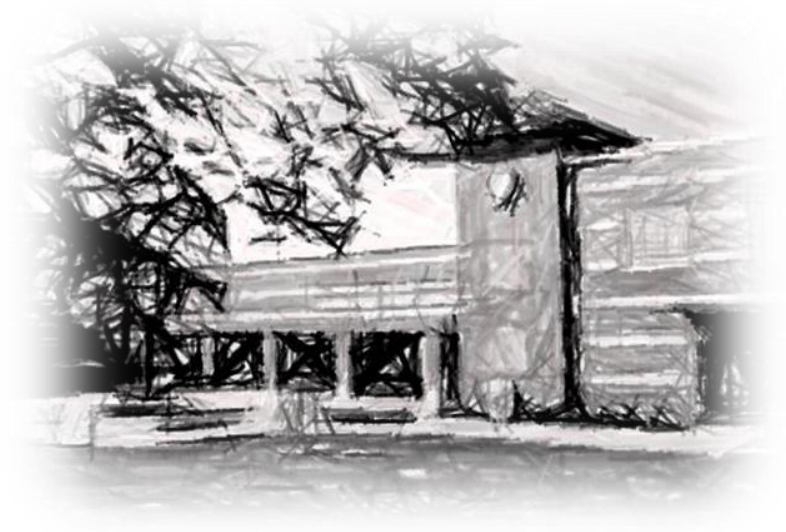




\section{Reflection}

1. When does the school board approve the campaign?

2. Who serves on the campaign committee?

3. What laws should the campaign committee be aware?

4. What are the functions of campaign committee members?

5. What subcommittees are essential to the campaign?

6. What existing restrictions or laws control fundraising and campaign contributions?

7. How long is the campaign? 
8. Who develops the election language?

9. Should marketing consultants be hired?

10. When does the district hire the architects?

11. When does the district hire the construction management company?

12. How does a district sell bonds?

13. How is the ballot message developed? 


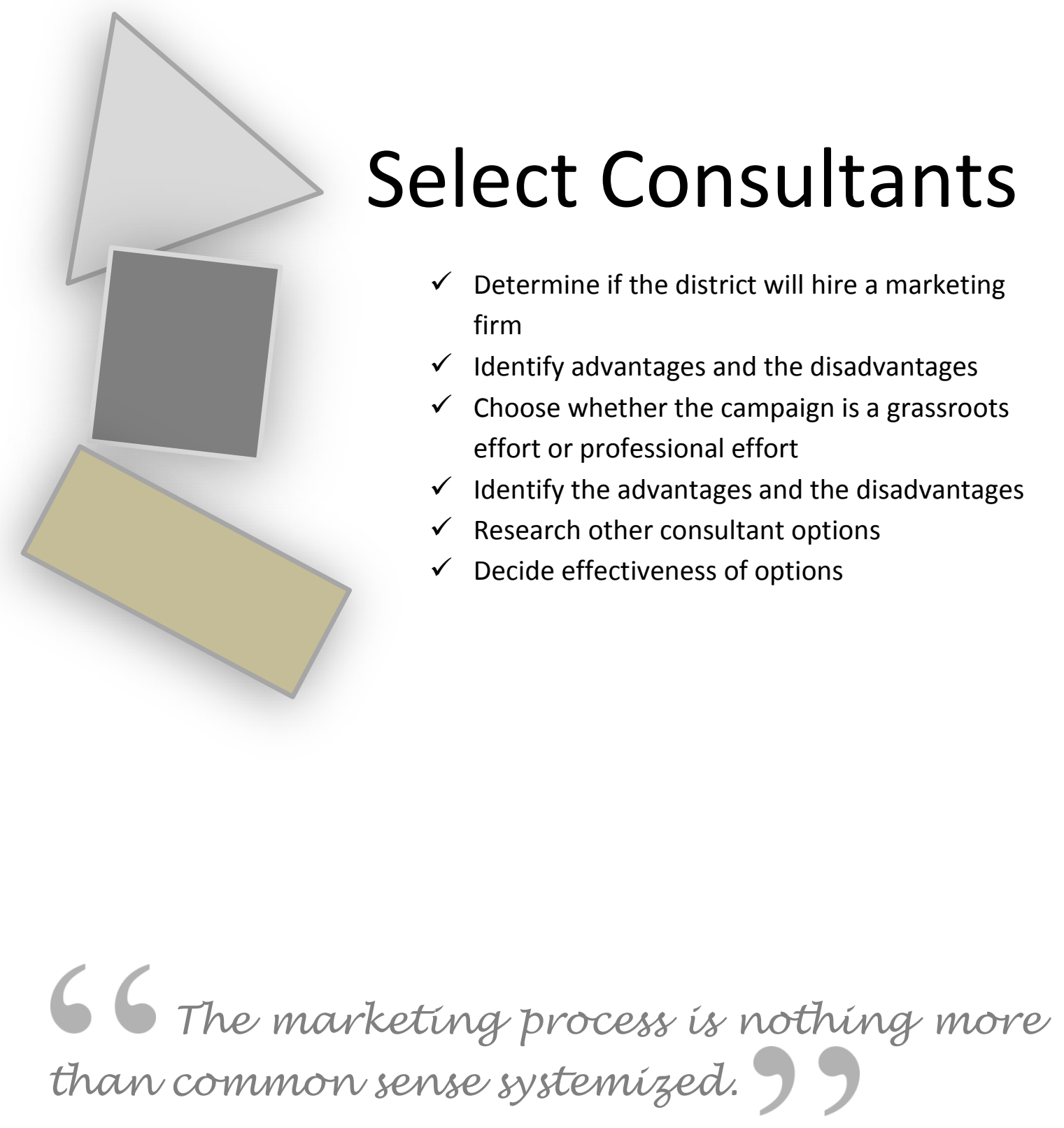

(Banach in Bagin et al., 2008) 


\section{Select Consultants}

Most districts cannot afford the luxury of hiring outside consultants to run the bond campaign. However, consultants are ultimately worth the investment and may make the difference in whether the bond passes.

Contracting with school planning and finance consultants conveys an objective perspective to the public. Superintendents, principals, and school boards often do not have the expertise to answer the public's questions about the school facilities and the financing of a bond.

Consultants' viewpoints and professional opinions confirm and endorse the messages from the school district.

A marketing firm or an individual consultant will also take the pressure off district personnel. The district may already have communications personnel with expertise in communicating both internally and externally. These district communications leaders and employees are already overworked with the needs of everyday school communication and certainly cannot take on a project with such magnitude as a school bond in addition to their own duties and responsibilities. While it is important to have a comprehensive district communications plan in place that includes all internal and externals constituents, including those who do not have children in the schools, additional help with the focus on the bond will be a wise decision to meet the needs of advertising and marketing the bond election.

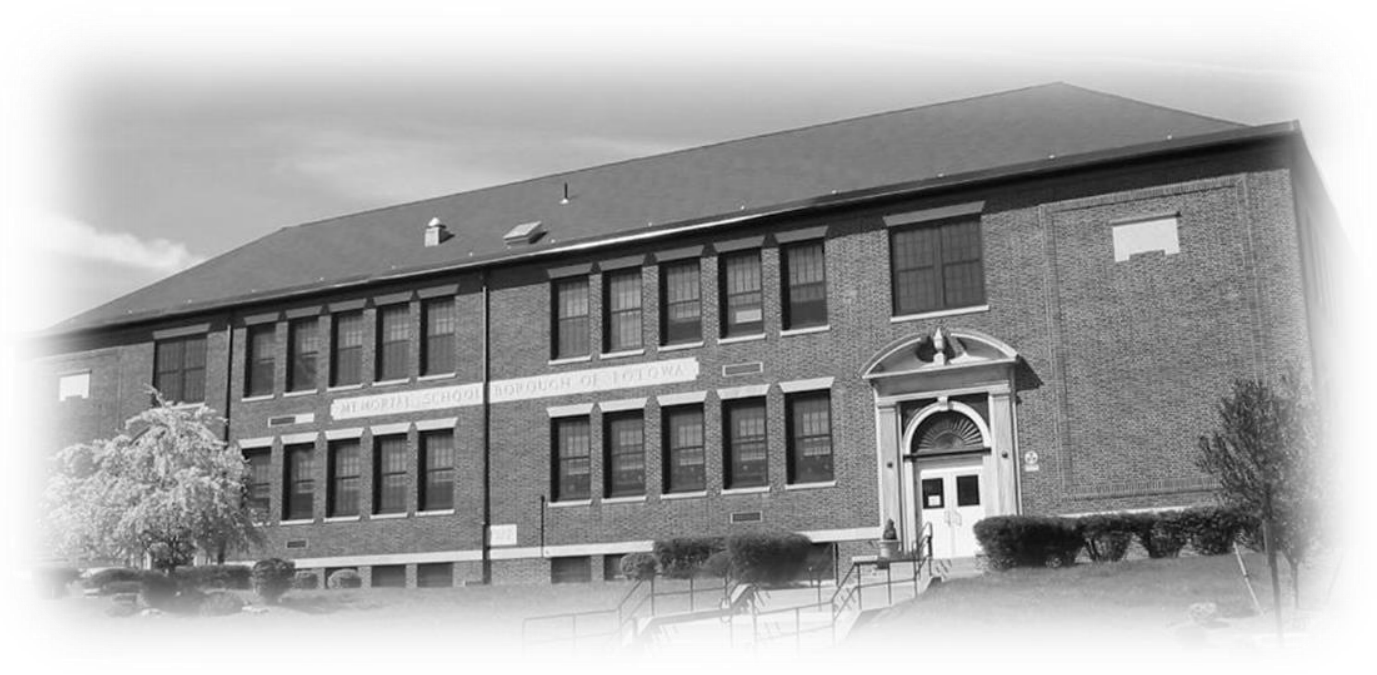


Reflection

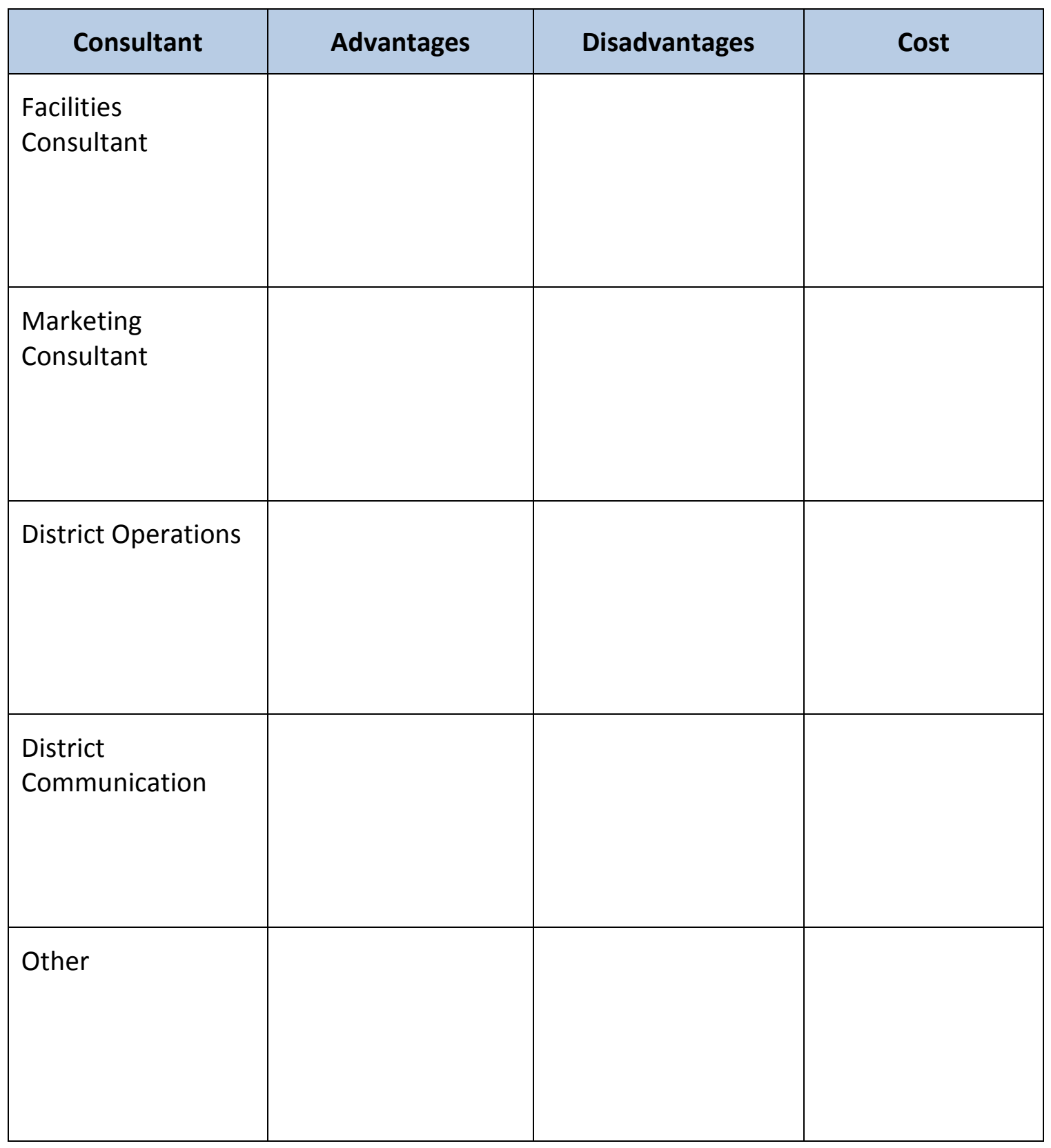




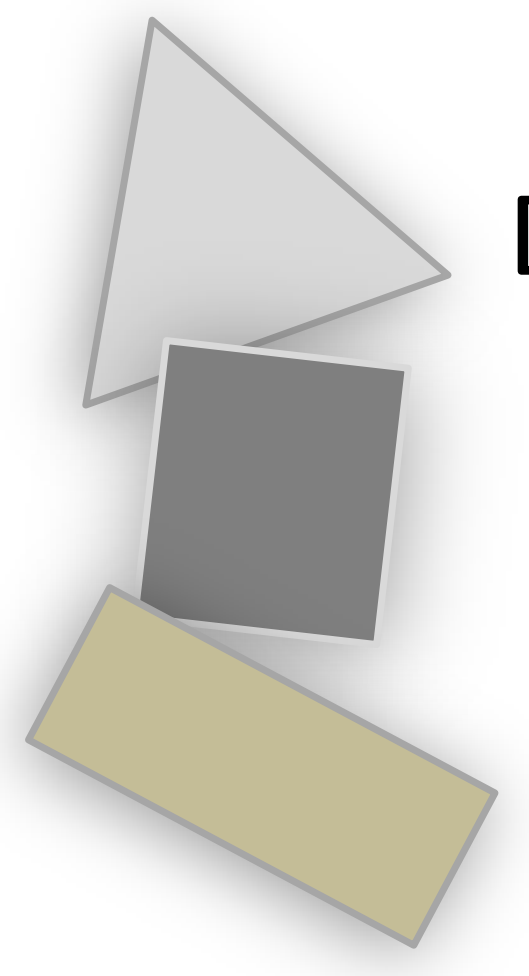

\section{Develop the Bond Calendars}

$\checkmark$ Choose the election date

$\checkmark$ Identify the 60 or 90-day window before the election

$\checkmark$ Schedule major campaign events on the calendar

$\checkmark$ Decide when the architect should be hired

$\checkmark$ Decide when the construction management company be hired

$\checkmark$ Decide whether district personnel should manage the projects

66

The first step in accomplishing these tasks is establishing a timeline to show graphically the steps required to prepare for an election and the length of time each step will take.

(Campbell \& Magmire, 2007) 


\section{Develop the Bond Calendars}

Two calendars or timelines should be developed: One by the Campaign Committee and one by the school district. The Campaign Committee calendar would include the 90-day calendar of events to lead a successful bond campaign. For example, it would include the development of all the campaign literature with dates of completion and how information would be disseminated.

The superintendent along with district personnel such as the director of communications, director of operations, and the director of finance or similar positions would also develop a timeline. These events would prepare the district for a smooth transition from the date of the successful bond election to breaking ground. The district's calendar would include events such as the hiring of the construction management company or architect, providing election law information to employees, board approving the bond resolution, and scheduling of speaking engagements with voter groups.

While there are two timelines, these two groups are not separate and the calendars should be developed in consort well in advance of the 60 or 90 -day campaign. Once the school board approves the bond election, the superintendent and other district employees are under the governance of Oregon elections law and can only legally convey factual information about the bond levy. But off-duty employees such as teachers and classified staff may work on the campaign but cannot use district resources such as paper, copy machines, computers, or phones.

Note: For more information about Oregon election laws and restrictions on Oregon public employees, the new manual is located at that following link:

www.oregonvotes.gov.

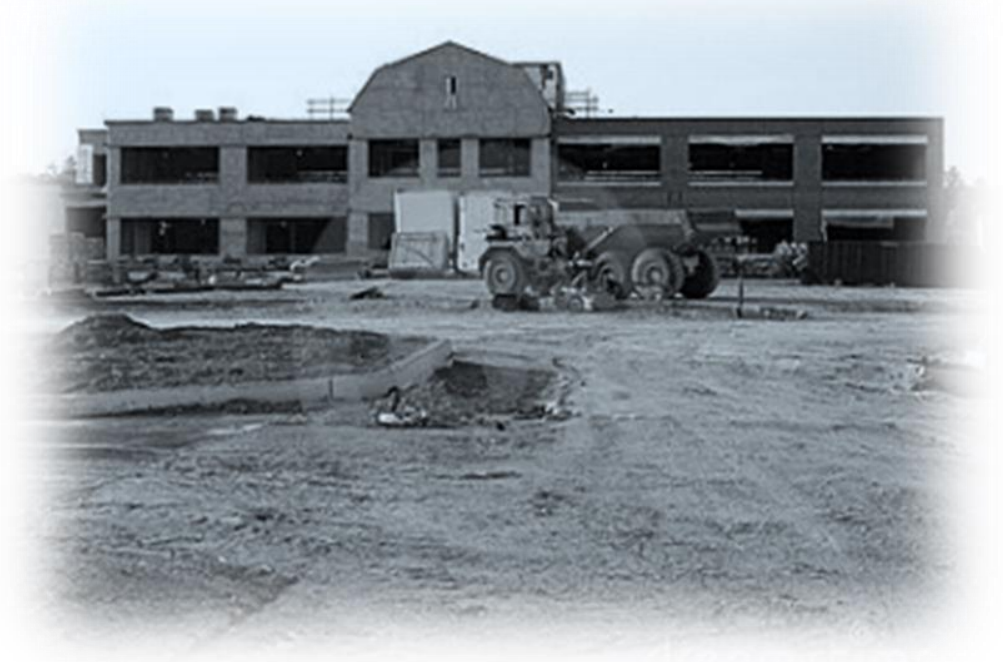




\title{
Reflection
}

\author{
Campaign Committee Calendar \\ Examples to Consider
}

\section{Key Election Dates}

1. Board approves resolution for bond election

2. Election campaign kick off

3. Ballot language due to the county

4. Last day to submit ballot arguments

5. Last day to mail publicity pamphlet

6. First day to early vote/vote by mail

7. Last day to register to vote

8. Election day

9.

10.

\section{Decisions}

1. Is there enough time to involve the community

2. Is there enough time for an effective campaign

3. Amount of campaign money to be raised

4.

5.

\section{Communication}

1. Develop communication tools

2. Identify, develop, and recruit campaign committee members: finance/fundraising, campaign materials, signage, speakers, writers, web-page developers, newsletters, television, radio, water bills.

3. Create a public speaking calendar with upcoming meetings: PTAs, chamber, and local service clubs

4. Develop talking points for superintendent, administrators, school board, and campaign committee members

5. Develop PowerPoint presentations, YouTube videos, and web page

6. Write and publish brochures and newsletters

7. Employ social media (YouTube, Facebook, twitter, blogs, etc.)

8. Set up press briefings and editorial boards

9. Walk reporters through the community involvement process

10. Discuss the benefits of the bond package

11. Create letters to the editors

12. Plan for the celebration

13.

14. 


\section{KEY ELECTION CAMPAIGN DATES 90-DAY CAMPAIGN}

\begin{tabular}{|l|l|l|l|l|}
\hline \multicolumn{1}{|c|}{ Date } & Event & $\begin{array}{c}\text { Specific Date of } \\
\text { Event/Activity }\end{array}$ & $\begin{array}{c}\text { Outcome/ } \\
\text { Description }\end{array}$ & $\begin{array}{c}\text { Person(s) in } \\
\text { Charge }\end{array}$ \\
\hline Pre-90 Days & & & & \\
\hline Pre-90 Days & & & & \\
\hline Pre-90 Days & & & & \\
\hline Week 1 & & & & \\
\hline Week 2 & & & & \\
\hline Week 3 & & & & \\
\hline Week 4 & & & & \\
\hline Week 5 & & & & \\
\hline Week 6 & & & & \\
\hline Week 7 & & & & \\
\hline Week 8 & & & & \\
\hline Week 9 & & & & \\
\hline Week 10 & & & & \\
\hline Week 11 & & & & \\
\hline Week 12 & & & & \\
\hline Other & & & & \\
\hline Other & & & & \\
\hline
\end{tabular}




\title{
Reflection
}

\author{
District Calendar:
}

Examples to Consider

1. School board policies reviewed and revised as needed

2. Facilities plan completed

3. Projects identified

4. Marketing consultant hired

5. Construction management RFT

6. Communications plan completed

7. Facilities task force formed

8. Facilities task force becomes campaign committee

9. District informational literature, pamphlets, articles written

10. District informational literature reviewed by Oregon elections office

11. Speaking engagements scheduled

12. Newspaper editorial boards meetings

13. Board approves bond counsel

14. Board approves bond sales

15. Bond counsel writes ballot title, question, and summary

16. Board approves resolution for bond

17. District notifies county elections office of district ballot intent

18. Ballot title, question, and summary submitted to county elections office

19. Board approval of duties of district owners team

20. Formation of District Owners Team, a decision-making group to minimize the number of decisions the school board needs to make; it includes at least two school board members, superintendent, director of operations, director of finance, construction management, facilities planning/campaign committee members, general manager, and others as identified by the superintendent and school board.

21. Board approval of duties of Citizens Oversight Committee

22. Citizens Oversight Committee advertised and appointed by board

23.

24.

25. 


\section{DISTRICT TIMELINE TWELVE-MONTH PLANNER}

\begin{tabular}{|l|l|l|l|l|}
\hline \multicolumn{1}{|c|}{ Month } & Events & $\begin{array}{c}\text { Specific Date of } \\
\text { Event/Activity }\end{array}$ & $\begin{array}{c}\text { Outcome/ } \\
\text { Description }\end{array}$ & $\begin{array}{c}\text { Person(s) in } \\
\text { Charge }\end{array}$ \\
\hline Month 1 & & & & \\
\hline Month 2 & & & & \\
\hline Month 3 & & & & \\
\hline Month 4 & & & & \\
\hline Month 5 & & & & \\
\hline Month 6 & & & & \\
\hline Month 7 & & & & \\
\hline Month 8 & & & & \\
\hline Month 9 & & & & \\
\hline Month 10 & & & & \\
\hline Month 11 & & & & \\
\hline Month 12 & & & & \\
\hline
\end{tabular}


NOTES 


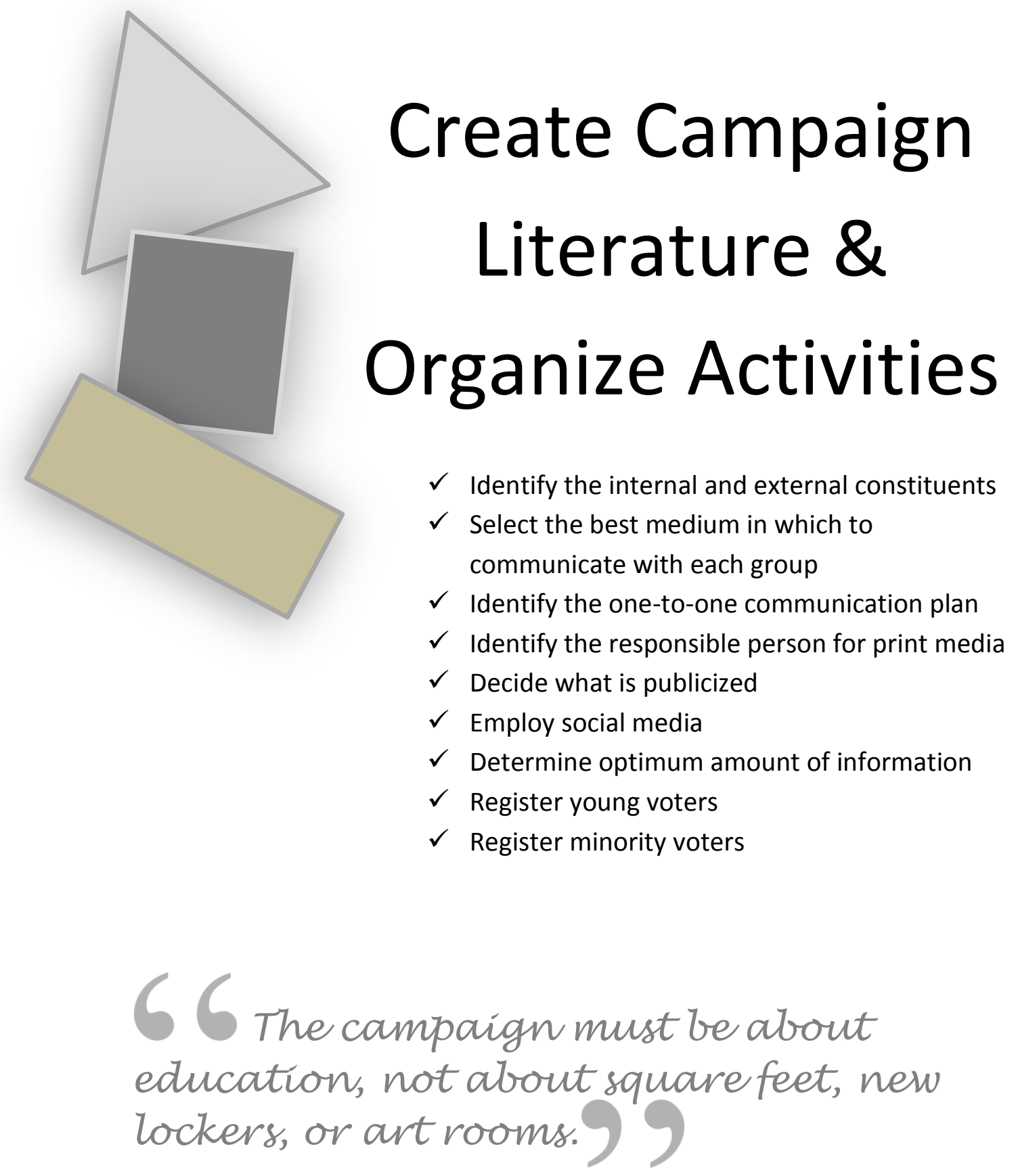

(Holt, 2002) 


\section{Create Campaign Literature \& Organize Activities}

The superintendent, board, and other personnel may use public resources to develop and distribute objective material about the bond projects and election. However, materials must be informational only and provide the public with unbiased literature or presentations of facts about the bond. The district cannot advocate a position; it cannot ask voters to vote "yes" or to support the bond. While they are on duty, district employees can encourage others to vote but they cannot ask others to support the district in passing the bond. They can say that the district is planning to build a new elementary school, but they cannot say the district really needs a new elementary school because of overcrowding. Essentially, public employees may not engage in political activity while on the job. This presents a problem for superintendents who are considered a 24/7 employee.

Any materials publicized by the district must be entirely factually based and objective. One word is all that is necessary to change a publication or speech to one that is biased and subjective. The superintendent and others may be liable for an elections fine. While the fines themselves are trivial, the resulting publicity is what is damaging. All district informational materials and documents should be sent to the Secretary of State's Elections Division for review before publication.

In recent years, six school district leaders, including a superintendent and the district's attorney, each paid $\$ 75$ for breaking state law by "writing, signing or approving fliers, emails, web postings or other documents that used persuasive language, images, or techniques to try to sway the public in favor of the bond" (Hammond, 2011, October 27). No one wants this type of publicity.

The campaign committee, however, can publish subjective information. Election law does not prohibit citizens, or non-district employees, from marketing and advertising a school district bond. School board members and employees outside their school day can campaign.

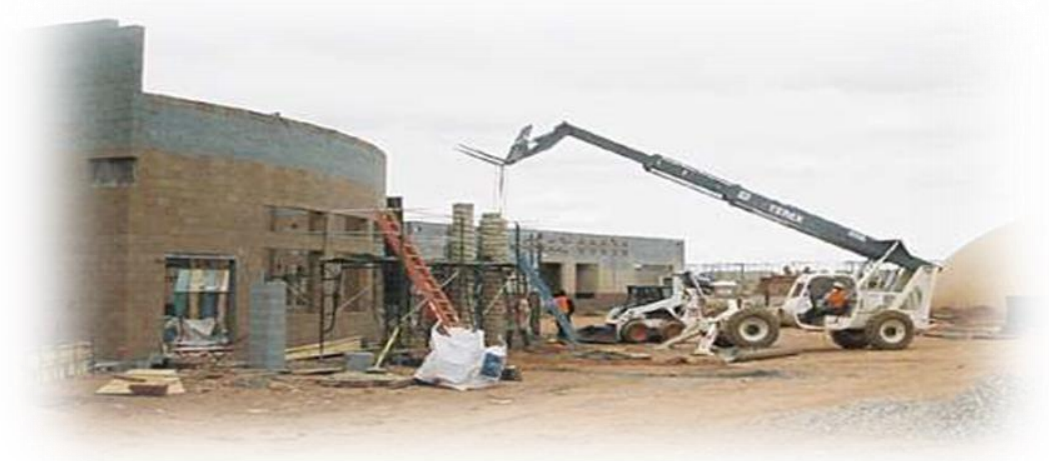

412 
Cost/Benefit Analysis:

Identification of Communication Strategies Compared to Costs

\begin{tabular}{|c|c|c|c|c|}
\hline & Strategy & $\begin{array}{l}\text { Used/ } \\
\text { Not } \\
\text { Used }\end{array}$ & Identify Specific Formal Types & Cost \\
\hline 1 & One-to-one, face-to-face & & & \\
\hline 2 & $\begin{array}{l}\text { Small group discussion or } \\
\text { meeting }\end{array}$ & & & \\
\hline 3 & $\begin{array}{l}\text { Speaking before a large } \\
\text { group }\end{array}$ & & & \\
\hline 4 & Phone conversation & & & \\
\hline 5 & Hand-written, personal note & & & \\
\hline 7 & $\begin{array}{l}\text { Typewritten, personal letter, } \\
\text { not a form letter or e-mail }\end{array}$ & & & \\
\hline 8 & Personal "form letter" & & & \\
\hline 9 & $\begin{array}{l}\text { Mass-produced, non- } \\
\text { personal letter }\end{array}$ & & & \\
\hline 10 & $\begin{array}{l}\text { Brochure or pamphlet sent } \\
\text { out as a direct mail piece }\end{array}$ & & & \\
\hline 11 & $\begin{array}{l}\text { Articles in organizational } \\
\text { newsletter, magazine, } \\
\text { tabloid }\end{array}$ & & & \\
\hline 12 & $\begin{array}{l}\text { News carried in popular } \\
\text { press }\end{array}$ & & & \\
\hline 13 & $\begin{array}{l}\text { Advertising in newspaper, } \\
\text { radio, television, magazines, } \\
\text { posters, etc. }\end{array}$ & & & \\
\hline
\end{tabular}




\section{Reflection}

1. Who are the internal and external constituents?

2. What is the best medium in which to communicate with each group?

3. What is the one-to-one plan?

4. Who is responsible for print media?

5. Who decides what is publicized? 
6. How will social media be employed?

7. How much is too much information?

8. What is the best way to register young voters?

9. What is the best way to register minority citizens to vote? 
NOTES

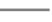




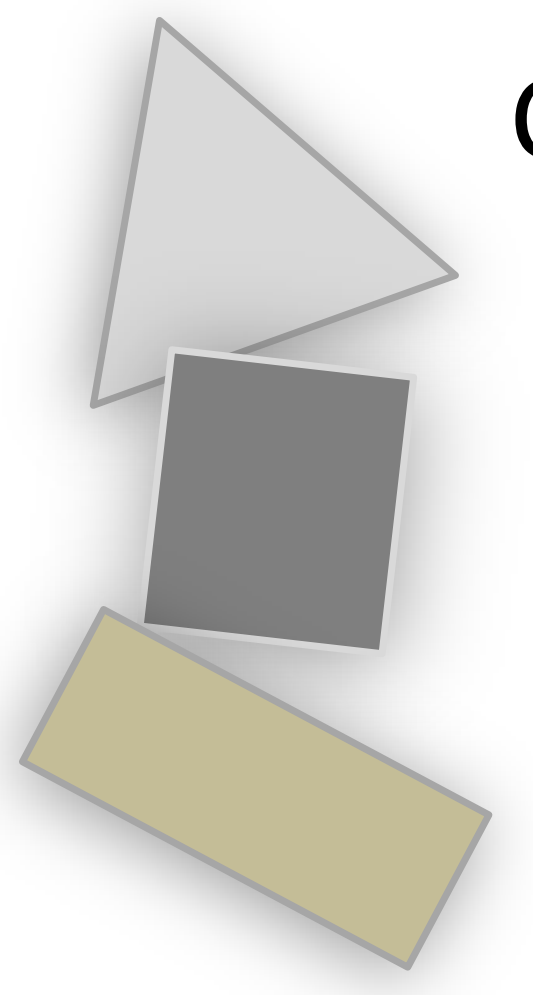

\title{
Communicate with
}

\section{the Media}

\author{
$\checkmark$ Identify local newspapers \\ $\checkmark \quad$ Identify various uses for the newspapers \\ $\checkmark$ Identify local TV stations \\ $\checkmark$ Identify various uses for TV stations \\ $\checkmark$ Identify local radio stations \\ $\checkmark$ Identify various uses for local radio stations \\ $\checkmark$ Discover available online sources \\ $\checkmark$ Identify various uses for online sources \\ $\checkmark$ Write editorial board messages
}

Regardless of district size, working with the media should be seen as a responsibitity for all superintendents and principals because, either regularly or intermittently, administrators will be spokespersons for their district or schools.

(Kowalski et al., 2007) 


\section{Communicate with the Media}

While newspaper reporters, editors, or publishers are usually ethically bound to pay for their own coffee or lunch, superintendents, assistant superintendents, and/or communications directors are highly encouraged to instead meet for lunch or coffee and to pay separately. A more congenial atmosphere without the business of being interviewed for an unflattering story will lead to a better working relationship with the press.

People who fear the press will end having more ink used on them. One superintendent never wanted to be interviewed and avoided the press altogether. This action certainly did not cause an endearing relationship. In fact, the relationship was so negative that reporters continued to dig up old information for each new story, further damaging the superintendent's reputation in the public's eyes. A rule of thumb: Never go to war with someone who purchases ink by the barrel.

In a different scenario, a new superintendent invited the publisher out to lunch and found they had a lot in common. Later, the superintendent met the education reporter each month for coffee to give the reporter a heads up on the latest news in the school district, even if it was not positive. A friendship developed which ensured the district looked favorable in the news articles. The superintendent even remarked that paraphrases sounded a lot better than the words actually stated.

The relationship with the media is wisely developed well in advance of the school bond levy and thereafter nurtured in an ongoing collaborative model.

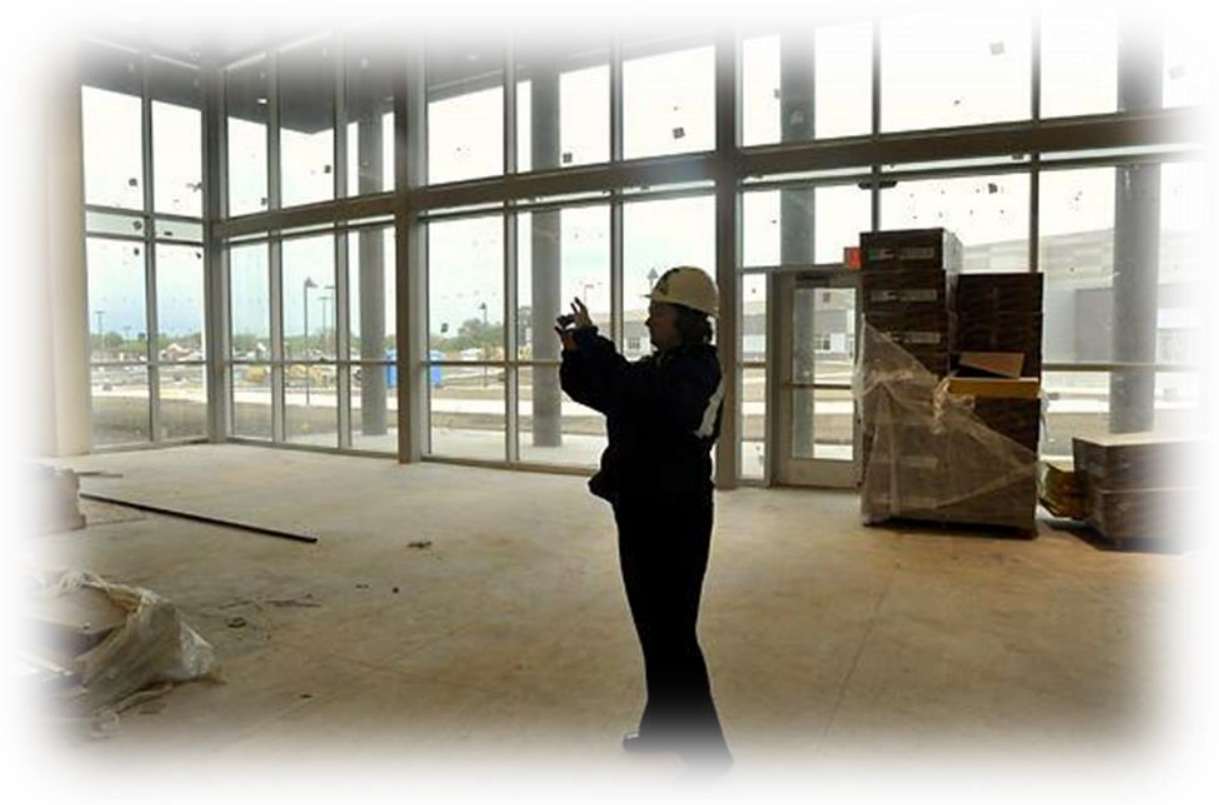




\section{Reflection}

1. What are the local newspapers?

2. How will they be used?

3. What are the local TV stations?

4. How will they be used?

5. What are the local radio stations? 
How will they be used?

6. What online sources are available?

7. How can they be used?

8. What will be the editorial board messages? 
NOTES 


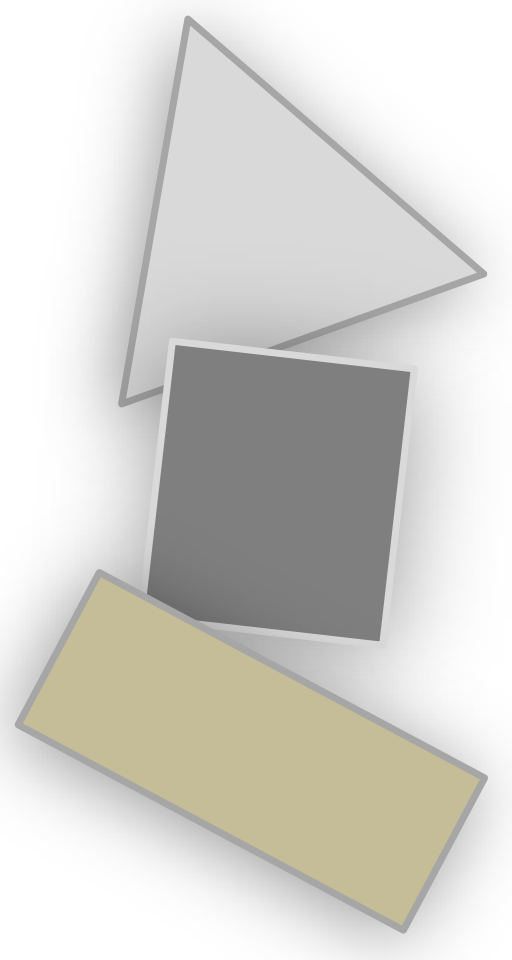

\section{Utilize}

Contemporary Marketing Strategies

$\checkmark$ Adopt strategies to use Facebook and other web-based media

$\checkmark \quad$ Identify voters reached using Facebook, Twitter, and Blogs

$\checkmark$ Research effectiveness of contemporary strategies

$\checkmark$ Develop an election web page

I'm convinced that if schools want to improve their image with taxpayers, they must begin to use social media.

Gagne (2012) 


\section{Utilize Contemporary Marketing Strategies}

Just as Barack Obama used key Internet strategies to set him in a position to win the 2008 Presidential election, social media, as strategic communications tools such as Facebook, Twitter, and blogging, are equally useful to gain public support in a bond campaign.

Use of Internet and social media strategies were groundbreaking in the 2008 Obama campaign. These electronic communication strategies captured the vote and support of younger citizens and raised valuable campaign dollars. Fast forward five years later and more recent media are now opportunities to gain an even wider audience.

When one school district decided to conduct a bond campaign during the 2009-10 school year, several younger teachers and young parents volunteered to serve on the campaign committee and began planning Internet campaign strategies. A Facebook page and Twitter account were developed. The Facebook page provided ongoing updates about the campaign, requested campaign contributions, and gave instructions on how to become involved. An online list showed hundreds of hits in support of the bond. Tweets were sent to encourage 18-year-old students to register to vote. Bloggers followed the local newspaper blogs and interjected when more accurate information was needed. Strategically-placed bloggers prevented negative comments about the district to spread. YouTube videos delivered personal accounts of the facilities and need for voters to support the bond. This 2010 bond campaign was truly a contemporary technological effort.

The results? An overwhelming "Yes."

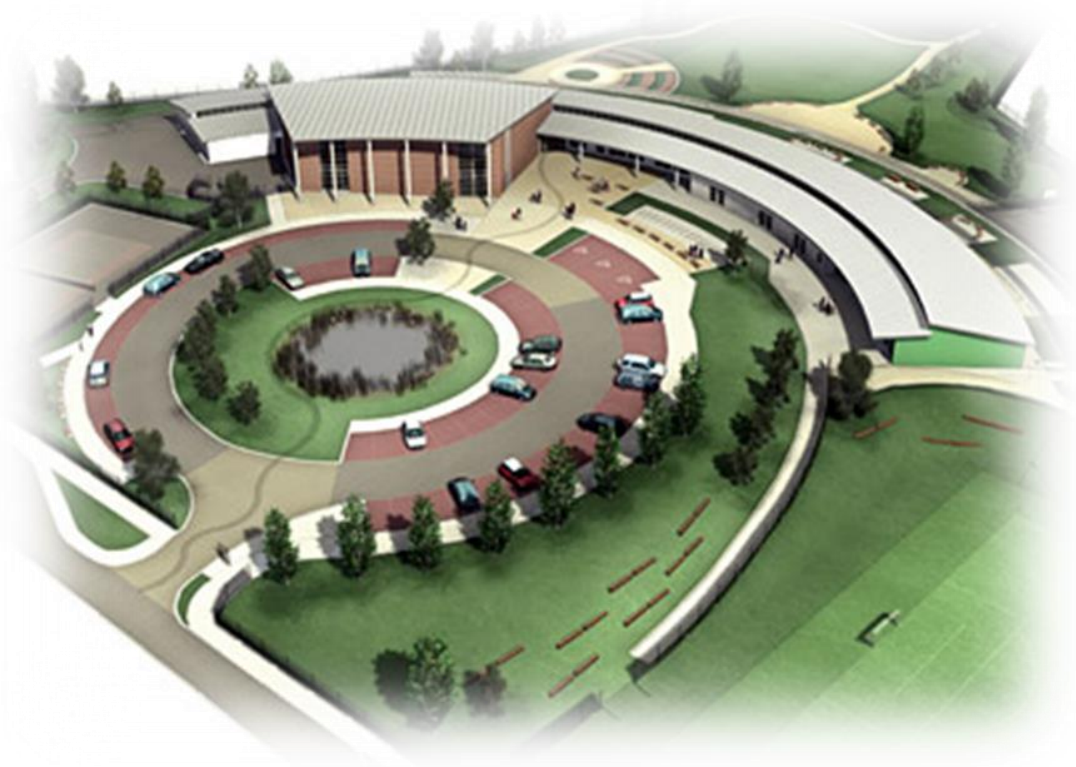




\section{Reflection}

\begin{tabular}{|l|l|l|l|l|l|l|}
\hline Strategy & Audience & $\begin{array}{c}\text { Projected } \\
\text { Outcome }\end{array}$ & Strengths & Caveats & $\begin{array}{c}\text { Cost } \\
\text { Estimate }\end{array}$ & $\begin{array}{c}\text { Person(s) } \\
\text { in Charge }\end{array}$ \\
\hline $\begin{array}{l}\text { Social } \\
\text { Networks }\end{array}$ & & & & & & \\
\hline Twitter & & & & & & \\
\hline $\begin{array}{l}\text { Twitter } \\
\text { Town Hall }\end{array}$ & & & & & & \\
\hline Blogs & & & & & & \\
\hline Wikis & & & & & & \\
\hline Videos & & & & & & \\
\hline Podcasts & & & & & & \\
\hline $\begin{array}{l}\text { Gamifica- } \\
\text { tion }\end{array}$ & & & & & & \\
\hline Ideation & & & & & & \\
\hline
\end{tabular}




\section{Types of Contemporary Media Beneficial to Bond Campaigns}

\section{Blogs}

A blog is an easy-to-update website or webpage where contributors write regular entries in a diary-like format. The most effective and interesting blogs allow readers to engage in conversations with the author and other readers.

Caveat: A contributor's message may be profoundly negative and difficult to control. The district or campaign committee should set up guidelines for use and vigilantly monitor the site.

\section{Gamification}

Gamification is the practice of using game technology for something that is not generally a game. Some examples include bronze, silver, and gold badges for reading a determined number of books, progress bars in online surveys, leader boards for top grades on an exam, or rewards for attending in-person events. Gamification is becoming increasingly common in government as a way to motivate behavior.

Gamification should not be confused with serious games that are designed to teach. Instead gamification uses the psychology and philosophy of video games employed by video game designers to motivate behavior.

When trying to motivate behavior, reach a general public audience, or build community, gamification is the right medium. It should be used only where appropriate. For example, if the campaign committee is trying to increase readership on a website, participation in a webinar, or raise campaign dollars, it would be appropriate.

Caveat: Locating a tech whiz to take this role may not be an easy task. If campaign dollars are fluid, this participant might be a good hire.

\section{Ideation Program}

A School Bond Ideation Program can elevate ideas and concerns from the district's constituency and help leaders implement ideas that have support and buy-in.

Ideation programs use crowdsourcing and brainstorming, or other ideation tools to collect innovative ideas. Selected campaign committee members can review and respond to suggestions in an online format such as a website, Facebook page, or blog. These tools often allow participants to rate and comment on each other's ideas, so the best ideas rise to the top.

Caveat: Some ideas may not be print worthy. Reviewers should set up parameters so participants are not anonymous. 


\section{Podcasts}

Podcasts are an efficient method of keeping up with current news. Government agencies, universities, and K-12 schools are using podcasts as a quick and easy way to distribute audio in addition to existing text.

The process for developing a podcast is relatively simple and inexpensive and leads to better communication with the public. Often students are assigned podcasts as an assignment in their courses, so participating students in the campaign could easily set these up. The benefit of podcasts is that users can listen to them whenever they want.

\section{Really Simple Syndication (RSS)}

RSS is a web-content format which, when used with an RSS aggregator, can allow the district or campaign committee members to alert users to new or exciting content on the bond website. These news feeds enable users to avoid conventional methods of browsing or searching for information on websites. With RSS the content they want is delivered directly to them. RSS is often used with key communicators.

RSS feeds are commonly used on weblogs (blogs), news web sites and other places with frequently updated content. Once users subscribe to an RSS feed, they can gather material from websites of their choosing. It's a very convenient format because it allows users to view all the new content from multiple sources in one location on their desktop.

\section{Social Networks}

Social networking sites, such as Facebook or MySpace, are platforms that connect people and allow them to engage in dialogue and sharing. Members can share comments, links, photos, videos, and more. A strategic Facebook page for a bond campaign captures the interest of a wide audience, especially younger voters who may not have children in school.

Facebook recently hit the one billion mark for number of users with the average age of 22 . It is a strategic tool in a bond campaign.

\section{Twitter Town Hall}

A Twitter town hall, or Twitter chat, is an event in which the district leaders or campaign committee would invite public engagement for a scheduled time period during which users can ask questions or find out more information about a topic via Twitter, much like a webinar.

Questions are tagged with a pre-designated hashtag, and the district or campaign members would respond to questions using the hashtag, follow-up via a blog post, or use another digital means of meaningfully responding to the public comment. 
Note: The \# symbol, called a hashtag, is used to mark keywords or topics in a Tweet. Twitter users created it as a way to categorize messages.

\section{Wikis}

If a district has policies or procedures, organizational charts, materials, or presentations to share, a wiki is a useful tool. A wiki is a type of collaborative work space; it's a collection of web pages that encourages users to contribute or modify the content. A simple web interface can help a community collaboratively develop a document or web page from anywhere.

Wikis can be public, meaning that anyone can see the content, or only open to a defined community.

\section{Video}

Video is an effective communication tool for reaching target audiences. Short videos can be produced inexpensively and played on computers and most mobile devices. Video is the communication format of choice for many younger voters. Videos can be shared on Facebook, Wikis, or posted to YouTube. 
NOTES 


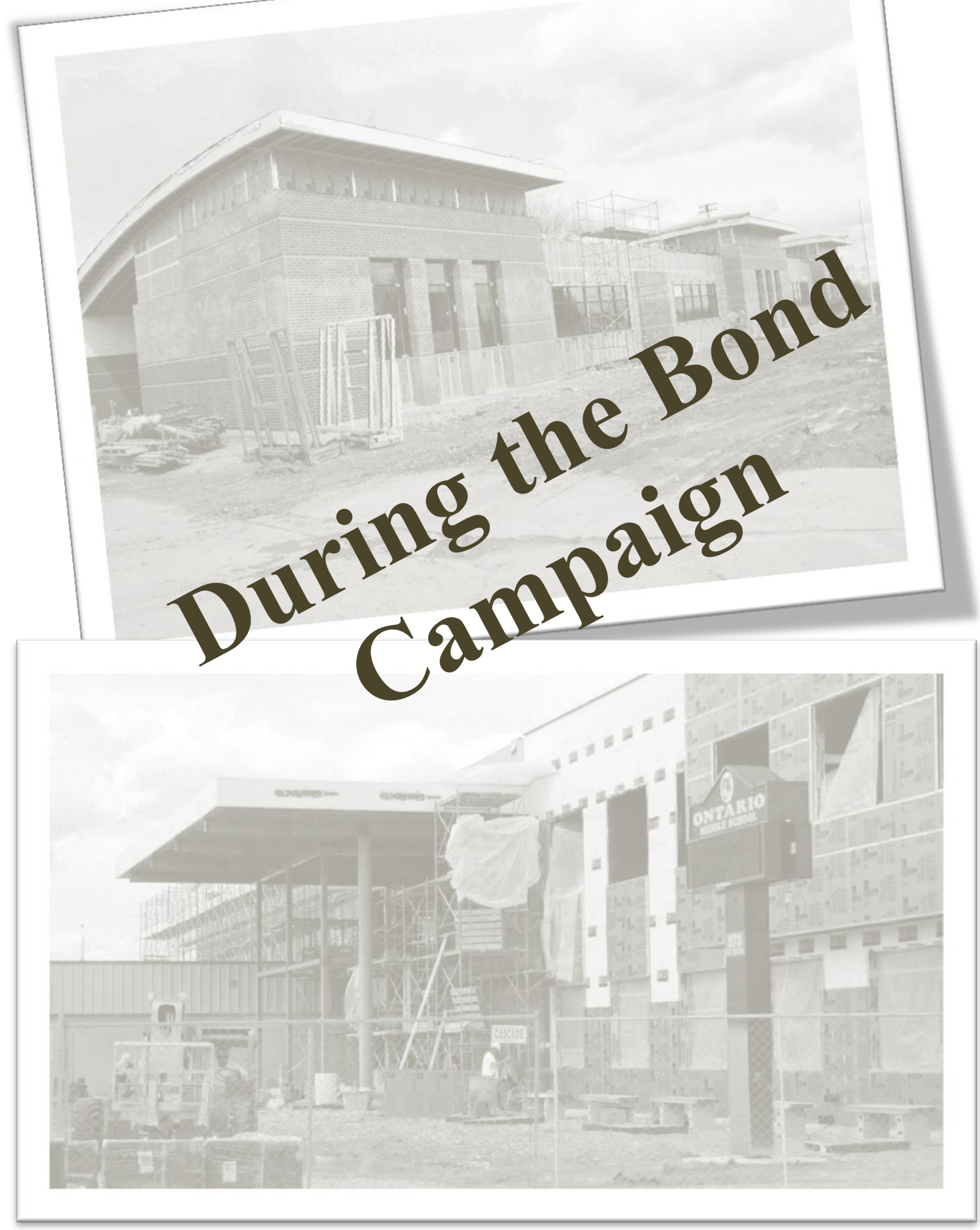




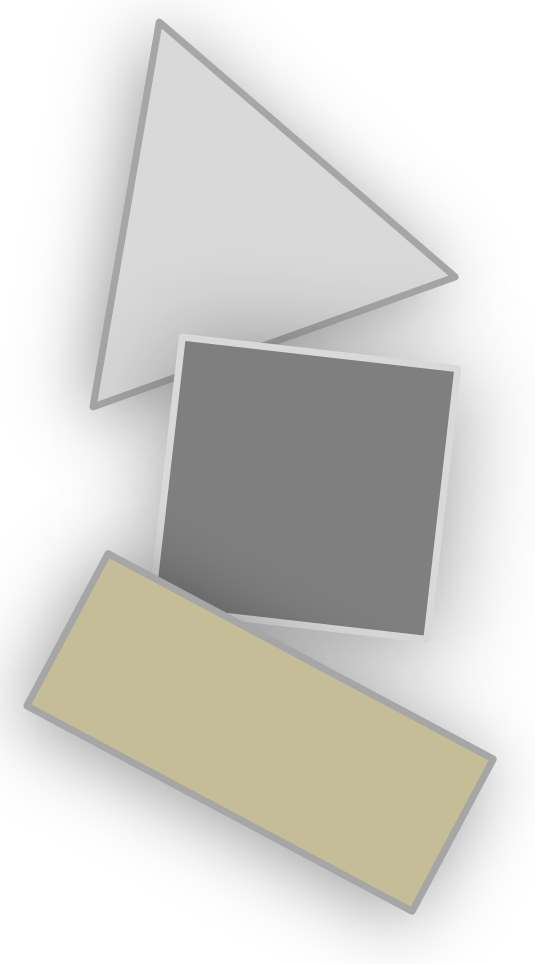

\section{Count Down to} Election Day

$\checkmark$ Redefine the 60 or 90-day plan

$\checkmark$ Develop and maintain designated committees

$\checkmark$ Assign duties and responsbilites to members

$\checkmark$ Differentiate between campaign committee functions and district-level functions

$\checkmark \quad$ Keep the district and campaign separate

$\checkmark$ Designate how campaign materials will be approved and published

$\checkmark$ Guarantee campaign materials do not commit the district to more than the bond entails

66

Successful elections require planning two campaigns on parallel tracks to avoid mixing district information with advocacy committee activities.

(Campbell \& Magmire, 2007) 


\section{Count Down to Election Day}

Ninety days will fly by.

Committees should be formed, members' tasks and duties defined, and the chairman or chairwoman roles identified for each committee. How these various groups communicate with each other will be of utmost importance as communication - or lack of it - will make or break the campaign from within.

A visual might help to keep committee members on task such as an organizational chart. The following is one example:

\section{Campaign Committee Organizational Chart}

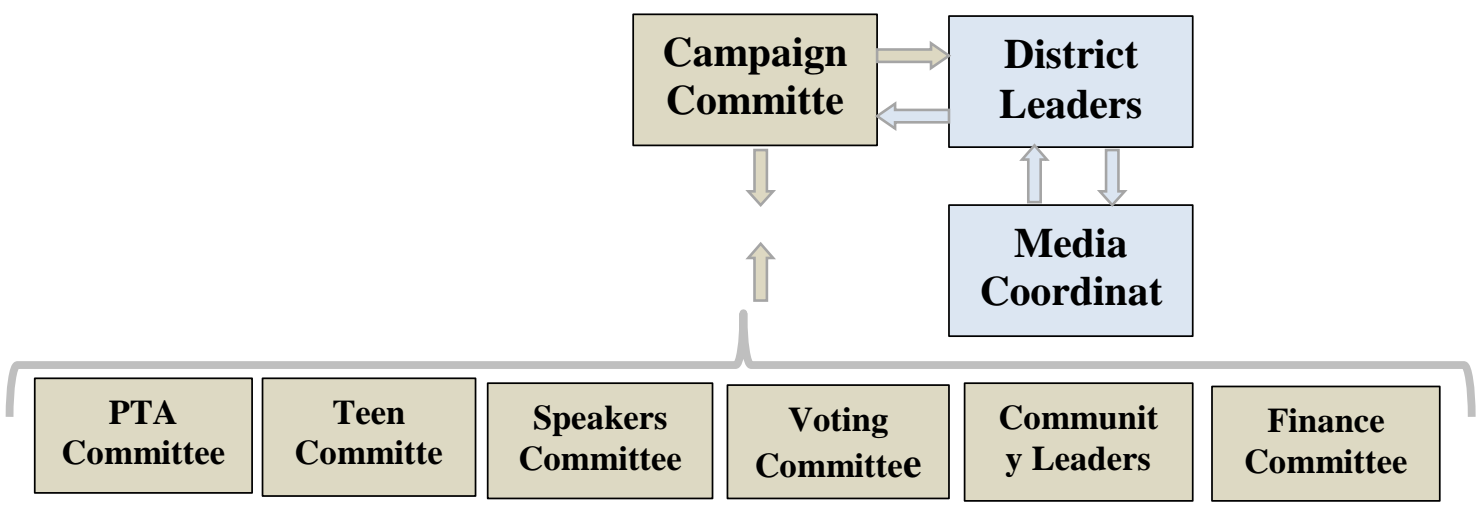




\section{Reflection}

1. What is the organizational chart? Sketch one here.

2. What district-level or school-level administrator will be responsible for each subcommittee?

3. What is the communication plan with each committee?

4. How often and when will district leaders meet with the Campaign Committee chair(s)?

5. What is the 90-day plan? 
6. What committees are required?

7. What are the members' tasks?

8. How are campaign committee functions different from district functions?

9. How will the campaign committee and district functions remain separate and comply with Oregon Election law?

10. How campaign materials will be approved and published?

11. How will campaign materials developed by the campaign committee be guaranteed not to commit the district to more than the bond election language declares? 
NOTES 


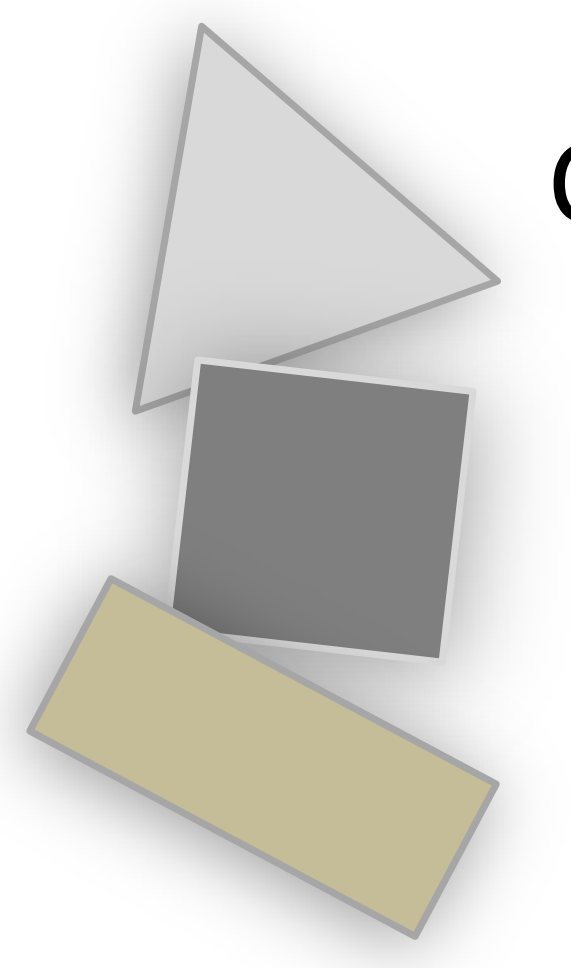

\section{Celebrate the Win}

$\checkmark$ Plan for a celebration whatever the outcome

$\checkmark$ Choose a celebration venue appropriate for schools

$\checkmark$ Invite media

$\checkmark$ Invite campaign committee members and district leaders

$\checkmark$ Prepare the district message and the campaign message - pro or con

\section{The Talent Schools bond measure passed} because of the generous support of the members of the Talent community. Thousands of students for many generations to come will benefit from these projects. Thank you for your dedication and hard work on behalf of this bond campaign and the students in the Talent School District community. 


\section{Celebrate the Win}

When Portland Public Schools received the official word of the overwhelmingly positive November 2012 election results, school officials were prepared in providing TV, radio stations, and local newspaper reporters prepared statements.

District officials, school board members, and the campaign committees need to be just as prepared for the win (or loss) as they were in campaigning. Celebration is mostly about the thanks to the taxpayers for supporting the bond and for the multitude of gracious volunteers who worked so hard in making it happen. A responsible communications director or communications consultant should accrue a list of all people, businesses, and organizations that volunteered and worked toward making the campaign a success. Moreover, every district leader's speaking engagement thereafter should continue to provide those words of thanks, appreciations, and acknowledgements until students enter their new or remodeled buildings.

The win at the polls does not mean communication or marketing ends or lessens. Instead, it is a new beginning to keep the public informed. The more informed the public is, the more likely voters will cast a positive ballot for schools in the future.

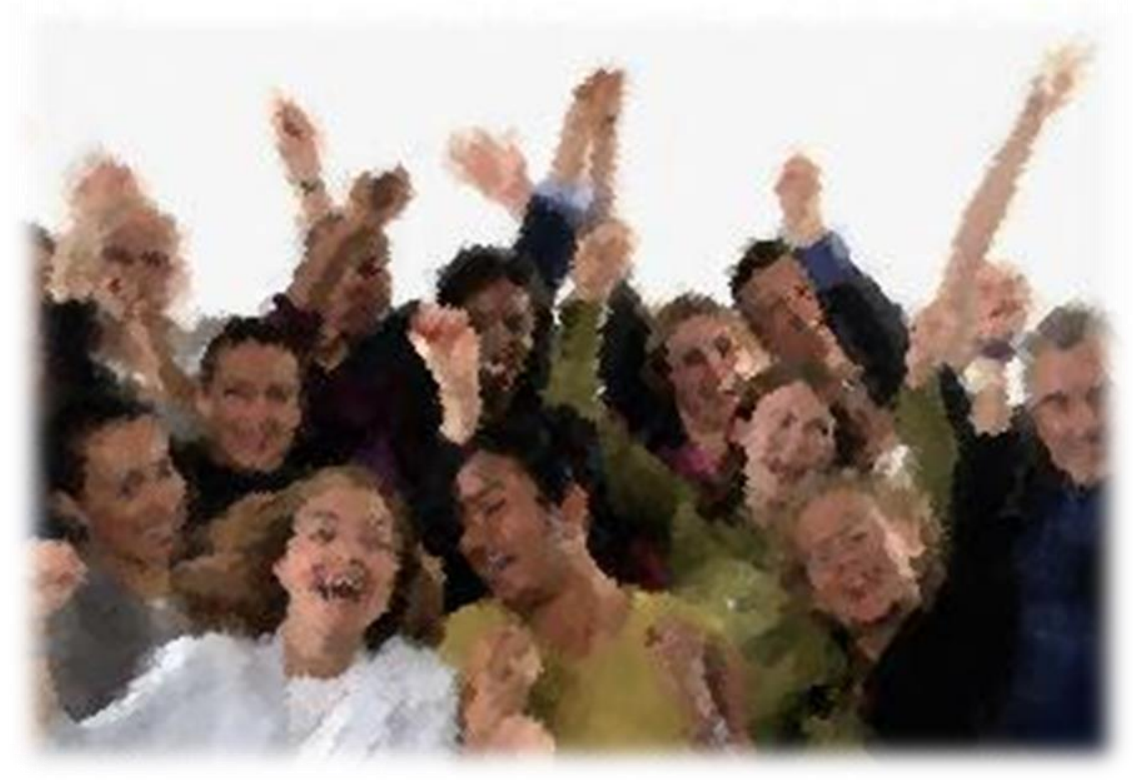




\section{Reflection}

1. Plan for a celebration whatever the outcome.

2. Choose a celebration venue appropriate for schools.

3. Invite media.

4. Invite campaign committee members and district leaders.

5. Prepare the district message and the campaign message - pro or con.

6. What are the plans to keep the positive message alive? 
NOTES 


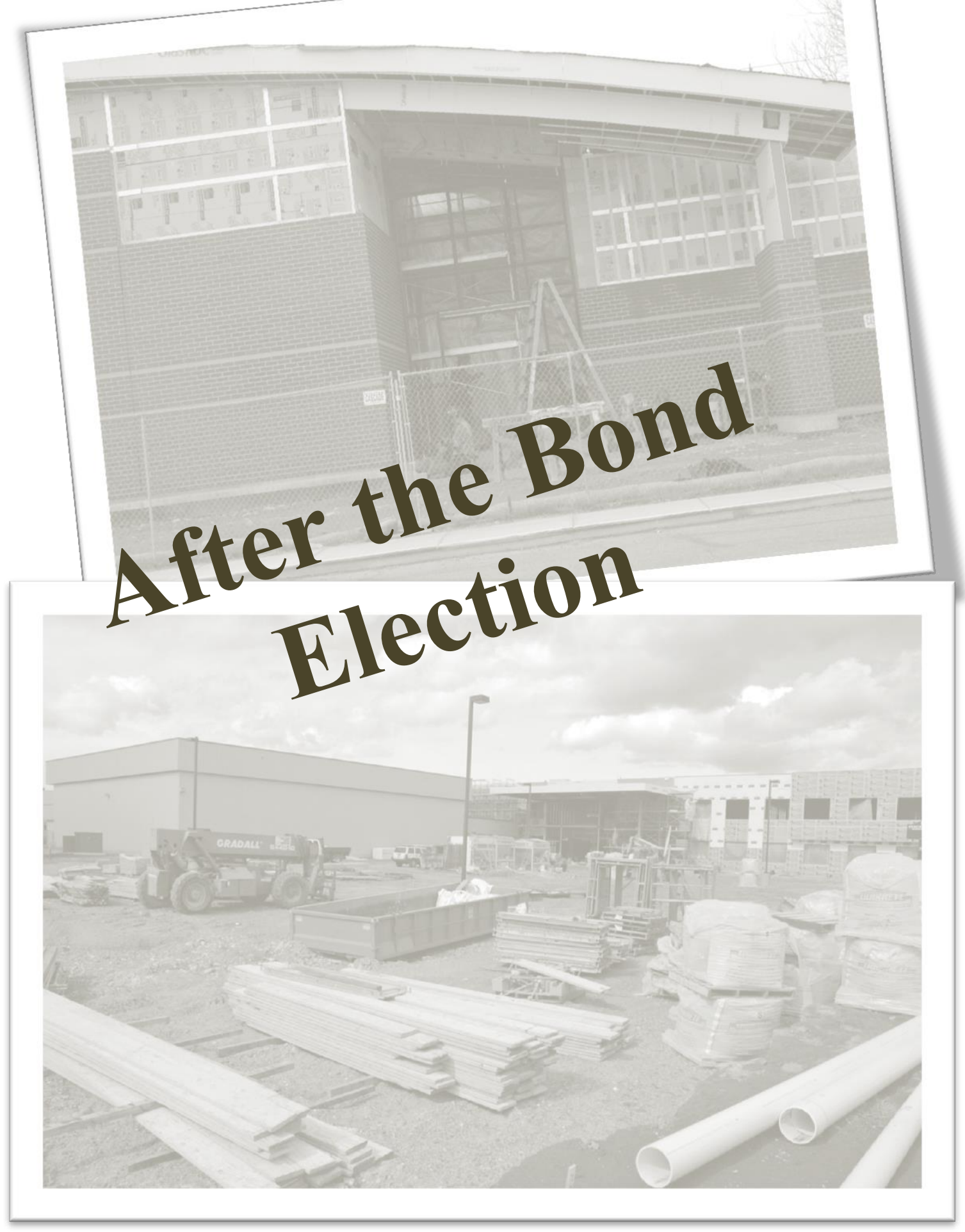




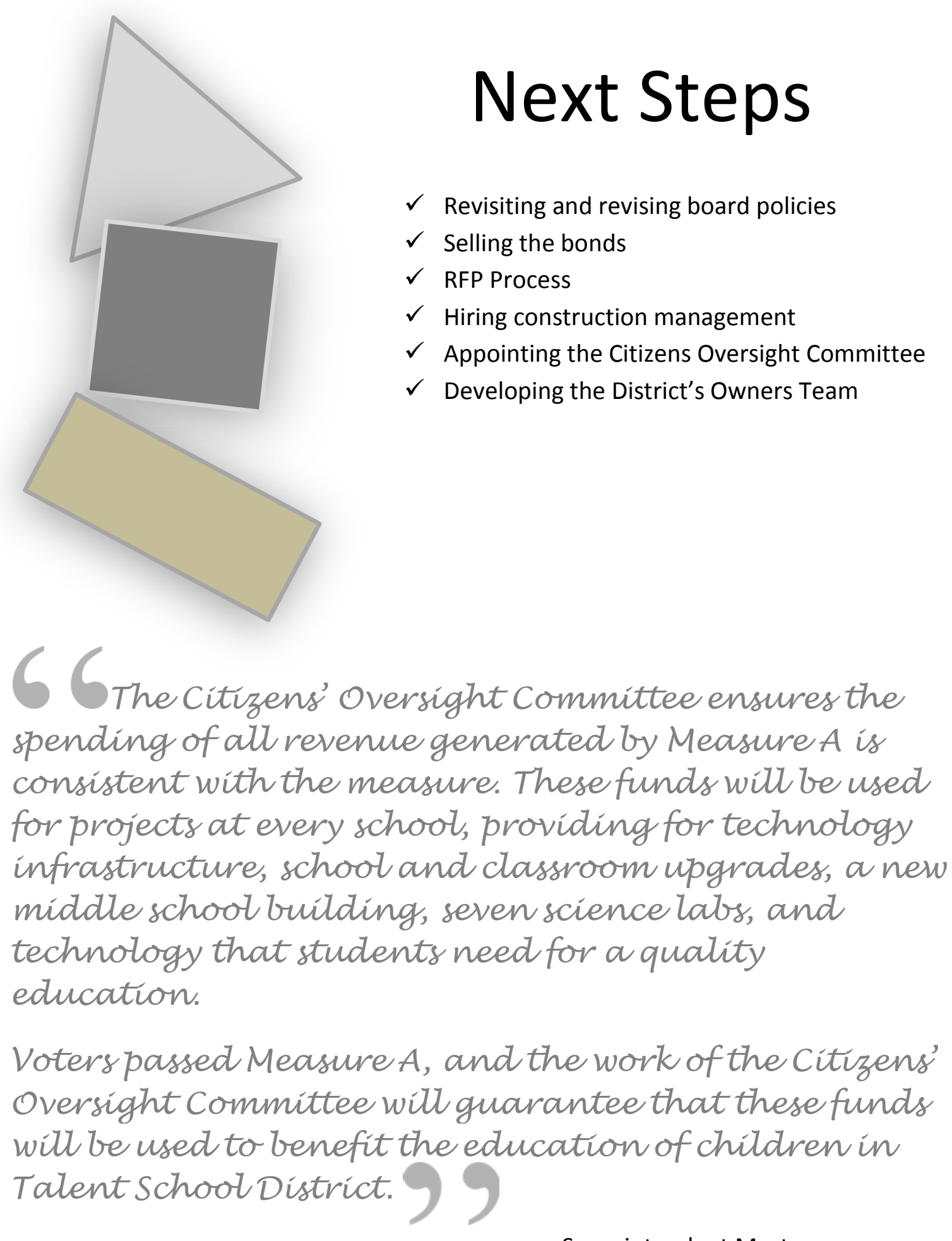

Superintendent Masters 


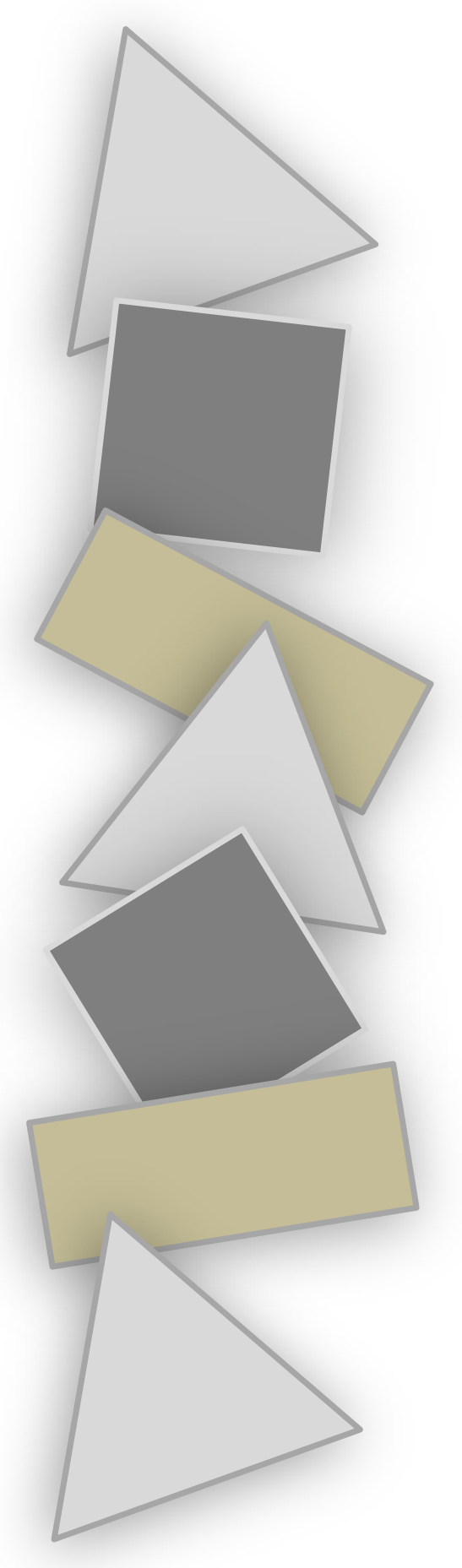

\section{Next Steps: Decisions to Make}

- Board adopts duties and responsibilities of Citizens' Oversight Committee.

- Board selects members of the Citizens Oversight Committee.

- Recommended: Formation of District Owners Team, a decision-making group to minimize the number of decisions the school board needs to make; it includes at least two school board members, superintendent, director of operations, director of finance, construction management, facilities planning/campaign committee members, general manager, and others as identified by the superintendent and school board.

- Board selects bond counsel: for example, Mersereau \& Shannon LLP; Orrick, Herrington \& Sutcliffel; or Hawkins, Delafield \& Wood.

- Board selects security company to sell bonds: for example, Seattle NW Securities Corp., D. A Davison \& Co., or Morgan Stanley.

- District personnel reviews procurement law, ORS 279C.100 to 279C.125, and board policies.

- District personnel understands RFP (Request for Proposal) process.

- District reviews and selects project delivery system: Design-Build or Design-Bid-Build.

- District selects construction management, general contractor, general manager, or other for project oversight.

- District personnel understands Davis-Bacon and Oregon wage laws: "Prevailing Wage Rates for Public Works Contracts in Oregon" publication.

- Words of Wisdom: "Follow through and follow up!" If the district plans to be successful in future bond levies, the superintendent and board need to act as prudent guardians of taxpayers' dollars. Open, honest communication must continue throughout the building process with updated information on the website, in the papers, in newsletters, several tours, ribbon cuttings, celebrations, and "thank you's." 


\section{Citizens' Bond Advisory Committee \\ August 5, 2011 \\ 5:30 PM - 8:30 PM \\ Four Rivers High School Library}

\section{CHARGE}

- Citizens' Advisory Committee is charged with developing recommendations on the scope of work for a proposed new district bond program.

- The goal of the CAC shall be to develop a scope of work that minimizes tax impact by focusing on projects of highest need, yet is comprehensive enough to equitably safeguard the long---term investments of taxpayers.

- In developing its recommendations, the CAC shall carefully consider all information provided by the district administration.

- In its deliberations, the CAC may consider, but is not limited to:

- Needs of academic, fine arts, athletic, and other district programs

- Overall tax impact on the community

- Future growth

- Overcrowded and under-utilized schools

- New facilities and maintenance of existing facilities

- Other capital improvement needs

- Energy efficiency and environmental responsiveness

○ Time---sensitive opportunities

\section{AGENDA}

6:00 - 6:30 Call to Order

Welcome and Introductions

6:30 - 6:40 Review of Materials

- Recognition of Visitors

- $\quad$ CBAC Meeting - Open Meeting

6:40 - 6:55 Citizens' Communication Citizens

6:55 - 7:15 Overview of Charter and Charge

7:15 - 7:30 Overview of Facility Master Plan Framework

7:30 - 7:45 Overview of Past Bond Programs

7:45 - 8:00 Explanation of Facility Condition Index (FCI)

8:00 - 8:30 Systematic Repairs

8:30 - 8:45 Requests for Information \& Updates
Lorraine Kaizer

Paul Tibbs

Lorraine Kaizer

Lorraine Kaizer

Paul Tibbs

Curt Schroeder

Curt Schroeder

Paul Tibbs

Agenda Items for Next Meeting

$\square$ Next meeting is June 19- Baker Administration Center - Cafeteria

$\square$ Functional Equity

Educational Adequacy

ADA Renovations

$\checkmark$ Programmatic Needs

$\checkmark$ Code Compliance 


\title{
Holding Successful School Bond Campaigns:
}

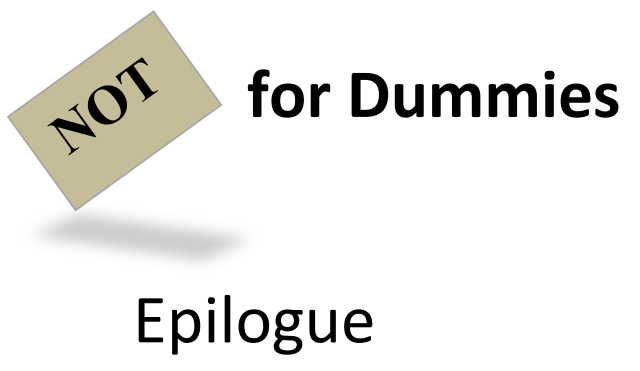

\begin{abstract}
About $40 \%$ of Oregon school districts attempting a bond levy will find themselves in a similar predicament as Novato School District \#1 and not pass their bond election. However, districts should not attempt another bond election until they craft some strategic changes different from their original plan. They should systematically evaluate all their strategies by using an evaluation tool such as a SWOT analysis to identify strengths, weaknesses, opportunities, and threats.

Campaign committee members should reconvene soon after the election, while the election is still fresh in their memories, and list the strengths of the bond campaign. What worked well? A more difficult process is identifying and discussing the weaknesses of the campaign or those areas in need of improvement. What was unsuccessful or not fully developed, utilized, or implemented?
\end{abstract}

Now that the election is over and the campaigners are exhausted, what possible opportunities can there be? While few will have the energy to think about next steps, identifying missed opportunities will help lay a foundation for the next campaign. Finally, what threats occurred that the campaign committee could not overcome? Is there a way to control negative individuals or political action groups? How can campaign literature target those threats before they gain too much influence?

One district attempted a bond levy, and a local realtor actively campaigned against it. The realtor sent misinformation to local voters about the costs of the bond explaining that their taxes would double in cost, which was completely unfounded. Needless to say, the election was not successful. Districts need to be prepared in case such propaganda is circulated. What steps can the district or campaign committee take to address misinformation?

The best advice for unsuccessful districts? Evaluate the campaign with a critical eye, learn from mistakes, study successful elections in other school districts, survey constituents, rewrite the plan, and strategize. Districts can learn a great deal from successful districts like Talent School District \#2. 


\section{SWOT Analysis}

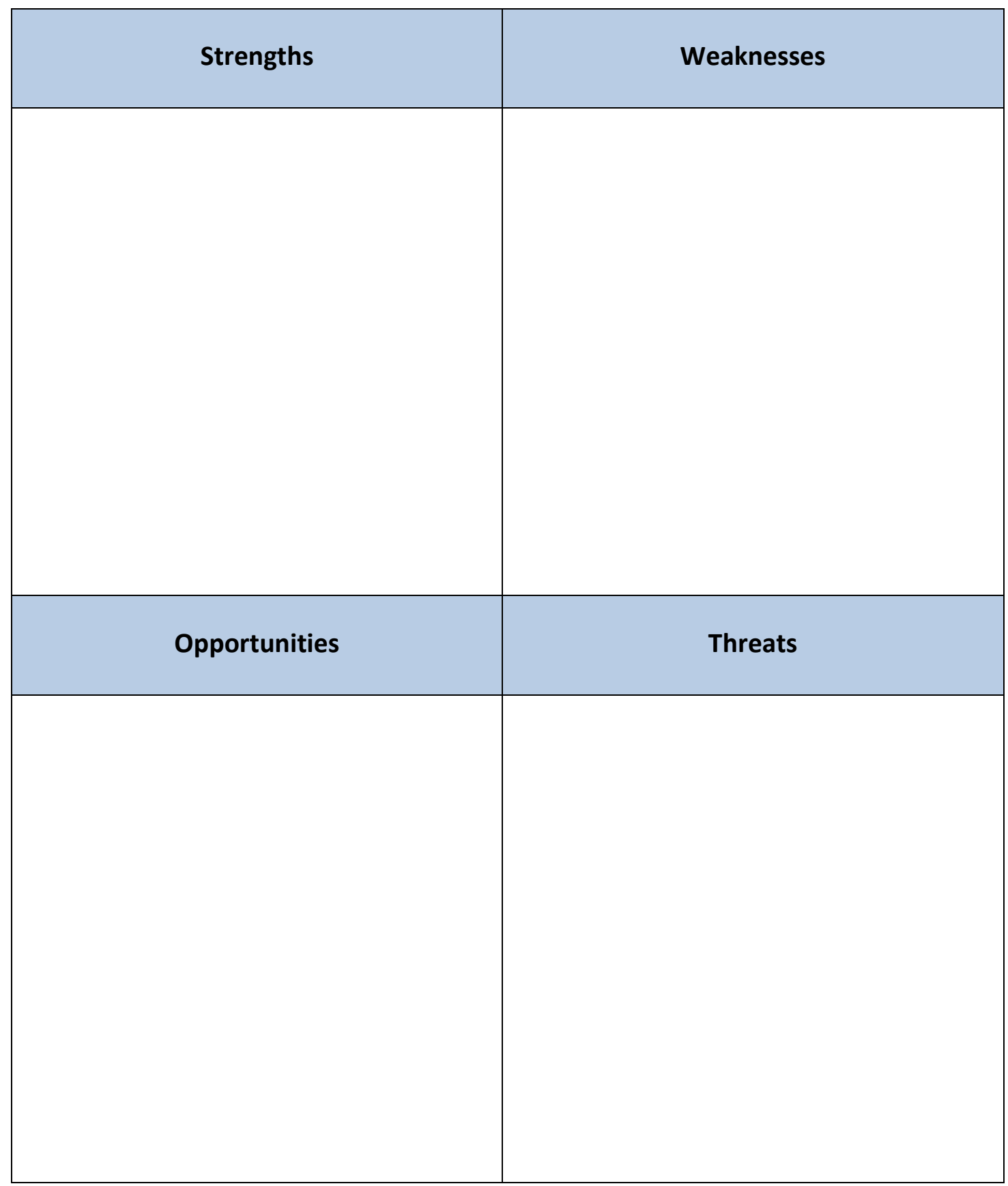




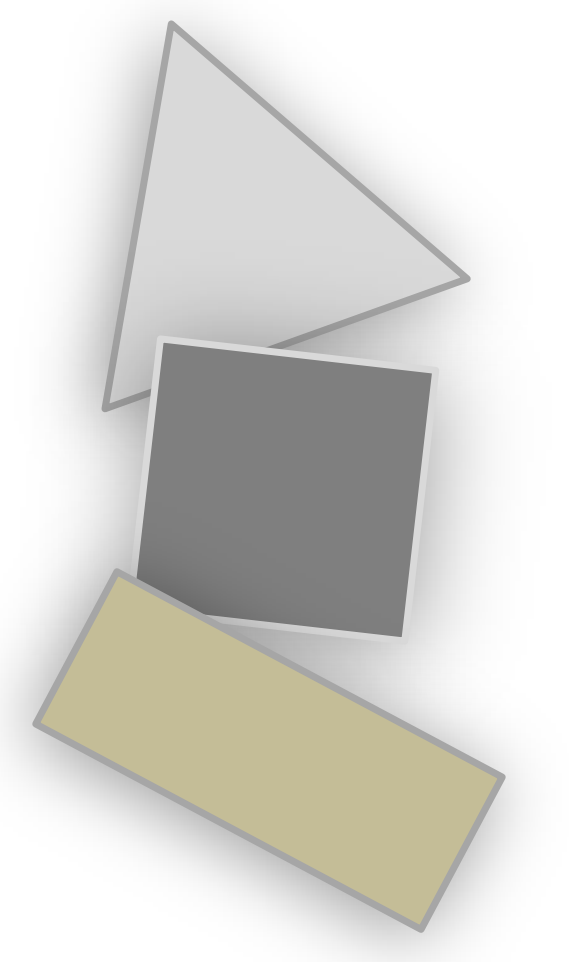

\section{Appendices}

$\checkmark$ Links to school bond campaign information

$\checkmark$ Oregon election law

$\checkmark$ Oregon procurement law

$\checkmark$ Definition of Terms

$\checkmark$ References

66

The community needs to see the benefit to every school, and that the money isn't earmarked for a school their kids won't ever attend.

- Concentrate efforts on regular voters

- Create end use a catchy campaign slogan

- Get graphic-show photos of school facility problems

- Form a citizens' committee for advocacy efforts

- Show how the bond will help every school, not just one

(Bagin \&Gallagher, 2008) 


\section{LINKS TO SCHOOL BOND CAMPAIGN INFORMATION}

\section{Ashland School District Sample Bond Resolution with Question, Title, and Summary}

Committee for Ashland Schools Bond. Investing in Ashland's Future. Retrieved from http://ashlandschoolsbond.org/Page.asp?NavID=5.

\section{Calendar of important campaign activities}

North Carolina Department of Education. Planning successful bond levies.

http://www.schoolclearinghouse.org/pubs/SuccessfulBondCamp.pdf

\section{Campaign Literature}

Equipping our teachers and students with tools for 21st century teaching and learning. (2013). Retrieved from http://www.usd497.org/FV1-0006E973/FV10006E839/FinalBondPoster.pdf.

Holland Public Schools. (2013). Build 21 progress. Retrieved from http://www.hollandpublicschools.org/vnews/display.v/ART/4bbf402f9ac0a

\section{Campaign tips}

lowa Association of School Boards. Tips for developing a bond referendum campaign. Retrieved from http://www.ia-sb.org/SchoolFacilities.aspx?id=548.

\section{Funding strategies}

Mahlum. Funding strategies: The little school district that could. Retrieved from http://www.mahlum.com/pdf/MahlumFundingStrategiesSept2011.pdf.

Gresham-Barlow School District Sample Bond Resolution with Question, Title, and Summary General obligation bond authorization. http://web.multco.us/elections/gresham-barlow-schooldistrict-measure-no-26-5.

Hillsboro School District Sample Bond Resolution with Question, Title, and Summary 
Hillsboro School District No.1J general obligation bond authorization.

http://web.multco.us/elections/hillsboro-school-district-measure-no-34-18.

Ontario School District 10-minute video tour of Ontario School District's facilities

Ontario Pride: Our Schools, Our Town. Retrieved from http://www.ontariopride.org/video.

Parkrose information on school bond - after the bond

Parkrose School District. http://do.parkrose.k12.or.us/Community/parkrose-bond.php.

Philomath news article on school bond measure

Forum on Philomath school bond measure. (2010, May 6). Retrieved from

http://www.gazettetimes.com/news/local/forum-on-philomath-school-bond-

measure/article_00593aec-592c-11df-a45b-001cc4c002e0.html.

Philomath School District PowerPoint thanking the public for its support

History of the school bond. (June 2013).

http://www.philomath.k12.or.us/documents/bond/PSDHistoryoftheBond_June2013.pdf

Portland Public Schools state Rep. Jules Bailey video explaining the economics of the Portland bond

BlueOregon. (2013). Jules Bailey explains Oregon economics. Retrieved from http://www.blueoregon.com/2012/10/jules-bailey-explains-school-bond.

\section{Portland Public Schools campaign website}

Our Portland, Our Schools: Great Schools Build a Great City. Retrieved from

http://www.ourportlandourschools.com . 


\section{Resources}

Oregon School Board Association. Bonds and Local Options resources.

http://www.osba.org/Resources/TagSearch.aspx?tag=\%7BA7C25662-B043-4409-87C5EC3A743405F0\%7D\&ptadd=\%20-\%20Bonds\%20and\%20Local\%20options.

\section{School Climate}

Center for Social and Emotional Education. (January, 2010). School climate research summary. 1 (1). Retrieved from http://www.schoolclimate.org/climate/documents/SCBrief_v1n1_Jan2010.pdf. 


\section{OREGON ELECTION LAW}

\section{1-2012 Oregon Election Laws}

Administrative Rules

Oregon Administrative Rules pertaining to the Oregon Election Law and the following Oregon Election Law topics can be obtained from the website below.

Chapter 246 - Administration of Election Laws

Chapter 247 - Qualification and Registration of Electors

Chapter 248 - Political Parties; Presidential Electors

Chapter 249 - Candidates; Recall

Chapter 250 - Initiative and Referendum

Chapter 251 - Voters' Pamphlet

Chapter 253 - Absent Electors

Chapter 254 - Conduct of Elections

Chapter 255 - Special District Elections

Chapter 258 - Election Contests; Recounts

Chapter 260 - Campaign Finance Regulations; Election Offenses

- Synopsis of Election Law Changes Enacted by the 2011 Legislative Assembly

- Vote by Mail Procedures Manual

- Election Law Summary for Candidates, PACs and Others

- Restrictions on Political Campaigning by Public Employees (ORS 260.432)

- Restrictions on Political Campaigning for Public Employees (ORS 260.432) Quick Reference

Oregon Secretary of State Kate Brown. (2012). Elections Division. Retrieved from http://www.oregonvotes.org/pages/publications/statutes.html. 


\section{OREGON PROCUREMENT LAW}

Oregon Procurement Law is a 112-page document that includes the following divisions: Division 246: General Provisions for Public Contracting; Division 247: Public Procurement of Supplies and Services; Division 248: Consultant Selection: Architectural, Engineering, Photogrammetric Mapping, Transportation Planning or [And] Land Surveying Services or [And] Related Services Contracts; Division 249: Public Contracts For Construction Services; and Alternative Contracting Methods. For more information and the unabridged Procurement Law document, the following Oregon.gov website for Procurement Services and Policy includes this information: http://www.oregon.gov/das/egs/ps/pages/index.aspx. 


\section{DEFINITION OF TERMS}

Bond Measure. A bond measure is a public school district election to finance a new construction or other capital projects. District school boards place these measures on the ballot to be approved or defeated by the voting public. Under Oregon law, all ballot measures must have a caption of not more than 10 words to headline the measure, a question of no more than 20 words that lists the purpose of the ballot question, a concise and impartial statement of not more than 175 words summarizing the measure and its major effect, along with a response of "I Vote Yes" or "I vote No."

Bond Campaign Committee. The bond campaign committee, a political action group, is a group of devoted citizens who manage the school district bond campaign. The committee's mission is to advocate for new construction and/or capital improvements, gain the support of "yes" voters, and help pass the bond levy. Campaign committee members, as long as they are not employees of the district, are not restricted by Oregon ethics laws and can openly promote the bond election.

Bond Cost. The bond cost is the cost assessed to the taxpayers to repay the district's indebtedness. It is based on payment of the principal plus interest as applied to the total property valuation in the school district. Interest rates are determined not only by the current interest rate but also the district's credit rating as determined by rating companies such as Moody's Investors Service and Standard and Poors Corporation. The rating is similar to an individual's credit score when purchasing a house or vehicle. The higher the rating, the lower the total cost. The taxpayer typically sees school district language about bond costs like the following example: The proposed $\$ 195$ million in bonds would cost property taxpayers an estimated average of 51 cents per $\$ 1,000$ of assessed value per year over the life of the bonds, generally twenty years. This tax would begin no sooner than the 2013-14 fiscal year. For example, a taxpayer who owns a $\$ 250,000$ home would pay an estimated $\$ 127.50$ per year or $\$ 10.63$ per month.

Bond Levy. A bond levy is an amount of money a district asks voters to approve in an election in order for the district to sell bonds to purchase land, build new schools, renovate existing facilities, purchase technology, and furnish and equip new construction.

Capital Projects/Capital Construction. Capital Projects/Capital Construction includes the acquisition of land or buildings, renovation of existing buildings, improvements to district facilities, and new construction.

Communications. Communications is the overall formal or informal exchange or transmission of information.

Community Partners. Community partners are individuals, businesses, or organizations who provide time, resources, or financial support to schools. Some business or organization partnerships may also be contractual in exchange for services provided to students. 
Constituents. Constituents are the people whom the organization serves, advocates for, or organizes.

Deferred Maintenance. Deferred maintenance is the upkeep of buildings and projects that is often put on hold, repair that is neglected, and preventive maintenance that is ignored because of limited resources.

Electorate. The electorate is the voting public.

Elections Law Violations. Oregon's constitutional and statutory provisions of elections laws are located in Chapters 246 through 260 from the Oregon Revised Statutes. Election law, ORS 260.432 , provides restrictions on any political campaigning by public employees. Specifically, for schools districts and school personnel, elections laws prohibit the use of taxpayer dollars to support a bond campaign. For example, school district employees would be in violation if, while on district time, wrote, edited, and published a brochure that would be considered a political ad. A comprehensive memorandum on ORS 260.432, "Restrictions on Political Campaigning by Public Employees," is available upon request from the Secretary of State's office.

Ethics Laws. Provisions of Ethics Law prohibit any public official from using the position or office held for financial gain. For example, a public official who authorizes or has a significant role in a contract while acting in an official capacity may not have a direct, beneficial, financial interest in the public contract in his or her current capacity or for two years after leaving the official position. Likewise, a member of a board or committee of the board or other governing body who participates in the authorization of a public contract may not have a direct, beneficial, financial interest (ORS 244.047). Members of a citizens oversight committee, appointed by the school board, for example, are considered a committee of the board and legal bound by the ethics law.

External Communications. External communications is the formal or informal exchange or transmission of information between a school or district and other organizations, groups, or individuals outside its formal structure.

General Obligation Bond. A general obligation bond (GO) or municipal bond is backed by the credit and taxing power of the issuing school district rather than the revenue from a given project. GO bonds are issued with the assurance that the school district will be able to repay its debt obligation through taxation. No assets are used as collateral.

Internal Communications. Internal communications is the formal or informal exchange or transmission of information within a school or district and other schools or individuals inside the school's or district's formal structure. It is the flow of information between or among employees or departments and across all levels or divisions of an organization.

Marketing. Marketing for a school district is creating or offering services that are perceived as valuable to others. Are children receiving the best education possible? Are parents satisfied with 
school district services? Do potential taxpayers and businesses want to relocate into the school district boundaries? The district markets its programs or creates services based on the perceptions and needs of the consumer. In this case, the consumer is defined as students, parents, taxpayers, and the greater community.

Modernization. Modernization refers to remodeling, upgrading, and/or renovating existing structures.

New Construction. New construction refers to site preparation and construction of an entirely new structure and/or significant extension to an existing building, whether or not the site was previously occupied.

School and Community Relations. School and community relations is the relationship that the school district develops with its external stakeholders and constituents through one-way and two-way, formal or informal, information flow, communications, and dialogue.

School Bonds. School bonds, also called general obligation bonds (GO), are bonds a school district sells to fund capital construction projects. School bonds are a cost to taxpayers in addition to school taxes and must be approved by the district's voters. When the bond election passes, the district sells bonds to investors who will then be paid principal and interest during a period of not more than 40 years.

Stakeholders. Stakeholders are the people who care about an organization and consider it their own. They are the school board, employees, volunteers, parents, business partners, and contracted businesses, groups and/or individuals.

Successful Bond Campaign. A successful bond campaign is a culmination of events and the united efforts of the school board, superintendent, parents, citizens, and school district employees, coupled with a well-developed strategic plan, to attract voters to support a school district's construction bond levy, which ends in an election victory. 


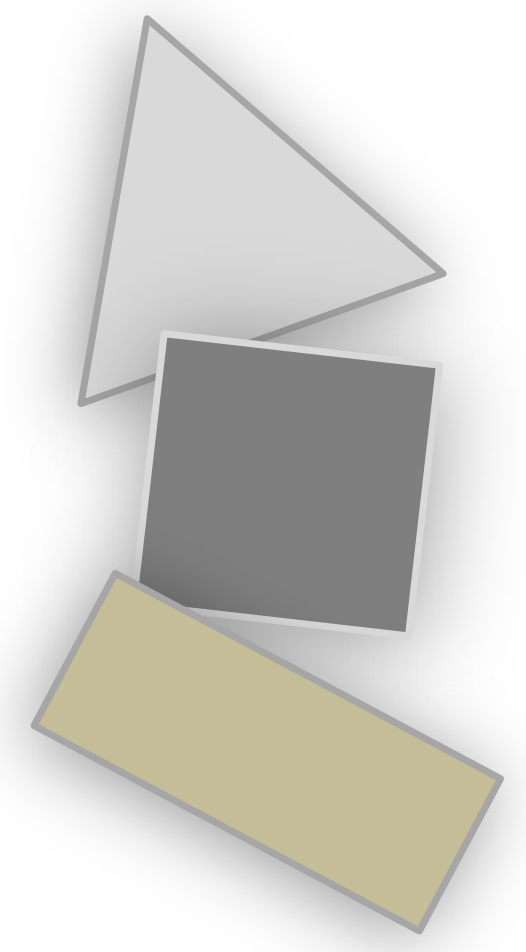

References 


\section{REFERENCES}

American Architectural Design. (2005). National summit of school design report. Retrieved from http://www.archfoundation.org/2005/12/national-summit-on-school-design-report.

Andrews, James B., and Richard Neuroth (October 1988). Environmentally related health hazards in the schools. Paper presented at the Annual Meeting of the Association of School Business Officials International in Detroit, Michigan. ED 300929.

Anderson, K. L. (2001). Kids in noisy classrooms: What does the research really say? Journal of Educational Audiology, 9, pp. 23-33. Retrieved from http://successforkidswithhearingloss.com/wp-content/uploads/2011/08/Kids-in-NoisyClassrooms-What-does-the-research-really-say.pdf

Apple. (2002).The impact of technology on student achievement: A summary of research findings on $\mathrm{i}$ in the classroom. Retrieved from http://gayleberthiaume.com/FGO/AppleEduResearch.pdf

Bagin, D., \& Gallagher, D. R. (2001). The school and community relations ( $7^{\text {th }}$ ed.). Boston: Allyn \& Bacon.

Bagin, D., Gallagher, D. R., \& Moore, E. H. (2008). The school and community relations ( $9^{\text {th }}$ ed.). Boston: Allyn \& Bacon.

Barnard, H. 1850. School architecture: The improvement of schoolhouses in America. New York: A. S. Barnes. Cited in A. Gulliford, America's country schools (Niwot, CO: University Press of Colorado, 1996).

Bradley, J. (1986). Speech intelligibility studies in classrooms. Journal of the Acoustical Society of America, 80(3), pp. 846-854. Retrieved from http://www.ncbi.nlm.nih.gov/pubmed/3760338 
Brock, Fritz. (May 2012). Communication key to why referendums pass, fail. Retrieved from http://sites.journalism.wisc.edu/edutopia/educational-costs/referendum

Bullock, C. (2007). The relationship between school building conditions and student achievement at the middle school level in the commonwealth of Virginia. Unpublished doctoral dissertation). Calvin C. Virginia Polytechnic Institute and State University. Blackburg, Virginia.

Campbell, G., APR, \& Magmer, J., APR. (2007). Election success: Proven strategies for public fiancé campaigns. Rockville, MD: National School Public Relations Association.

Carr, N. (2010, December 15). Demographic shifts require changes in school communication: School leaders must broaden their thinking to engage new groups of parents and stakeholders. eSchool News. Technology news for today's K-20 educator. Retrieved from http://www.eschoolnews.com/2010/12/15/demographic-shifts-require-changesin-school-communication

Carroll, S. R., \& Carroll, D. (2000). EdMarketing: How smart schools get and keep community support. Bloomington, IN: National Education Service.

Center for Innovative School Facilities. (n.d.). School facilities and student achievement. Retrieved from http://www.cisforegon.org/about/documents/Policy\%20Brief\%20(8.5x11).pdf Ciardullo, J. (2001). Creating a welcome message in the physical environment. The School Administrator. Retrieved from http://www.aasa.org/SchoolAdministratorArticle.aspx?id=10820 
Claus, R.N., \& Girrbach, C. J. (1985). An assessment of the Saginaw successful schools project. Paper presented at a meeting of the Evaluation Research Society in Toronto, Ontario, Canada. (ED264285).

Copa, G. (2008). Linking learning and school design: Responding to emerging Ideas. In Visioning school facility planning and design for the 21st century: Creating optimal learning environments. Berkeley: University of California, pp. 22-24.

Corcoran, T. B., Walker, L. J., \& White, J. L. (1988). Working in urban schools. Washington, DC: Institute for Educational Leadership. Retrieved from http://clinton4.nara.gov/WH/EOP/nec/html/doc061600.html

Covey, S. R. (1989). The 7 habits of highly effective people: Powerful lessons in personal change. New York: Free Press.

Crandell, C. C. (October, 2000). Classroom acoustics for children with normal hearing and with hearing impairment. Language Speech and Hearing Services I Schools, 31, pp. 362-370. Retrieved from http://gofrontrow.com/files/documents/background_research_classroom_acoustics_fo r_children_with_normal_hearing_and_with_hearing_impairment.pdf

Evans, G. W., Hygge, S., \& Bullinger, M. (1995). Chronic noise and psychological stress. Psychological Science, 6, pp. 333-338. Retrieved from http://www.jstor.org/discover/10.2307/40062885?uid=3739856\&uid=2129\&uid=2\&uid $=70 \&$ uid $=4 \&$ uid $=3739256 \&$ sid $=21102658844363$

Fiore, D J. (2011). School community relations ( $3^{\text {rd }}$ ed.). Larchmonth, NY: Eye on Education. Florence, L. (2013). School District Bond Campaigns: Strategies That Ensure Successful Outcomes. (Unpublished doctoral dissertation). Portland State University. 
Fraser, M., and Dutta, S. (2008, November 19). Barack Obama and the Facebook election. US News. Retrieved from http://www.usnews.com/opinion/articles/2008/11/19/barackobama-and-the-facebook-election

Freiberg, H. J. (1998). Measuring school climate: Let me count the ways. Educational Leadership, 56(1), pp. 22-26.

Fritz, B. (2012, May 8). Communication key to why referendums pass, fail. EdUtopia Wisconsin. Retrieved from http://sites.journalism.wisc.edu/edutopia/educationalcosts/referendum

Grandoni, D. (2012, October 14). Facebook has 1 billion users, Mark Zuckerberg announces in a status update. The Huffington Post. Retrieved from http://www.huffingtonpost.com/2012/10/04/facebook-1-billion-users_n_1938675.html

Gunther, V., McGowan, J., \& Donegan, K. (2011). Strategic communications for school leaders. New York: Rowman \& Littlefield.

Hammond, B. (2011, October 27). Top Portland school leaders pay fines for breaking election law. The Oregonian. Retrieved from http://www.oregonlive.com/portland/index.ssf/2011/10/top_portland_school_leaders_ pa.html

Hartmann, D. (2008). High school sports participation and educational attainment: Recognizing, assessing, and utilizing the relationship; Report to the LA84 Foundation. University of Minnesota. http://thesocietypages.org/files/2013/03/HighSchoolSportsParticipation1.pdf 
Healthy Schools Network (HSN). (2012).School renovation and construction: What you need to know to protect child and adult environmental health. Retrieved from http://www.healthyschools.org/downloads/Renovation_and_Construction_Guide.pdf. Heschong Mahone Group. (2003) Re-analysis report: Daylighting in schools, for the California Energy Commission. New Buildings Institute. Retrieved from http://www.h-mg.com/projects/daylighting/projects-pier.htm

Heschong Mahone Group. (2010). Daylighting Forum 2010 - Report. Retrieved from http://www.h-m-g.com/DaylightPlus/Daylighting\%20Forum\%20Report\%20FINAL\%200824-2010.pdf

Hew, K. F. \& Brush, T. (June, 2007). Integrating technology into K-12 teaching and learning: Current knowledge gaps and recommendations for future research. Educational Technology, Research and Development 55(3) 223-252.

Holt, C. R. (2002). School bond success: A strategy for building America's schools. Lanham, MD: Scarecrow Education.

Holt, C. R., Wendt, M. A., \& Smith, R. M. (2006, Winter). School bond success: An exploratory case study. The Rural Educator, 27(2), 11-17.

Hoy, W. K., \& Miskel, C. G. (2001). Educational administration: Theory, research, and practice $\left(6^{\text {th }}\right.$ ed.). Boston: McGraw Hill.

Hoyle, J. R., English, F. W., \& Steffy, B. E. (1994). Skills for successful school leaders: Why are some administrators more successful than others? $\left(2^{\text {nd }}\right.$ ed.). Arlington: American Association of School Administrators.

Hughes, L. W., \& Hooper, D. W. (2000). Public relations for school leaders. Boston: Allyn \& Bacon. 
Kjærvang, U. (2006). Power of aesthetics to improve student learning: View from Denmark: Reimagining spaces of learning. Design Share: Designing for the Future of Learning. Retrieved from http://www.designshare.com/index.php/articles/aesthetics-andlearning

Kotler, P. (2000). Marketing management: The millennium edition. Upper Saddle River, NJ: Prentice Hall.

Kowalski, T. J., Petersen, G. J., \& Fusarelli, L. D. (2007). Effective communications for school administrators: A necessity in an information age. Toronto: Rowman \& Littleton Education.

Lamborn, S.D., Brown, B.B., Mounts, N.S., \& Steinberg, L. (1992). Putting School in perspective: The influence of family, peers, extracurricular participation, and part-time work on academic engagement. Chapter 6 in Student engagement and achievement in American secondary schools, pp. 153-181. (ED371047)

O'Brien, E., \& Rollefson, M. (June 1995). Extracurricular participation and student engagement. National Center for Education Statistics. Retrieved from http://nces.ed.gov/pubs95/web/95741.asp

Oregon School Boards Association (OSBA). (2009, January). Update: Bond and local option levy, 2008 election. Salem, OR: Oregon School Boards Association.

Our Portland, Our Schools. (2013). A vision for teaching and learning. Retrieved from http://www.ourportlandourschools.com/bond.html

Perez, J., Montano, J., \& Perez, J. (2006). Room temperature and its impact on student test scores. Healthy schools as a learning tool. Council of Educational Facility Planning International. Retrieved from http://healthyschools.cefpi.org/temperature.html 
Poplin, M., \& Weeres, J. (1992). Voices from the Inside: A report on schooling from inside the classroom. Part one: Naming the problem. The Institute for Education in Transformation at the Claremont Graduate School. Retrieved from http://www.cgu.edu/PDFFiles/poplin/Voices-BW.pdf.

Porterfield, K., \& Carnes, M. (2008). Why school communication matters: Strategies from $P R$ professionals. New York: Rowman \& Littlefield Education.

Porterfield, K., \& Carnes, M. (2012). Why social media matters: School communication in the Digital Age. Bloomington, IN: AASA.

Smith, J. (2008, Dec 16). Facebook now growing by over 600,000 users a day. Inside Facebook. Retrieved from http://www.insidefacebook.com/2008/12/16/facebook-now-growingby-over-600000-users-a-day-and-new-engagement-stats.

Ulrich, R.S., Simons, R.F., Losito, B. D., Fiorito, E., Miles, M. A. and Zelson, M. (1991). Stress recovery during exposure to natural and urban environments. Journal of Environmental Psychology, 11(3), pp. 201-230. Retrieved from http://www.sciencedirect.com/science/article/pii/S0272494405801847

U.S. Department of Education. (1995). National education longitudinal study, Second follow-up. National Center for Education Statistics. http://nces.ed.gov/surveys/els2002.

U.S Department of Education (2000). Schools as Centers of Community: A citizens guide for planning and design. Retrieved from http://www2.ed.gov/offices/OESE/archives/inits/construction/commguide.pdf.

U.S. Green Building Council. (2007). LEED for schools for new construction and major renovations. Retrieved from http://www.usgbc.org/Docs/Archive/General/Docs2593.pdf 
Vance, A. (2012, October 4). Facebook: The making of 1 billion users. Businessweek. Retrieved from http://www.businessweek.com/articles/2012-10-04/facebook-the-making-of-1billion-users.

Wargocki, P. and D.P. Wyon, "The effect of moderately raised classroom temperatures and classroom ventilation rate on the performance of schoolwork by children". HVAC\&R Research, 2007. 13(2): p. 193-220.

Young, E. (2003). Do K-12 School facilities affect education outcomes? A staff information report. Nashville, TN: The Tennessee Advisory Commission on Intergovernmental Relations. Retrieved from http://www.state.tn.us/tacir/PDF_FILES/Education/SchFac.pdf 